JOHN H. WILLIAMS

\title{
LABORATORYOF
}

\section{NUCLEAR PHYSICS}

$$
\text { COO-1265- } 94
$$

ANNUAL REPORT 1970

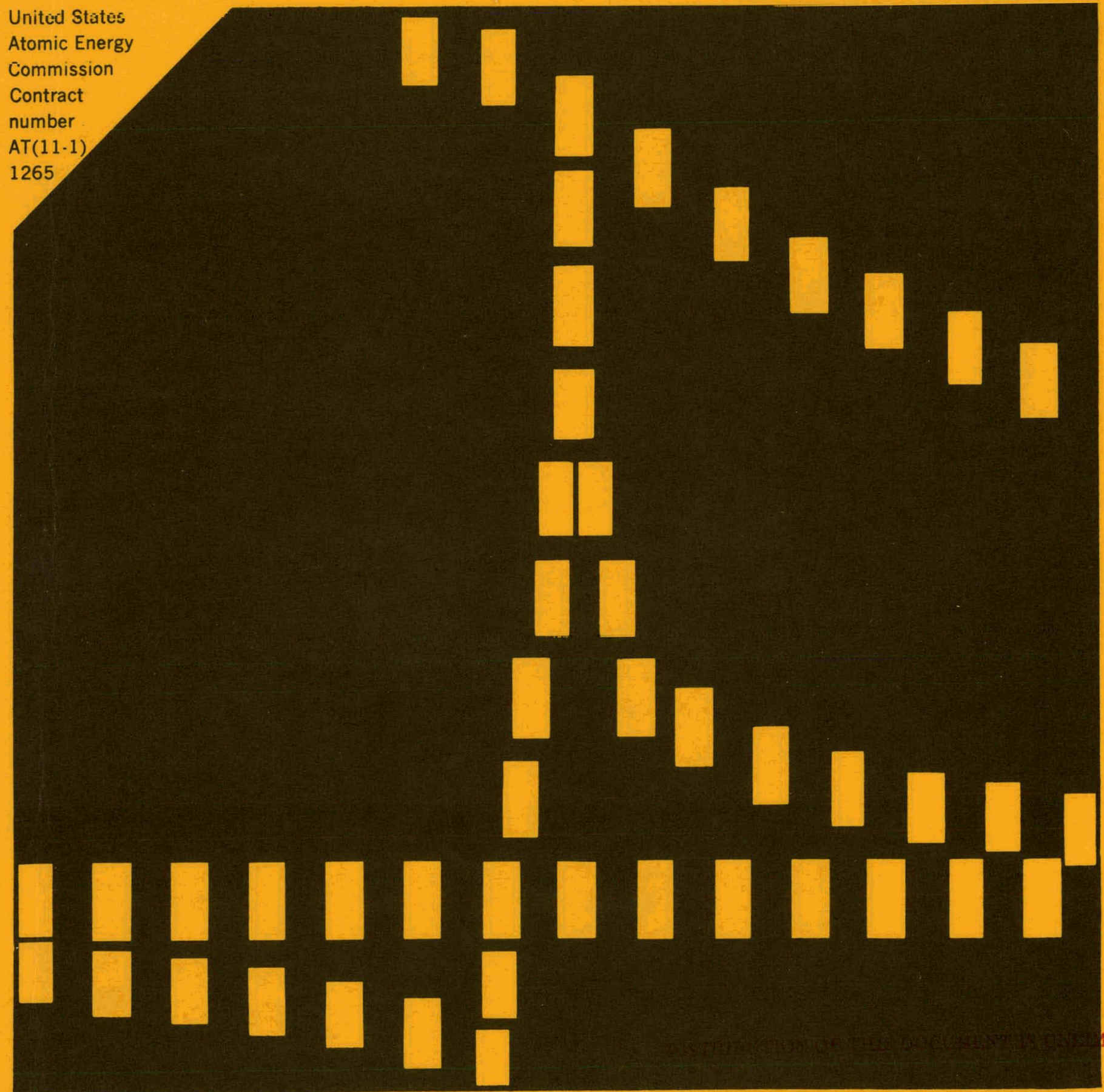

UNIVERSITY OF MINNESOTA 


\section{DISCLAIMER}

This report was prepared as an account of work sponsored by an agency of the United States Government. Neither the United States Government nor any agency Thereof, nor any of their employees, makes any warranty, express or implied, or assumes any legal liability or responsibility for the accuracy, completeness, or usefulness of any information, apparatus, product, or process disclosed, or represents that its use would not infringe privately owned rights. Reference herein to any specific commercial product, process, or service by trade name, trademark, manufacturer, or otherwise does not necessarily constitute or imply its endorsement, recommendation, or favoring by the United States Government or any agency thereof. The views and opinions of authors expressed herein do not necessarily state or reflect those of the United States Government or any agency thereof. 


\section{DISCLAIMER}

Portions of this document may be illegible in electronic image products. Images are produced from the best available original document. 


\section{CoO-1265-94}

ANNUAL REPORT 1970

JOHN H. WILLIAMS LABORATORY

OF

NUCLEAR PHYSICS

UNIVERSITY OF MINNESOTA

August, 1970

LEG A L - NOTICE

This report was prepared as an account of work sponsored by the United States Government. Neither the United States nor the United States Atomic Energy Commission, nor any of their employees, nor any of their contractors, subcontractors, or their. employees, makes any warranty, express or implied, or assumes any legal liability or responsibility for the accuracy, completeness or usefulness of any information, apparat us, product or process disclosed, or represents that its use would not infringe privately owned rights.

1 .

\section{U.S. Atomic Energy Commission}

Contract $\operatorname{AT}(11-1)-1265$ 


\section{THIS PAGE \\ WAS INTENTIONALLY \\ LEFT BLANK}




\section{CONTENTS}

Introduction

vii

\section{A. RESEARCH PROGRAM}

I. Scattering And Reactions In Light Nuclei

1. Proton-Proton Scattering Near $10 \mathrm{MeV}$

2. Exchange Effects in ${ }^{3} \mathrm{He}+{ }^{4} \mathrm{He}$ Elastic Scattering 4

3. Reactions In Resonating-Group Calculations 9

4. Study of The 1-p Shell With $40-\mathrm{MeV}\left(p,{ }^{3} \mathrm{He}\right)$ And $(p, t)$ Reactions

II. Spectroscopy of Nuclei From F Through Ca

5. The $(p, t)$ And $\left(p,{ }^{3}\right.$ He $)$ Reactions on Oxygen And Neon At $40 \mathrm{MeV}$

6. Elastic And Inelastic Scattering of $15 \mathrm{MeV}$ Deuterons From ${ }^{19}$ F

7. Energy Levels of ${ }^{19} \mathrm{Ne}$ And Differential Cross Sections From the ${ }^{19} \mathrm{~F}\left({ }^{3} \mathrm{He}, \mathrm{t}\right){ }^{19} \mathrm{Ne}$ Reaction

8. Reactions of $\mathrm{Ne}$ Isotopes With $40 \mathrm{MeV}$ Protons

9. The (d, $\left.{ }^{3} \mathrm{He}\right)$ Reaction at $20 \mathrm{MeV}$ on ${ }^{27} \mathrm{Al}$ and ${ }^{26} \mathrm{Mg}$

10. Elastic And Inelastic Scattering of $20 \mathrm{MeV}$ Deuterons From ${ }^{27} \mathrm{Al}$ And of $17.67 \mathrm{MeV}^{3} \mathrm{He}$ From ${ }^{26} \mathrm{Mg}$

11. Elastic Scattering of 19.0-MeV Deuterons 63

12. ${ }^{29} \mathrm{Si}(\mathrm{d}, \mathrm{p}){ }^{30} \mathrm{Si}$ Reaction 63

13. ( $\left.{ }^{3} \mathrm{He}, \mathrm{d}\right)$ Reactions On The Three Silicon Isotopes 64

14. ${ }^{40} \mathrm{Ca}(\mathrm{d}, \mathrm{p})$ and $(\mathrm{d}, \mathrm{d})$ Reaction Between 13 and $19 \mathrm{MeV} 65$

15. ${ }^{44} \mathrm{Ca}\left({ }^{3} \mathrm{He}, \mathrm{t}\right){ }^{44} \mathrm{Sc}$ Reaction 65

III. Spectroscopy of Nuclei From Sc Through Ni

16. Levels in ${ }^{44}$ Sc From The ${ }^{42} \mathrm{Ca}(\alpha, d)$ Reaction 69

17. Levels of ${ }^{44}$ Sc From The ${ }^{45} \mathrm{Sc}(\mathrm{d}, \mathrm{t})^{44} \mathrm{Sc}$ Reaction 72 
18. The Energy Levels of ${ }^{46} \mathrm{~V}$ studied By The ${ }^{46} \mathrm{Ti}\left({ }^{3} \mathrm{He}, \mathrm{t}\right)$ Reaction

19. The (d, $\left.{ }^{3} \mathrm{He}\right)$ Reaction on ${ }^{46} \mathrm{Ti}$ and ${ }^{48} \mathrm{Ti}$

20. Btudy of the $(d, \alpha)$ Reaction on the Titanium Isotopco

21. Nuclear Structure of ${ }^{48} \mathrm{Sc}$ From The ${ }^{49} \mathrm{Ti}\left(\mathrm{d},{ }^{3} \mathrm{He}\right)^{48} \mathrm{Sc}$ Reaction

22. States in ${ }^{50} \mathrm{~V}$ studied With The ${ }^{49} \mathrm{Ti}\left({ }^{3} \mathrm{He}, \mathrm{d}\right)$ and

${ }^{51} \mathrm{~V}(\mathrm{~d}, \mathrm{t})$ Reactions

23. J-Dependence in the (d,p) Reaction on ${ }^{50} \mathrm{Ti}$ and ${ }^{54} \mathrm{Fe}$

24. Intermediate Coupling Model and Shell Model

Description of ${ }^{53} \mathrm{Cr}$ and ${ }^{55} \mathrm{Fe}$

25. Review Article on $\mathrm{f}_{7 / 2}$ Shell

IV. Spectroscopy of Deformed Nuclei

26. A Study of Even Samarium Isotopes Using The $(p, t)$

Reaction

27. Elastic and Inelastic Scattering of Protons on ${ }^{176} \mathrm{Yb} 100$

28. $(p, t)$ Reactions on Deformed Nuclei

V. Interaction of Single Particle and Vibration States

29. ( $(\mathrm{p}, \mathrm{t})$ Reactions on $\mathrm{Ag}$ and Pd Isotopes

30. Levels of ${ }^{210}$ Po From the ${ }^{209} \mathrm{Bi}\left({ }^{3} \mathrm{He}, \mathrm{d}\right){ }^{210}$ Po Reaction 112

31. The Interaction of Alpha-particles With ${ }^{208} \mathrm{~Pb}$ and ${ }^{209} \mathrm{Bi}$ Below The Barrier

32. Half-Lives of $211 \mathrm{~g}, 211 \mathrm{~m}_{\text {Pu }}$ and $212 \mathrm{~g}, 212 \mathrm{~m}_{\mathrm{At}}$

33. The Quadrupole Moment of The $3^{-}$State In ${ }^{208} \mathrm{~Pb}$ :

A Summary

VI. Analog States And Coulomb Displacement Energies

34. The $\left({ }^{3} \mathrm{He}, t\right)$ Reaction To Analog States 
35. Coulomb Displacement Energies Using The $\left({ }^{3} H e, t\right)$ Reaction

36. The ${ }^{137} \mathrm{Ba}\left({ }^{3} \mathrm{He}, \mathrm{d}\right){ }^{138}$ La Reaction at $30 \mathrm{MeV}$

VII. Optical Model of The Nucleus

37. Elastic Scattering of $9.8 \mathrm{MeV}$ Protons

38. The Elastic Scattering of $16 \mathrm{MeV}$ Protons

39. Elastic and Inelastic Scattering of $18.6 \mathrm{MeV}$

Protons By ${ }^{68} \mathrm{Zn},{ }^{90} \mathrm{Zr}$, and ${ }^{114} \mathrm{Cd}$

40. Elastic Scattering of ${ }^{3} \mathrm{He}$ From ${ }^{58} \mathrm{Ni}$ and ${ }^{48} \mathrm{Ti}$

41. The Elastic Scattering of Alpha Particles

42. An Analysis of $30.3 \mathrm{MeV}$ Elastic Scattering Data

$$
\text { From }{ }^{40} \mathrm{Ca} \text { and }{ }^{59} \mathrm{Co}
$$

43. An Analysis of $30.3 \mathrm{MeV}$ Elastic Scattering From

$$
{ }^{58_{\mathrm{Ni}},}{ }^{120} \mathrm{Bu}_{\mathrm{H}} \text { and }{ }^{208_{\mathrm{Pb}}}
$$

44. Investigation of $\ell$-Dependent Effects In The Optical Model

\section{B . EXPER IMENTAL INSTRUMENTATION}

45. Beam-Current-Integrator Calibration

46. Position-Sensitive Detector Set-Up

47. True-Charge Pulser

48. Additions To The On-Line Computer

49. High Resolution Proton Spectrometer (HRS) And Scattering Chamber For The Los Alamos Meson Physics Facility (LAMPF) 
C. ACCELERATOR PERFORMANCE AND DEVELOPMENT

50. General Operation of The Tandem Van De Graaff 160

51. On-Line Computers, 3100 - PDP 8L 163

52. The Enge Split-Pole Spectrometer 164

53. Polarized Negative-Ion Source For The MP Tandem. 165

54. Accelerator Improvements 168

55. Revision of The Safety Survey And Interlock Systems 170

APPENDIX

56. Laboratory Personnel . . . 173

57. Advanced Degrees Granted, Academic Year 1969-70 175

58. Reports And Publications 176 


\section{INTRODUCTION}

This report summarizes the work done at the John H. Williams Laboratory of Nuclear Physics at the University of Minnesota during the year ending in August 1970. The work was supported by the United States Atomic Energy Commission under Contract AT(11-1)-1265.

Part A of this report describes the research conducted by the faculty, research associates, and students of the University of Minnesota. As in other recent years, much of the work of this laboratory has been directed towards improving our understanding of the optical model of the nucleus through the performance of precision elastic scattering experiments and the analysis of the resulting data. Another active field of work has been the study of the energy levels of many of the nuclei from boron through nickel by means of charged particle redctions produced by beams of protons, deuterons, ${ }^{3}$ He, and ${ }^{4}$ He. Other experiments dealt with the spectroscopy of some of the rare earth nuclei and of some of the nuclei at the heavy end of the periodic table.

Most of the work described in this report was conducted using the Minnesota MP tandem Van de Graaff machine, but a few sections describe the analysis of data taken with the proton linear accelerator (operation discontinued in January 1969) or with work done in collaboration with other Iaboratories.

Our most heavily used piece of experimental equipment was the charged particle magnetic spectrometer. The CDC- 3100 computer was used extensively for accumulation of data with arrays of charged particle detectors in the spectrometer and in other target chambers.

Part $B$ of this report describes some improvements to the experimental instrumentation.

Part $C$ discusses our operating experience with the tandem, the 
viii

computer, and the speclrumeter during the year. Tt also describes the final stages of development of the polarized negative ion source for the tandem and other improvements on the tandem and in the laboratory. An Appondix lists the laboratory personnel, advanced degrees granted during the past year, and publications resulting from our work.

J. M. Blair 


\section{A. RESEARCH PROGRAM \\ I. SCATTERING. AND REACTIONS IN LIGHT NUCLEI}

1.

\section{Proton-Proton Scattering Near $10 \mathrm{MeV}$}

R. E. Brown, N. Jarmie ${ }^{*}$, R. L. Hutson ${ }^{*}$, and J. L. Detch, Jr.

Discrepancies in existing, low-energy, proton-proton, scattering data have recently been pointed out in an analysis by Sher, Signell, and Heller. ${ }^{1}$ In order to attempt to resolve some of these discrepancies, differential cross sections for $p-p$ scattering have been measured ${ }^{2}$ at two energies near $10 \mathrm{MeV}$. One energy, $9.918 \mathrm{MeV}$, is one at which data have been reported by Slobodrian, et $a 1 .{ }^{3}$ and the other, $9.690 \mathrm{MeV}$, is one at which data have been reported by Johnston and Young. ${ }^{4}$ These two previously-reported data sets have been shown ${ }^{1 ; 5}$ to be mutually inconsistent.

The tandem Vain le Gradf accelerator and gas target facility at the Los Alamos Scientific Laboratory were used to make the present measurements. These measurements were reported in ref. 2 and were analyzed by Holdeman, Signell, and Sher, ${ }^{6}$ who concluded that the central, p-wave, phase parameter $\Delta_{C}$ extracted from these data was consistent with that obtained from data at higher and lower energies and was in definite disagreement with that obtained from the data of Slobodrian, et al. $^{3}$ However, the $s$-wave phase shift which they extracted from our data agreed with that extracted from the data of Slobodrian, et al. and was not consistent with analyses at other energies. Because of this apparent inconsistency in our data, a thorough reexamination of all experimental parameters was undertaken, and it was found that a malfunction in the device used to measure the detector collimator geometry had caused an approximate $2 \%$ systematic error in the absolute normalization. The corrected data are listed here in Table 1-1. 
The $s$-wave phase shift extracted from the data in this table is consistent with that at other energies and is in disagreement with that of Slobodrian, et al. It therefore appears as though the present data resolves the discrepancies which were present near $10-\mathrm{MeV}$.

\section{References}

* Permanent Address: Los Alamos Scientific Laboratory, Los Alamos, New Mexico 81544.

1M. S. Sher, P. Signel1, and L. Heller, Ann. Phys. (N.Y.) 58, 1 (1970).

2 N. Jarmie, R. E. Brown, R. L. Hutson and J. L. Detch, Jr., Phys. Rev. Letters 24,240 (1970).

3.R. J. Slobodrian, H. E. Conzett, E. Shield, and W. F. Tivol, Phys. Rev. 174, 1122 (1968).

4L. H. Johnston and D. E. Young, Phys. Rev. 116, 989 (1959).

${ }^{5}$ M. H. MacGregor, R. A. Anndt, and R. M. Wright, Phys. Rev. $\underline{179}, 1624$ (1969).

$6_{J}$. Holdeman, P. Signe11, and M. Sher, Phys. Rev. Letters 244, 243 (1970).

${ }^{7}$. Jarmie, J. H. Jett, J. L. Detch, Jr., and R. L. Hutson, Phys. Rev. Letters 25, 34 (1970). 
TABLE 1-1

Differential Cross Sections $p+p$ Elastic Scattering

\section{$2.918 \mathrm{MeV}$}

\begin{tabular}{|c|c|c|c|c|c|}
\hline $\begin{array}{l}\theta_{1 \mathrm{ab}} \\
\text { deg. }\end{array}$ & $\begin{array}{c}\sigma(\theta)_{1 \mathrm{ab}} \\
\mathrm{mb} / \mathrm{sr}\end{array}$ & $\begin{array}{l}\theta_{\text {c.m. }} . \\
\text { deg. } \\
\end{array}$ & $\begin{array}{c}\sigma(\theta) \mathrm{c} \cdot \mathrm{m} . \\
\mathrm{mb} / \mathrm{sr} \\
\end{array}$ & $\begin{array}{c}\text { Relative } \\
\text { Error } \\
\% \\
\end{array}$ & $\begin{array}{c}\text { Absolute } \\
\text { Error } \\
\% \\
\end{array}$ \\
\hline 10.00 & 296.22 & 20.05 & 74.83 & 0.80 & 0.90 \\
\hline $12 \cdot 50$ & 212.58 & 25.06 & 54.18 & 0.41 & 0.56 \\
\hline 15.00 & 194.83 & 30.08 & 50.20 & 0.39 & 0.54 \\
\hline 17.50 & 191.72 & 35.09 & 50.04 & 0.37 & 0.52 \\
\hline 20.00 & 189.03 & 40.10 & 50.09 & 0.37 & 0.52 \\
\hline 25.00 & 185.92 & 50.12 & 51.11 & 0.41 & 0.55 \\
\hline 30.00 & 180.31 & 60.13 & 51.91 & 0.34 & 0.50 \\
\hline 35.00 & 172.44 & 70.14 & 52.53 & 0.34 & $0.50^{\circ}$ \\
\hline 40.00 & 161.56 & 80.15 & 52.69 & 0.34 & 0.50 \\
\hline 45.00 & 148.37 & 90.15 & 52.46 & 0.36 & 0.52 \\
\hline 50.00 & 135.58 & 100.15 & 52.78 & 0.36 & 0.51 \\
\hline
\end{tabular}

\section{$2.690 \mathrm{MeV}$}

\begin{tabular}{|c|c|c|c|c|c|}
\hline $\begin{array}{l}\theta_{180} \\
\text { dcs. } \\
\end{array}$ & $\begin{array}{c}\sigma(\theta)_{1 \mathrm{lab}} \\
\mathrm{mb} / \mathrm{sr} \\
\end{array}$ & $\begin{array}{l}\theta_{\mathrm{c} . \mathrm{m} .} . \\
\mathrm{deg} . \\
\end{array}$ & $\begin{array}{c}\sigma(\theta) \mathrm{cm} . \\
\mathrm{mb} / \mathrm{sr} \\
\end{array}$ & $\begin{array}{c}\text { Relative } \\
\text { Error } \\
\% \\
\end{array}$ & $\begin{array}{c}\text { Absolute } \\
\text { Error } \\
\% \\
\end{array}$ \\
\hline 13.00 & 215.29 & 26.06 & 54.98 & 0.41 & $0.5:$ \\
\hline 15.00 & 201.79 & 30.07 & 51.99 & 0.39 & 0.53 \\
\hline 20.00 & 196.07 & 40.09 & 51.96 & 0.36 & 0.52 \\
\hline 25.00 & 192.56 & 50.11 & 52.94 & 0.40 & 0.54 \\
\hline 30.00 & 186.90 & 60.13 & 53.82 & 0.41 & 0.55 \\
\hline
\end{tabular}




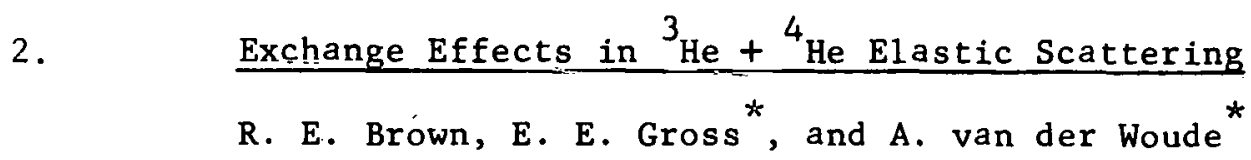

Theoretical calculations of the elastic scattering of ${ }^{3}$ He by ${ }^{4} \mathrm{He}$ in which the resonating-group method in Lle une-ehanncl approximatinn is employed have yielded ${ }^{1}$ reasonably good agreement with experiment. These calculations predict ${ }^{2,3}$ a resonance in the scattering which is rather sharply backward peaked, which occurs at about $39 \mathrm{MeV}{ }^{3} \mathrm{Hc}$ lab energy, and which has a width of about $10 \mathrm{MeV}$ (lab). This predicted resonance arises from exchange terms which are present in the calculation because the Pauli Principle is fully taken into account. We have found by experiment that such a resonance does actually occur in ${ }^{3} \mathrm{He}+$ ${ }^{4}$ He scattering.

The experimental observation was made by using the ${ }^{3}$ He beam produced by the Oak Ridge Isochronous Cyclotron and using the Oak Ridge, Elbek type ${ }^{4}$ broad-range spectrograph (BRS). The ${ }^{3}$ He beam entered a target gas cell containing ${ }^{4}$ He at a plessure of 300 Torr and at a temperature of $21^{\circ} \mathrm{C}$. Recoil ${ }^{4} \mathrm{He}$ nuclei were observed with the BRS set at an angle of $3.4^{\circ}$ to the incident beam, and were detected at the BRS focal surface with a $600-\mu$ thick, position-sensitive, silicon, surface-barrier detector. The recoil spectra were quite free from. background, and a speclıum at $29.4 \mathrm{MoV}^{3}$ He energy is shuwn in Fig. $2-1$. The recoil $1 \mathrm{ab}$ angle of $3.4^{\circ}$ corresponds to a c.m. angle of $173.2^{\circ}$ for the scattered ${ }^{3}$ He nucleus. By varying the ${ }^{3}$ He beam energy from about $20 \mathrm{MeV}$ to about $50 \mathrm{MeV}$ an excitation curve for the c.m. differential cross section at $173.2^{\circ}$ was measured. The absolute cross section scale was determined by normalization at $25 \mathrm{MeV}(1 \mathrm{ab})$ and $42^{\circ}$ (1ab) to the 
data of Jacobs and Brown ${ }^{2}$. The measured cross sections are given in Table 2-1 and are shown in Fig. 2 -2. Also shown in Fig. 2-2 are two calculated curves, data of Jacobs and Brown ${ }^{2}$ at $155^{\circ}$, and data of Schwandt et ${ }^{2} .{ }^{5}$ at $162^{\circ}$. It is clear that a resonance structure appears at $173.2^{\circ}$ which is absent at the more forward angles shown. The solid curve in Fig. 2-2 is the resonating-group prediction which uses $1.66 \mathrm{~F}$ for the rms radius of the ${ }^{3} \mathrm{He}$ cluster. ${ }^{1}$ Although the energy at which the resonance structure occurs is given rather well by the calculation, the strength of the structure is overestimated. One possible reason for this overestimation is the lack of inclusion of reactions in the calculation. Another possible reason is that the low-density regions of the ${ }^{4} \mathrm{He}$ and ${ }^{3} \mathrm{He}$ wave functions are not given correctly by the Gaussian forms used in the calculation ${ }^{1}$, and it is precisely these regions that one would expect to be important in backward-peaked exchange phenomena. The dashed curve in Fig. 2-2 is a calculation performed in which the rms radius of the ${ }^{3} \mathrm{He}$ cluster has been increased to $1.89 \mathrm{~F}$. The improved agreement with experiment suggests that to explain the present data it is important to describe properly the long-range parts of the cluster wave functions.

\section{$\underline{\text { References }}$}

*Permanent address: Oak Ridge National Laboratory, Oak Ridge Tennessee 37830 .

${ }^{1}$. E. Brown and Y. C. Tang, Phys. Rev. 176, 1235 (1968).

${ }^{2}$ C. G. Jacobs, Jr., and R. E. Brown, Phys. Rev. C 1 , 1615 (1970).

${ }^{3} \mathrm{Y}$. C. Tang, in Proceedings of the International Conference on Clustering Phenomena in Nuclei, Bochum, Germany 1969 (International Atomic Energy Agency, Vienna, 1969), p. 109.

${ }^{4} \mathrm{~J}$. Borggreen, B. Elbek, and L. P. Nielsen, Nucl. Instr. Methods 24,1 (1963).

${ }^{5}$ P. Schwandt, B. W. Ridley, S. Hayakawa, L. Put, and J. J. Kraushaar, Phys. Letters 30B, 30 (1969). 
Table 2-1. Differential cross section (c.m.) for ${ }^{4} \mathrm{He}\left({ }^{3} \mathrm{He},{ }^{3} \mathrm{He}\right)^{4} \mathrm{He}$ at a. c.m. angle of $173.2^{\circ}$. The indicated errors are relative, and in addition to these there is an error of $\pm 5 \%$ in the absolute cross-section scale.

\begin{tabular}{c|c}
$\begin{array}{c}E_{1 \mathrm{ab}} \\
(\mathrm{MeV})\end{array}$ & $\begin{array}{l}\sigma_{\mathrm{c} . \mathrm{m} .} \\
(\mathrm{mb} / \mathrm{sr})\end{array}$ \\
\hline 19.5 & $87.3 \pm 2.7$ \\
24.6 & $89.9 \pm 2.7$ \\
29.4 & $90.9 \pm 2.8$ \\
34.2 & $96.3 \pm 2.9$ \\
39.1 & $93.1 \pm 2.8$ \\
43.5 & $76.1 \pm 2.2$ \\
51.1 & $49.0 \pm 1.4$
\end{tabular}




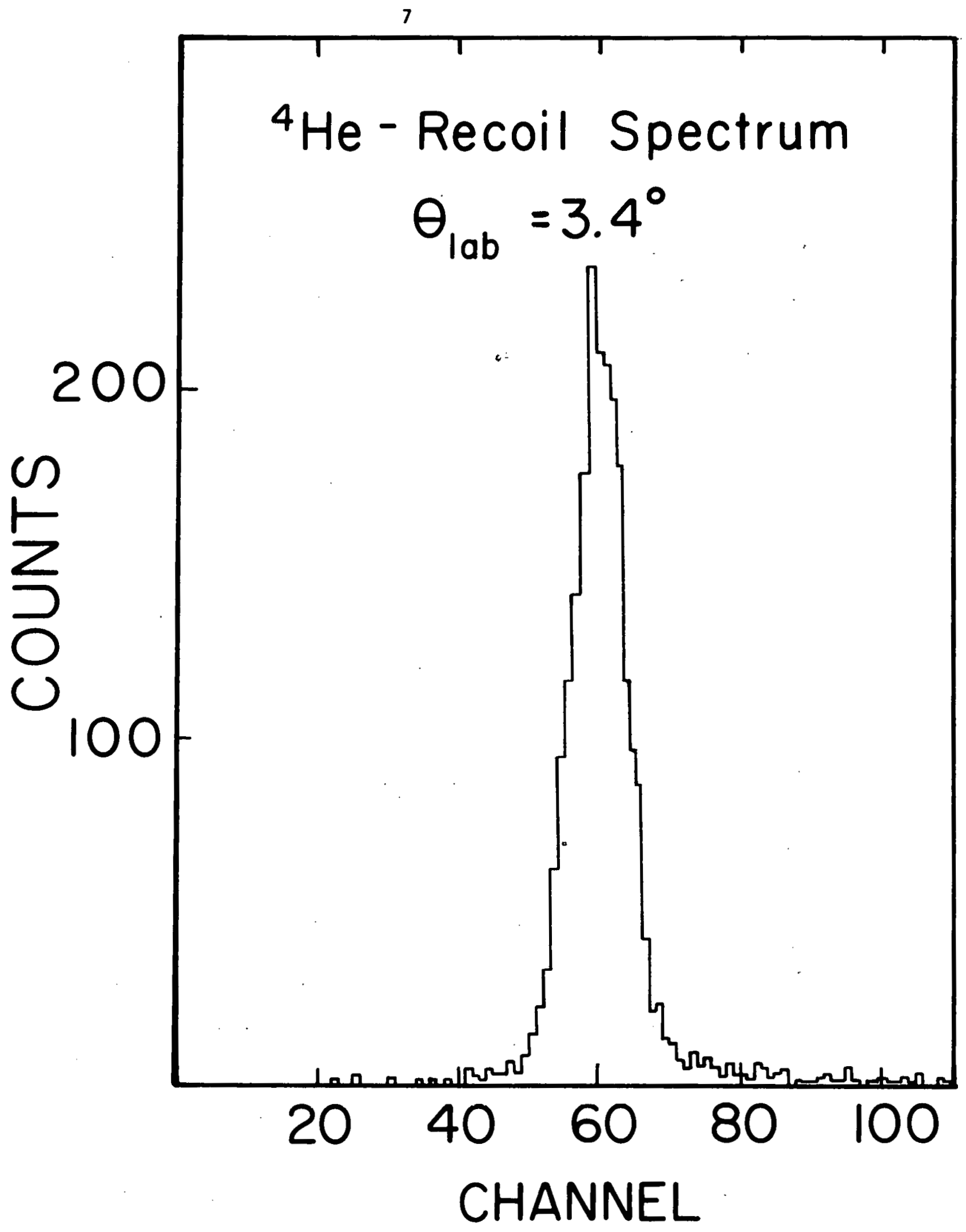

Fig. 2-1. ${ }^{4}$ He spectrum at $3 \cdot 4^{\circ}$ (1ab) from the bombardment of ${ }^{4}$ He with 29.4-MeV (lab) ${ }^{3}$ He particles. The channel axis corresponds to the position-times-energy output from a position-sensitive detector placed at the focal surface of a magnetic spectrograph. High Channels correspond to low ${ }^{4}$ He energy (low BP). 


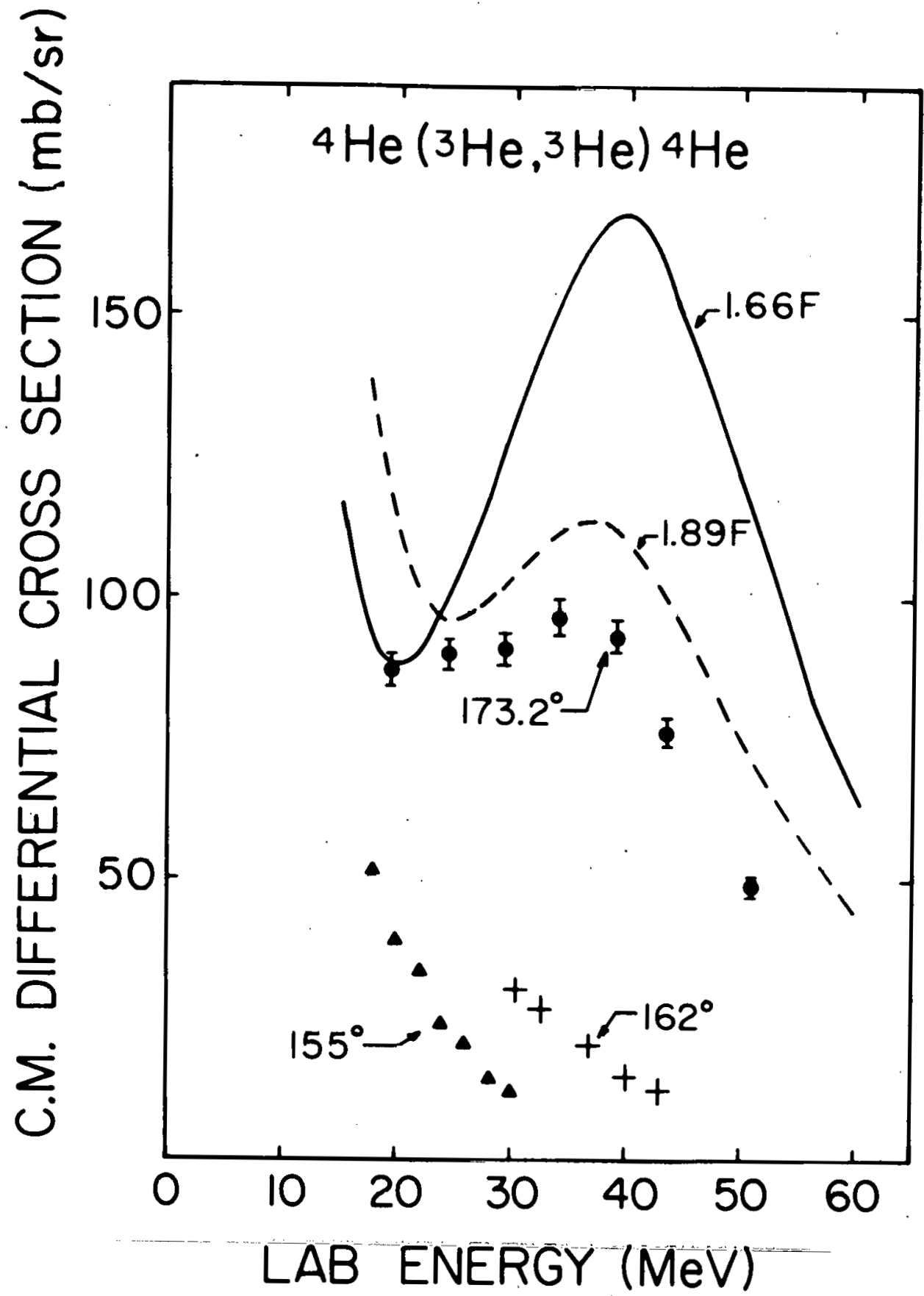

Fig. 2-2. Differential cross section (c.m.) vs lab energy for ${ }^{4} \mathrm{He}\left({ }^{3} \mathrm{He},{ }^{3} \mathrm{He}\right)^{4} \mathrm{He}$. The data at $173.2^{\circ}$ (c.m.) are those of the present experiment, the data at $162^{\circ}$ (c.m.) are those of ref. 5, and the data at $155^{\circ}$ (c.m.) are those of ref. 2. The curves are the results of theoretical calculations in which the indicated rms radii for ${ }^{3}$ He were used. 


\section{R. E. Brown and Y. C. Tang}

\section{Successes with resonating-group calculations in the one-channel} approximation have encouraged attempts to include effects of reactions, even if only in a phenomenological way. In the one-channel approximation. the radial scattering function $f_{\ell}(r)$ satisfies the equation ${ }^{1}$

$$
\left[\frac{\hbar^{2}}{2 \mu}\left(\frac{d^{2}}{d r^{2}}-\frac{\ell(l+1)}{r^{2}}\right)+E-V_{D}(r)-V_{C}(r)\right] f_{l}(r)=\int k\left(r_{l} r^{\prime}\right) f_{l}\left(r^{\prime}\right) d r^{\prime}
$$

where $V_{D}, V_{C}$, and $k_{\ell}$ are found from the resonating-group method ${ }^{2}$ in which a nucleon-nucleon potential and fully antisymmetrized wave function are used. A simple but somewhat inconsistent way to include in the cheory effects of reactions on elastic scattering is to add a local, phenomenological, imaginary potential $i W(r)$ to the direct potenciai $v_{D}$. Such a modification has been made in the existing resonating-group codes $1,3,4$ for the systems ${ }^{3} \mathrm{He}+{ }^{4} \mathrm{He},{ }^{4} \mathrm{He}+{ }^{4} \mathrm{He}$, and ${ }^{3} \mathrm{He}+{ }^{3} \mathrm{He}$. Investigation of the effects of this modification are in progress. Fig. $3-i$ indicates how the inclusion of an imaginary potentiai affects the: comparison with $30-\mathrm{MeV}(\mathrm{lab}),{ }^{3} \mathrm{He}+{ }^{4} \mathrm{He}$, elastic scattering data.

\section{$\underline{\text { References }}$}

${ }^{i}$ Y. C. Tang, E. Schmid, and K. Wildermuth, Phys. Rev. 131, 2631 (1963):

R. E. Brown and y. C. Tang, Phys. Kev. 176, 1235 (1968).

${ }^{2}$ K. Wildermuth and W. McClure, in Springer Tracts in Modern Physics, ed. by G. Hohler (Springer-Verlag, Berlin, 1966), Vol. 41.

${ }^{3}$ I. Reichstein and Y. C. Tang, Nucl. Phys. A139, 144 (1969).

${ }^{4}$ D. R. Thompson and Y. C. Tang, Phys. Rev. 159, 806 (1967).

${ }^{5}$ C. G. Jacobs, Jr., and R. E. Brown, Phys. Rev. C 1, 1615 (1970). 


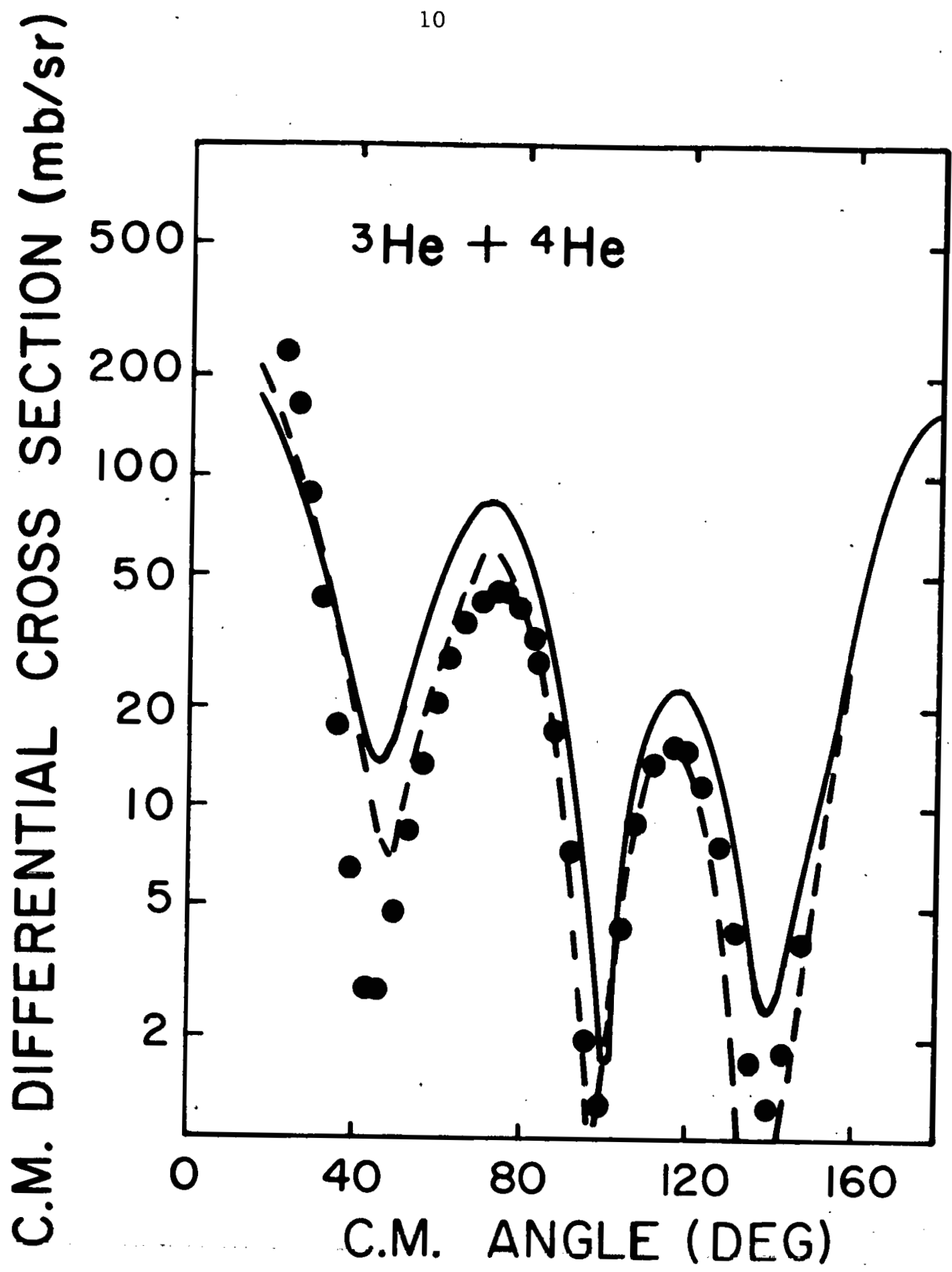

Fig. 3-1. Comparison of resonating-group calculations with the $30-\mathrm{MeV}$ (lab) ${ }^{3} \mathrm{He}+{ }^{4} \mathrm{He}$ elastic scattering data (points) of ref. 5. The solid curve is the result of a calculation with no imaginary potential present, whereas the dashed curve is obtained with an imaginary potential of Saxon-Woods shape having a depth of $4 \mathrm{MeV}$; a radius of $2.5 \mathrm{~F}$, and a diffuseness of $0.4 \mathrm{~F}$. 


\section{Study of the $1-p$ Shell with $40-\mathrm{MeV}\left(p,{ }^{3} \mathrm{He}\right)$ and $(\mathrm{p}, \mathrm{t})$ Reactions \\ D. K. Olsen and R. E. Brown}

Data ${ }^{1,2}$ obtained with the University of Minnesota Proton Linear Accelerator ${ }^{3}$ involving two-nucleon-transfer reactions to nuclei in the 1-p shell have been analyzed by means of the distorted-wave Born approximation (DWBA). The initial and final nuclear states were described by the $1 \mathrm{p}$-shell wave functions of Cohen and Kurath. ${ }^{4,5}$ Table 4-1 shows the transitions which have been analyzed and lists the coefficients of fractional parentage (CFP) derived from the $1 p$-sheli wave functions. The proton optical-model parameters were taken from the work of Watson, et al. $^{6}$ and are given in Table 4-2. The calculations were carried out with 3 sets of mass-3 optical-model parameters, which are 1 isted as Potentials A, B, and C in Table 4-2. Potential A is that used hy Hiebert, et al. ${ }^{7}$ Potential $B$ is from an analysis by Becchetti ${ }^{8}$ of a large amount of data for ${ }^{3}$ He scattering from medium and heavy nuclei. Potential $C$ is from the analysis of Buffa, et al. ${ }^{9}$ of ${ }^{3}$ He elastic scattering from ${ }^{10} \mathrm{~B}$.

Figures showing comparisons of the calculations with experiment have been given by $01 \operatorname{sen}^{10}$ and will not be shown here. Instead we simply make several comments concerning the shape comparisons. Potential A gave the best fits to $L=2$ shapes; Potential B gave the best fits to $\mathrm{L}=0$ shapes except for the ${ }^{12} \mathrm{C}$ target; Potential $\mathrm{C}$ gave the best fit to the $\mathrm{L}=0$ transition ${ }^{12} \mathrm{C}\left(\mathrm{p},{ }^{3} \mathrm{He}\right){ }^{10} \mathrm{~B}(1.74)$. Generally the calculated shapes are comparable to the experimental shapes; however, for several transitions for which both $\mathrm{L}=0$ and $\mathrm{L}=2$ are allowed, the calculation predicts far more $\mathrm{L}=0$ component than is actual 1 y observed. 
Comparison of the experimental, ratio-to-ground-state, angle-, integrated cross section with that of the calculation is made in Table

4 -3. The effective-interaction, singlet-triplet ratio $R$ was

taken to he 3.0. Two major points of discrepancy between experiment and calculation may he noted in this table. First, the ratio of the ${ }^{14} \mathrm{C}(\mathrm{p}, \mathrm{t}){ }^{12} \mathrm{C}(4.43)$ to ${ }^{14} \mathrm{C}(\mathrm{p}, \mathrm{t}){ }^{12} \mathrm{C}(\mathrm{g} . \mathrm{s}$.$) cross sections is calculated$ to be much larger than is actually observed. Second, the calculated ratios for the $\mathrm{T}=1$ transitions from the ${ }^{16} \mathrm{O}$ and ${ }^{12} \mathrm{C}$ targets are generally in worse agreement with experiment than are the ratios for the $\mathrm{T}=0$ transitions. Otherwise, the agreement is within about $25 \%$.

\section{$\underline{\text { References }}$}

${ }^{1}$. E. Brown, N. M. Hintz, C. G. Hoot, J. R. Maxwell, and A. Scott, John H. Williams Laboratory of Nuclear Physics Annual Report, 1966, p. 70 (unpub1 ished).

${ }^{2}$ D. K. Olsen, W. D. Harrison, R. E. Brown, and C. A. Barnes, John H. Williams Laboratory of Nuclear Physics Annual Report, 1.968, p. 83 (unpublished).

3 Deceased.

${ }^{4}$ S. Cohen and D. Kurath, Nucl. Phys. $\underline{75}, 1$ (1965).

${ }^{5}$ S. Cnhen and D. Kurath, to be published, and Private Communication.

6. A. Watson, P. P. Singh, and R. E. Segel, Phys. Rev.. 182, 977 (1969).

7 J. C. Hiebert, E. Newman, and R. H. Bassel, Phys. Rev. 154, 898 (1967).

${ }^{8}$ F. D. Becchetti, Jr., Ph.D. Thesis, University of Minnesota, 1970 (unpublished).

${ }^{9}$ A. J. Buffa, Jr., J. S. Allen, and M. K. Brussel, Bull. Am. Phys. Soc. 14, 488 (1969) and Private Communication.

10D. K. O1sen, Ph.D. Thesis, University of Minnesota, 1970 (unpub1ished). 
Table 4-1.

1p Shell Transitions

$$
\begin{aligned}
& \text { Reaction and } Q \quad J_{1}^{\pi}, T_{1} \quad E_{X}(M e V) \quad J_{f}^{\pi}, T_{f} \quad J \quad T \quad 2 j_{1} \quad 2 j_{2} \quad \text { CFP }
\end{aligned}
$$

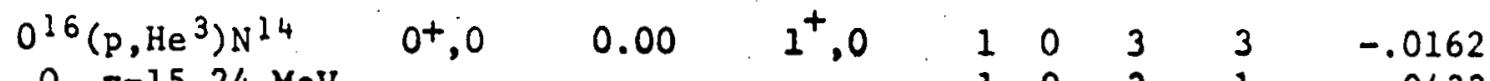

$$
\begin{aligned}
& \mathrm{Qgs}^{=-15.24 \mathrm{MeV}} \quad \begin{array}{lllll}
1 & 0 & 3 & 1 & -.0433
\end{array} \\
& \begin{array}{lllll}
1 & 0 & 1 & 1 & .2079
\end{array}
\end{aligned}
$$

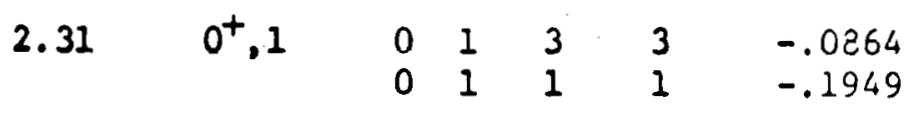

$$
\begin{aligned}
& \begin{array}{lllllll}
3.95 & 1+, 0 & 1 & 0 & 3 & 3 & .06 \% 8
\end{array} \\
& \begin{array}{lllll}
1 & 0 & 3 & i & -.1987
\end{array} \\
& \begin{array}{lllllllll}
C^{14}(p, t) C^{12} & 0^{+}, 1 & 0.00 & 0^{+}, 0 & 0 & 1 & 3 & 3 & .0667 \\
Q_{g s}=-4.64 \mathrm{Mev} & & & & .0 & 1 & 1 & 1 & .052
\end{array}
\end{aligned}
$$

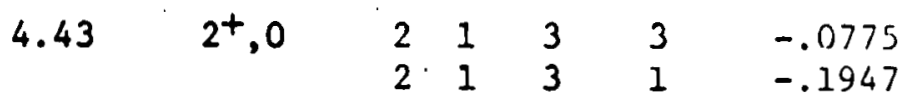

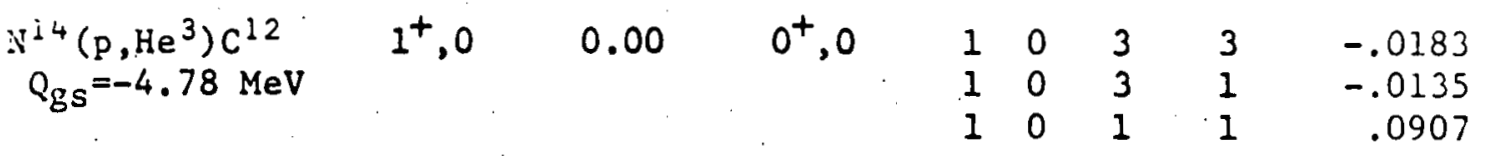

$$
\begin{aligned}
& \begin{array}{lllllll}
4.43 & 2^{+}, 0 & 1 & 0 & 3 & 3 & -.0471
\end{array} \\
& \begin{array}{lllll}
1 & 0 & 3 & 1 & .1242
\end{array} \\
& \begin{array}{lllll}
1 & 0 & 1 & i & -.0201
\end{array} \\
& \begin{array}{lllll}
2 & 0 & 3 & 1 & -.1033
\end{array} \\
& \begin{array}{lllll}
3 & 0 & 3 & 3 & -.00: 6
\end{array} \\
& \begin{array}{lllllllll}
C: 2\left(\mathrm{p}, \mathrm{He}^{3}\right) \mathrm{B}^{10} & 0^{+}, 0 & 0.00 & 3^{+}, 0 & 3 & 0 & 3 & 3 & -.3428 \\
& & .72 & 1^{+}, 0 & 1 & 0 & 3 & 3 & -.1248 \\
& & & 1 & 0 & 3 & 1 & .2146 \\
& & & 1 & 0 & 1 & 1 & .0089
\end{array} \\
& \begin{array}{lllllll}
1.74 & 0^{+}, 1 & 0 & 1 & 3 & 3 & -.2753 \\
& & 0 & 1 & 1 & 1 & -.1532
\end{array} \\
& 2.15 \quad 1+.0 \quad \begin{array}{lllll}
1 & 0 & 3 & 3 & -.196 \% \\
1 & 0 & 3 & 1 & -.0289 \\
1 & 0 & 1 & 1 & .0985
\end{array} \\
& \begin{array}{lllllll}
3.59 & 2^{+} .0 & 2 & 0 & 3 & 1 & -.1955
\end{array}
\end{aligned}
$$


Table 4-2

OPTICAL MODEL PARAMETERS FOR IP SHELL

Protons

\begin{tabular}{|c|c|c|c|c|c|c|c|c|}
\hline Target & $R_{0}$ & $\mathbf{a}$ & $\mathrm{v}$ & $R_{1}$ & $a_{1}$ & $\mathrm{w}_{\mathrm{v}}$ & $w_{s}$ & $\mathrm{R}_{\mathrm{c}}$ \\
\hline$c^{12}$ & 1.11 & .57 & 47.9 & 1.11 & .50 & 4.6 & 7.4 & 1.11 \\
\hline$c^{14}$ & 1.11 & .57 & 51.7 & 1.11 & .50 & 5.1 & 8.8 & 1.11 \\
\hline$N^{24}$ & 1.11 & .57 & 47.7 & 1.11 & .50 & 5.1 & 7.4 & 1.11. \\
\hline 016 & 1.11 & .57 & 47.5 & 1.11 & .50 & 5.4 & 7.4 & 1.11 \\
\hline
\end{tabular}

Potential

$\begin{array}{lllllllll}\text { A } & 1.14 & .675 & 169.0 & 1.82 & .566 & 32.1 & 0.0 & 1.40 \\ \text { B } & 1.20 & .72 & 152 .-.17 \mathrm{E} & 1.43 & .84 & 41.0-.33 \mathrm{E} & 0.0 & 1.30 \\ \text { A } & 1.078 & .825 & 171.8 & 1.912 & .403 & 16.0 & 0.0 & 1.07\end{array}$




\section{TABLE 4-3}

INTEGRATED CROSS SECTION RATIOS NORMALIZED TO INDIVINUAL GROUND STATES

DWBA

Pot. A Pot: B Pot. C

ction

$0^{16}\left(\mathrm{p}, 1 \mathrm{Hc} \mathrm{c}^{3}\right) \mathrm{H}^{14}$ (g.s.) $0 \quad 10^{\circ} 65^{\circ} \quad 292$

$(2.31) \quad 1^{\text {a }} 10^{\circ} 80^{\circ} \quad 551$

(3.95) $0 \quad 10^{\circ} 70^{\circ} \quad 531$

$\mathrm{C}^{14}(\mathrm{p}, \mathrm{t}) \mathrm{C}^{12}(\mathrm{~g} . \mathrm{s}) \quad .1 \quad 10^{\circ} 75^{\circ} \quad 1075$

$(4.43) \quad 1 \quad 10^{\circ} 75^{\circ} \quad 2026$

$\begin{array}{rrrrr}\mathrm{N}^{14}\left(\mathrm{p}, H \mathrm{e}^{3}\right) \mathrm{C}^{12} \text { (g.s.) } & 0 & 10^{\circ} & 80^{\circ} & 233 \\ (4.43) & 0 & 10^{\circ} & 70^{\circ} & 882\end{array}$

$\mathrm{C}^{12}\left(\mathrm{p}, \mathrm{He}^{3}\right) \mathrm{B}^{10}(\mathrm{g.s.}) \quad 0 \quad 10^{\circ} 75^{\mathrm{s}} \quad 7: \mathrm{s}$

$(.72) \quad 0 \quad 10^{\circ} 75^{\circ} \quad 475$

$(1.74) \quad 1^{a} \quad 10^{\circ} 80^{\circ} .686$

$(2.15) \quad 0 \quad 10^{\circ} 80^{\circ} \quad 303$

292

377

444

1075

3558

$\begin{array}{ll}233 & 233 \\ 729 & 745\end{array}$

$72 y-745$

$7: 9$

583

96.5
$22 !$
292

385

505

1075

6385

745

748
688

1189

276

75

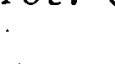

748
583
1055
247
67

Pot. A Pot. B Pot. C

1.00

.68
.83

1.00

.70

$1.00 \quad 1.00$

$1.75 \quad 3.12$

1.00 .1 .00

$.83 \quad .55$

$1.00 \quad \because .00 \quad 1.00$

$\begin{array}{lll}1.23 & 1.45 & 1.23\end{array}$

1.4] $\quad 1.72 \quad 1.54$

$.74 \quad .91 \quad .89$

aThe value $R=3.0$ has been ues?, and it arrects only thesi $T:=1$ transitions. 


\section{SPECTROSCOPY OF NUCLEI FROM F THROUGH $\mathrm{Ca}$}

\section{5. The $(p, t)$ and $\left(p,{ }^{3} \mathrm{He}\right)$ Reactions on Oxygen and Neon at $40 \mathrm{MeV}$}

D. K. 01 sen and R. E. Brown

Some of the two-nucleon-transfer data ${ }^{1,2}$ on oxygen and neon isotopes obtained with the proton linear accelerator have been analyzed ${ }^{3}$ by use of the distorted-wave Born approximation (DWBA). We here brief1y report some of the results.

$17 \mathrm{O}(\mathrm{p}, \mathrm{t})^{15} \mathrm{O}$ and ${ }^{17} \mathrm{O}\left(\mathrm{p},{ }^{3} \mathrm{He}\right)^{15} \mathrm{~N}$. Studied were transitions to the $1 / 2^{-}$ground states and lowest $3 / 2^{-}$states in the mirror nuclei ${ }^{15} \mathrm{O}$ and ${ }^{15} \mathrm{~N}$. The states in the residual nuclei were taken as $1 \mathrm{p}_{1 / 2}$ and $1 \mathrm{p}_{3 / 2}$ holes in an ${ }^{16} 0$ core, and the ${ }^{17} 0$ ground state was taken as a $1 d_{5 / 2}$ neutron outside an ${ }^{16} 0$ core. In such a description the coefficients of fractional parentage (CFP) for two-nucleon transfer are given by ${ }^{4}$ $(\mathrm{CFP})^{2}=(2 \mathrm{~J}+1)(2 \mathrm{~T}+1) / 12$, where $\mathrm{J}$ and $\mathrm{T}$ are the angular momentum and isospin of the transferred pair. These CFP are given in Table 5-1. The optical-model parameters used in the proton channel are those of Watson, et $a 1 .{ }^{5}$, and those used in the mass-3 channel are close to those of Becchetti. ${ }^{6}$ Quite acceptable fits to the experimental, differential-cross-section shapes were obtained for three of the four transitions. The exception is the ${ }^{17} \mathrm{O}\left(\mathrm{p},{ }^{3} \mathrm{He}\right){ }^{15} \mathrm{~N}$ (g.s.) transition whose cross_section_decreases_with angle much_more_rap1dly_with angle than does the DWBA calculation.

Experimental and calculated, angle-integrated cross sections are compared in Table, 5-2. When the $(p, t)$ and $\left(p,{ }^{3} \mathrm{He}\right)$ transitions are considered separately, calculated and experimental ratios of the $3 / 2^{-}$ crosis section to the $1 / 2^{-}$cross section agree within $30 \%$; however the ratios of $\left(p,{ }^{3} \mathrm{He}\right)$ cross sections to the mirror-state $(p, t)$ cross section are calculated to be about twice as large as actually observed. 
The latter fact is an example of previously noted ${ }^{7}$ difficulties in comparing $(p, t)$ transitions with $\left(p,{ }^{3} \mathrm{He}\right)$ transitions.

Unfavored Transitions. The reactions ${ }^{18} \mathrm{o}(\mathrm{p}, t){ }^{16} \mathrm{O}(8.88)$ and ${ }^{22} \mathrm{Ne}(\mathrm{p}, \mathrm{t}){ }^{20} \mathrm{Ne}(4.97)$ are transitions from $0^{+}$initial states to $2^{-}$final states and, as such, violate the standard selection rules for direct, two-nucleon pickup. Differential cross sections for these two reactions were measured. The integrated cross sections are about one-tenth of those for "allowed" transitions, and the angular distributions appear to have an $\mathrm{L}=3$ shape. Our DWBA code gives zero probability for these reactions.

${ }^{22} \mathrm{Ne}(\mathrm{p}, \mathrm{t})^{20} \mathrm{Ne}$. The Nilsson mode ${ }^{8}$ was used to describe the states involved in transitions to the $0^{+}, 2^{+}, 4^{+}$members of the ground-state, $\mathrm{K}=0$, rotational band $\left(0,1.63,4.25 \mathrm{MeV}\right.$ of excitation) of ${ }^{20} \mathrm{Ne}$ and transitions to the $0^{+}, 2^{+}$members of an excited, $\mathrm{K}=0$, band $(6.72$ and $7.43 \mathrm{MeV}$ of excitation) in ${ }^{20} \mathrm{Ne}$. The optical-model parameters in the proton channel were those of Fricke, et $a 1.9$ for ${ }^{27} \mathrm{Al}$ and in the triton channel were those of Becchetti. ${ }^{10}$ The CFP for the transitions are given $^{11}$ in Table $5-3$, as a function of deformation $\eta$. Evidence from elastic scattering and E2-transition rates has indicated that for ${ }^{20} \mathrm{Ne}$ $\eta$ is large and positive. The calculated cross section shapes ${ }^{3}$ for $\eta=+6$ are adequate. Table 5-4 shows a comparison of experimental and calculated integrated cross sections normalized to 100 for the groundstate transition. The calculated values are quite insensitive to variations in the optical potentials used. Striking discrepancies between the simple Nilsson-model calculations and experiment are evident in the table. For example, for $\eta=+6$ the cross section for excitation of the 
1.63-MeV state is calculated to be only about one-half of the measured value, whereas that of the $4.25 \mathrm{MeV}$ state is calculated to be five times the measured value. In addition the cross section ratios to the ground state for the $6.72-$ and $7.43-\mathrm{MeV}$ states are calculated to be about 15 times that experimentally observed. Our conclusion is that the simple Nilsson model does not give an adequate description of the nuclear states in question.

\section{References}

${ }^{1}$ D. K. Olsen and R. E. Brown, John H. Williams Laboratory of Nuclear Physics Annual Report, 1968, p. 86 (unpublished).

${ }^{2}$ D. K. Olsen and R. E. Brown, John H. Williams Laboratory of Nuclear Physics Annual Report, 1969, p. 17 (unpublished).

3. K. Olsen, Ph.D. Thesis, University of Minnesota, 1970 (unpub1ished).

${ }^{4}$ B. F. Bayman, Private Communication.

5B. A. Watson, P. 0. Singh, and R. E. Segal, Phys. Rev. 182, 977 (1969).

${ }^{6}$ F. D. Becchetti, Jr., Ph.D. Thesis, University of Minnesota, 1970 (unpublished).

7. G. Fleming, J. Cerny, and N. K. Glendenning, Phys. Rev. 165, 1153 (1968).

${ }^{8}$. G. Nìisoñ, Kğl. Uanske Videnskab. Selskab, Mat."Fys. Medd. 29, 16 (1955).

${ }^{9}$ M. P. Fricke and G. R. Satchler, Phys. Rev. 139, B567 (1965).

${ }^{10}$ Ref. 6 and Private Communication.

${ }^{11}$ R. Ibarra, Private Communication. 
TABLE 5-1

COEFFICIENTS OF FRACTIONAL PARENTAGE FOR STATES IN MASS 15

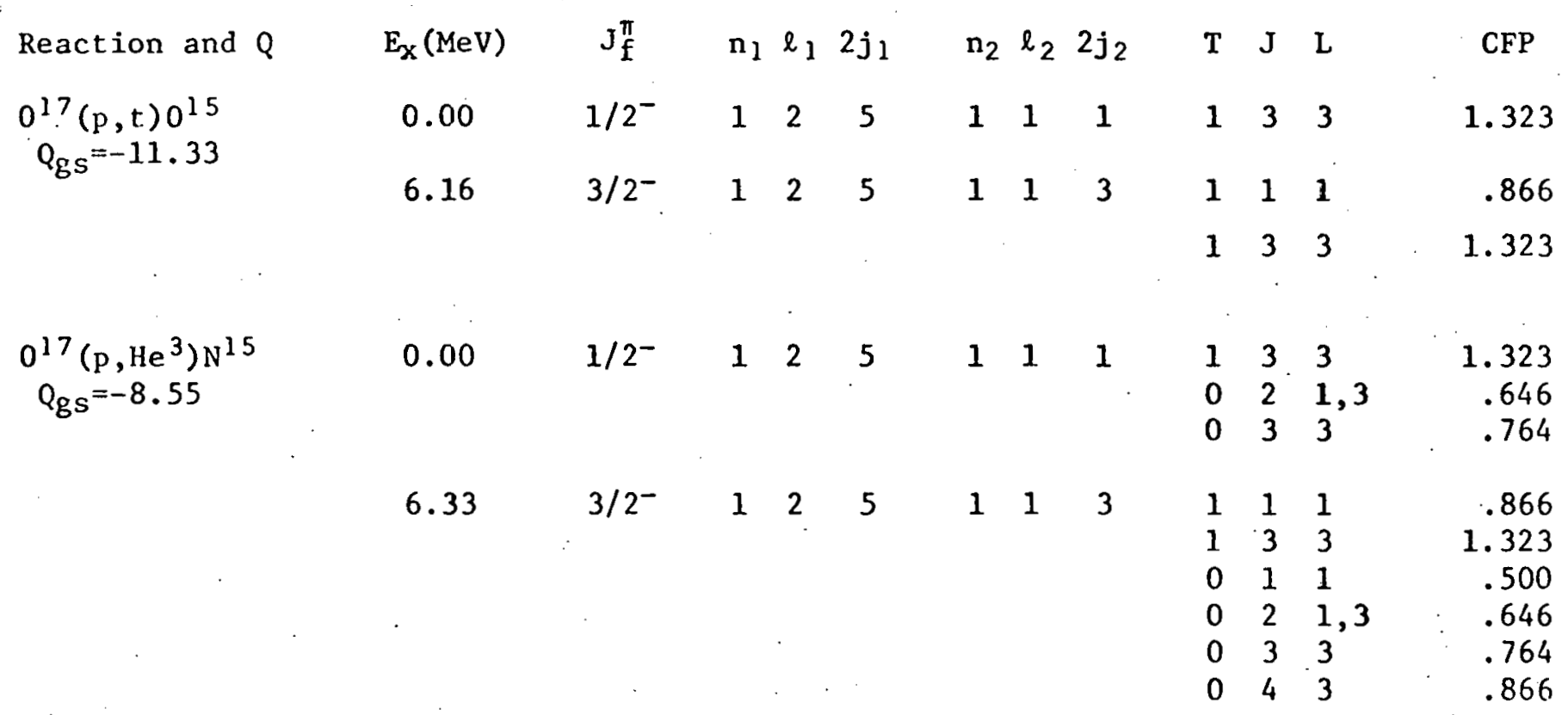

TABLE 5-2

INTEGRATED CROSS SECTION RATIOS FOR STATES IN MASS 15

\begin{tabular}{|c|c|c|c|c|c|c|c|c|}
\hline \multirow[b]{2}{*}{ Reaction } & \multirow[b]{2}{*}{$\mathrm{J}_{\mathrm{I}}^{\pi}$} & \multirow[b]{2}{*}{$\theta_{i}$} & \multirow[b]{2}{*}{$\theta_{\mathrm{f}}$} & \multirow{2}{*}{$\sigma-\mu b$} & \multicolumn{2}{|c|}{$\begin{array}{l}\text { DWBA normalized to } \\
\text { individual ground states }\end{array}$} & \multicolumn{2}{|c|}{$\begin{array}{l}\text { DWBA normelized to } \\
0^{17} \cdot(\mathrm{p}, \mathrm{t}) 0^{15}(\mathrm{~g} . \mathrm{s} .)\end{array}$} \\
\hline & & & & & DWBA & DLSBA/o & DWBA & $D N B A / \sigma$ \\
\hline $\begin{array}{r}0^{17}(p, t) 0^{15}(g . s .) \\
(6.16)\end{array}$ & $\begin{array}{l}1 / 2^{-} \\
3 / 2^{-}\end{array}$ & $\begin{array}{l}7.5^{\circ} \\
7.5^{\circ}\end{array}$ & $\begin{array}{l}70.0^{\circ} \\
70.0^{\circ}\end{array}$ & $\begin{array}{l}635 \\
553\end{array}$ & $\begin{array}{l}63.5 \\
653\end{array}$ & $\begin{array}{l}1.00 \\
1.18\end{array}$ & $\begin{array}{l}635 \\
653\end{array}$ & $\begin{array}{l}1.00 \\
1.18\end{array}$ \\
\hline $\begin{array}{r}0^{17}\left(\mathrm{p}, 11 \mathrm{e}^{3}\right) \mathrm{N}^{15}(\mathrm{~g} \cdot \mathrm{s} .) \\
(6.36)\end{array}$ & $\begin{array}{l}1 / 2^{-} \\
3 / ?^{-}\end{array}$ & $\begin{array}{l}7.5^{\circ} \\
7.5^{\circ}\end{array}$ & $\begin{array}{l}70.0^{\circ} \\
60.0^{\circ}\end{array}$ & $\begin{array}{l}193 \\
167\end{array}$ & $\begin{array}{l}193 \\
216\end{array}$ & $\begin{array}{l}1.00 \\
1.29\end{array}$ & $\begin{array}{l}340 \\
381\end{array}$ & $\begin{array}{l}1.76 \\
2.25\end{array}$ \\
\hline
\end{tabular}


TABLE 5-3

COEFFICIENTS OF FRACTIONAL PARENTAGE FOR ${ }^{22} \mathrm{Ne}(\mathrm{p}, \mathrm{t})^{20} \mathrm{Ne}$

Ground state band. Pickup from Nilsson orb1t $\# 7(\Omega=3 / 2)$

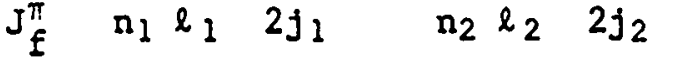

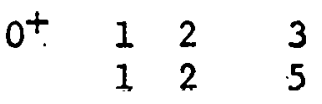

$2^{+} \quad \begin{array}{lll}1 & 2 & 3 \\ 1 & 2 & 3 \\ 1 & 2 & 5\end{array}$

$4^{+} \quad \begin{array}{lll}1 & 2 & 3 \\ 1 & 2 & 5\end{array}$ $n=-2$

$\begin{array}{llll}1 & 2 & 3 & .0196 \\ 1 & 2 & 5 & .3922\end{array}$

$\begin{array}{llll}1 & 2 & 3 & .0196\end{array}$

$\begin{array}{llll}1 & 2 & 5 & -.1798\end{array}$

$\begin{array}{lllll}1 & 2 & 5 & -.1048\end{array}$

$\begin{array}{llll}1 & 2 & 5 & -.0734 \\ 1 & 2 & 5 & -.5447\end{array}$ $n=+2^{\text {CFP }}$

$n=+4$

$n=+6$

$.0080 \quad .0205 \quad .0318$

$.4018 \quad .3916 \quad .3823$

$\begin{array}{lll}.0079 & .0205 & .0318\end{array}$

$\begin{array}{lll}.1155 & .1834 & .2258\end{array}$

$\begin{array}{lll}-.1074 & -.1047 & -.1022\end{array}$

$\begin{array}{rr}.0472 & .0749 \\ -.5580 & -.5438\end{array}$

.0922

$-.5309$

Excited band. Pickup from Nilsson orbit $\# 6(\Omega=1 / 2)$

$J_{f}^{\pi} \quad n_{1} \ell_{1} \quad 2 j_{1}$

$\mathrm{n}_{2} \ell_{2} \quad 2 \mathrm{j} \mathrm{j}_{2}$

$\begin{array}{llll}0^{+} & 2 & 0 & 1 \\ & 1 & 2 & 3 \\ 1 & 2 & 5\end{array}$

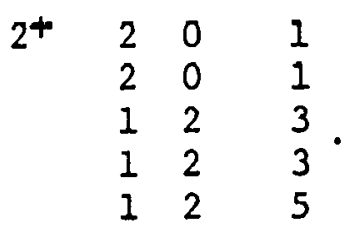

$\begin{array}{llll}2 & 0 & 1 & .1527 \\ 1 & 2 & 3 & .0018 \\ 1 & 2 & 5 & .1461\end{array}$

$\begin{array}{llll}1 & 2 & 3 & -.0278\end{array}$

$\begin{array}{llll}1 & 2 & 5 & -.2779\end{array}$

$1 \quad 2 \quad 3 \quad-.0018$

$\begin{array}{llll}1 & 2 & 5 & .0136\end{array}$

$\begin{array}{llll}1 & 2 & 5 & -.1561\end{array}$

$\begin{array}{rrrr}1 & 2 & 5 & -.0332 \\ 1 & 2 & 5 & .1352\end{array}$ $\begin{array}{lll}1 & 2 & 3 \\ 1 & 2 & 5\end{array}$ $n=+2$ CFP

$n=+4$

$n=+6$

$.0640, .1006 .1159$

$.0050 \quad .0166$

.0271

$.1946 \quad .1640 \quad .1466$

$\begin{array}{rrr}.0302 & .0688 & .0942 \\ .02077 & .2391 & .2426 \\ -.0050 & -.0166 & -.0271 \\ .0262 & .0438 & .0527 \\ -.2080 & -.01753 & -.1568\end{array}$

$\begin{array}{lll}-.0641 & -.1071 & -.1292\end{array}$

.1802 


\section{TABLE $\quad 5-4$}

INTEGRATED CROSS-SECTION RATIOS FOR $\mathrm{Ne}^{22}(p, t) \mathrm{Ne}^{20}$ TO POSITIVE PARITY, $K=0$ BANDS

\begin{tabular}{|c|c|c|c|c|c|c|c|c|c|}
\hline \multirow[t]{2}{*}{$\mathrm{J}^{\pi}$} & \multirow[t]{2}{*}{$\mathrm{E}_{\mathrm{x}}(\mathrm{MeV})$} & \multirow[t]{2}{*}{$\theta_{i}$} & \multirow[t]{2}{*}{$\theta_{f}$} & \multirow[t]{2}{*}{$\sigma-\mu b$} & \multirow[t]{2}{*}{ Exp } & \multicolumn{4}{|c|}{ Theory } \\
\hline & & & & & & $\eta=-2$ & $n=+2$ & $\eta=+4$ & $n=4$ \\
\hline $0^{+}$ & 0.00 & $10^{\circ}$ & $80^{\circ}$ & 719 & 100 & 100 & 100 & 100 & 1 \\
\hline $2^{+}$ & 1.63 & $10^{\circ}$ & $80^{\circ}$ & 207 & 29 & 5 & 10 & 14 & \\
\hline $4^{+}$ & 4.25 & $10^{\circ}$ & $80^{\circ}$ & 177 & 25 & 51 & 107 & 120 & \\
\hline $0^{+}$ & 6.72 & $10^{\circ}$ & $45^{\circ}$ & 46 & 6 & 129 & 79 & 97 & \\
\hline $2^{+}$ & 7.43 & $10^{\circ}$ & $45^{\circ}$ & 17 & 2 & 148 & 16 & 38 & \\
\hline $4^{+}$ & 9.02 & $10^{\circ}$ & $45^{\circ}$ & $?$ & ? & 3 & 7 & 10 & \\
\hline $0^{+}$ & 7.20 & $10^{\circ}$ & $45^{\circ}$ & $<46$ & $<6$ & 129 & 79. & 97 & \\
\hline $2^{+}$ & 7.84 & $10^{\circ}$ & $45^{\circ}$ & 24 & 3 & 148 & 16 & 38 & \\
\hline
\end{tabular}

Note: The experimental differential cross sections integrated from $10^{\circ}$ to $45^{\circ}$ of the $0^{+}, 2^{+}$, and $4^{+}$members of the ground state band are 543, 127 , and $68 \mathrm{\mu b}$ respectively.

6. Elastic and Inelastic Scattering of $15 \mathrm{MeV}$ Deuterons From ${ }^{19} \mathrm{~F}$

D. Dehnhard and N. M. Hintz

For the excitation of the g.s. rotational band in ${ }^{19} \mathrm{~F}$ via inelastic scattering of $15 \mathrm{MeV}$ deuterons ${ }^{1}$ we are presently performing a coupled channels calculation using the computer code JUPITER $1 .^{2}$ We find that the maxima and minima in the angular distributions are fitted quite well by the calculated curves, which, however, still show considerably more structure than the experimental angular distributions. Previous fits with complex collective formfactors without channel coupling were considerably poorer. $\beta$ values for the $L=2$ transitions were found to be essentially the same $(\beta \approx 0.45)$. We are now trying to fit the elastic and inelastic scattering data simultaneously by varying the optical model parameters. 
In ref. 1 we reported a rather small $\mathrm{B}(\mathrm{E} 3)$ value for the $1.35 \mathrm{MeV}$ $\left(5 / 2^{-}\right)$to $0.0 \mathrm{MeV}\left(1 / 2^{+}\right)$transition: $B(E 3) / B(E 3)_{S P}=0.9-1.4 \mathrm{~W} . \mathrm{U}$. in sharp contrast to previous measurements. It is interesting to note that a recent measurement of this quantity by inelastic electron scattering ${ }^{3}$ reproduces the largest previously determined value:

$$
\mathrm{B}(\mathrm{E} 3) / \mathrm{B}(\mathrm{E} 3)_{\mathrm{SP}}=12 \pm 2.4 \mathrm{~W} . \mathrm{U} \text {. }
$$

Further studies of this peculiar transition seem to be needed to resolve these discrepancies.

References

${ }^{1}$ D. Dehnhard and N. M. Hintz, Phys. Rev. C1, 460 (1970).

2 T. T. Tamura, Private Communication.

${ }^{3}$ Th. Walcher and P. Strehl, Z. Physik, 232, 342 (1970).

7. Energy Levels of ${ }^{19} \mathrm{Ne}$ and Differential Cross Sections from the ${ }^{19} \mathrm{~F}\left({ }^{3} \mathrm{He}, t\right){ }^{19}$ Ne Reaction

D. Dehnhard and H. Ohnuma

The measurement of differential cross sections of the ${ }^{19} \mathrm{~F}\left({ }^{3} \mathrm{He}, \mathrm{t}\right){ }^{19} \mathrm{Ne}$ reaction, reported previous $1 \mathrm{y}^{1}$, has now been extended to include states of excitation energies between 2.79 and $6.4 \mathrm{MeV}$. Three position-sensitive detectors together with the magnetic spectrometer were used to take spectra at nine angles between $9^{\circ}$ and $60^{\circ}$. Several high resolution spectra were also taken for the 6 lowestlying states to complement the data obtained previously.

The angular distributions are now being analyzed with the aid of distorted wave calculation ${ }^{2}$ using complex collective and microscopic formfactors. 


\section{References}

${ }^{1}$ John H. Williams Laboratory, Annual Report, 1969, p. 15.

${ }^{2}$ We are indebted to Dr. P. D. Kunz for making his computer code DWUCK available to us.

8.

Reactions of Ne Isotopes With $40 \mathrm{MeV}$ Protons

Dave Madland and Norton M. Hintz

The analysis of the elastic, Inelastic and $(p, d)$ experiments on $20,21,22 \mathrm{Ne}$ at $40 \mathrm{MeV}$ has been completed. A brief summary of some of the final results is presented here.

A. $20 \mathrm{Ne}$ and $22 \mathrm{Ne}$ Elastic Scattering

Searches were made on the elastic scattering data using the optical model program RAROMP. ${ }^{1}$ Various initial parameter sets, including the results of the global search by Becchetti and Greenlees, ${ }^{2}$ the best fit parameters from $\sigma(\theta)$ and $P(\theta)$ data on ${ }^{28} \mathrm{Si}$ at $40 \mathrm{MeV}$, and ${ }^{24} \mathrm{Mg}$ at $49 \mathrm{MeV}$ were tried. The final best fit set was independent of the starting parameters. The results are shown in Fig. $8-1$ and the parameters in Table 8-I. The best fit parameters for ${ }^{20} \mathrm{Ne}$ and ${ }^{22} \mathrm{Ne}$ are similar except for the imaginary central parts. The fits were significantly worse if the search was constrained to $w_{d}=0$ for ${ }^{20} \mathrm{Ne}$ and $w_{V}=0$ for ${ }^{22} \mathrm{Ne}$. B. $20 \mathrm{Ne},{ }^{21} \mathrm{Ne}$ and ${ }^{22} \mathrm{Ne}$ Inelastic Scattering

The inelastic data has been analyzed both with the DWBA using collective form factors (JULIE) and with the coupled channel program of Tamura (Version JP-1)*. In the DWBA, both real (RFF) and complex (CFF)

*An error was discovered in the radius expansion in the program JP- 1 . The function $Y_{6}$ rather than $Y_{4}$ was called in the program in the $\beta_{4}$ term. This error affected only rotational couplings in the JP-1 program. 
form factors were employed. Optical parameters were taken from the elastic fits discussed above. In all cases only the central potential was deformed. The effects, including Coulomb excitation (CE) in the DWBA, were found to be small and were left out of the coupled channel calculation. Only the $0^{+}, 2^{+}$and $4^{+}$states were included in the coupling.

An Important feature of the data is the nearly identical cross section, and hence $\beta_{2}$, to the $2^{+}$states in ${ }^{20}{ }_{\mathrm{Ne}}$ and ${ }^{22} \mathrm{Ne}$, whereas the $4^{+}$member of the ground rotational band is nearly a factor of 10 weaker for ${ }^{22} \mathrm{Ne}$ than for ${ }^{20} \mathrm{Ne}$, indicating a strong direct $\mathrm{B}_{4}$ term in the ${ }^{20} \mathrm{Ne}$ $4^{+}$cross section. As can be seen from Figs. $8-2$ and $8-3$, the first $2^{+}$states in both Neons are reasonably well fit by the simple one-step DWBA with collective form factors. The $4^{+}$states are not reproduced by the DWBA, especially that of ${ }^{22} \mathrm{Ne}$. The $7 / 2^{+}$state in ${ }^{2 l_{i}} \mathrm{Ne}$, shown in Fig. $8-4$; which can go by either $\mathrm{L}=2$ or $\mathrm{L}=4$ was found to be nearly pure $\mathrm{L}=2$. DWBA fits to the octupole state in ${ }^{20} \mathrm{Ne}$ and ${ }^{22} \mathrm{Ne}$ are shown in Figs. 8-5 and 8-6. The $3^{-}$state in ${ }^{22}$ Ne was not previously known. To obtain reliable values for $\beta_{2}$ and $\beta_{4}$ in the Neon ground state bands the coupled channel formalism ${ }^{3}$ was employed. The optical parameters were as quoted above except that the imaginary parts were multiplied by factors $.8, .9$ and 1.0 for the $0^{+}, 2^{+}$and $4^{+}$channels, respectively. The value of .8 was necessary to fit the ground state. The other values were chosen somewhat arbitrarily.... The final results of the coupled channel analysis are shown in Figs. 8-7 and $8-8$ and given in Table \&2. The values of $\beta_{2}$ were assumed to be the same for the $2^{+} \rightarrow 4^{+}$transition as for the $0^{+} \rightarrow 2^{+}$transition. It is seen that the effect of the $\beta_{4}$ term is stronger for ${ }^{20} \mathrm{Ne}$.

In Fig. 8-9 we have shown our values of $\beta_{2}$ and $\beta_{4}$ for the $\mathrm{Ne}$ isotopes, along with other $\left(p, p^{\prime}\right)$ results from the literature for neighboring s-d shell nuclei. 
C. ${ }^{20} \mathrm{Ne},{ }^{21} \mathrm{Ne}$ and ${ }^{22} \mathrm{Ne}(\mathrm{p}, \mathrm{d})$ Reactions

Spectroscopic factors, calculated with JULIE in the zero range local (ZRL) and FRNL are given in Table 8-3. Neutron transfer from factors were calculated with the variable well depth assumption (wel1 depth adjusted to give experimental separation energies). Optical parameters for the protons were those of section A above; for deuterons, parameters derived from $15 \mathrm{MeV}$ deuteron scattering on ${ }^{22} \mathrm{Ne}{ }^{3}$ gave the best fit without the necessity of employing radial cutoffs. These parameters are:

$$
\begin{array}{lll}
\mathrm{v}_{\mathrm{r}}=101.9 & \mathrm{w}_{\mathrm{V}}=29.56 & \mathrm{v}_{\mathrm{s}}=8 \\
\mathrm{r}_{\mathrm{o}}=1.289 & \mathrm{w}_{\mathrm{D}}=0 & \mathrm{r}_{\mathrm{s}}=1.289 \\
\mathrm{a}=.706 & \mathrm{r}_{\mathrm{o}}^{\prime}=1.353 & \mathrm{a}_{\mathrm{s}}=.706 . \\
\mathrm{a}^{\prime}=.594 &
\end{array}
$$

Some of the $(p, d)$ data together with the DWBA results are shown in Figs. 8-10- 8-17. The $7 / 2^{+}$state in ${ }^{21} \mathrm{Ne}(1.750 \mathrm{MeV})$ can only be reached via a small $g_{7 / 2}$ component in the ${ }^{22}$ Ne ground state or by a multiple step process. An $l=4$ calculation gives a reasonable fit to the $7 / 2^{+}$state but a well depth of $161 \mathrm{MeV}$ was used to give the experimental separation energy and hence the spectroscopic factor of $\mathrm{C}^{2} \mathrm{~s}=.3$ is probably meaningless.

In ${ }^{21} \mathrm{Ne}(\mathrm{p}, \mathrm{d}){ }^{20} \mathrm{Ne}$ to the $2^{+}$member of the ground band, the $\mathrm{K}-$ selection rule requires a pure $\ell=2$ transfer, although $\ell=0,2$ and 4 are all allowed by total angular momentum selection rules. A very good fit is seen for a pure $\ell=2$, confirming the $\mathrm{K}$-selection rule. (An admixture of the $\mathrm{K}=2^{+}, \gamma$-vibrational band into the ground state band would allow $\ell=0$ to the $2^{+}$state.) 
The spectroscopic factors are presented in Table 83 along with predictions for a simple imdependent particle Nilsson model, employing

a Woods-Saxon wel1 with a quadrupole deformation of $\beta=0.5$, calculated by the program ROST ${ }^{4}$. Fig. 8-18 shows a summary of $C^{2} S$ for the Ne states. On the same plot are the Nilsson spectroscopic factors vs. $\beta$. The general trend of the data is well reproduced but the quantitative agreement is not wholly satisfactory for any reasonable value of $\beta$. The Neon experiments are now being written up for publication.

\section{References}

${ }^{1}$ G. Pyle, Private Communication. .

2F. Becchetti and G. W. Greenlees, Phys. Rev. 182, 1190 (1969).

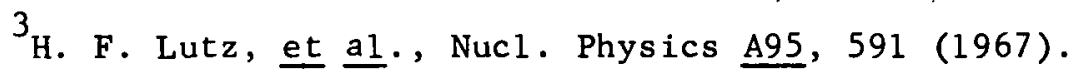

${ }^{4}$ E. Rost, Private Communication. 
Table 8-I

\begin{tabular}{l|c|c|c|c|c|c|c|c|c|c|c|c|c}
\hline & $v_{r}$ & $r_{0}$ & $a$ & $w_{v}$ & $w_{d}$ & $r_{o}^{\prime}$ & $a^{\prime}$ & $v_{s}$ & $r_{s}$ & $a_{s}$ & $r_{c}$ & $\sigma_{R}$ & $x^{2} / N$ \\
\hline${ }^{20} \mathrm{Ne}$ & 43.00 & 1.135 & 0.704 & 0.000 & 5.424 & 1.341 & 0.660 & $(6.470)$ & $(1.089)$ & $(0.741)$ & $(1.250)$ & 608.1 & 1.556 \\
\hline $22 \mathrm{Ne}$ & 43.79 & 1.133 & 0.701 & 7.289 & 0.225 & 1.541 & 0.564 & $(6.955)$ & $(1.089)$ & $(0.741)$ & $(1.250)$ & 635.5 & 3.906 \\
\hline
\end{tabular}

Notes: 1) quantities in parentheses are held fixed.

2) units are MeV, fermis, and millibarns. 
Table 8-2, Inelastic Analysis

\begin{tabular}{|c|c|c|c|c|c|c|c|}
\hline \multirow[b]{2}{*}{ Target } & \multirow{2}{*}{$\begin{array}{r}E_{\bar{x}} \\
M e V\end{array}$} & \multirow[b]{2}{*}{$\mathrm{J}, \pi$} & \multirow[b]{2}{*}{$\mathrm{L}$} & \multicolumn{3}{|c|}{$\begin{array}{c}\left|\beta_{L}\right| \\
\text { Collective Form Factor }\end{array}$} & \multirow[t]{2}{*}{$\begin{array}{c}\beta_{L} \\
\text { Coupled Cliall }\end{array}$} \\
\hline & & & & $\overline{\mathrm{RFF}}$ & CFF & $\mathrm{CFF}+\mathrm{CE}$ & \\
\hline \multirow[t]{3}{*}{${ }^{20} \mathrm{Ne}$} & 1.630 & $2^{+}$ & 2 & $.64 \pm .02$ & $.49_{ \pm} .01$ & $.51 \pm .01$ & $+.42 \pm .05$ \\
\hline & 4.250 & $4^{+}$ & 4 & $.34 \pm .01$ & $.27 \pm .01$ & $.27 \pm .01$ & $+.22 \pm .05$ \\
\hline & $(5.623$ & $3^{-}$ & 3 & -- &.- & $.36 \pm .04$ & \\
\hline (a) & $(5.785$ & $1^{-}$ & 1 & $\cdots$ & -- & $.10 \pm .01$ & \\
\hline${ }^{21} \mathrm{Ne}$ & 1.750 & $7 / 2^{+}(\mathrm{b})$ & 2 & $.61 \pm .03$ & $.49 \pm .02$ & $.51 \pm .02$ & --- \\
\hline \multirow[t]{3}{*}{${ }^{22} \mathrm{Ne}$} & 1.275 & $2^{+}$ & 2 & $.63 \pm .02$ & $.49 \pm .01$ & $.50 \pm .01$ & $+.44 \pm .05$ \\
\hline & 3.340 & $4^{+}$ & 4 & $.13 \pm .004$ & $.10 \pm .003$ & $.11_{ \pm .003}$ & $+.08 \pm .05$ \\
\hline & 5.92 & $\left(3^{-}\right)$ & 3 & $.29 \pm .01$ & $.23 \pm .01$ & $.23 \pm .01$ & \\
\hline
\end{tabular}

(a) Unresolved doublet, errors in unfolding $\mathrm{L}=3$ and $\mathrm{L}=1$ estimated at $\pm 20 \%$.

(b) $\beta_{L}$ values derived assuming strong coupling-rotational. 
Table $8-3$

Spectroscopic Factors From Neutron Pickup Reactions on the Neon Isotopes

\begin{tabular}{|c|c|c|c|c|c|c|}
\hline \multirow[b]{2}{*}{ Target } & \multirow[b]{2}{*}{$\mathrm{E}_{\mathrm{x}}(\mathrm{MeV})^{(\mathrm{a})}$} & \multirow[b]{2}{*}{$\mathrm{J}_{\text {final }}^{\pi}$} & \multicolumn{3}{|c|}{ Present Experiment* } & \multirow[b]{2}{*}{ Theory $(\mathrm{g})$} \\
\hline & & & $\ell_{n}, j_{n}$ & $c^{2} s(p, d)^{(b)}$ & $c^{2} s(p, d)^{(c)}$ & \\
\hline $22 \mathrm{Ne}$ & 0.000 & $3 / 2^{+}$ & ld $3 / 2$ & $0.25 \pm .02$ & $0.23 \pm .01$ & 0.107 \\
\hline${ }^{22} \mathrm{Ne}$ & 0.350 & $5 / 2^{+}$ & $1 d 5 / 2$ & $2.99 \pm .18$ & $2.72 \pm .16$ & 1.886 \\
\hline${ }^{22} \mathrm{Ne}$ & 1.750 & $7 / 2^{+}$ & $\lg 7 / 2$ & -- & $\leq 0.30^{(\mathrm{d})}$ & 0.006 \\
\hline${ }^{21} \mathrm{Ne}$ & 0.000 & $0^{+}$ & $1 d 3 / 2$ & $0.055 \pm .006$ & $0.052 \pm .005$ & 0.028 \\
\hline${ }^{21} \mathrm{Ne}$ & 1.630 & $2^{+}$ & $1 d 3 / 2^{(h)}$ & $1.07 \pm .11$ & $0.95 \pm .10$ & 0.028 \\
\hline${ }^{21} \mathrm{Ne}$ & 1.630 & $2^{+}$ & $\operatorname{ld} 5 / 2^{(h)}$ & $1.33 \pm .13$ & $1.23 \pm .12$ & 0.804 \\
\hline${ }^{21} \mathrm{Ne}$ & 4.250 & $4^{+}$ & $1 d 5 / 2$ & $0.39 \pm .04$ & $0.37 \pm .04$ & 0.134 \\
\hline${ }^{21} \mathrm{Ne}$ & 4.970 & $2^{-}$ & $1 \mathrm{p} 1 / 2^{(\mathrm{h})}$ & $0.55 \pm .06$ & $0.53 \pm .05$ & 0.835 \\
\hline${ }^{21} \mathrm{Ne}$ & 4.970 & $2^{-}$ & $1 \mathrm{p} 3 / 2^{(h)}$ & $0.67 \pm .07$ & $0.62 \pm .06$ & -- \\
\hline${ }^{20} \mathrm{Ne}$ & 0.000 & $1 / 2^{+}$ & $2 \mathrm{~s} \quad 1 / 2$ & $0.29 \pm .02$ & $0.38_{ \pm} .02$ & 0.514 \\
\hline${ }^{20} \mathrm{Ne}$ & (e) $)^{(0.241}$ & $5 / 2^{+}$ & $1 \mathrm{~d} 5 / 2$ & $1.95 \pm .39$ & $1.78_{ \pm} .36$ & 1.380 \\
\hline${ }^{20} \mathrm{Ne}$ & $(0.280$ & $1 / 2^{-}$ & $1 \mathrm{p} 1 / 2$ & $2.44 \pm .49$ & $2.18 \pm .44$ & 1.704 \\
\hline
\end{tabular}

* Quoted uncertainties include on $1 y$ the absolute experimental errors.

(a) Excitation energies taken as those from Table of Isotopes (Lederer, Hollander and Perlman) (John Wiley

(b) Present experiment (ZRL interaction, SE, NRCO). and Sons - 1967).

(c) Present experiment (FRNL interaction, SE, NRCO).

(d) Should be considered as an upper limit because the separation energy prescription for calculating the form factor for a $1 \mathrm{~g} 7 / 2$ contribution to the ${ }^{22} \mathrm{Ne} g . s$. is unrealistic, i.e., a well depth of $160.5 \mathrm{MeV}$ is required.

(e) Experimentally unresolved doublet. Errors in folding $\ell=2$ and $\ell=1$ predictions estimated as $\pm 20 \%$.

(g) Simple Nilsson calculation using deformed Woods-Saxon well with $\beta=0.5$.

(h) Assumed pure configuration. 


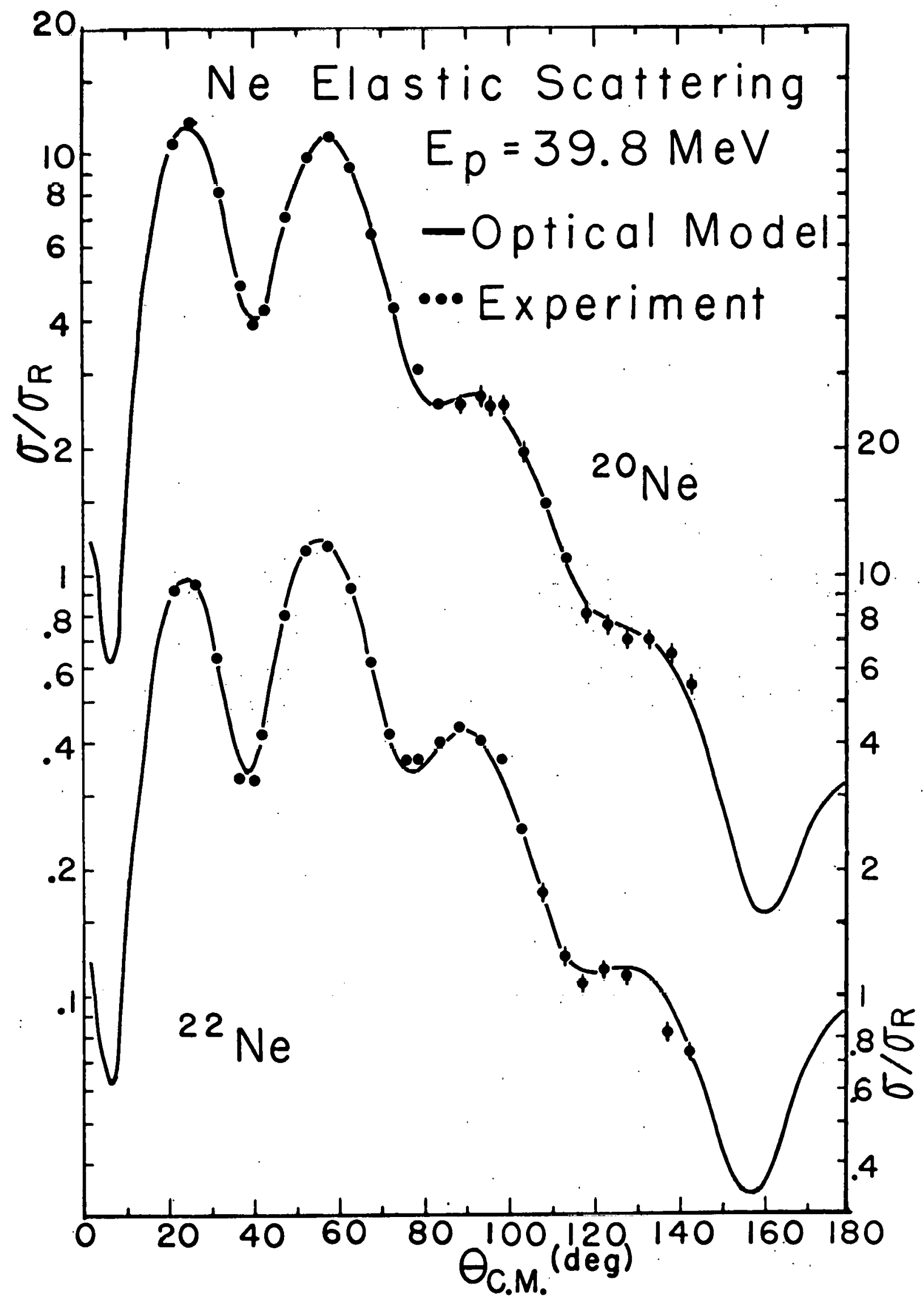

Fig. 8-1 


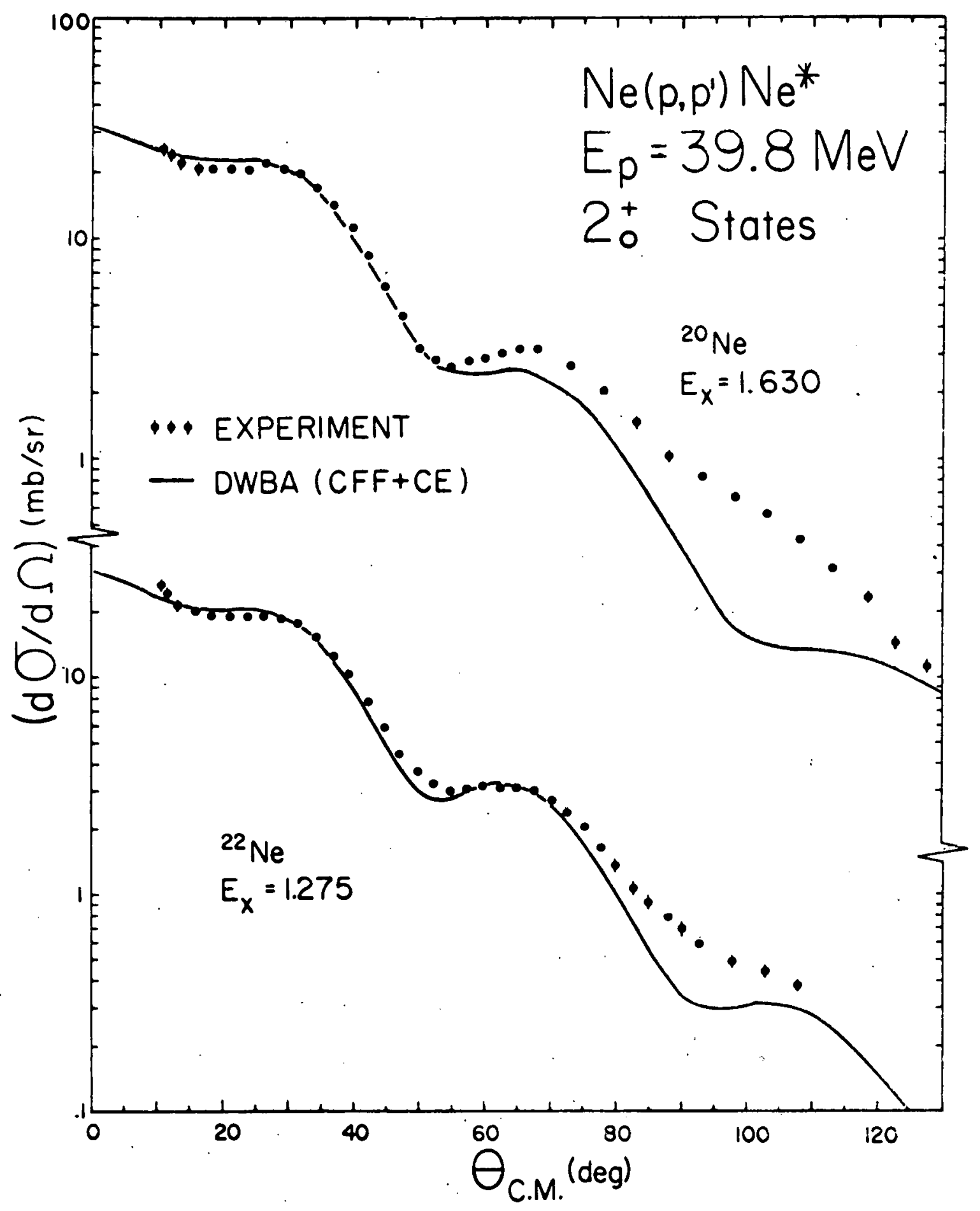

Fig. 8-2 
32

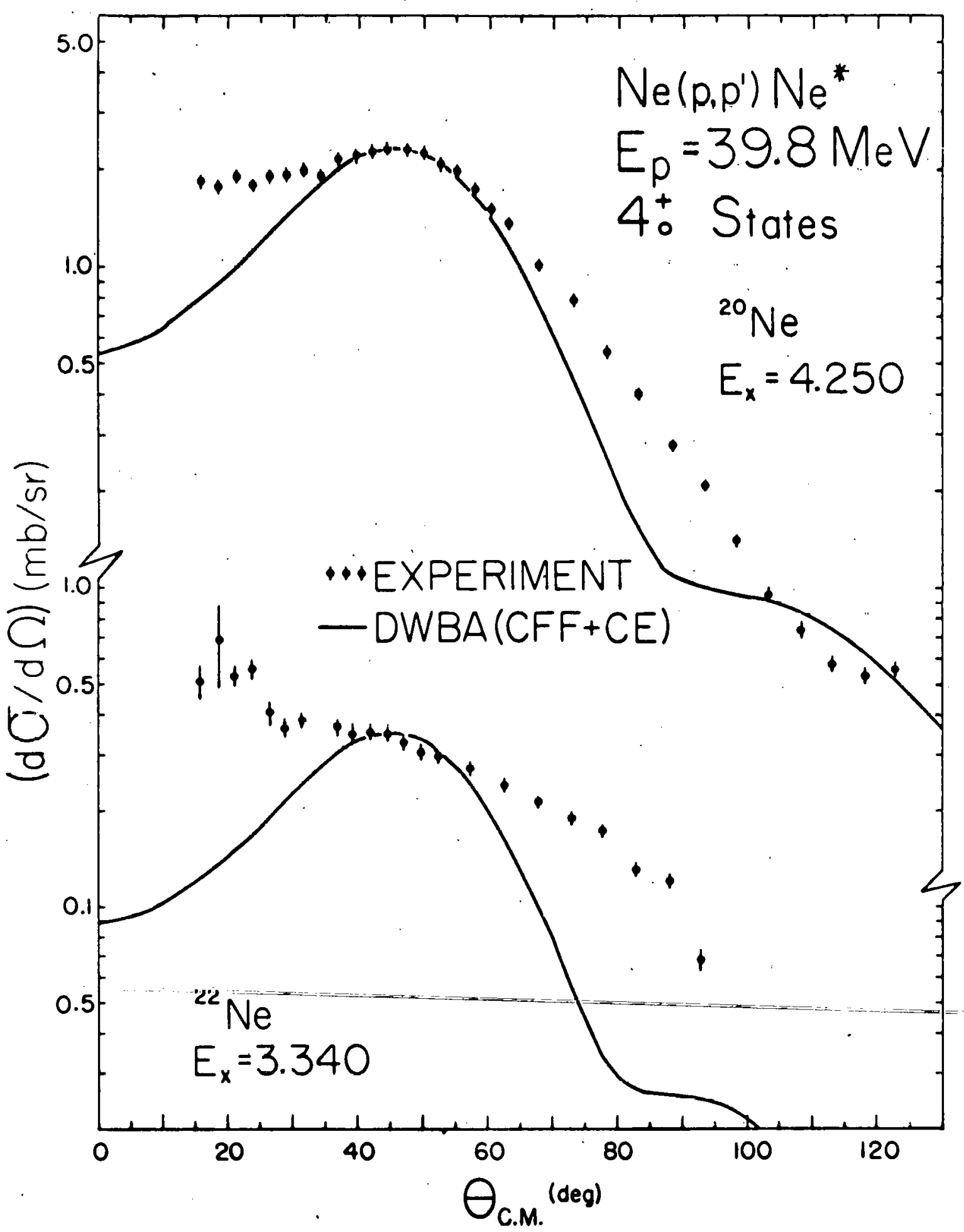

Fig. 8-3 


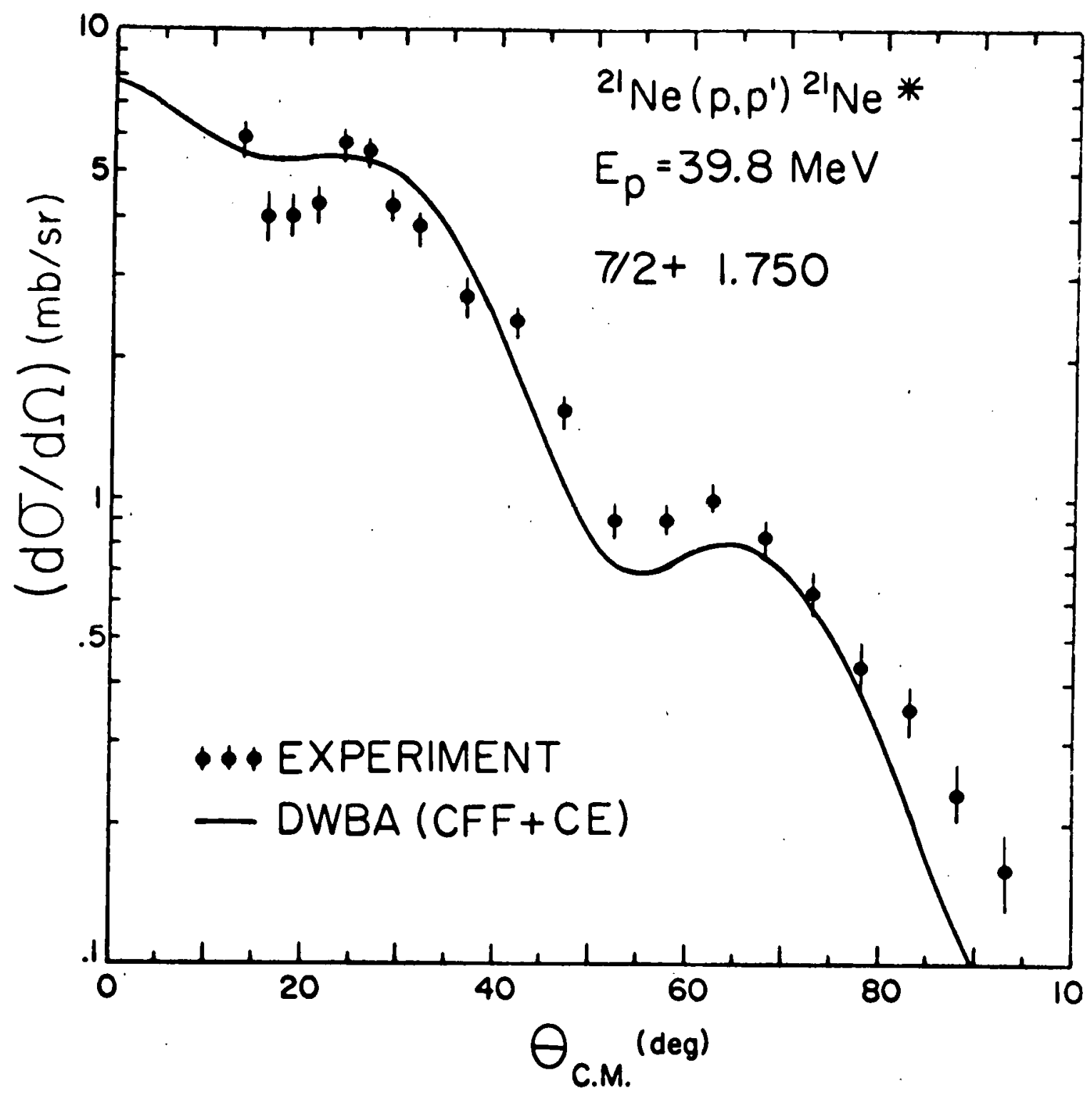

Fig. 8-4 


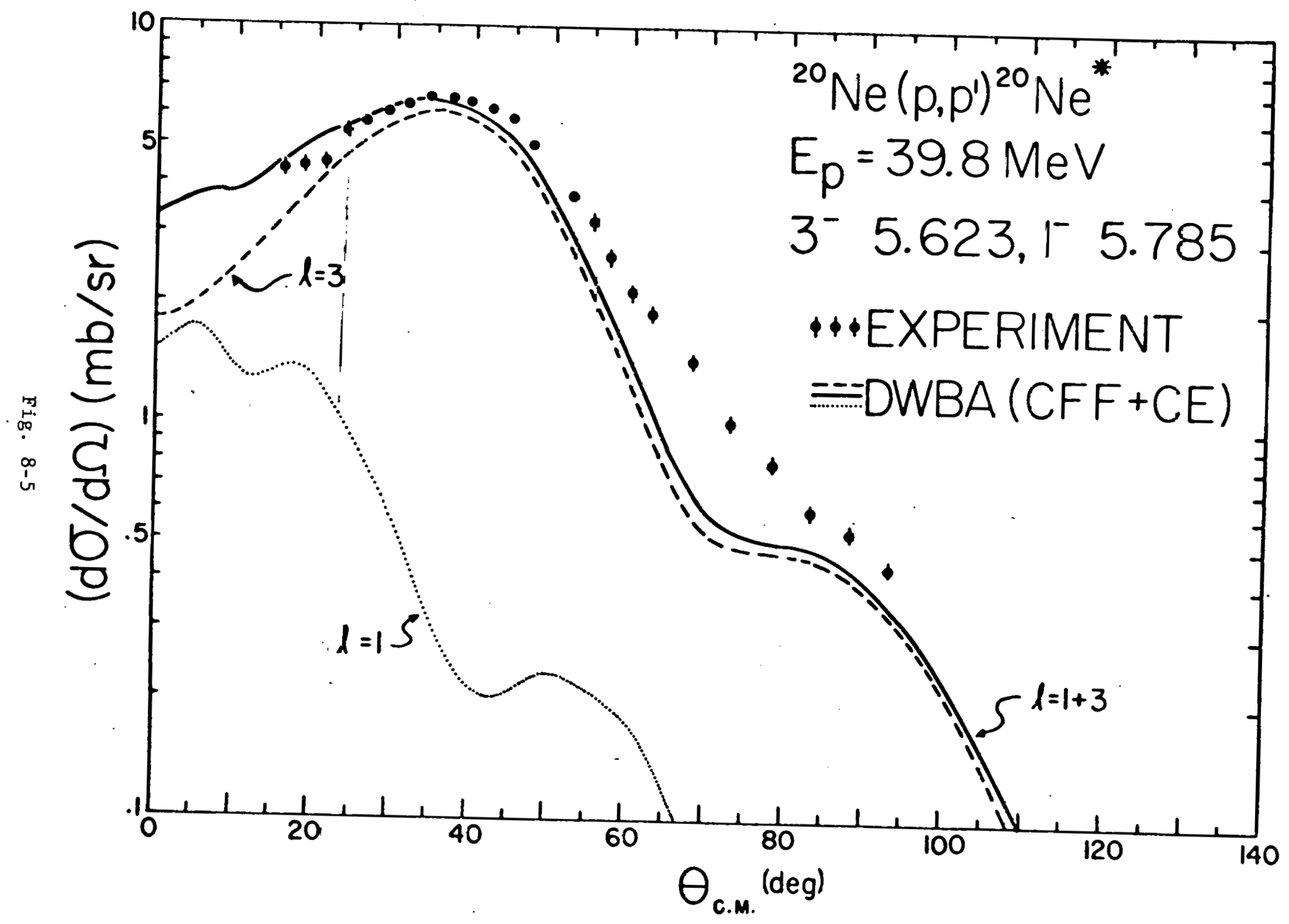




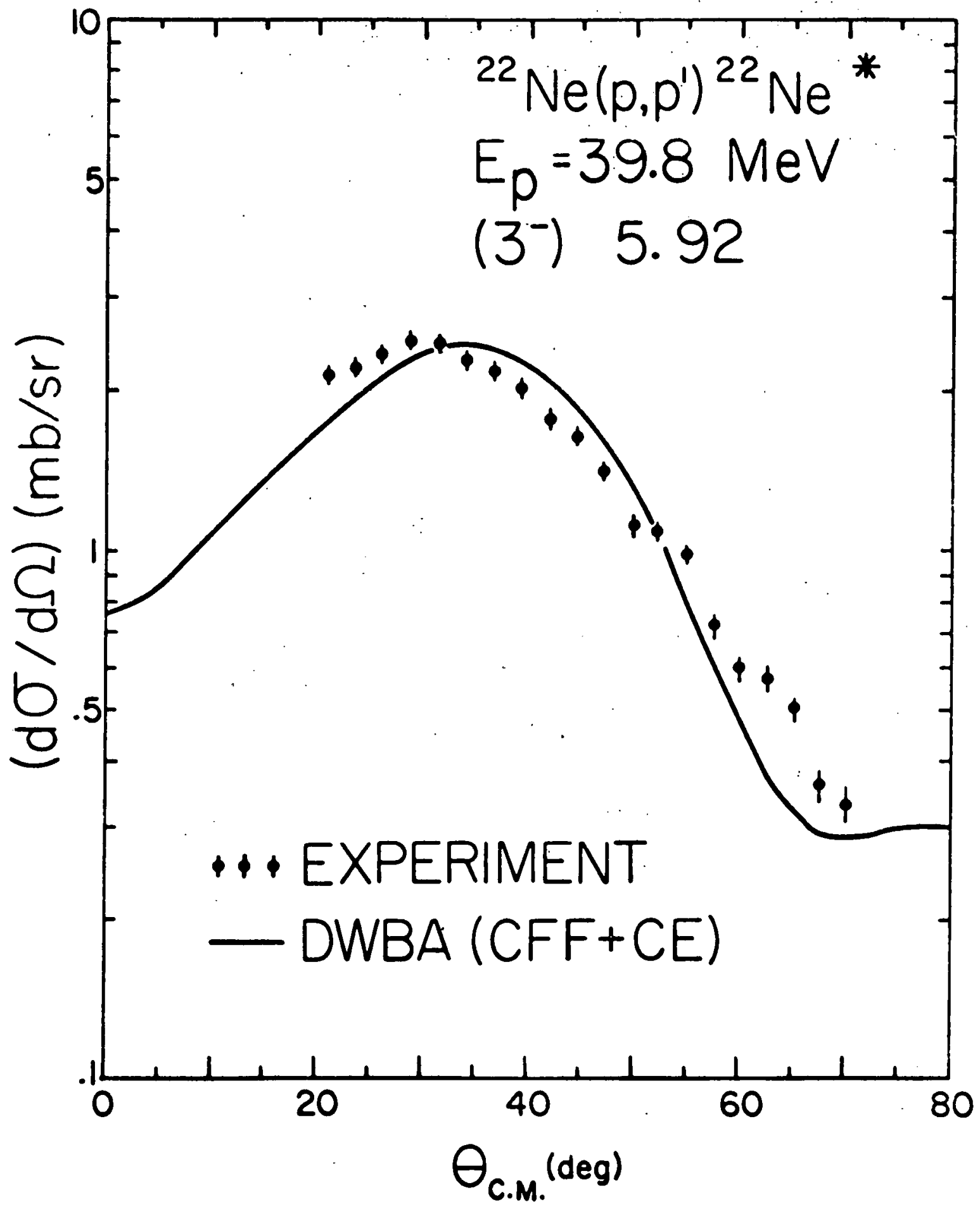

Fig. 8-6 


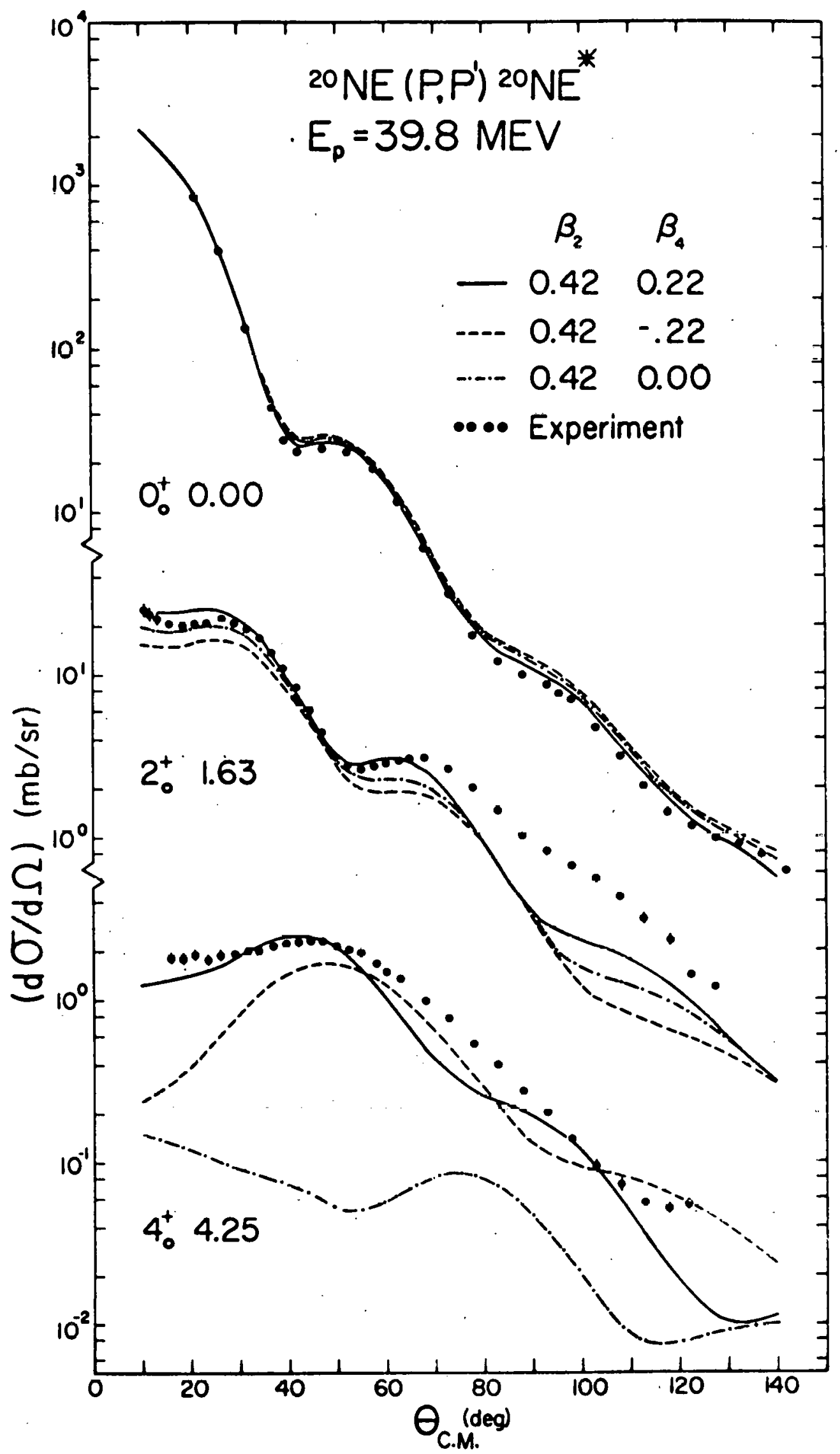

Fig. 8-7 


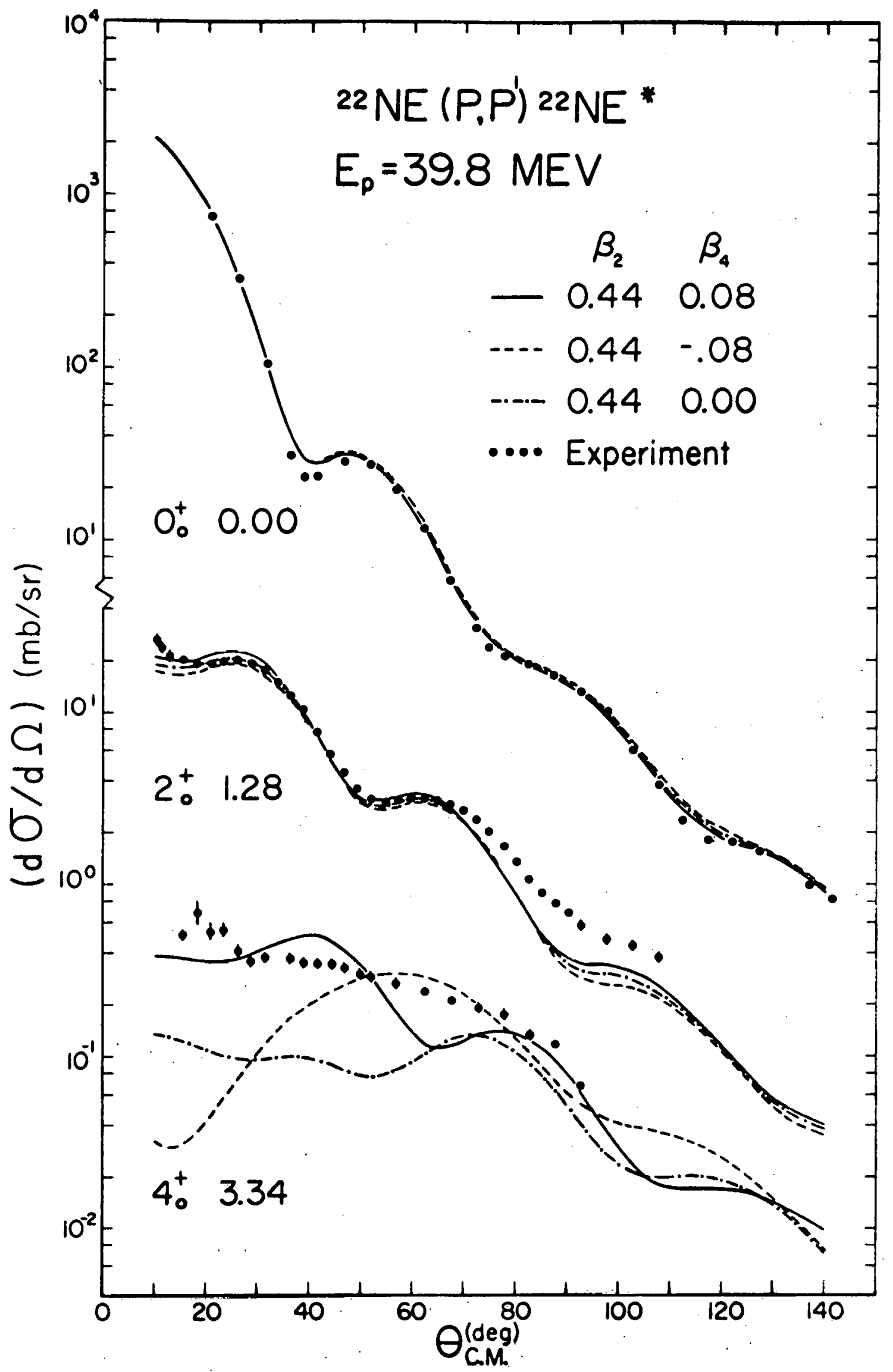

Fig. 8-8 


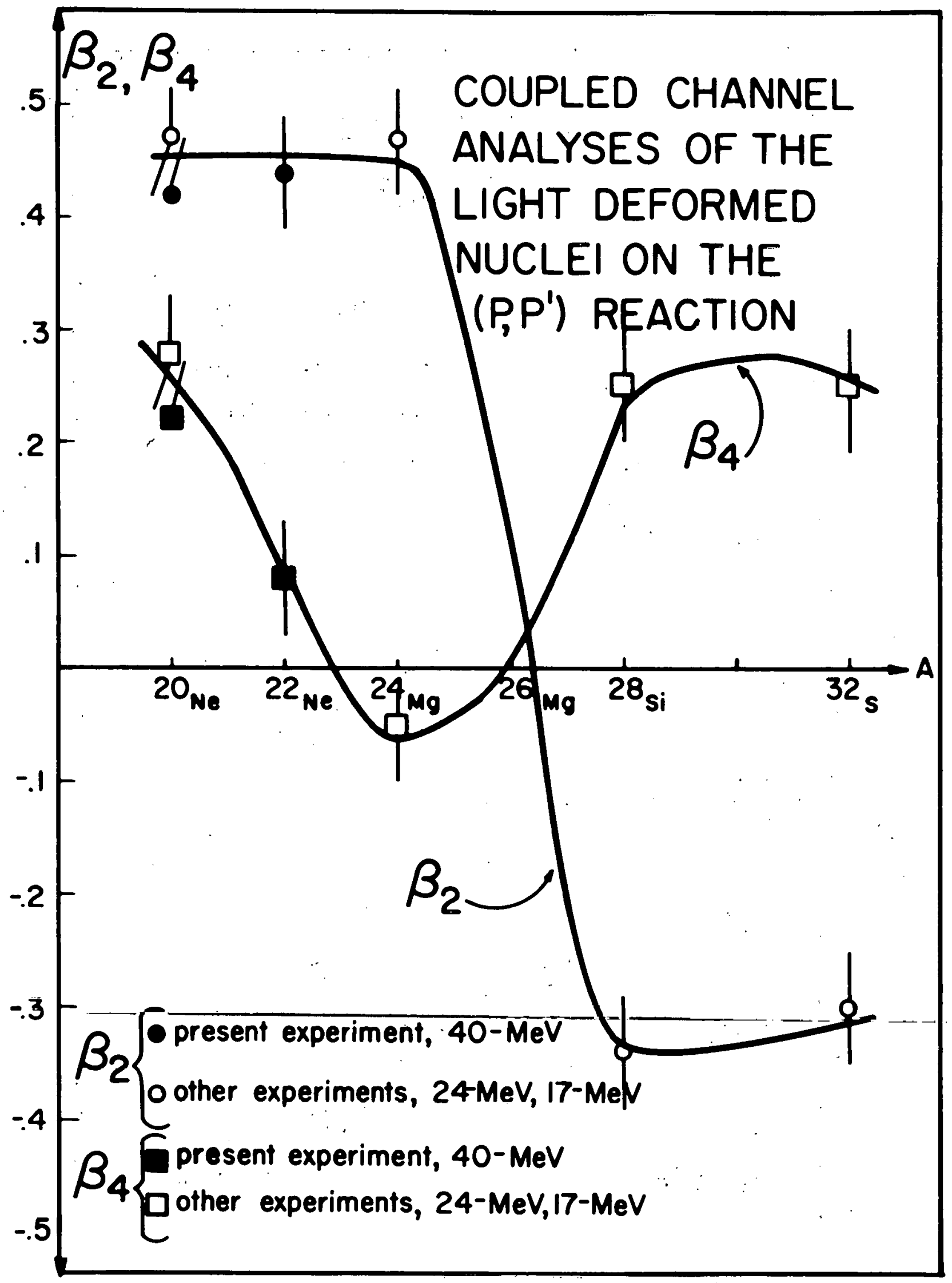

Fig. 8-9 


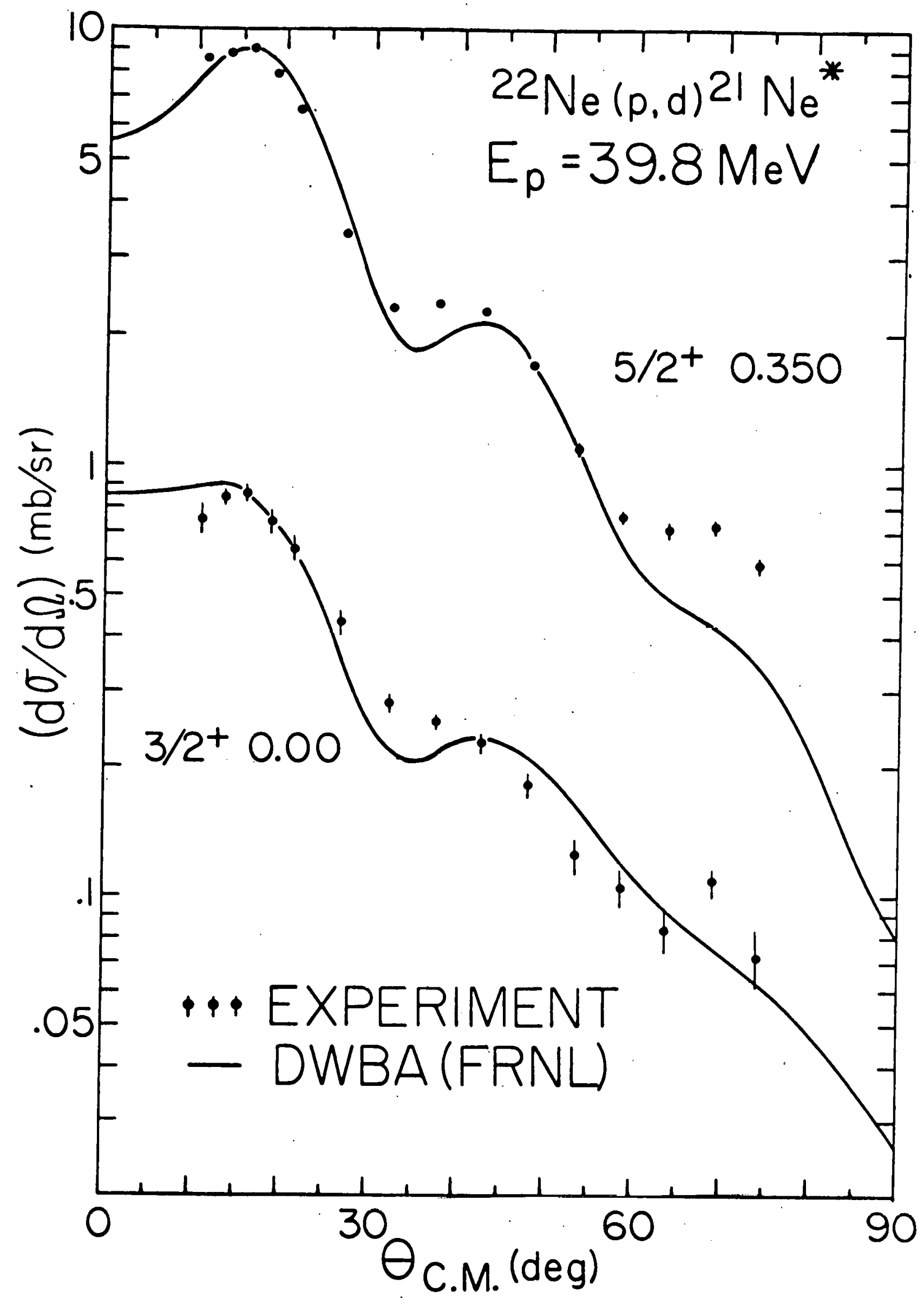

Fig. $8-10$ 


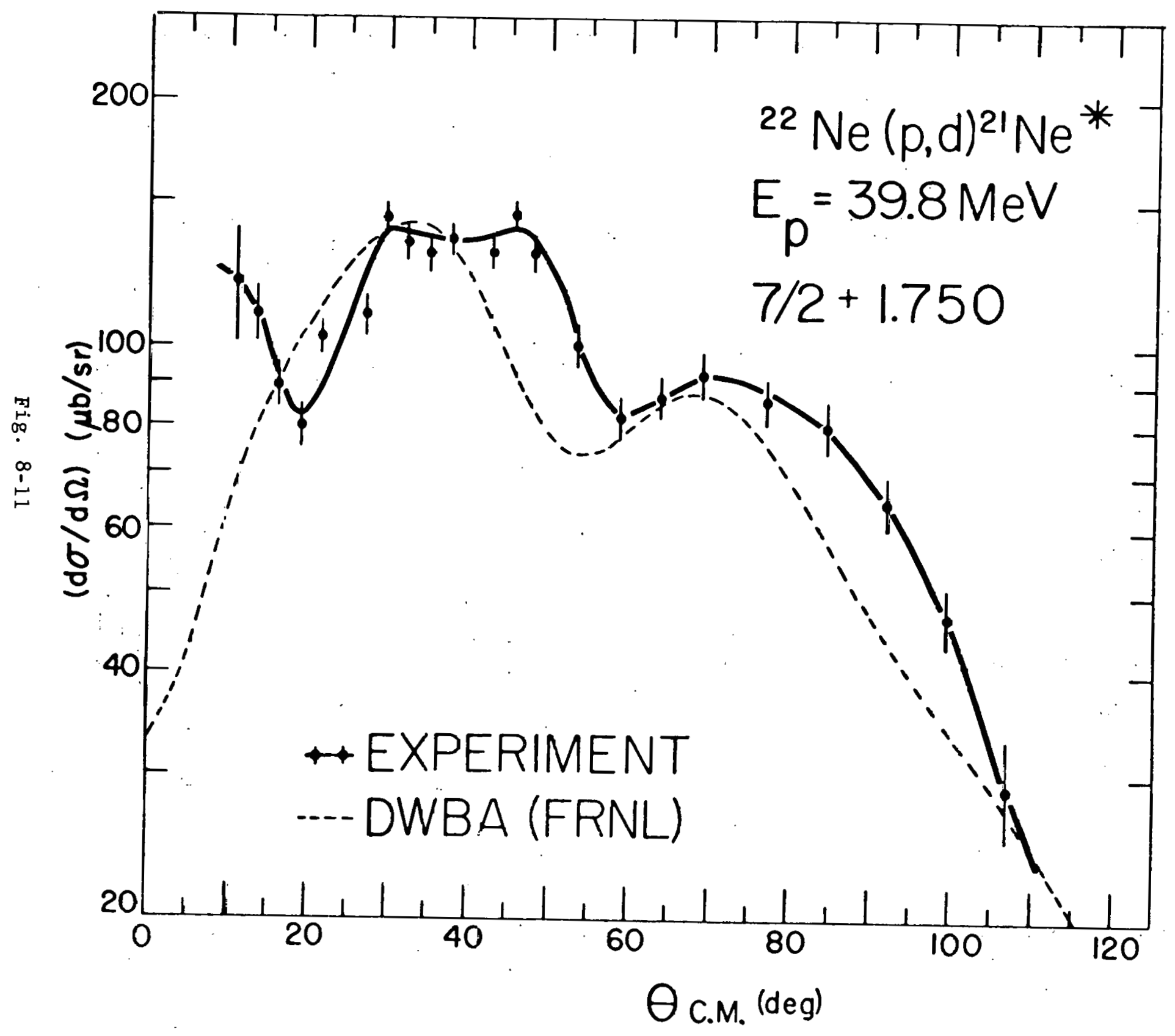




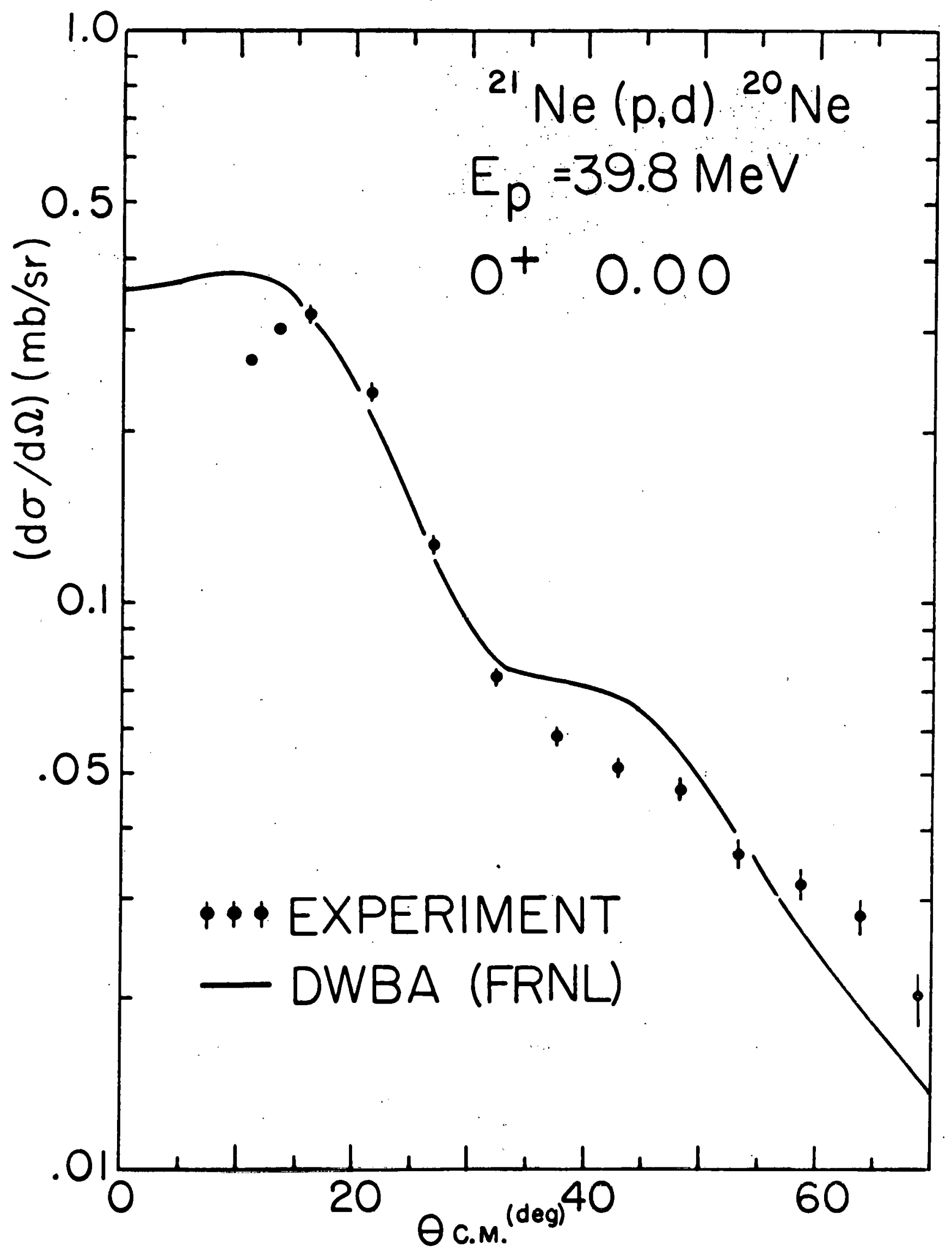

Fig. 8-12 


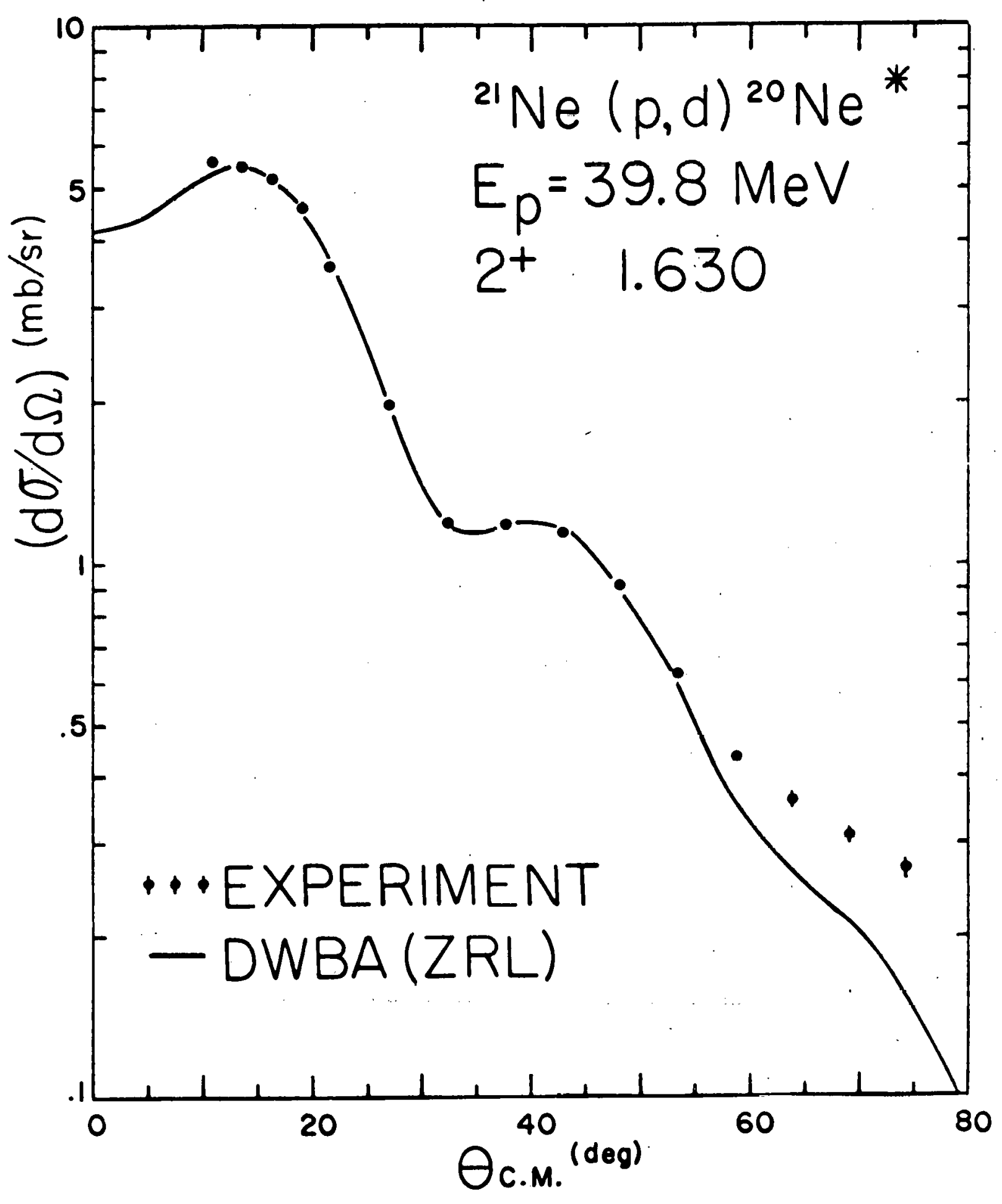

Fig. 8-13 


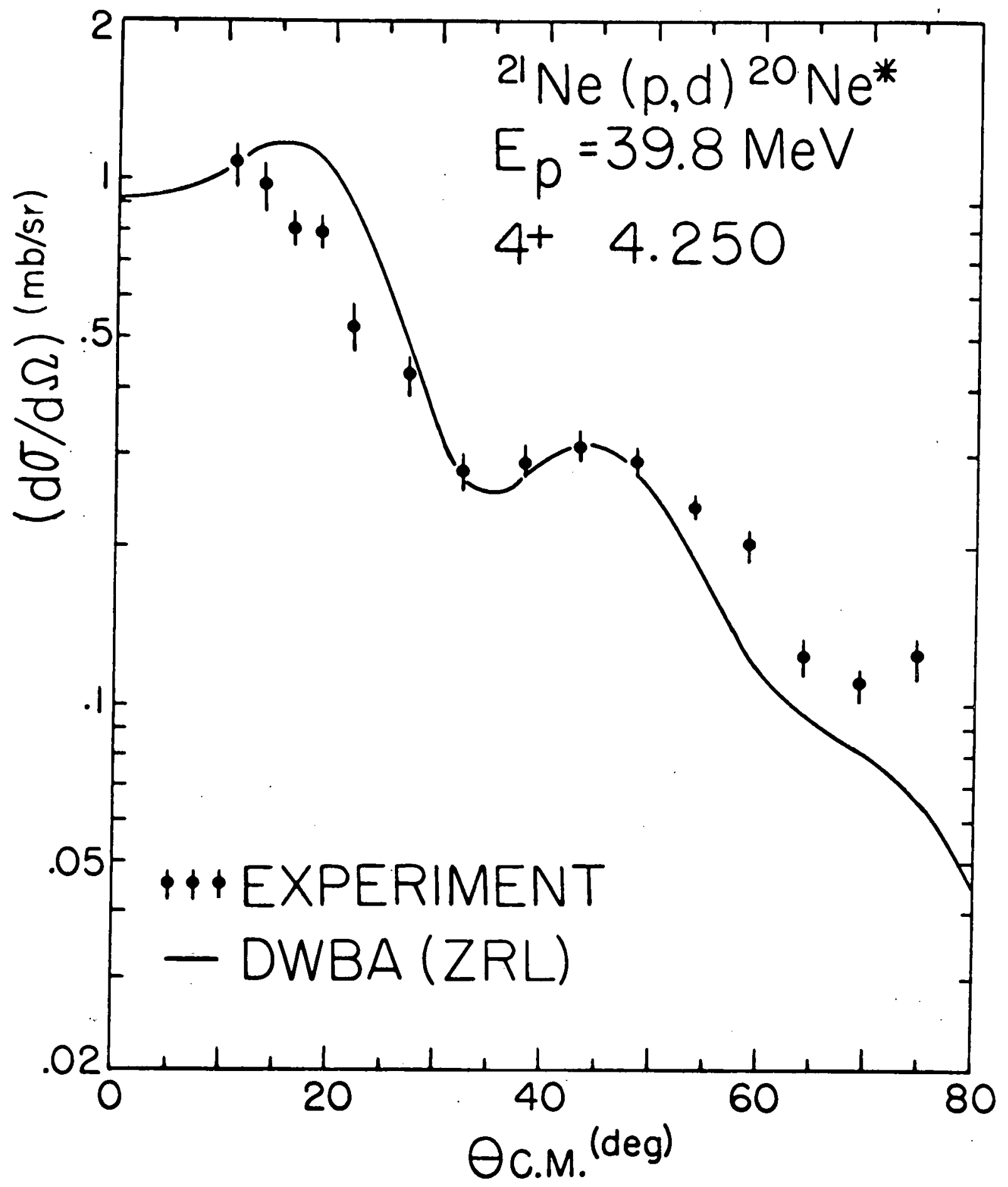

Fig. $8-14$ 


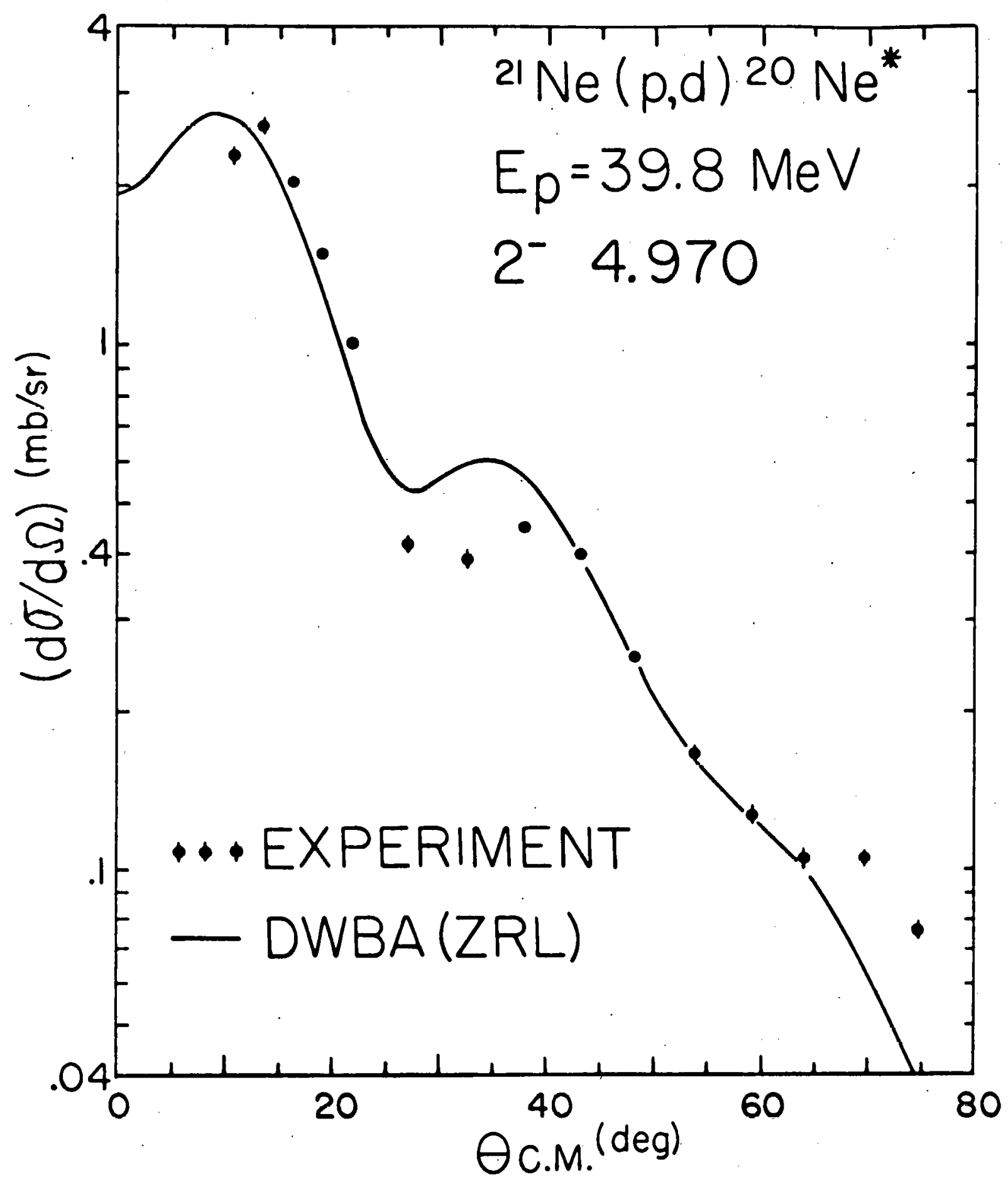

Fig. 8-15 


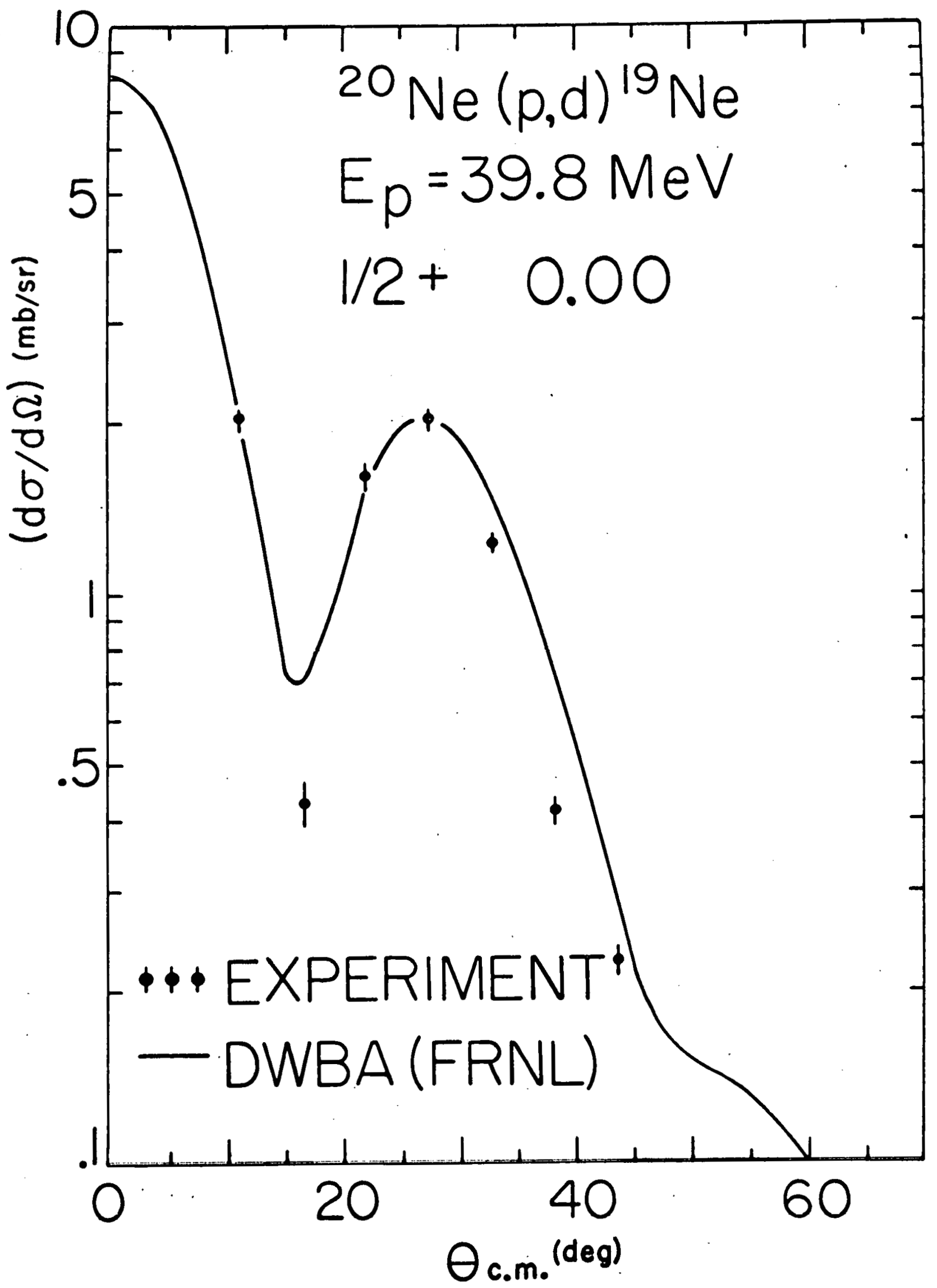

Fig. 8-16 


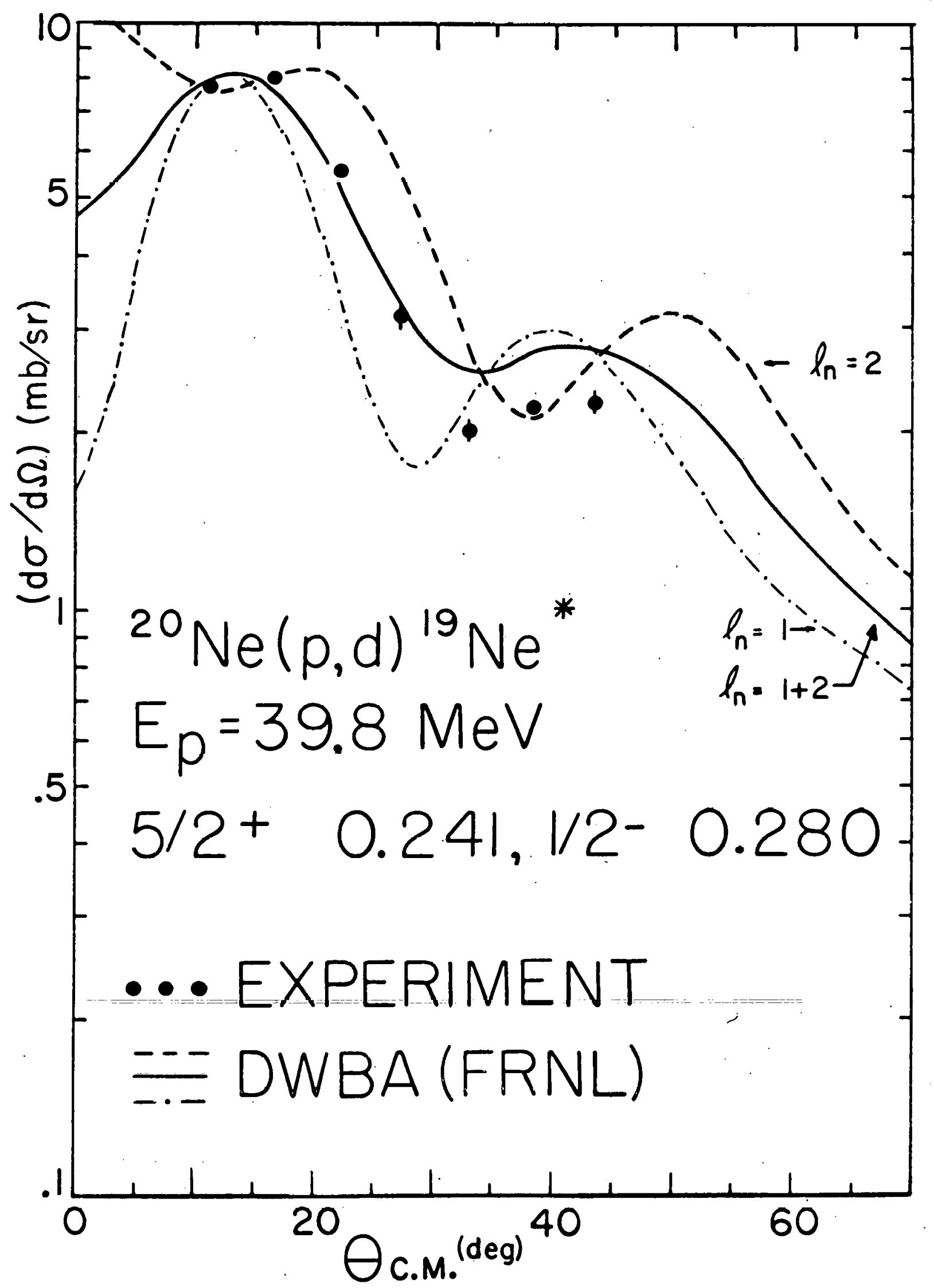

Fig. 8-17 


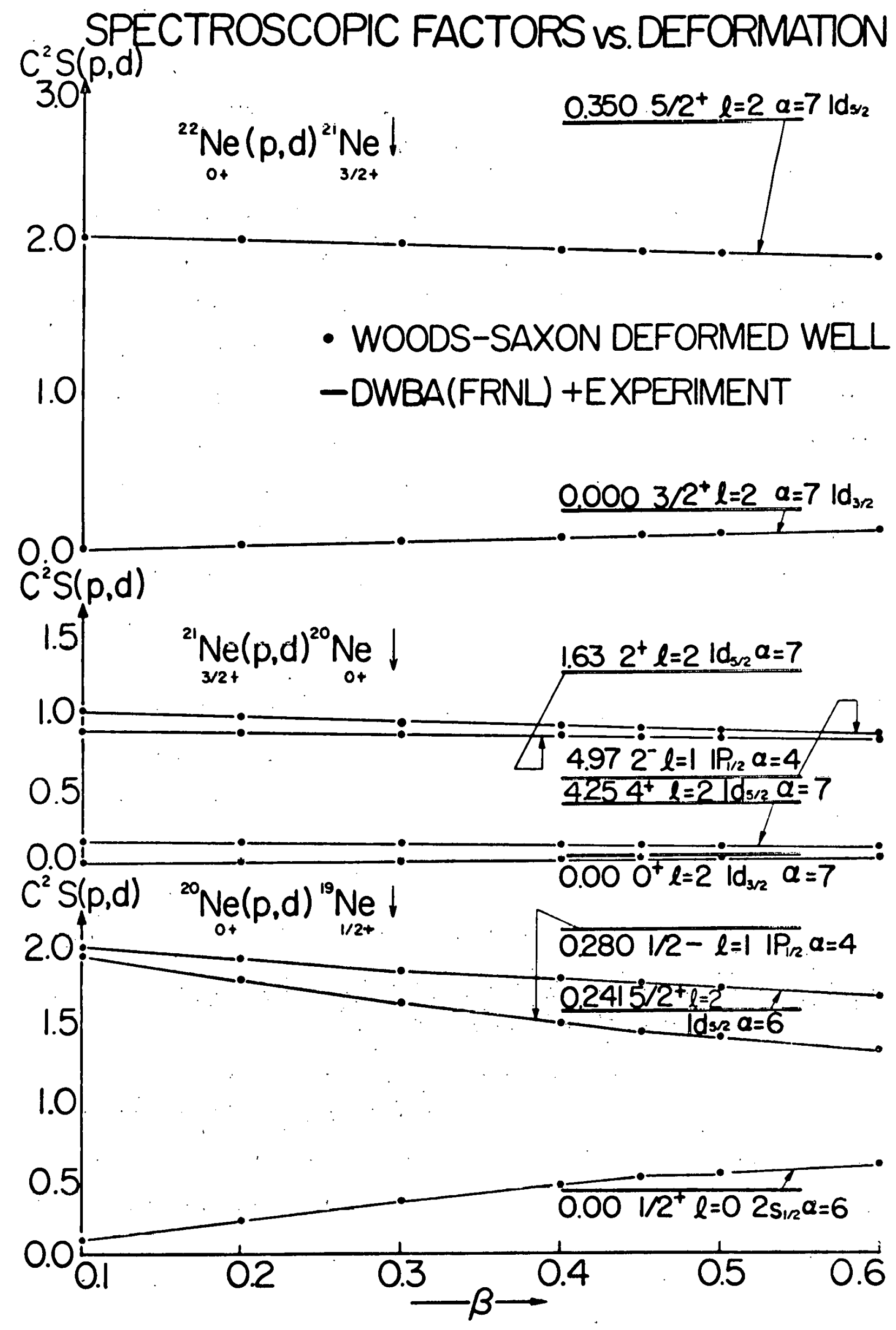

Fig. $8-18$ 
9. The $\left(d,{ }^{3} \mathrm{He}\right)$ Reaction at $20 \mathrm{MeV}$ on ${ }^{27} \mathrm{Al}$ and ${ }^{26} \mathrm{Mg}$

R. DeLong and D. Dehnhard

To complement data reported previously, ${ }^{1}$ the ${ }^{27} \mathrm{Al}\left(\mathrm{d},{ }^{3} \mathrm{He}\right){ }^{26} \mathrm{Mg}$ reaction was investigated using a $20 \mathrm{MeV}$ deuteron beam to get angular distributions of the g.s. $0^{+}, 1.81 \mathrm{MeV} 2^{+}, 2.94 \mathrm{MeV}^{+}$, and the $4.3 \mathrm{MeV}$ triplet of states. The scattering was done in an ORTEC 17-in. scattering chamber using a $150 \mu \mathrm{g} / \mathrm{cm}^{2}$ self-supporting ${ }^{27}$ Al target. The ${ }^{3} \mathrm{He}$ particles were detected using an E- $\triangle E$ particle identifying telescope consisting of a $73 \mu \Delta E$ detector and a $1000 \mu E$ detector. The overall resolution of $150 \mathrm{keV}$ allowed separation of the $4.3 \mathrm{MeV}$ triplet from the 3.94 MeV and $4.9 \mathrm{MeV}$ states but the triplet was not resolved. This triplet was resolved previously ${ }^{1}$ using the Enge split-pole spectrometer (ESP) and a position-sensitive detector. This work was repeated using a $24 \mu \mathrm{g} / \mathrm{cm}^{2}{ }^{27} \mathrm{Al}$ on $10 \mu \mathrm{g} / \mathrm{cm}^{2}{ }^{12} \mathrm{C}$ backing target allowing $10 \mathrm{keV} \mathrm{re}-$ solution. The ESP data were analyzed using a Gaussian peak fitting routine. $^{2}$ The experimental cross sections are shown in Figs. $9-1$ and 9-2.

The computer code DWUCK was used to perform distorted wave calculations to extract the spectroscopic factors $\left(c^{2} s\right)$. The results are shown in Table 9-1 along with those of Wildenthal et. al. ${ }^{3}$ and the shell model ${ }^{4}$ and Nilsson model ${ }^{5}$ predictions. The value we find for the $4^{+}$ state $\left(C^{2} S=1.0\right)$ is smaller than the one reported by Ref. $3\left(C^{2} S=1.8\right)$. The latter value is probably more reliable than our value because the DWBA calculations at the lower incident energy (20 MeV) for a $Q$ value of $\mathbf{- 7} \mathrm{MeV}$ (for the $4.3 \mathrm{MeV}$ triplet) is more uncertain than at higher energy ( $34.4 \mathrm{MeV})$. 
The good agreement with the shell model calculation ${ }^{4}$ is striking. Furthermore, the rather large discrepancy between the experimental spectroscopic factor for the transition to the $4.313 \mathrm{MeV}$ state $\left(\mathrm{J}^{\pi}=4^{+}\right)$ and the Nilsson model prediction for the $\mathrm{J}^{\pi}=4^{+}$member of the $\mathrm{g} . \mathrm{s}$. rotational band implies that the latter state cannot belong to the g.s. rotational band or that the rotational model is not applicable to ${ }^{26} \mathrm{Mg}$.

We have reported previously, ${ }^{1}$ that the $4.331 \mathrm{MeV}$ state could be a second $4^{+}$state. After retaking the data it appears that hoth the 4. $331 \mathrm{MeV}$ and the $4.350 \mathrm{MeV}$ states go primarily by $\ell=0$ (Fig. $9-2$ ). This implies that they could not be $4^{+}$states.

Figure $9-3$ shows the experimental cross sections of the g.s., $.090 \mathrm{MeV}$, and $1.0 / \mathrm{MeV}$ states from the ${ }^{26} \mathrm{Mg}\left(\mathrm{d},{ }^{3} \mathrm{He}\right)^{25} \mathrm{Na}$ reaction. This figure was given in last year's report ${ }^{6}$ with a wrong scale.

\section{$\underline{\text { References }}$}

$1_{R}$. DeLong and D. Dehnhard, Williams Laboratory Annual Report, 1969, p. 20.

${ }^{2}$. W. Goodwin, Private Communication. We are indebted to R. Goodwin for the use of his peak fitting code.

3B. H. Wildenthal and E. New̄man, Phys. Rev. 175, 1435 (1968).

${ }^{4}$ B. H. Wildenthal et. al., Nuc1. Phys. 26B, 692 (1968).

${ }^{5}$ G. R. Satchler, Ann. Phys. 3, 275 (1958).

${ }^{6}$ D. Dehnhard and R. DeLong, Williams Laboratory Ánnual Report, 1969, p. 22 . 
TABLE I SPECTROSCOPIC FACTORS $\left(C^{2} S\right)$ FOR ${ }^{27} \mathrm{AL}\left(\mathrm{d},{ }^{3} \mathrm{He}\right)^{26} \mathrm{Mg}$

\begin{tabular}{|c|c|c|c|c|c|c|}
\hline $\begin{array}{c}\text { Excitation Energy } \\
\text { Ex(MeV) }\end{array}$ & $J^{\pi}$ & $j_{\text {transfer }}^{\pi}$ & $\begin{array}{l}C^{2} S \operatorname{sexp} \\
20 \mathrm{MeV}\end{array}$ & $\begin{array}{l}C^{2} S_{(o)}^{(0)} \\
34.4 \mathrm{MeV}\end{array}$ & $\begin{array}{l}C^{2} S_{\text {theo }}^{(b)} \\
\text { Shell model }\end{array}$ & $\begin{array}{c}C^{2} S_{\text {theo }}^{(c)} \\
\text { Nilsson model }\end{array}$ \\
\hline 0.0 & $\mathrm{O}^{+}$ & $5 / 2^{+}$ & 0.23 & 0.30 & 0.29 & 0.33 \\
\hline \multirow[t]{2}{*}{1.81} & $2^{+}$ & $5 / 2^{+}$ & 0.81 & $|1.04-1.06|$ & 0.75 & 0.60 \\
\hline & & $1 / 2^{+}$ & $<.02$ & $<.01$ & 0.014 & $0.0^{(d)}$ \\
\hline \multirow[t]{2}{*}{2.94} & $2^{+}$ & $5 / 2^{+}$ & 0.22 & $0.20-0.26$ & 0.29 & $(0.0)^{(e)}$ \\
\hline & & $1 / 2^{+}$ & $<.02$ & $<.01$ & 0.0032 & (0.0) \\
\hline 4.313 & $4^{+}$ & $5 / 2^{+}$ & 1.0 & & 1.80 & 0.07 \\
\hline 4.331 & $\left(2^{+}\right)$ & $\left(1 / 2^{+}\right)$ & 0.09 & $0-23\}$ & & 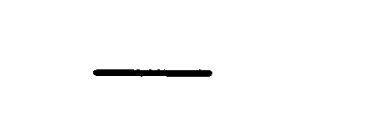 \\
\hline 4.350 & $\left(2^{+}\right)$ & $\left(1 / 2^{+}\right)$ & 0.06 & & & - \\
\hline
\end{tabular}

a) Ref. 3 ; b)Ref. 4 ; c) Ref.5; d) If $K$ selection rule holds

e) If $2.94 \mathrm{MeV}$ state is a member of $\delta$-vibrational band 


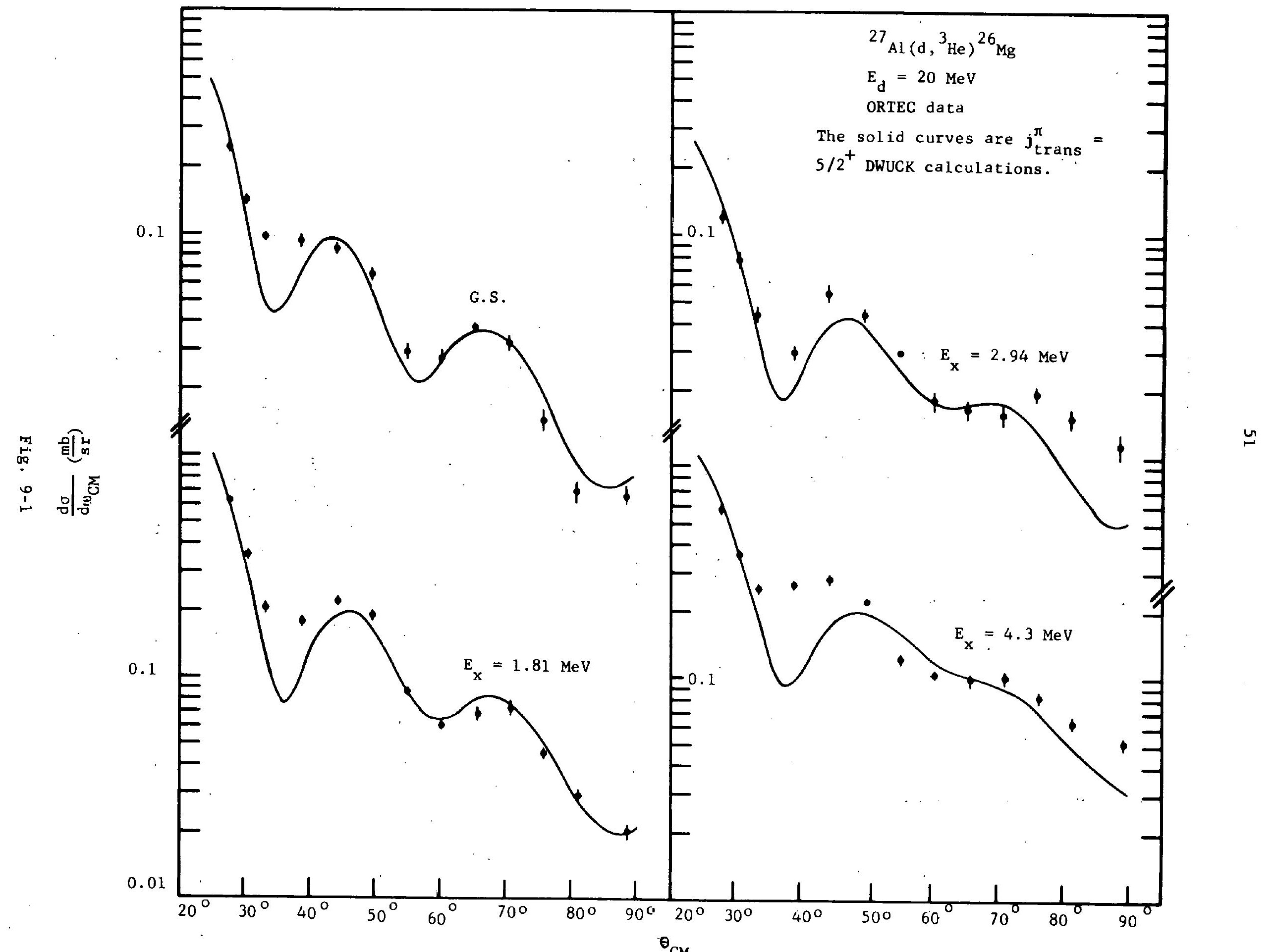




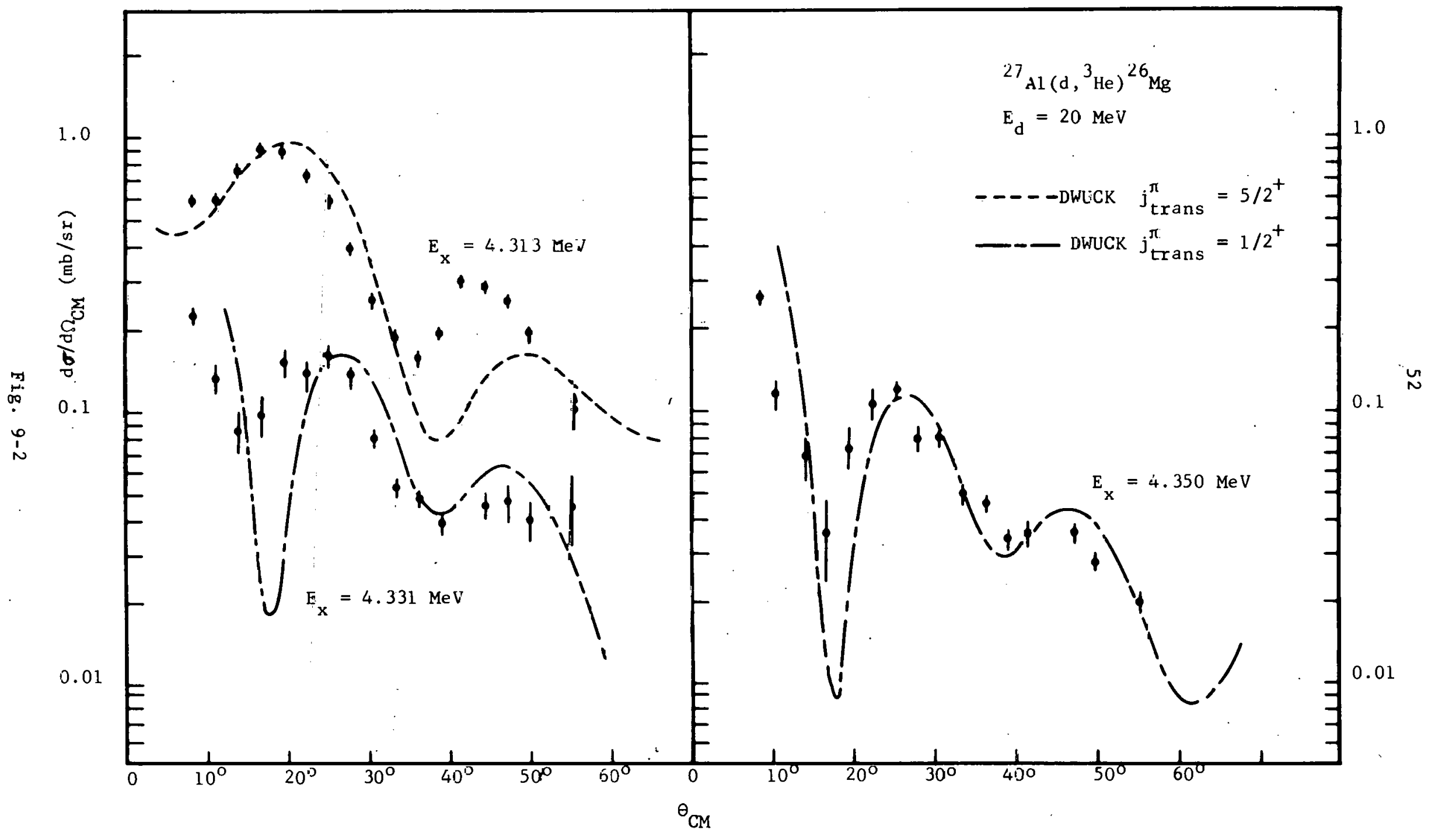




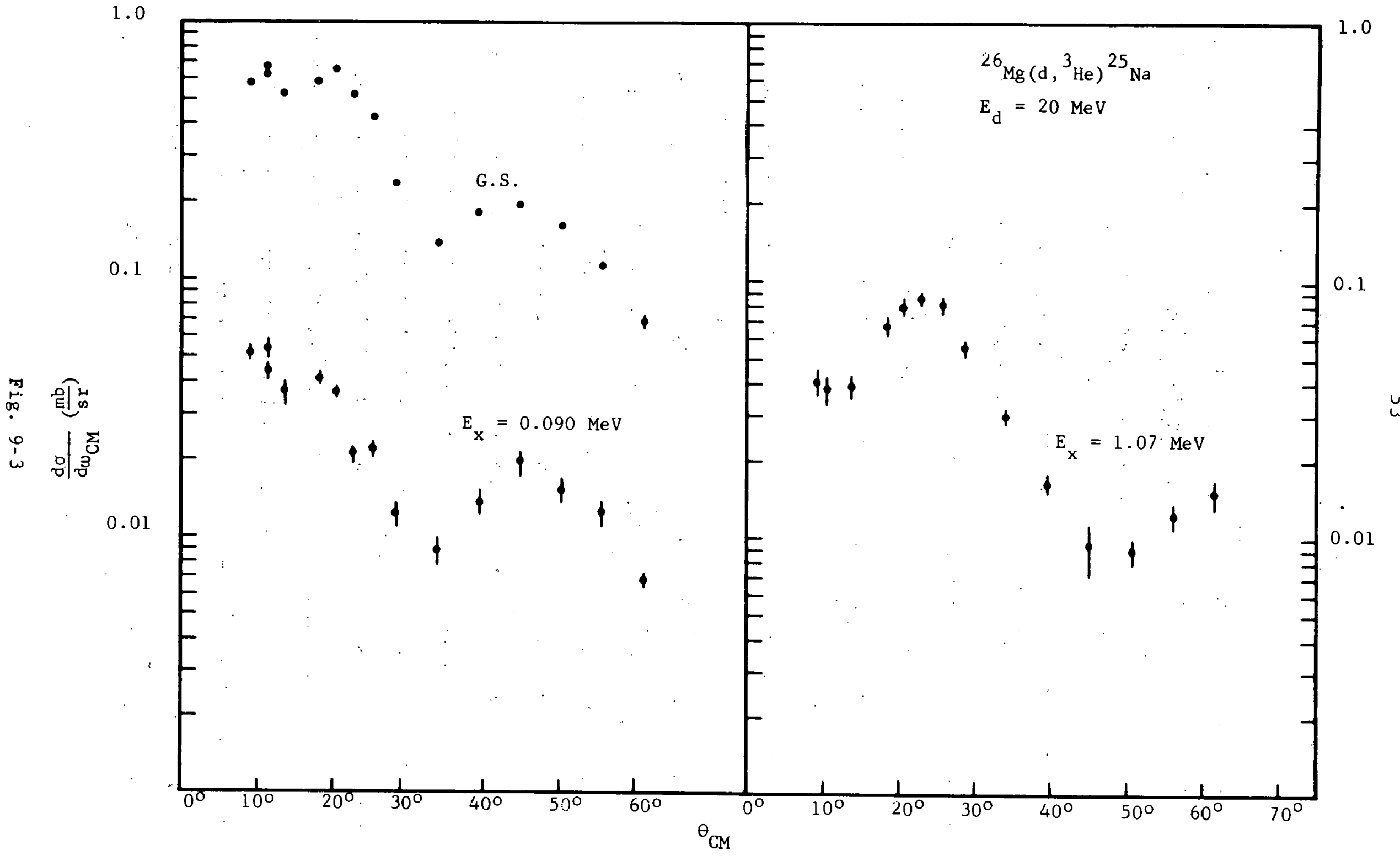


10. Elastic and Inelastic Scattering of $20 \mathrm{MeV}$ Deuterons from ${ }^{27} \mathrm{Al}$ and of $17.67 \mathrm{MeV}{ }^{3} \mathrm{He}$ from ${ }^{26} \mathrm{Mg}$

R. DeLong and D. Dehnhard

To study the effect of two step processes on the ${ }^{26} \mathrm{Mg}\left(\mathrm{d},{ }^{3} \mathrm{He}\right){ }^{25} \dot{\mathrm{Na}}$ and the ${ }^{27} \mathrm{Al}\left(\mathrm{d},{ }^{3} \mathrm{He}\right){ }^{26} \mathrm{Mg}$ reactions ${ }^{1}$ the elastic and inelastic scattering of deuterons from ${ }^{27} \mathrm{Al}$ and of ${ }^{3} \mathrm{He}$ 's from ${ }^{26} \mathrm{Mg}$ were measured. The differential cross sections were analyzed using the optical model search programs RAROMP ${ }^{2}$ and SNOOPY ${ }^{3}$, the DWBA program DWUCK, ${ }^{4}$ and Tamura's coupled channels program JUPITER I. 5

The experiment was performed using a $20 \mathrm{MeV}$ deuteron beam and a $17.67 \mathrm{MeV}^{3}$ He beam. The latter energy was chosen to correspond to the equivalent outgoing energy in the ${ }^{27} \mathrm{Al}\left(\mathrm{d},{ }^{3} \mathrm{He}\right)^{26} \mathrm{Mg}$ reaction (20 MeV) to the g.s. of ${ }^{26} \mathrm{Mg}$. To facilitate resolving ${ }^{12} \mathrm{C}$ and ${ }^{16} \mathrm{O}$ contaminants the forward angie deuteron scattèring $\left(8^{\circ}-68^{\circ}\right.$ Lál.) was done uoing the Enge split-pole spectrometer and a $160 \mu \mathrm{g} / \mathrm{cm}^{2}$ self-supporting ${ }^{27}$ Al target. The resolution was limited to $15 \mathrm{keV}$ by the target thickness. Angular distributions of the g.s., $.842 \mathrm{MeV}, 1.013 \mathrm{MeV}$, and $3.01 \mathrm{MeV}$ states were taken by use of three position-sensitive detectors. The scattering cross sections at larger angles $\left(42.5^{\circ}-157.5^{\circ}\right.$ tab.) were measured using the same target in the 17 -in. diameter ORTEC scattering chamber. $A \triangle E, E$ particle identification system was employed consisting of a $700 \mu$ thin $\triangle E$ and a $3 \mathrm{~mm}$ thick Li drifted $E$ detector. An overall resolution of $100 \mathrm{keV}$ was obtained. Angular distributions were taken for the g.s. and the first five excited states in ${ }^{27} \mathrm{Al}$. 
The ${ }^{3}$ He scattering was measured with two position-sensitive detectors in the spectrometer using a $90 \mu \mathrm{g} / \mathrm{cm}^{2}$ rolled ${ }^{26} \mathrm{Mg}$ foil. Angular distributions were taken for the g.s. and the $1.81 \mathrm{MeV}$ state from $12^{\circ}$ to $96^{\circ}$ Lab. Some of the data are shown in Figs. $10-1, \quad 10-2$ and 10-3 with the besl optical model fits. The error bars represent statistical errors only.

The elastic ${ }^{3}$ He data were first analyzed using the standard optical model as contained in RAROMP without spin orbit coupling. The best fit parameters are given in Table 10-1. Parameter set 1 was used in a complex form factor analysis using the code DWUCK to get estimates of $\beta_{2}$ for the excitation of the $1.81 \mathrm{MeV}$ state. The effects of Coulomb excitation of this state (Fig. $10-4$ ) were also investigated. It was found that Coulomb excitation improves the fit to the data, however yields essentially the same value for the deformation parameter $\beta_{2},\left(\beta_{2}=0.36\right.$ without and $\beta_{2}=0.35$ with Coulomb excitation). The value $\beta_{2}=0.3 .6$ and the optical model parameter set 2 were put into the JUPITER 1 coupled channels code using the rotational model mode with non-adiabatic coupled channels (NACC). It should be mentioned, however, that it is not yet clear $^{1}$ whether the rotational or the vibrational model should be applied to ${ }^{26} \mathrm{Mg}$. So far the coupled channels calculations have been made without Coulomb excitation, although, as we know from the complex form factor analysis (Fig. 10-4), Coulomb excitation affects the shape of the angular distribution.

Channel coupling affects the elastic cross section strongly so that the original optical model parameters have to be modified. In . preliminary calculations the imaginary well depth $\left(\mathrm{W}_{V}\right)$ and $\beta$ were varied in JUPITER ${ }^{1}$ for a better fit. It was found that the fits are not very sensitive to the variations of $\mathrm{W}_{\mathrm{V}}$. To improve the fits, varying other 
optical model parameters was found to be necessary. Some preliminary results are shown in Fig. $10-2$ and the best parameters to date are given in Table10-1.

Fitting of the elastic deuteron scatering data was done using SNOOPY ${ }^{2}$, an optical model search routine that includes a spin orbit term for spin 1 particles. A spin orbit potential of the form

$$
U_{80}=2 V_{80} \frac{1}{r}\left(\frac{d}{d r}\right)\left(1+e^{x^{\prime \prime}}\right)^{-1} E \cdot \sigma \quad \text { where } x^{n}=\left(r-r_{80} A^{1 / 3}\right) / a_{80}
$$

was used. Fig. 10-1 shows the best optical model fits with and without a spin orbit term. The best fit parameters are given in Table 10-2.

In the excited core model the inelastic cross section to the excited states in ${ }^{27} \mathrm{Al}\left(\mathrm{J}^{\pi}=1 / 2^{+}\right.$through $\left.9 / 2^{+}\right)$is given by $\sigma_{\left(J_{i} \rightarrow J_{f}\right)}=\frac{2 J_{f}+1}{2 J_{i}+1} \frac{1}{2 L+1} \beta_{L}^{2} \sigma_{D_{W U C K}}$

Employing complex collective formfactors we obtained closely the same $\beta$ value for all the excited states except for the $\mathrm{J}^{\pi}=\mathrm{J} / 2^{+}$state which is probably mixed with the g.s. (see ref. 6 and references therein.) The distorted wave curves in Fig. $10-2$ contain $\frac{2 \mathrm{~J}_{f}+1}{30} \beta_{2}{ }^{2}$ with $B_{2}=0.35$ as a factor.

Niewodniczan'ski et. al. ${ }^{6}$ found a larger value, $\beta_{2}=0.44$, from a

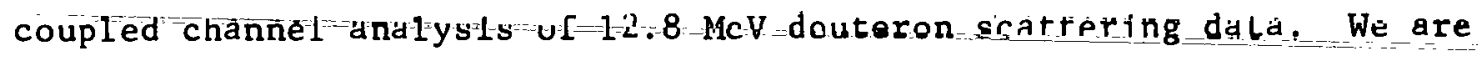
now doing such a coupled channels analysis of our $20 \mathrm{MeV}$ data. Preliminary results are values of approximately $\beta=0.30$.

It is planned to do the pickup reaction calculations for the $\left(d^{3}{ }^{3} \mathrm{He}\right)$ reaction ${ }^{1}$ including coupled channels in both the incoming and outgoing waves using the results discussed above. 


\section{References}

$1_{R}$. Delong and D. Dehnhard, Williams Laboratory, Annual Report, 1969, p. 20 and section 9 . of this report.

${ }^{2}$ G. J. Pyle, A Computer Code for Reformulated Optical Model Calculations, Williams Laboratory of Nuclear Physics, Computer Code C00-1265-64.

${ }^{3}$ P. Schwandt, Colorado University, Program Number 6836.

${ }^{4}$ P. D. Kunz, Private Communication.

5T. T. Tamura, Private Communication. We are indebted to Drs. P. Schwandt, P. D. Kunz, and T. T. Tamura for making their respective computer code available.to us. We are also indebted to Dr. D. Bes for his help in the use of the coupled channels code JUPITER 1.

${ }^{6}$ H. Niewodniczański, et. al., Nuclear Physics 55, 386-396 (1964). 
Table 10-1. ${ }^{26} \mathrm{Mg}\left({ }^{3} \mathrm{He},{ }^{3} \mathrm{He}\right){ }^{26} \mathrm{Mg}$ at $17.67 \mathrm{MeV}$

\begin{tabular}{|c|c|c|c|c|c|c|c|c|c|c|c|c|c|}
\hline Code & $\mathrm{VR}^{(\mathrm{a})}$ & $R R$ & $\mathrm{AR}$ & WV & WD & RI & $\mathrm{AI}$ & VS $^{\circ}$ & RS & AS & $\mathrm{RC}$ & $\beta$ & hl \\
\hline RAROMP set 1 & $159.28^{(b)}$ & 1.149 & .683 & 17.86 & 0.0 & 1.567 & .878 & 0.0 & 0.0 & 0.0 & 1.25 & -- & -- \\
\hline RAROMP set 2 & 145.24 & 1.23 & .646 & 19.9 & 0.0 & 1.468 & .931 & 0.0 & 0.0 & $0: 0$ & 1.25 & -- & -- \\
\hline JUPITER-1 & 145.24 & 1.23 & .646 & 19.9 & 0.0 & 1.60 & .931 & 0.0 & 0.0 & 0.0 & 1.25 & .36 & .85 \\
\hline
\end{tabular}

Table 10-2. ${ }^{27} \mathrm{AL}(\mathrm{d}, \mathrm{d}){ }^{27} \mathrm{AL}$ at $20 \mathrm{MeV}$

\begin{tabular}{l|c|c|c|c|c|c|c|c|c|c|c}
\hline \multicolumn{1}{|c|}{ Parameter } & $\mathrm{VR}^{(\mathrm{a})}$ & $\mathrm{RR}$ & $\mathrm{AR}$ & $\mathrm{WV}$ & $\mathrm{WD}$ & $\mathrm{RI}$ & $\mathrm{AI}$ & $\mathrm{VS}$ & $\mathrm{RS}$ & $\mathrm{AS}$ & $\mathrm{RC}$ \\
\hline Rode & $74.83^{(\mathrm{b})}$ & $1 .^{279}$ & .7995 & 0.0 & 27.96 & 1.511 & .447 & 0.0 & 0.0 & 0.0 & 1.25 \\
\hline SNOROMP & 103.6 & 1.02 & .85 & 0.0 & 11.82 & 1.413 & .695 & 8.19 & 1.02 & .856 & 1.25 \\
\hline \hline
\end{tabular}
(a) Parameter symbols are listed as defined in RAROMP.
(b) All potentials are given as positive. 


$$
\operatorname{th} 3
$$




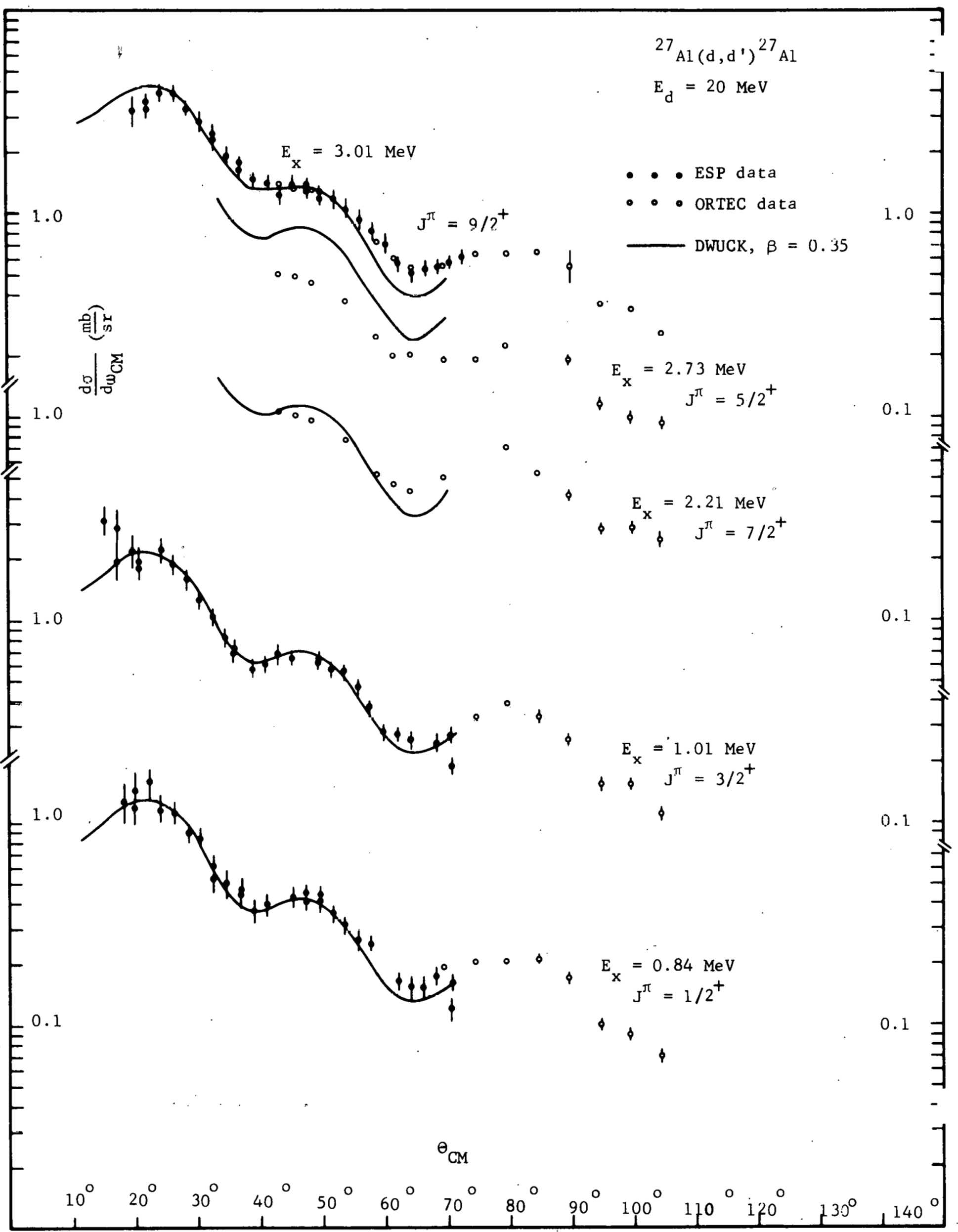

Fig. $10-2$ 


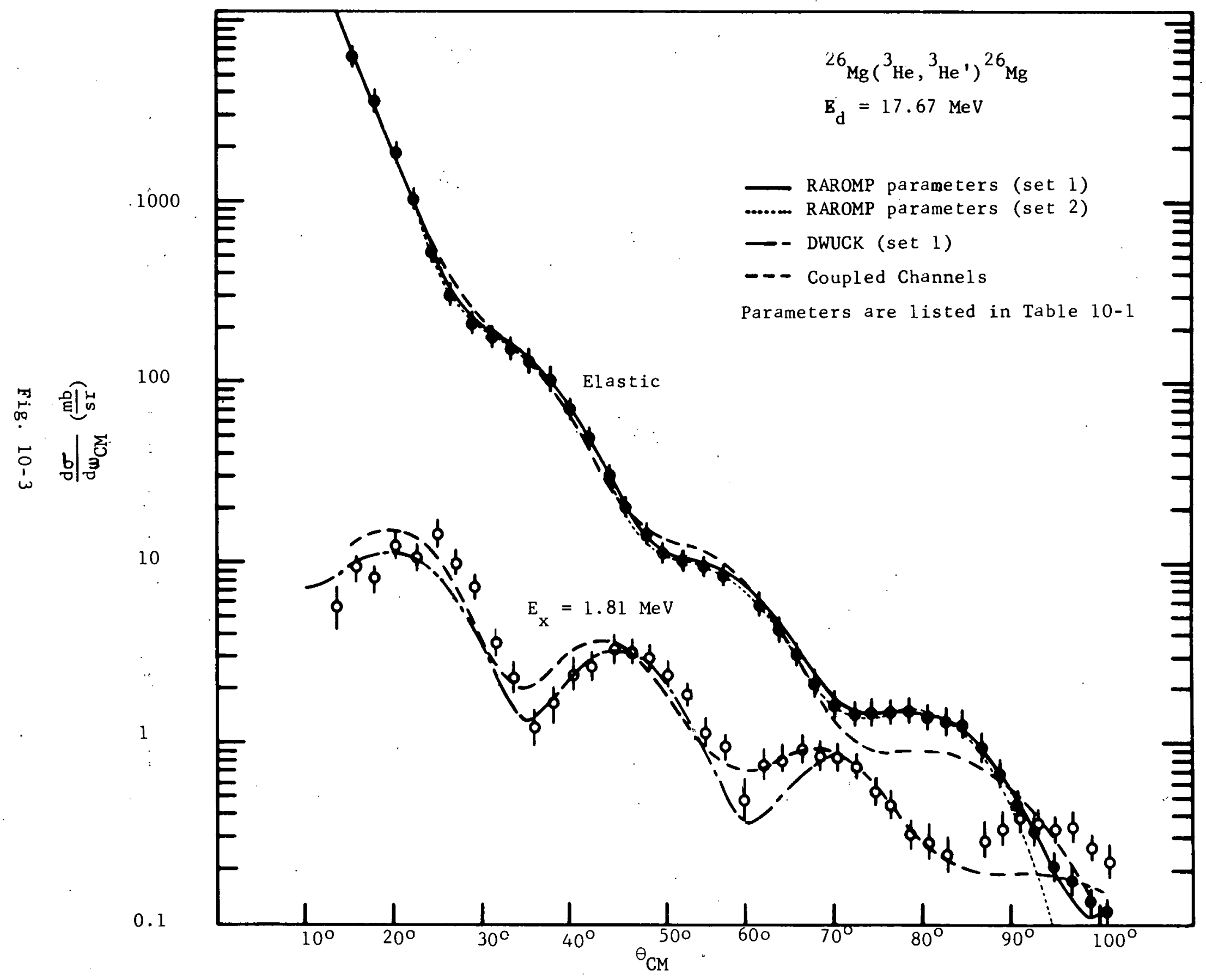




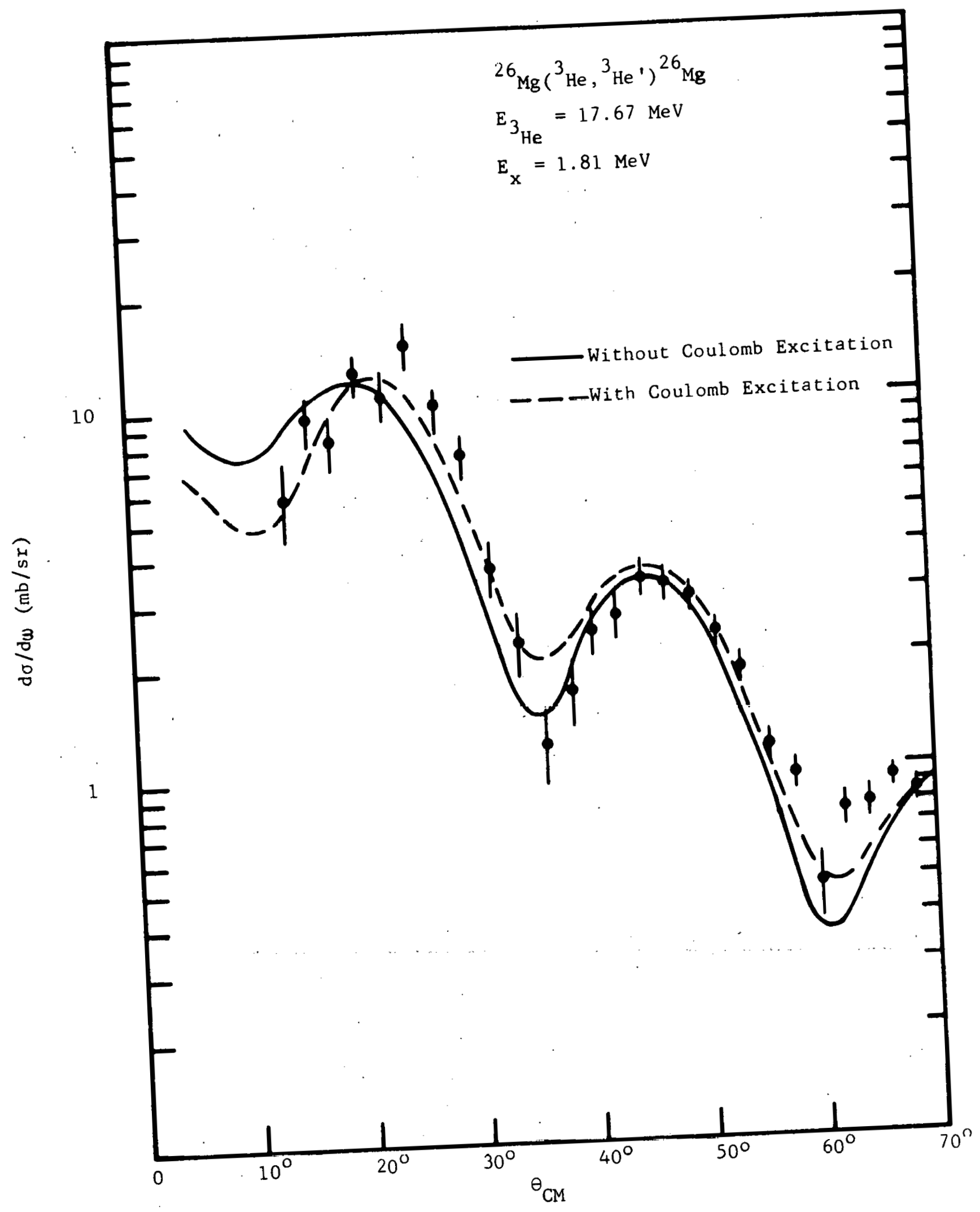

Fig. $10-4$ 
11. Elastic Scattering of $19.0-\mathrm{MeV}$ Deuterons

C. H. Poppe, H. Ohnuma, R. Wallen and D. L. Watson

A program to measure the elastic scattering of $19.0 \mathrm{MeV}$ deuterons has been undertaken. Over most of the angular range measurements are made in the Ortec chamber using $\mathrm{E}-\triangle \mathrm{E}$ detector telescopes in conjunction with the particle identification routine of the CDC-3100 computer. However, in order to separate deuterons scattered from target impurities in some of the targets, the ESP spectrometer was used for small angle measurements .

To date, elastic scattering of deuterons from ${ }^{60} \mathrm{Ni}$ over the angular range $40^{\circ}$ to $162^{\circ}$, from ${ }^{48} \mathrm{Ti}$ over the angular range $10^{\circ}$ to $150^{\circ}$, and from ${ }^{50} \mathrm{Ti}$ over the angular range $15^{\circ}$ to $140^{\circ}$ has been completed. Scattering experiments on ${ }^{46} \mathrm{Ti},{ }^{90} \mathrm{Zn},{ }^{16} \mathrm{O}$ and ${ }^{12} \mathrm{C}$ are in progress.

12. ${ }^{29} \mathrm{Si}(\mathrm{d}, \mathrm{p}){ }^{30} \mathrm{Si}$ Reaction

H. Ohnuma and D. Dehnhard

Information on the ${ }^{29} \mathrm{Si}(\mathrm{d}, \mathrm{p}){ }^{30} \mathrm{Si}$ reaction has been obtained at $16 \mathrm{MeV}$ to supplement previous data at $20 \mathrm{MeV}^{1}$. The split-pole magnetic spectrometer and nuclear emulsion plates have been used to analyze and detect the.protons. Plates are currently being scanned.

\section{Reference}

${ }^{1}$ H. Ohnuma and D. Dehnhard, John H. Williams Laboratory of Nuclear Physics Annual Report 1969, p. 26. 
13.

$\left({ }^{3}\right.$ He,d) Reactions on the Three Silicon Isotopes

W. W. Dykoski and D. Dehnhard

In the simple shell model for. the ground state of ${ }^{28} \mathrm{Si}$ the $1 \mathrm{~d}_{5 / 2}$ shell is filled with neutrons and protons while the $2 s_{1 / 2}$ and $1 d_{3 / 2}$ shells are empty. There is, however, considerable evidence for admixtures of $2 \mathrm{~s}_{1 / 2}$ and $1 \mathrm{~d}_{3 / 2}$ particles in the g.s. of ${ }^{28} \mathrm{Si}$. These admixtures seem to be similar for the other two silicon isotopes as known from single particle pickup reactions. The stripping reaction (neutron or proton) can be used as an independent way to determine the $2 \mathrm{~s}_{1 / 2}$ and $1 d_{3 / 2}$ admixtures, because it determines the "number of holes" in the shell model configuration of the target ground state.

We have investigated the $\left({ }^{3} \mathrm{He}, \mathrm{d}\right)$ reaction as the three $\mathrm{Si}$ isotopes at an incident energy of $25 \mathrm{MeV}$ employing $\mathrm{Si}$ oxide targets enriched in ${ }^{28} \mathrm{Si},{ }^{29} \mathrm{Si}$, and ${ }^{30} \mathrm{Si}$, respectively.

The data were taken with the magnetic spectrometer using nuclear emulsions and position-sensitive detectors independently (see also last year's Williams Laboratory Report, 1969, p. 26 J. The cross sections for the reactions on the varlous isotopes were normalized to each other by also taking spectra on a target of natural isotopic composition. Absolute cross sections were obtained by comparing the elastic ${ }^{3}$ He scattering yield with.an optical model prediction. Spectroscopic factors were extracted in che usuall-fashion-For tho 28 Si and ${ }^{30} \mathrm{Si}\left({ }^{3} \mathrm{He}, \mathrm{d}\right)$ reactions the results agree quite well with previously obtained values from $(d, n)$ and $\left({ }^{3} \mathrm{He}, d\right)$ reactions.

We calculated numbers of proton holes from the above spectroscopic factors and found values consistent with the proton occupation numbers obtained from the $\left(d,{ }^{3} H e\right)$ reaction on the $S i$ isotopes. 
14. ${ }^{40} \mathrm{Ca}(\mathrm{d}, \mathrm{p})$ and (d,d) Reaction Between 13 and $19 \mathrm{MeV}$

H. Ohnuma and D. L. Watson

To obtain information on the shell closure at $\mathrm{N}, \mathrm{Z}=20$ and the direct reaction mechanism, the ${ }^{40} \mathrm{Ca}(\mathrm{d}, \mathrm{p})$ reaction was studied at 13 , 15, 17 , and $19 \mathrm{MeV}$ using solid state detectors. Elastic angular distributions were taken at the same time, and also separately with counter telescopes at 15 and $19 \mathrm{MeV}$. Small angle data for both reactions were taken with a magnetic spectrometer and position-sensitive detectors. Preliminary analysis indicates that the spectroscopic factors for the ground state of ${ }^{41} \mathrm{Ca}$ stay fairly constant in the energy region studied $((2 \mathrm{~J}+1) \mathrm{S} \approx 7.0)$. The ratio of the cross section of the $2.46 \mathrm{MeV}$ state to that of the $1.95-\mathrm{MeV}$ state is about $1 / 3$, also showing little energy dependence. Fig.14-1 shows some $(d, p)$ angular distributions obtained at $19 \mathrm{MeV}$.

15.

$$
{ }^{44} \mathrm{Ca}\left({ }^{3} \mathrm{He}, \mathrm{t}\right){ }^{44} \mathrm{Sc} \text { Reaction }
$$

H. Ohnuma, W. Makofske, and D. Dehnhard The ${ }^{44} \mathrm{Ca}\left({ }^{3} \mathrm{He}, \mathrm{t}\right){ }^{44} \mathrm{Sc}$ reaction has been studied at $29 \mathrm{MeV}$ in order to obtain information on the level structure of ${ }^{44} \mathrm{Sc}$ and on the $\left({ }^{3} \mathrm{He}, t\right)$ reaction mechanism. A magnetic spectrometer and positionsensitive detectors were used to analyze reaction products. Some of the angular distributions are shown in Fig. 15-1. Solid lines are to guide the eyes. The following tentative spin assignments are made based on shapes of angular distributions for in-shell transitions: $0 \mathrm{keV}, 2^{+}$; $271 \mathrm{keV}, 6^{+} ; 353 \mathrm{keV}, 4^{+} ; 670 \mathrm{keV}, 1^{+} ; 765 \mathrm{keV}, 3^{+} ; 971 \mathrm{keV}, 7^{+} ; 1056$ $\mathrm{keV}, 5^{+} ; 1187 \mathrm{keV}, 3^{+} ; 1536 \mathrm{keV},\left(5^{+}\right) ; 2790 \mathrm{keV}, 0^{+}$(IAS). 


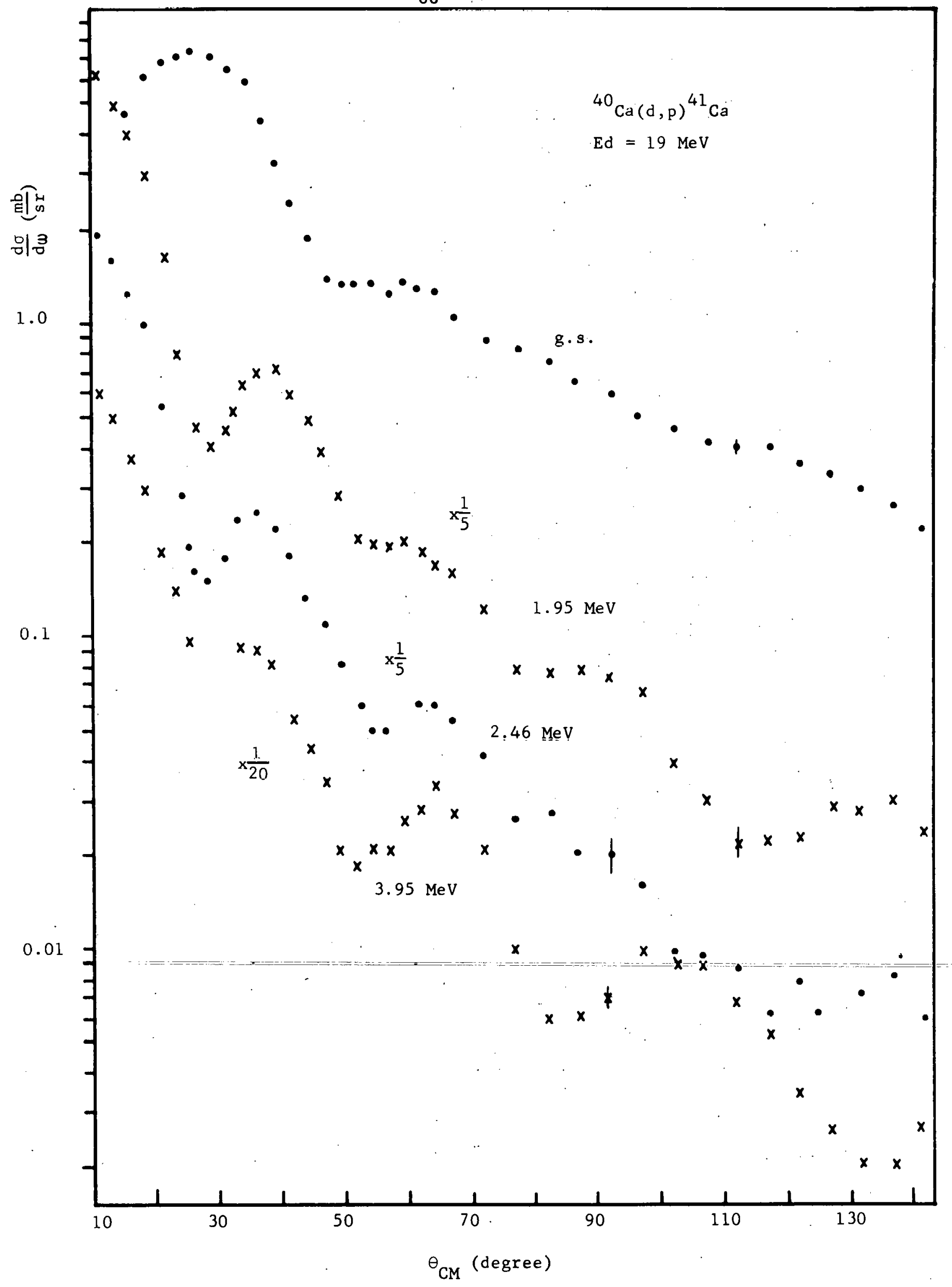

Fig. 14-1 


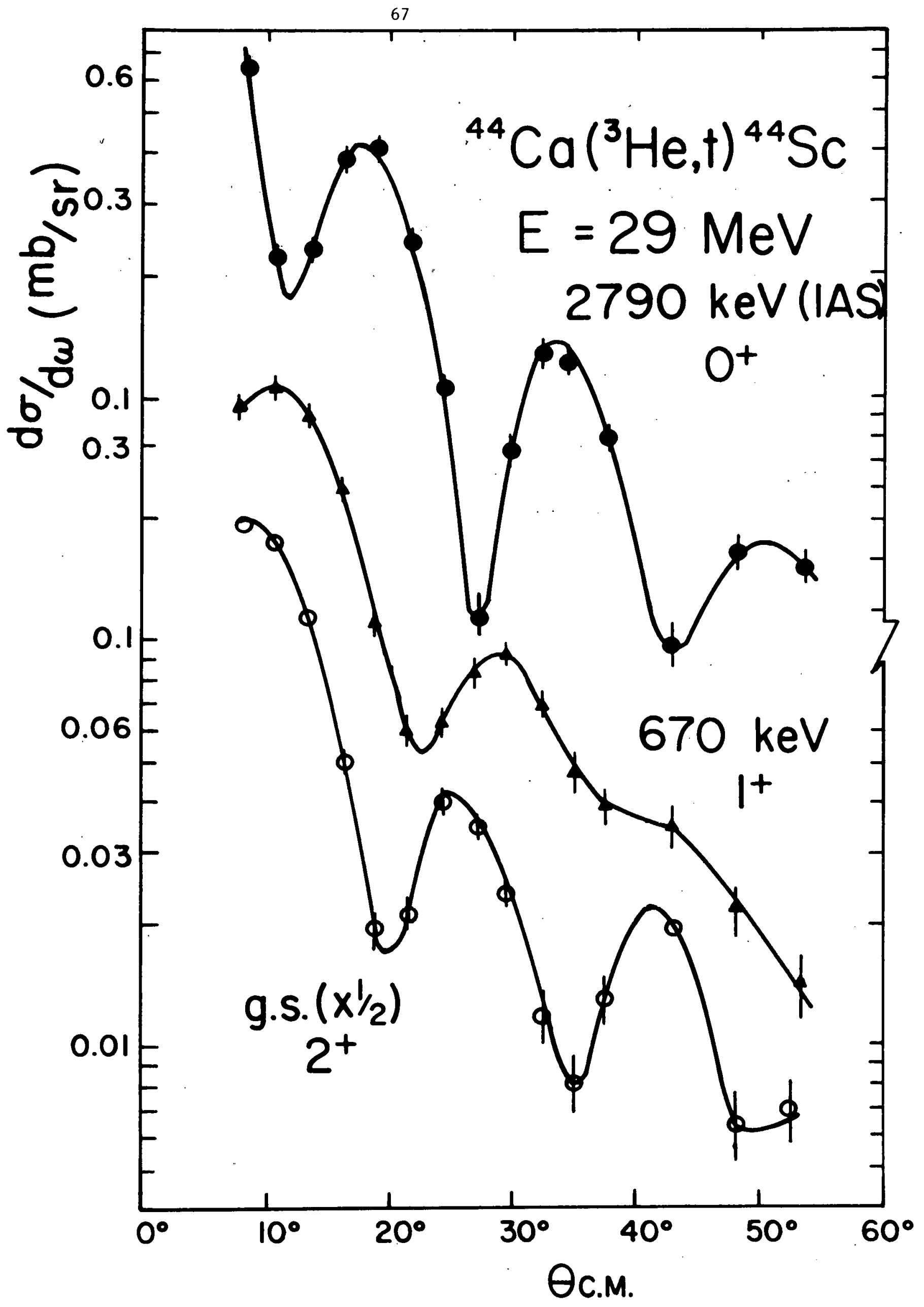

Fig. 15-1 
A number of cross-shell transitions are also observed, and some of them are as strong as in-shell transitions. There seems to be a correlation between the strength of cross-shell transitions and $\left({ }^{3} \mathrm{He}, d\right)$ or $(d, t)$ spectroscopic factors to the same final states:

The results are now being analyzed using the computer code DWUCK ${ }^{1}$ employing microscopic formfactors.

\section{Reference}

${ }^{1}$ P. D. Kunz, Private Communication. We are endebted to Dr. P. D. Kunz for making his computer code available to us. 
III. SPECTROSCOPY OF NUCLEI FROM SC THROUGH $\mathrm{Ni}$

16. Levels in ${ }^{44} \mathrm{Sc}$ from the ${ }^{42} \mathrm{Ca}(\alpha, \mathrm{d})$ Reaction

R. H. Cornett, H. Ohnuma, and N. M. Hintz

The ${ }^{42} \mathrm{Ca}(\alpha, \mathrm{d}){ }^{44} \mathrm{Sc}$ reaction has been studied with a $26.5 \mathrm{MeV}$ alphaparticle beam from the Williams Laboratory tandem Van de Graaff accelerator. The reaction products were analyzed by the split-pole magnetic spectrometer and solid-state position-sensitive detectors. The targets were isotopically enriched $(\sim 95 \%)$ metallic calcium-42 deposited on thin carbon foils, prepared and transferred to the spectrometer target chamber under vacuum.

Spectra were taken for laboratory angles from $\theta=10^{\circ}$ to $\theta=55^{\circ}$ in $2.5^{\circ}$ steps. A typical deuteron spectrom, at $\theta_{1 \mathrm{ab}}=22.5^{\circ}$, averaged over three channels, is shown in Fig.16-1. The peak marked "A" results from an incorrect particle-discrimination setting and is composed of alphas from the elastic reaction ${ }^{42} \mathrm{Ca}(\alpha, \alpha)$.

Angular distributions for the stronger states have been prepared and are currently being compared with predictions obtained using code JULIE. Two typical angular distributions are shown in Fig.16-2. 


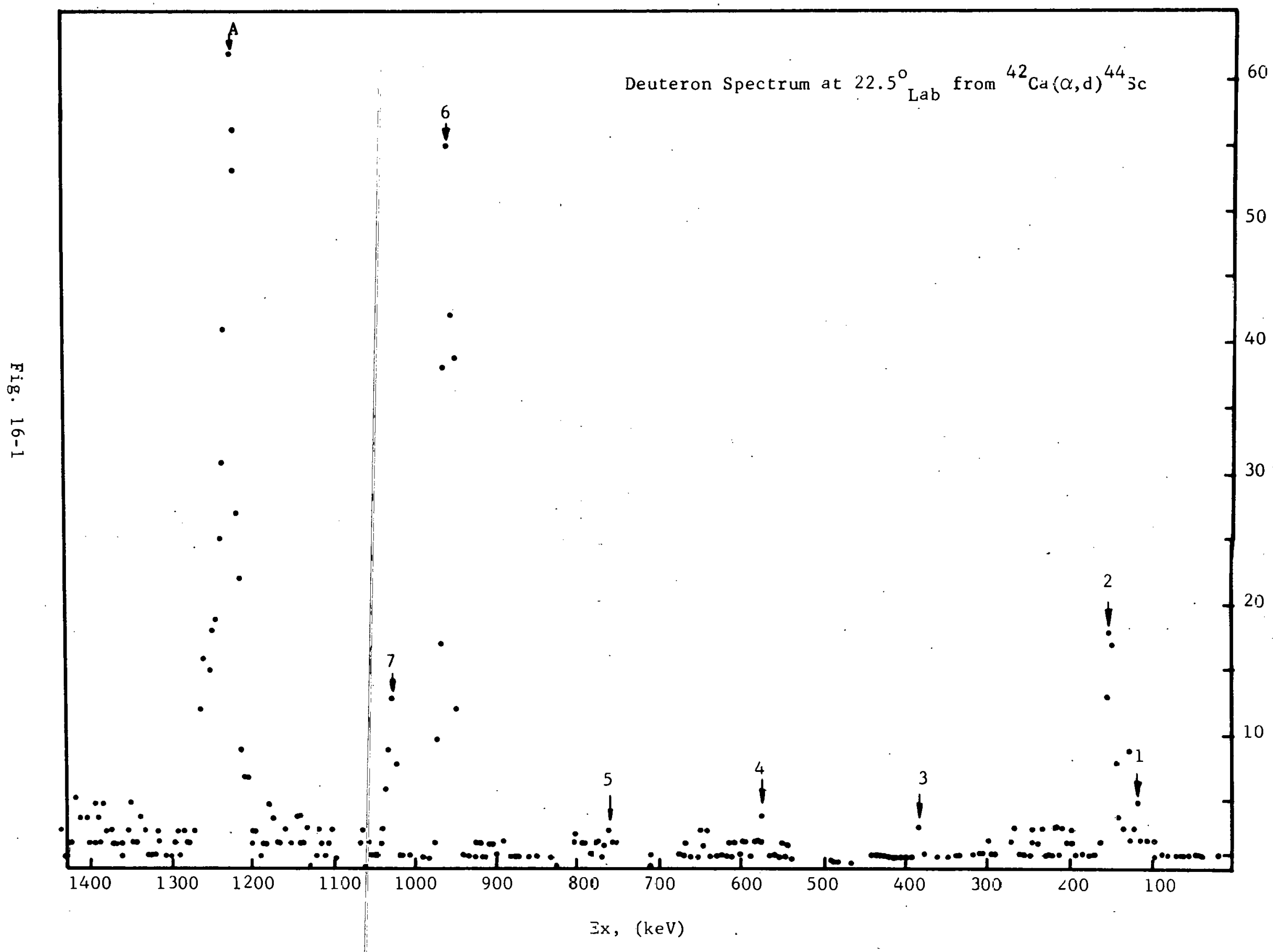




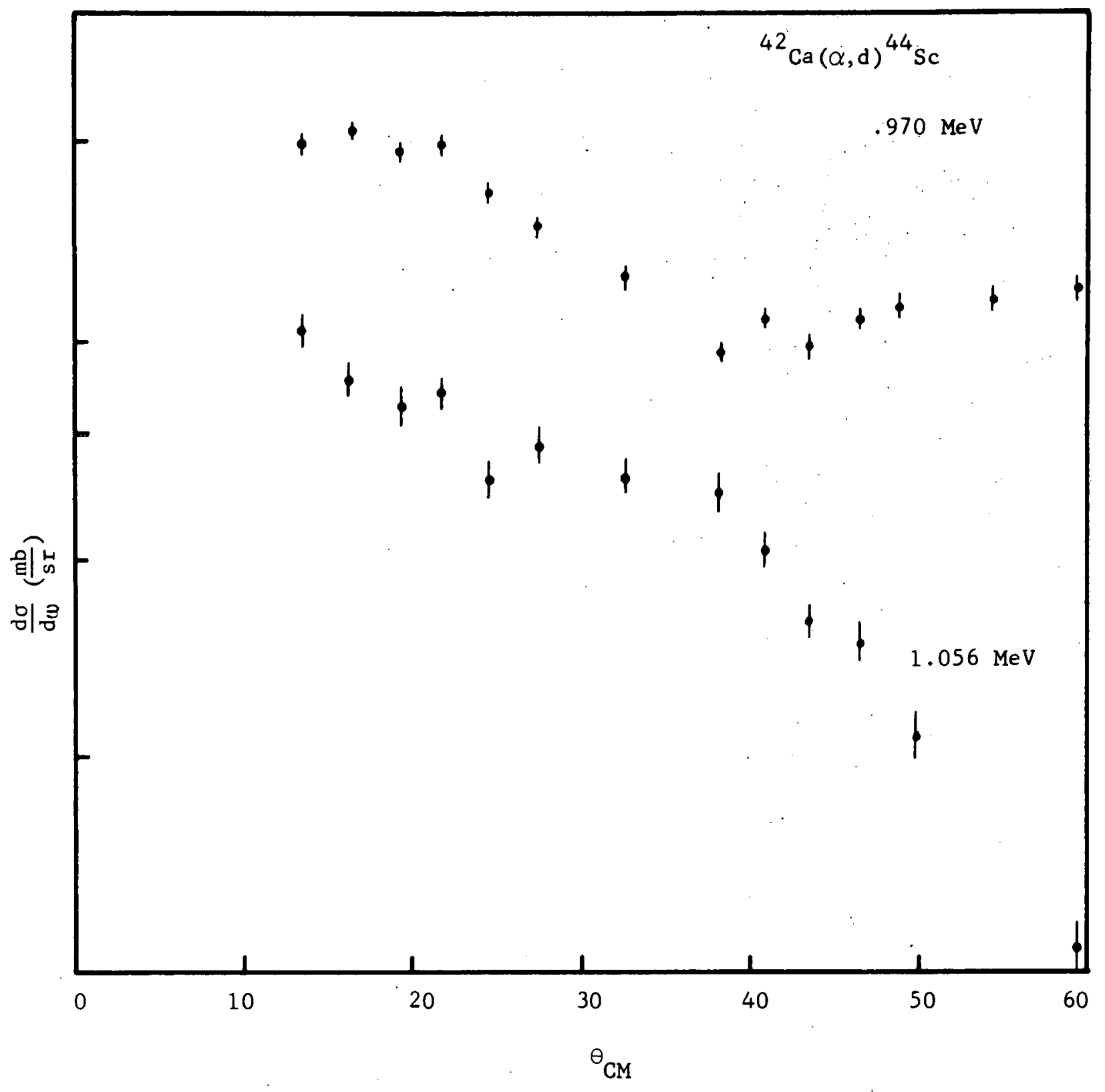

Fig. 16-2 
17. Levels of ${ }^{44} \mathrm{Sc}$ from the ${ }^{45} \mathrm{Sc}(\mathrm{d}, \mathrm{t})^{44} \mathrm{Sc}$ Reaction

H. Ohnuma and A. M. Sourkes

Energy levels in ${ }^{44} \mathrm{Sc}$ have been studied using the ${ }^{45} \mathrm{Sc}(\mathrm{d}, \mathrm{t}){ }^{44} \mathrm{Sc}$ reaction at $19.5 \mathrm{MeV}$ incident energy. Thirty-six levels in ${ }^{44} \mathrm{Sc}$ below an excitation energy of $3.2 \mathrm{MeV}$ were observed. Angular distributions were measured, and compared with distorted-wave Born approximation theory to obtain transferred $\ell$-values and spectroscopic factors. A considerable amount of $\ell=1$ strength was found, indicating the presence of $2 p$-neutrons in the ground state of ${ }^{45} \mathrm{Sc}$. A recent shell model calculation by Bayman et al. using an $\left(\mathrm{f}_{7 / 2}\right)^{4}$ configuration shows qualitative agreement with experiment. In Table 17-1 the present results are summarized. The spectroscopic factors obtained in this experiment sum to 4.17 for $\ell=3,0.15$ for $\ell=1,2.53$ for $\ell=2$, and 0.75 for $\ell=0$.

18. The Energy Levels of ${ }^{46} \mathrm{~V}$ studied by the ${ }^{46} \mathrm{Ti}\left({ }^{3} \mathrm{He}, \mathrm{t}\right)$ Redction W. Makofske and H. Ohnuma

The ESP spectrometer and position-sensitive detectors were used to study the ${ }^{46} \mathrm{Ti}\left({ }^{3} \mathrm{He}, \mathrm{t}\right){ }^{46} \mathrm{~V}$ reaction at $29 \mathrm{MeV}$ in order to obtain information on the level structure of ${ }^{46} \mathrm{~V}$.

Spectra were taken on a target composed of approximately $77 \%$

${ }^{46} \mathrm{Ti}$ between 0 and about $3 \mathrm{MeV}$ excitation at $18^{\circ}(1 \mathrm{ab})$. Strong states at excitation energies of $798,996,1235,1377,2470$ and (2710) $\pm 5 \mathrm{keV}$ were observed. 
Table 17-1. Summary of the Present Results.

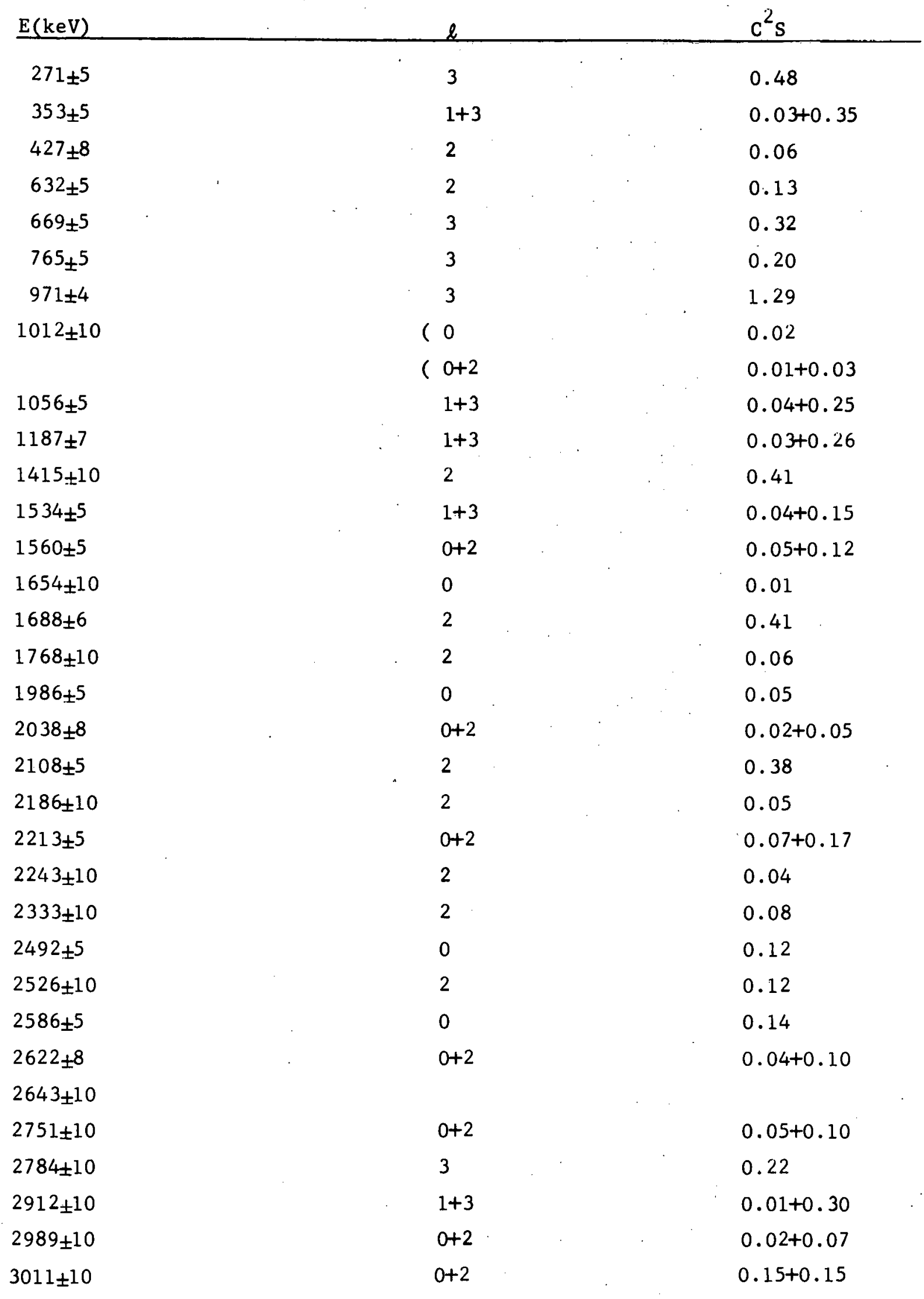


Comparison with a recent $\left({ }^{3} \mathrm{He}, \mathrm{t}\right)$ experiment at $3 / . / \mathrm{MeV}^{1}$ shows substantial agreement except for the state at $2710 \mathrm{keV}$. When the above results are compared with a $(p, n \gamma)$ experiment ${ }^{2}$, a discrepancy is observed in the quoted energy of the second exciled state ( 910 vs $996 \mathrm{kcV}$ ).

References

$1_{R}$. E. L. Green et a1., Bul1. Am. Phys. Soc. 15, No. 4, 594 (1970).

${ }^{2}$ s. Chen et a1., Bul1. Am. Phys. Soc. 15, No. 4, 594 (1970). 
19.

The $\left(\mathrm{d},{ }^{3} \mathrm{He}\right)$ Reaction on ${ }^{46} \mathrm{Ti}$ and ${ }^{48} \mathrm{Ti}$

\section{Hajime Ohnuma}

The $\left(\mathrm{d},{ }^{3} \mathrm{He}\right)$ reaction on ${ }^{46} \mathrm{Ti}$ and ${ }^{48} \mathrm{Ti}$ was studied at $19.5 \mathrm{MeV}$

using a magnetic spectrometer. Results were analyzed in terms of distorted wave Born approximation theory from which transferred $\ell$-values and spectroscopic factors were obtained. Transitions with $\ell^{=1}$ to the $0.808-\mathrm{MeV}$ state in ${ }^{47} \mathrm{Sc}$ and three states in ${ }^{45} \mathrm{Sc}$ were observed, indicating the presence of $2 \mathrm{p}$-protons in the ground state of $\mathrm{Ti}$. Single-particle strengths appear concentrated in one level in ${ }^{47} \mathrm{Sc}$, and considerable splitting of strength is seen in ${ }^{45} \mathrm{Sc}$. Especially most of the $\mathrm{d}_{3 / 2}$ strength is carried by the $0.763-\mathrm{MeV}$ state of ${ }^{47} \mathrm{Sc}$, while the spe ctroscopic factor for the first $3 / 2^{+}$level in ${ }^{45} \mathrm{Sc}$, at $12 \mathrm{keV}$, is 2.8 , or about $70 \%$ of the sum rule limit. Three more states with $\ell=2$ were found in ${ }^{45} \mathrm{Sc}$, one of them a known $5 / 2^{+}$. Assuming the other two (1.304- and $1.799-\mathrm{MeV}$ levels) are $3 / 2^{+}$, the sum of the spectroscopic factors for them is 1.07 , or about $25 \%$ of the sum rule 1imit. Present results are summarized in Table19-1 and Fig.19-1. 
Table 19-1. Summary of The Present Results.

\begin{tabular}{|c|c|c|c|c|c|c|c|}
\hline Nucleus & $E(k e V)$ & $\ell$ & $j^{\pi}$ & $c^{2} s$ & (a) & (b) & (c) \\
\hline \multirow[t]{8}{*}{${ }^{47} \mathrm{Sc}$} & 0 & 3 & $7 / 2^{-}$ & 1.95. & 2 & 1.93 & 1.8 \\
\hline & $763 \pm 5$ & 2 & $3 / 2^{+}$ & 3.93 & 2.8 & 3.63 & 3.4 \\
\hline & $808 \pm 7$ & 1 & $3 / 2^{-}$ & 0.24 & & . & \\
\hline & $1156+10$ & (2) & $5 / 2^{+}$ & 0.15 & & & \\
\hline & & & $3 / 2^{+}$ & 0.21 & & & \\
\hline & & (3) & $7 / 2^{-}$ & 0.18 & & & \\
\hline & & & $5 / 2^{-}$ & 0.35 & & & \\
\hline & $1384 \pm 5$ & 0 & $1 / 2^{+}$ & 1.90 & (2) & 2.12 & 1.4 \\
\hline \multirow[t]{14}{*}{${ }^{45} \mathrm{Sc}$} & 0 & 3 & $7 / 2^{-}$ & 1.43 & 2 & & \\
\hline & $12 \pm 3$ & 2 & $3 / 2^{+}$ & 2.80 & 4 & & \\
\hline & $381 \pm 5$ & 1 & $3 / 2^{-}$ & 0.23 & & & \\
\hline & $543 \pm 7$ & 2 & $5 / 2^{+}$ & 0.08 & & & \\
\hline & $728 \pm 10$ & 3 & $5 / 2^{-}$ & 0.15 & & & \\
\hline & $943 \pm 5$ & 0 & $1 / 2^{+}$ & 1.55 & 2 & & \\
\hline & $1067 \pm 7$ & 1 & $\left(3 / 2^{-}\right)$ & 0.09 & & & \\
\hline & $1235 \pm 10$ & & & & & & \\
\hline & $1304 \pm 5$ & 2 & $3 / 2^{+}$ & 0.51 & & & \\
\hline & & & $5 / 2^{+}$ & 0.35 & & & \\
\hline & $1417 \pm 10$ & (3) & $\left(5 / 2^{-}\right)$ & 0.25 & & & \\
\hline & $1556 \pm 7$ & 1 & $\left(3 / 2^{-}\right)$ & 0.03 & & & \\
\hline & $1799_{ \pm} 7$ & 2 & $3 / 2^{+}$ & 0.56 & & & \\
\hline & & & $5 / 2^{+}$ & 0.39 & & & \\
\hline
\end{tabular}

(a) J. L. Yntema and G. R. Satchler, Phys. Rev. 134, B976 (1964).

(b) E. Newman and J. C. Hiebert, Nuc1. Phys. A110, 366 (1968).

(c) F. Hinterberget et al., Z. Phys. 202, 236 (1967). 
MeV $\quad l\left(\mathrm{He}^{3}, \mathrm{~d}\right) \quad \mathrm{MeV} \quad l\left(\mathrm{~d}, \mathrm{He}^{3}\right)$

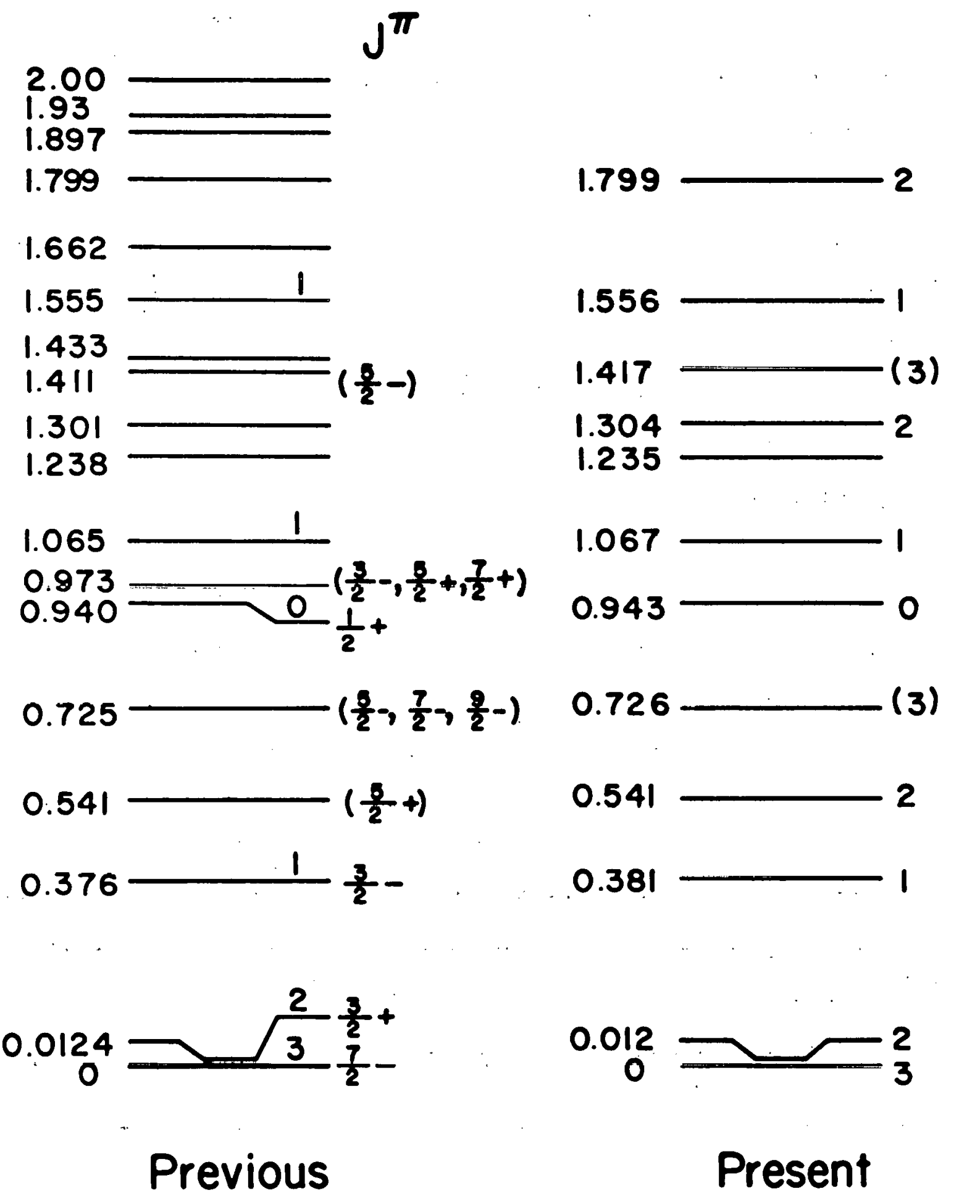

\section{$S c^{45}$}

Fig. 19-1 
20. Study of the $(d, \alpha)$ Reaction on the Titanium Isotopes

R. A. Wallen, H. Ohnuma, and N. M. Hintz

During the past year we have continued our study of the $(d, \alpha)$

reaction on all titanium isotopes, using a $19 \mathrm{MeV}$ deuteron beam and the split pole spectrograph. Using position-sensitive detectors, angular distributions have been obtained on some 100 states from 10 to 90 degrees, with excitations as high as $5 \mathrm{MeV}$. Typical resolution has been $\sim 10 \mathrm{keV}$, with relative $Q$ values measured in many cases to $\pm 1 \mathrm{keV}$. Characteristic shapes of the $7^{+}, 6^{+}, 5^{+}, 4^{+}, 3^{+}, 1^{+}, 2^{-}, 4^{-}$states for the reaction studies have greatly facilitated assignments of spin and parities. (See Fig. $20-1$. )

Optical model studies on the even-even titanium isotopes using both deuteron and alpha beams have been carried out (See Watson, Wallen, and Poppe, this Report). This work was done to facilitate DWBA analysis using codes DWUCK AND TWOPAR.

States believed to be excited by the transfer of an $\left(f_{7 / 2}\right)$ pair are given in Table I, along with tentative spin and parity assignments.

\begin{tabular}{l|lllllll}
\hline & $1^{+}$ & & $3^{+}$ & $4^{+}$ & $5^{+}$ & $6^{+}$ & $7^{+}$ \\
\hline \hline $48 \mathrm{Sc}$ & 2.518 & .624 & .254 & .131 & G.S & 1.096 \\
\hline $4 \mathrm{~h}_{\mathrm{Sc}}$ & & .221 & & .774 & .052 & .983 \\
\hline $44 \mathrm{Sc}$ & .667 & .765 & .354 & 1.046 & .271 & .966 \\
\hline
\end{tabular}




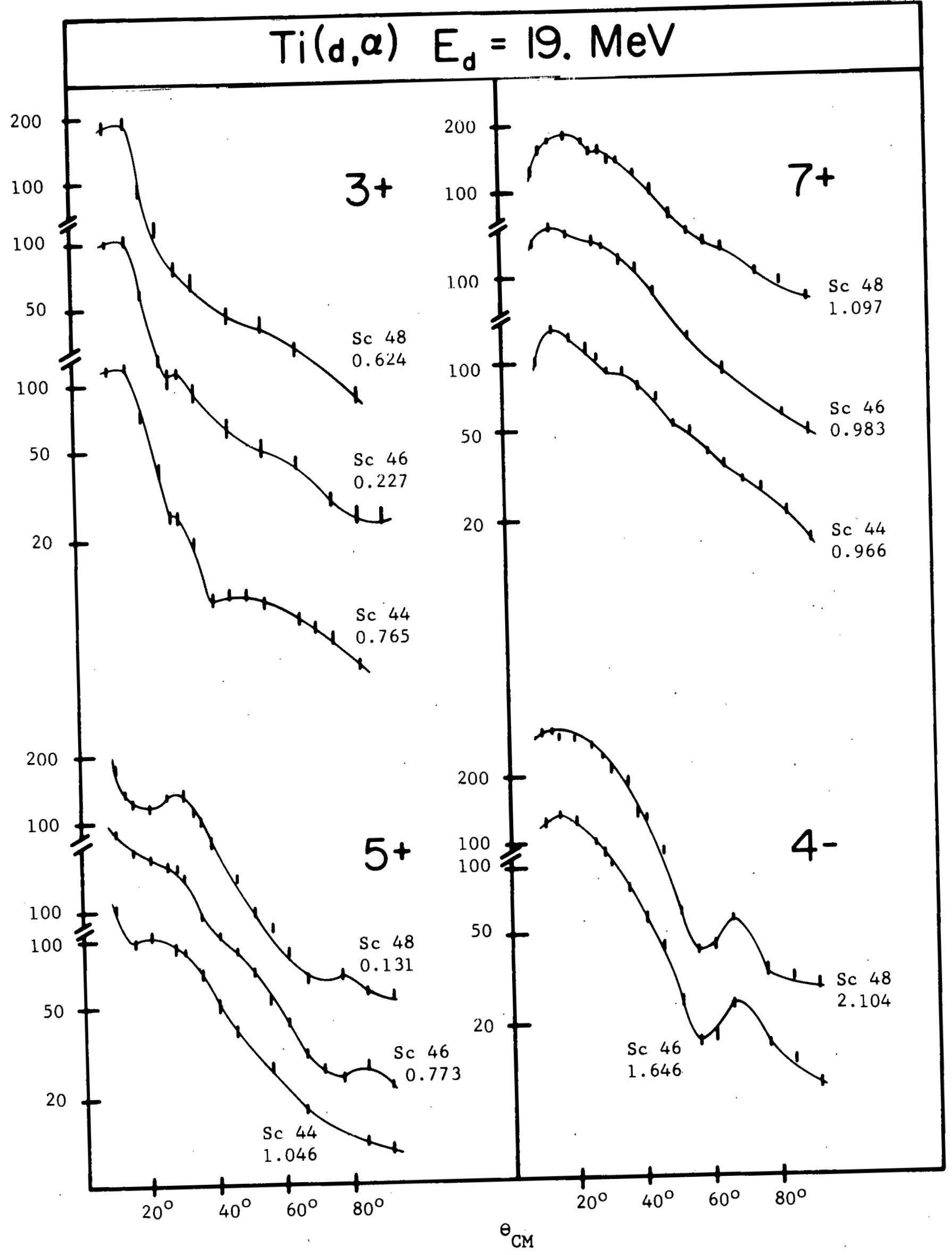




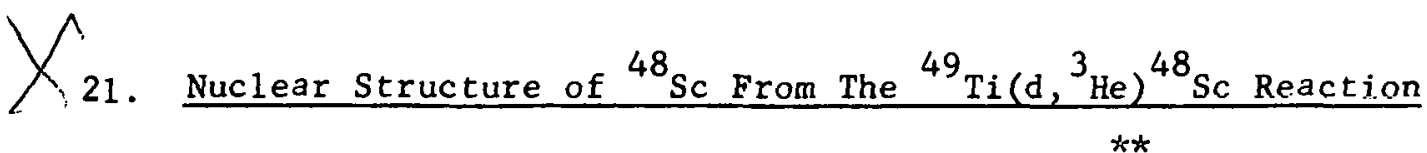

H. Ohnuma and J. L. Yntema ${ }^{* *}$

The work of Schwartz ${ }^{1}$ on the ${ }^{49} \mathrm{Ti}(t, \alpha)^{48}$ reaction and its comparison with a calculation ${ }^{2}$ has led to the postulation of a considerable amount of configuration mixing in the ${ }^{48} \mathrm{Sc}$ nucleus. Several calculations ${ }^{2-4}$ have been performed with the assumption of the pure $\left(\pi f_{7 / 2}\right)\left(\nu f_{7 / 2}^{-1}\right)$ configuration (or, briefly, the $\mathrm{f}_{7 / 2}$ configuration). The previous ${ }^{49} \mathrm{Ti}\left(\mathrm{d},{ }^{3} \mathrm{He}\right){ }^{48} \mathrm{Sc}$ experiment of Yntema and Satchler ${ }^{5}$ did not have the energy resolution necessary for an adequate test. There are serious discrepancies between the present results and the results of Schwartz. Our data are consistent with a description in which the low-lying states of ${ }^{48} \mathrm{Sc}$ correspond to a fairly pure $\mathrm{f}_{7 / 2}$ configuration.

We reinvestigated the ${ }^{49} \mathrm{Ti}\left(\mathrm{d},{ }^{3} \mathrm{He}\right){ }^{48} \mathrm{Sc}$ reaction at $19.45 \mathrm{MeV}$ with a magnetic spectrograph and at $22.4 \mathrm{MeV}$ with a counter telescope. Spectroscopic factors were obtained by comparing the experimental angular distributions with the distorted-wave (DW) cheory. Importanl fealuses of Llie ${ }^{48} \mathrm{Sc}$ nucleus observed in the present experiment are as follows. (1) Four states in ${ }^{48} \mathrm{Sc}$ (the ground state and the $0.133-, 0.257-$, and $0.622-\mathrm{MeV}$ states) are excited by $\ell=3$ pickup; and states at 1.091 and $1.150 \mathrm{MeV}$ are probably excited by an $\ell=3$ reaction. This result supports the asoignment (madc-in Rof.-1) that these states are the $h^{+} 5^{+}, 4^{+} 3_{-}^{+} 7_{-1}^{+}$ and $2^{+}$members of the $\mathrm{f}_{7 / 2}$ configuration. Some calculations ${ }^{1-2}$ predicted the $2^{+}$state around $600 \mathrm{keV}$, but no $\ell=3$ transition to such a state was found. (2) Spectroscopic factors for these states are in overall agreement with a shell-model calculation ${ }^{3}$ with the assumption of pure $f_{7 / 2}$ configuration. The anomalously large cross section to the $4^{+}$state seen in the $(t, \alpha)$ experiment ${ }^{1}$ was not observed. (3) A transition to a state 
at $2.73 \mathrm{MeV}$ was seen, and its angular distribution can be fitted either by $l=3$ or a mixture of $\ell=0$ and $\ell=2$. However, the $\ell=3$ assignment suggested by Schwartz ${ }^{1}$ is unlikely, because then the sum of the $\ell=3$ spectroscopic factors would considerably exceed the sum-rule limit. The $2.53-\mathrm{MeV}$ level, which Ref. 4 assigned to be the $1^{+}$level of the $\mathrm{f}_{7 / 2}$ configuration, was not sean in the present experiment. This is in accordance with the small predicted ${ }^{3}$ spectroscopic factor. (4) Levels at $0.388 \mathrm{MeV}$ and $0.77 \mathrm{MeV}$ (seen by Schwartz ${ }^{1}$ and by Yntema and Satchler, 5 respectively, to be excited by $\ell=2$ ) are not seen. The lowest state with any hole strength is at $1.40 \mathrm{MeV}$; it was not reported by schwartz ${ }^{1}$ but was observed by Yntema and Satchler. ${ }^{5}$ Therefore the centroid of the $d_{3 / 2}$-hole strength is much higher than had been thought. (5) In summary, the ${ }^{48} \mathrm{Sc}$ nucleus looks like a good one-particle one-hole nucleus within the framework of the present experiment.

However, in the course of the present experiment it was found that the $0.81-\mathrm{MeV}$ level ${ }^{6}$ of ${ }^{47} \mathrm{Sc}$ was excited in the ${ }^{48} \mathrm{Ti}\left(\mathrm{d},{ }^{3} \mathrm{He}\right)^{47} \mathrm{Sc}$ reaction. This indicates that there is a $\mathrm{p}_{3 / 2}$ proton mixture in the ground state of ${ }^{48} \mathrm{Ti}$, even though the $\mathrm{DW}$ curve does not fit the experimental angular distribution very well. If about the same amount of the $p_{3 / 2}$ admixture is present in the ground state of ${ }^{49} \mathrm{Ti}$ and its strength is spread among the $2^{+}, 3^{+}, 4^{+}$, and $5^{+}$states of ${ }^{48} \mathrm{Sc}$, it would be difficult to observe in the present experiment.

The experiment at $19.45 \mathrm{MeV}$ was performed with the University of Minnesota tandem Van de Graaff and a split-pole magnetic spectrograph with position-sensitive detectors in its focal plane. Targets were metallic self-supporting foils, enriched to $77 \%$ in ${ }^{49} \mathrm{Ti}$ and having thicknesses ranging from about 70 to $200 \mu \mathrm{g} / \mathrm{cm}^{2}$. The overall resolution 
width was typically $15 \mathrm{keV}$.

The same reaction was studied with a counter telescope and the 22.4-MeV deuteron beam from the Argonne cyclotron. In this case the overall resolution width was about $150 \mathrm{keV}$, and the first two states in ${ }^{48} \mathrm{Sc}$ and the ground state of ${ }^{47} \mathrm{Sc}$ were not resolved. Therefore, spectra from the ${ }^{48} \mathrm{Ti}\left(\mathrm{d},{ }^{3} \mathrm{He}\right){ }^{47} \mathrm{Sc}$ reaction were measured with a $99 \%$ pure ${ }^{48} \mathrm{Ti}$ target and subtracted from the spectra with the ${ }^{49} \mathrm{Ti}$ target after proper normalization. Then a peak-fitting program was applied to obtain the area under each peak. Spectroscopic factors were obtained in a similar way.

Some angular distributions are shown in Fig. 21-1. In Table 21:-1, absolute and relative spectroscopic factors are compared with the calculation by $\mathrm{Ball}^{3}$ and with results from the $(t, \alpha)$ experiment. ${ }^{1}$

\section{References}

*Address: Argonne National Laboratory, Argonne, Illinois 60439.

1 J. J. Schwartz, Phys. Rev. Letters 18, 174 (1967).

${ }^{2}$ S. S. M. Wong, Nucl. Phys. A113, 481 (1968); J. J. Schwartz and S. S. M. Wong, Bul1. Am. Phys. Soc. 12, 587 (1967).

3 J. B. Bal1, Bul1. Am. Phys. Soc. 11,349 (1966) and private communication.

${ }^{4}$ H. Ohnuma, J. R. Erskine, J. A. Nolen, Jr., J. P. Schiffer, and N. Williams, International Conference on Nuclear Structure, Tokyo, 1967, contribution 4.74; Phys. Rev. Cl, 496 (1970).

5. L. Yntema and G. R. Satchler, Phys. Rev. 134, B976 (1964).

6. J. Schwartz, W. P. Alford, and A. Marinov, Phys. Rev. 153, 1248 (1967).

${ }^{7}$ R. H. Bassel, Phys. Rev: 149,79 (1966).

$8_{E}$. Newman and J. C. Hiebert, Nucl. Phys. Al10, 366 (1968).

${ }^{9}$ F. Hinterberger, G. Mairle, U. Schmidt-Rohr, P. Turek, and G. J. Wagner, Z. Physik 202, 236 (1967). 
83

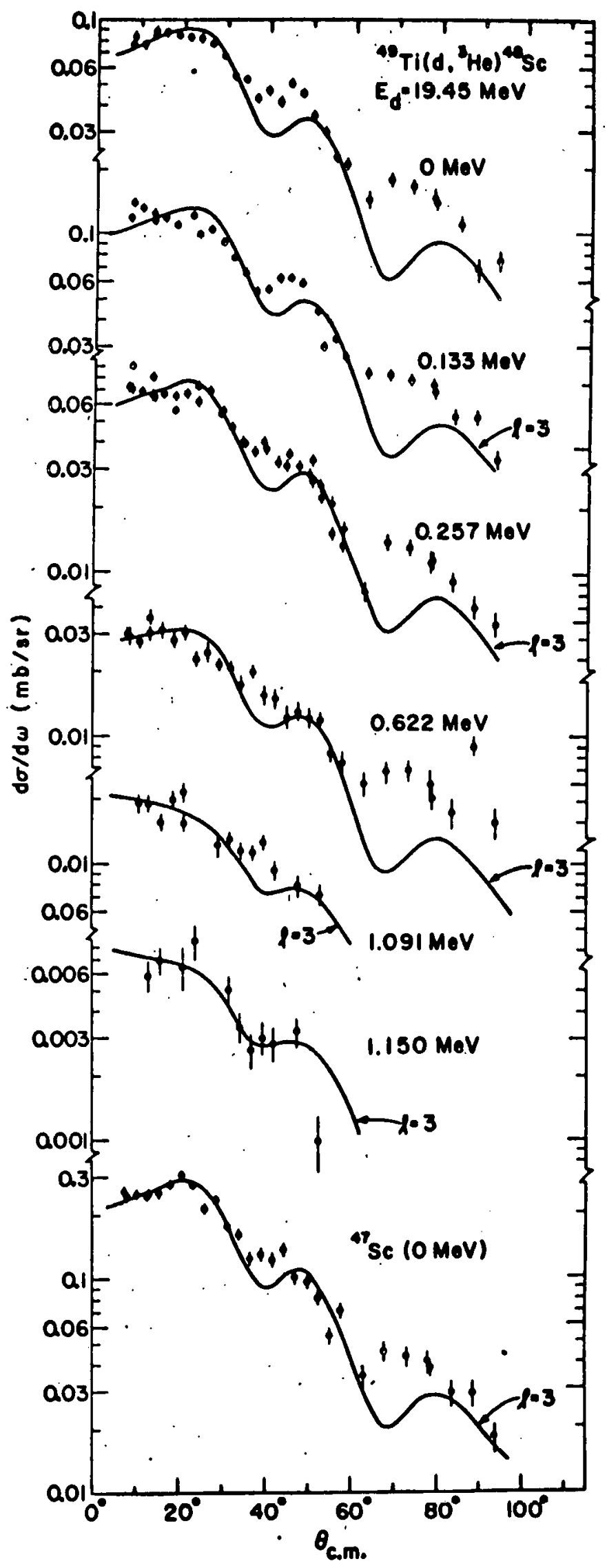

Fig, 21-1 
Table 21-1. Summary of the present restlts and comparison with the shell-model calculation (Ref. 3) and with previous work.

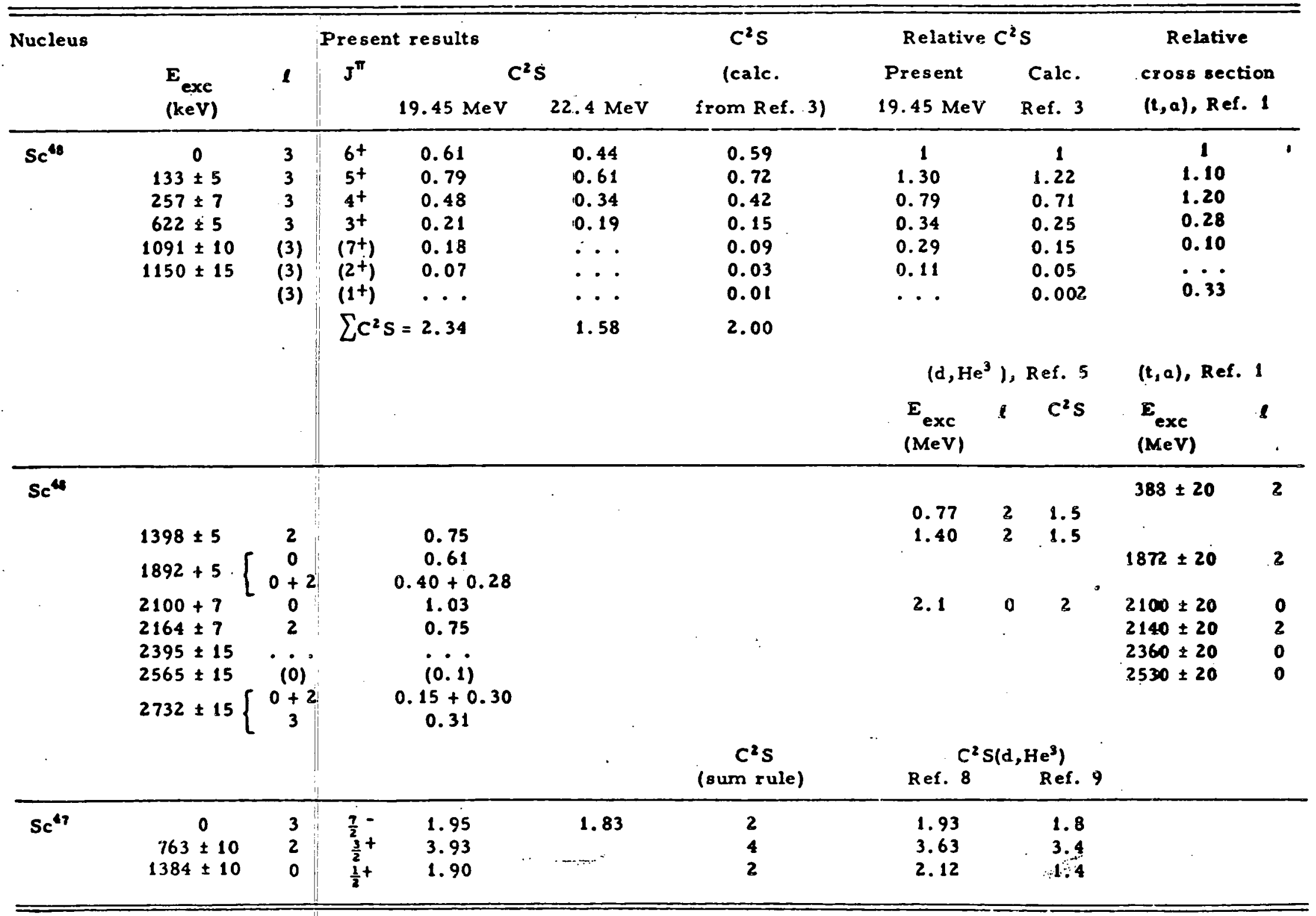


22. States in ${ }^{50} \mathrm{~V}$ studied with the ${ }^{49} \mathrm{Ti}\left({ }^{3} \mathrm{He}, \mathrm{d}\right)$ and ${ }^{51} \mathrm{~V}(\mathrm{~d}, \mathrm{t})$ Reactions

A. M. Sourkes, H. Ohnuma and N. M. Hintz

A partial ${ }^{49} \mathrm{Ti}\left({ }^{3} \mathrm{He}, \mathrm{d}\right)$ spectrum taken at $17.5^{\circ}$ with a split-pole magnetic spectrometer and nuclear track plates is shown in Fig. 22-1. The spectrum shows excited states in ${ }^{50} \mathrm{~V}$ up to $1.330 \mathrm{MeV}$. Peak $1 \mathrm{C}$ is the ${ }^{50} \mathrm{Ti}\left({ }^{3} \mathrm{He}, \mathrm{d}\right)$ ground state and peak $2 \mathrm{C}$ the ${ }^{48} \mathrm{Ti}\left({ }^{3} \mathrm{He}, \mathrm{d}\right) \mathrm{g.s}$.

Figure 22-2 shows the DWBA fit to the g.s. angular distribution using pure $\ell=3$. As far as the angular distributions of the other states, peaks $1,5,7$, and 8 have significant $\ell=1$ components, while 2 and 4 show some $l=1$ contribution. Peak 3 appears to be almost pure $\ell=3$; the rest of the states shown $(1 \mathrm{C}, 0,6,2 \mathrm{C})$ seem to be excited by pure $\ell=3$.

Table 22-1 lists the excitation energies of the numbered peaks. Analysis of the more highly excited states is in progress. Work on the ${ }^{51} \mathrm{~V}(\mathrm{~d}, \mathrm{t}){ }^{50} \mathrm{~V}$ reaction ${ }^{1}$ is also continuing, to study states above $1.5 \mathrm{MeV}$.

\section{Reference}

${ }^{1}$ John H. Williams Laboratory Annual Report, 1969, p. 55.

Table 22-1

\begin{tabular}{c|c|c|c}
\hline $\begin{array}{l}\text { Peak } \\
\text { Number }\end{array}$ & $\begin{array}{c}\text { Energy } \\
\text { keV }\end{array}$ & $\begin{array}{c}\text { Peak } \\
\text { Number }\end{array}$ & $\begin{array}{c}\text { Energy } \\
\text { keV }\end{array}$ \\
\hline 0 & G.S. & 5 & 840 \\
1 & 230 & 6 & 910 \\
2 & 320 & 7 & 1300 \\
3 & 360 & 8 & 1330 \\
4 & 390 & & \\
\hline
\end{tabular}




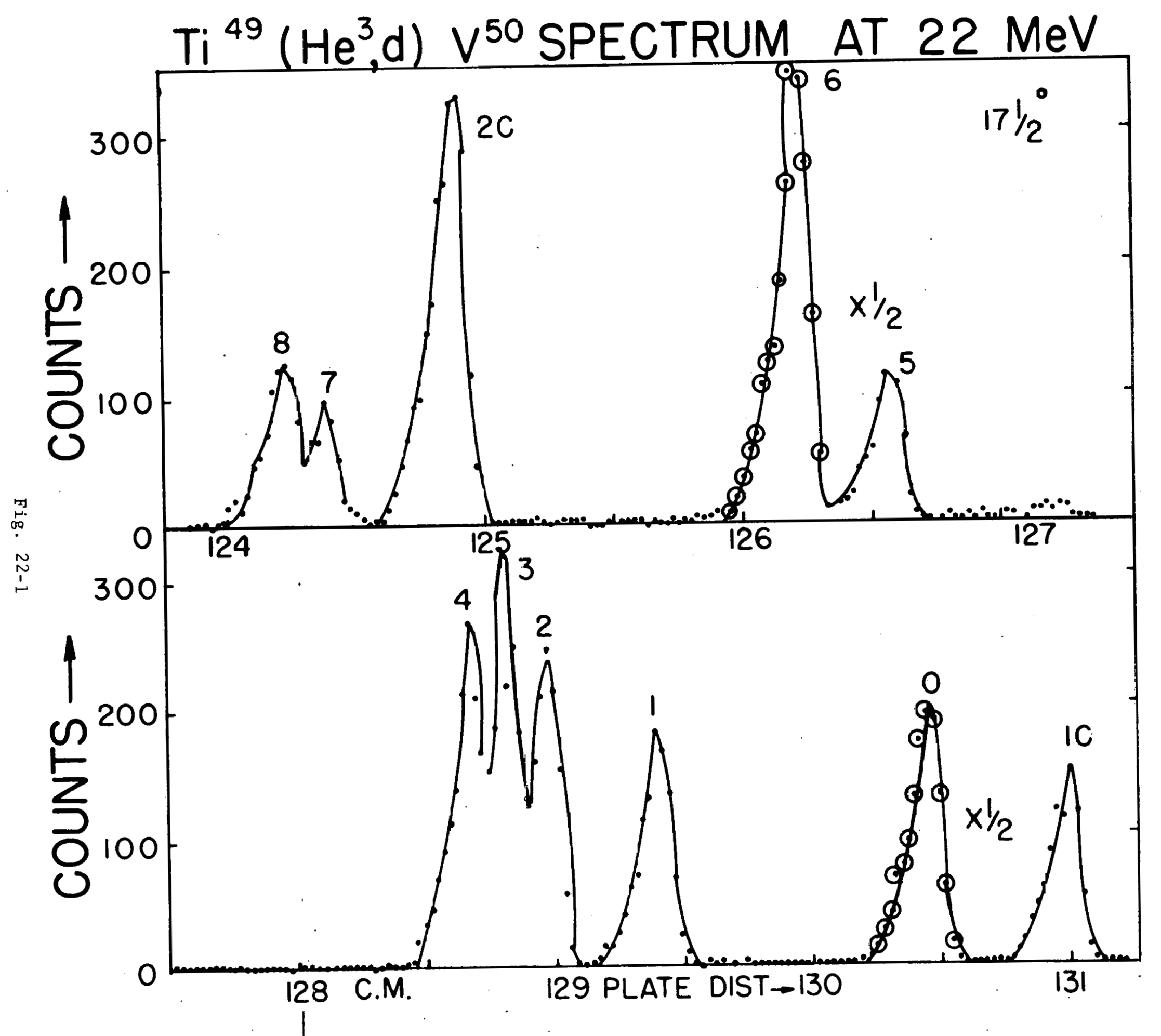


DWBA FIT TO G.S. ANGULAR DISTRIBUTION

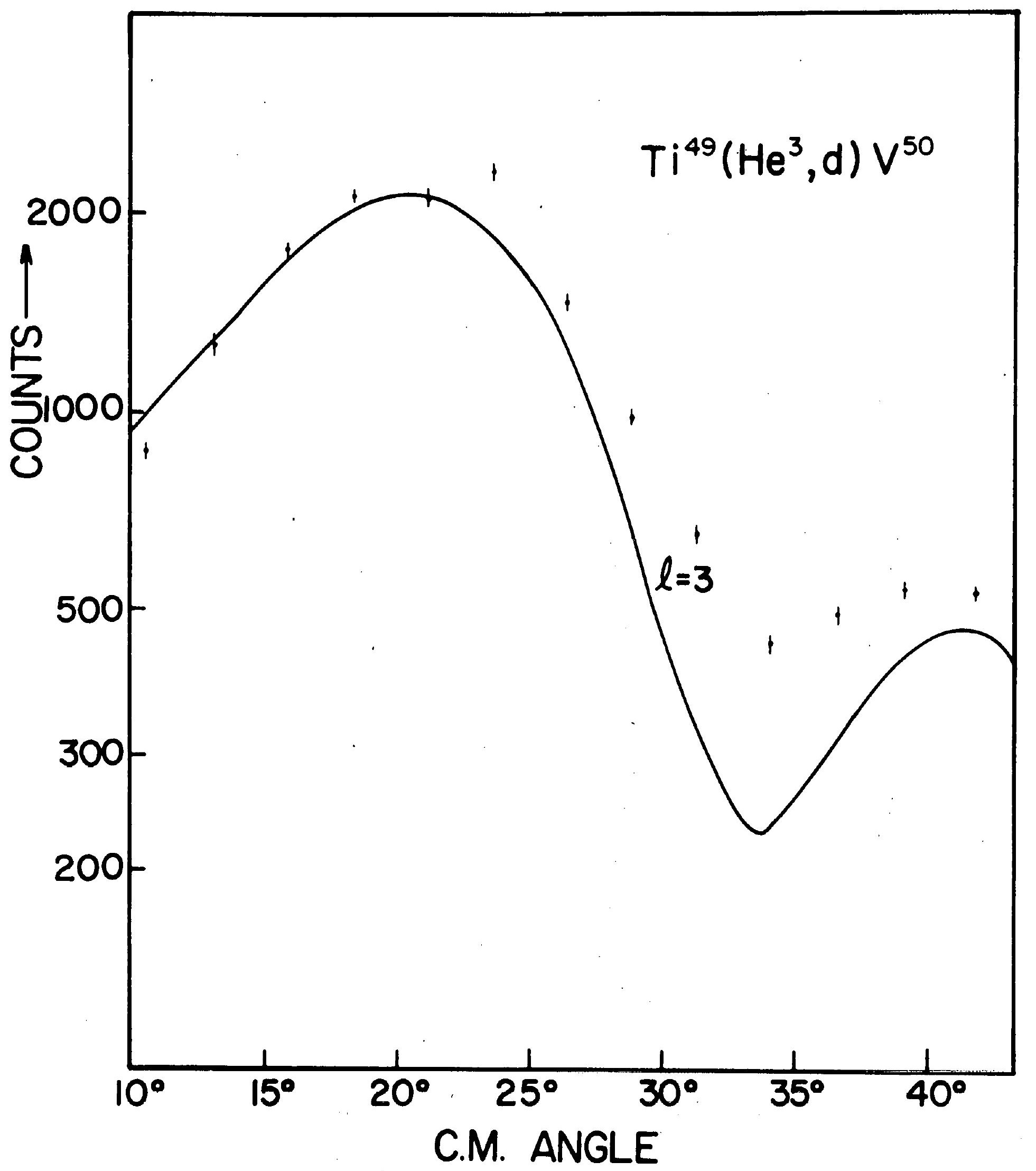

Fig. 22-2 
23. J-Dependence in the (d,p) Reaction on ${ }^{50} \mathrm{Ti}$ and ${ }^{54} \mathrm{Fe}$

H. Ohnuma, W. Makofske, and J. L. Yntema *

In order to obtain further information on the energy variation of thè $\mathrm{J}$-dependence for $\ell=1$ transitions, the ${ }^{54} \mathrm{Fe}(\mathrm{d}, \mathrm{p})^{55} \mathrm{Fe}$ and ${ }^{50} \mathrm{Ti}(\mathrm{d}, \mathrm{p})^{51} \mathrm{Ti}$ reactions were studied at $16 \mathrm{MeV}$ and $18 \mathrm{MeV}$, respectively. Elastic angular distributions were also obtained at the same time. A deuteron beam from the University of Minnesota tandem Van de Graaff and solid state counters were used. Angular distributions for the ground state $\left(3 / 2^{-}\right)$and the $1.16-\mathrm{MeV}$ state $\left(1 / 2^{-}\right)$in ${ }^{51} \mathrm{Ti}$ obtained at $18 \mathrm{MeV}$ are compared in Fig. 23-1. Results are being analyzed together with previous data ${ }^{1}$. Preliminary results indicate that the conventional distorted-wave Born approximation (DWBA) can explain the $l=1 \mathrm{~J}$-dependence at lower energies, while discrepancies between experiments and DWBA calculations become larger with increasing incident beam energy.

* Argonne National Laboratory Referenrie

$1 \mathrm{~J} . \mathrm{L}$. Yntema, H. Ohnuma, and H. T. Fortune, Bu11. Am. Phys. Soc., 13, 699 (1969).

24. Intermediate Coupling Model and Shell Model Description of ${ }^{53} \mathrm{Cr}$ and ${ }^{55} \mathrm{Fe}$ T. P. G. Carola (University of Alberta) and H. Ohnuma

Energy levels, spectroscopic factors, transition probabilities, and static moments of ${ }^{53} \mathrm{Cr}$ and ${ }^{55} \mathrm{Fe}$ were calculated using the intermediate coupling model and the shell model of nuclei. The two calculations give similar results, and are in overall agreement with experiment. In Table 24-1, B(E2)-values calculated for the ground state transitions 


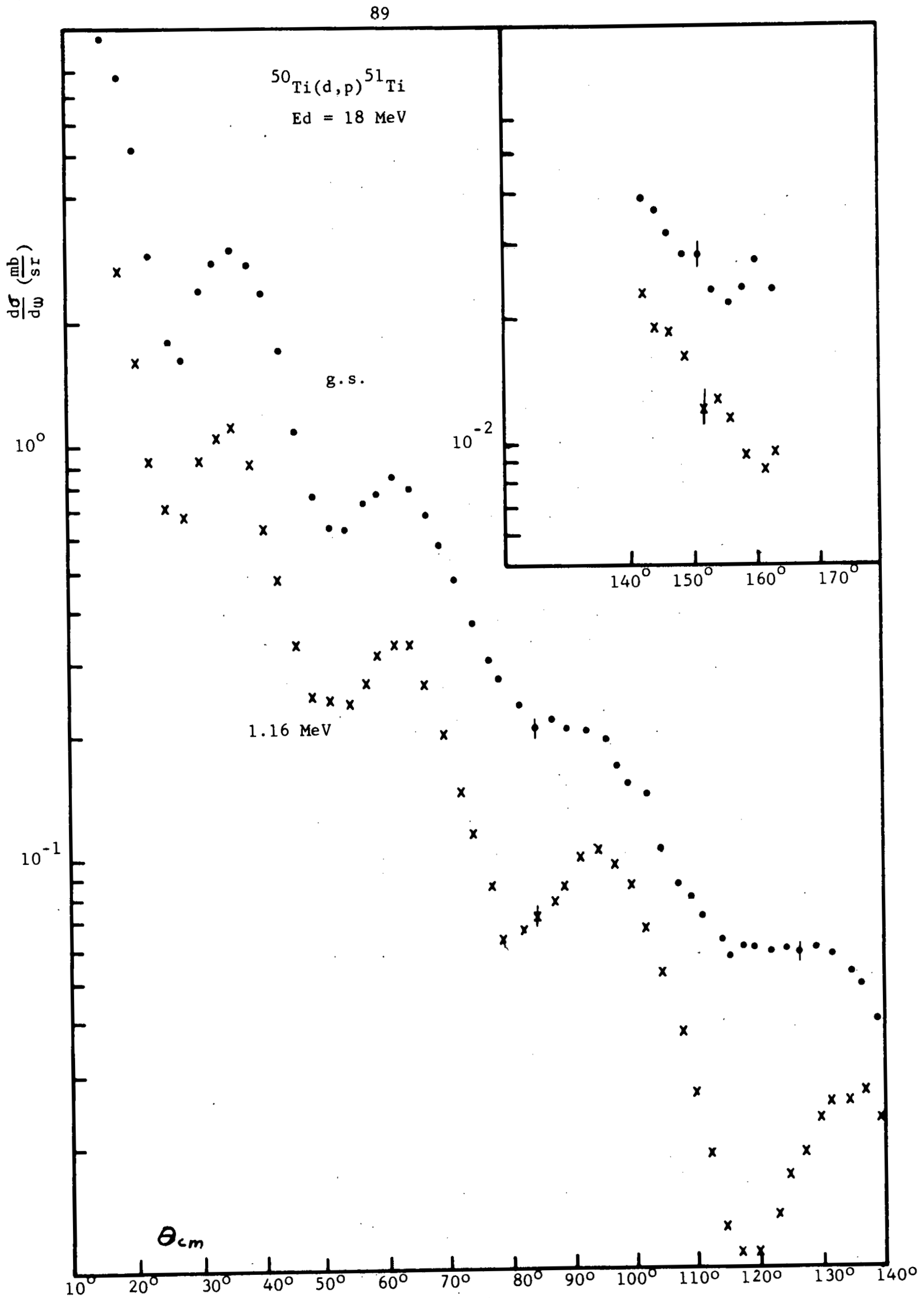


in ${ }^{53} \mathrm{Cr}$ are compared with experiment ${ }^{1,2}$ and a calculation by Philpott and $\operatorname{True}^{2}$ who used the Thankappan-True model.

\section{References}

${ }^{1}$ J. R. Meriwether et $\underline{\text { a1. }}$, Phys. Rev. 146, 804 (1966).

2. N. Galperin et al., Sov. J. Nucl. Phys. 9, 133 (1969).

${ }^{3}$ R. J. Philpott and W. W. True, to be published.

\section{Table 24-1}

$B(E 2)$ values in units of $e^{2}-\mathrm{fm}^{4}$ for decay to ground of lower

states of ${ }^{53} \mathrm{Cr}$. Experimental values are based on $\left(\alpha, \alpha^{\prime}\right)$

experiment (Ref. 1) and Coulomb excitation (Ref. 2).

\begin{tabular}{|c|c|c|c|c|c|c|}
\hline \multirow[b]{2}{*}{$\begin{array}{r}\text { Encrgy } \\
(\mathrm{MeV})\end{array}$} & \multicolumn{2}{|c|}{ Experiment } & \multirow[b]{2}{*}{$\begin{array}{l}\text { Int. } \\
e_{n}=U\end{array}$} & \multirow[b]{2}{*}{$\begin{array}{c}\text { coupling } \\
e_{n}=e\end{array}$} & \multirow{2}{*}{$\begin{array}{l}\text { T.T. model } \\
\text { (Ref. 3) d) }\end{array}$} & \multirow{2}{*}{$\begin{array}{l}\text { Shell model } \\
e_{p}=2 \dot{e}, e_{n}=e\end{array}$} \\
\hline & $\overline{\operatorname{Ref}} .1$ & Ret. 2 & & & & \\
\hline 0.564 & 178 & 220 & 101 & 197 & 146 & 40 \\
\hline 1.006 & 35 & 14 & 54 & 75 & 35 & 22 \\
\hline 1.285 & 69 & 120 & 112 & 139 & 63 & 117 \\
\hline 1.971 & & & 33 & 29 & 62.1 & 88 \\
\hline
\end{tabular}

a) $\mathrm{e}_{\mathrm{n}}=1.64 \mathrm{e}$ 
25.

Review Article: on $\mathrm{f}_{7 / 2}$ She11

N. M. Hintz

Work is continuing on the review of theory and experiment for the nuclei from ${ }^{40} \mathrm{Ca}$ to ${ }^{56} \mathrm{Ni}$, with Ben Bayman (Minnesota), John McCullen (Arizona), and Larry Zamick (Rutgers). The paper will summarize experimental information on energy levels, decay schemes, moments, and nucleon transfer spectroscopic factors. All known published data has been collected and discussed in relation to current theoretical papers. Any recent or unpublished data should be sent to the authors before the end of 1970 if it is to be included in the review. 
26. A Study of Even Samarium Isotopes Using the $(p, t)$ Reaction

Philip Debenham and Norton M. Hintz

The $(p, t)$ reaction has been studied on the even samarium isotopes ${ }^{154} \mathrm{Sm},{ }^{152} \mathrm{Sm},{ }^{150} \mathrm{Sm}$, and ${ }^{148} \mathrm{Sm}$, by $19 \mathrm{MeV}$ protons. The outgoing tritons were analyzed with the split-pole spectrometer, and their angular distributions were recorded on nuclear track plates. The ${ }^{152} \mathrm{Sm}(\mathrm{p}, t){ }^{150} \mathrm{Sm}$ reaction was discussed in previous editions of this report ${ }^{1,2}$ and in a recent article. ${ }^{3}$ The other reactions are discussed in what follows. ${ }^{154} \mathrm{Sm}(\mathrm{p}, \mathrm{t})^{152} \mathrm{Sm}$. The angular distribution of the ${ }^{154} \mathrm{Sm}(\mathrm{p}, \mathrm{t}){ }^{152} \mathrm{Sm}$ reaction has been recorded at reaction angles between $10^{\circ}$ and $85^{\circ}$ at $5^{\circ}$ intervals, and the plates have been scanned. The triton energy spectrum at $25^{\circ}$ is shown in Fig. $26-1$, and in Table 261 the triton groups are identified with energy levels in the residual ${ }^{152}$ Sm nucleus.

Since $L=0$ transitions go through a maximum near $25^{\circ}, 0^{+}$states dominate the spectrum. Notably absent is the $1.091 \mathrm{MeV}^{+}$state which is excited strongly in the ${ }^{150} \mathrm{Sm}(t, p){ }^{152} \mathrm{Sm}$ reaction. ${ }^{4,5}$ Its absence in the $(p, t)$ reaction was noticed by McLatchie et al. ${ }^{6}$ and implies a mostly spherical shape for the state. The excitation region near $2 \mathrm{MeV}$ is dominated by states at $1.775,1.905$, and $2.252 \pm .010 \mathrm{MeV}$.

As in the ${ }^{152} \mathrm{Sm}(\mathrm{p}, \mathrm{t}){ }^{150} \mathrm{Sm}$ reaction, only the $\mathrm{L}=0$ angular distributions have a distinctive shape. ${ }^{2}$ The $L=L$ and other angular distributions vary from state to state and consequently do not give unambiguous information about the angular momentum of the final state. ${ }^{150} \mathrm{Sm}(\mathrm{p}, \mathrm{t}){ }^{148} \mathrm{Sm}$. The angular distribution of the ${ }^{150} \mathrm{Sm}(\mathrm{p}, t){ }^{148} \mathrm{Sm}$ reaction has been recorded between $10^{\circ}$ and $75^{\circ}$ at $5^{\circ}$ intervals, and so far plates have been scanned for two angles. The triton spectrum at 
$25^{\circ}$ and the corresponding excitation spectrum of ${ }^{148} \mathrm{Sm}$ are given in Fig. $26-2$ and Table 26-2. The only states of ${ }^{148} \mathrm{Sm}$ which are strongly excited are the ground state and the state at $1.428 \pm .007 \mathrm{MeV}$. At the two angles for which we have data the angular distributions for these two states are identical. This indicates that the $1.428 \mathrm{MeV}$ state has $\mathrm{J}^{\pi}=0^{+}$. ${ }^{148} \mathrm{Sm}(\mathrm{p}, \mathrm{t}){ }^{146} \mathrm{Sm}$. The angular distribution of the ${ }^{148} \mathrm{Sm}(\mathrm{p}, \mathrm{t}){ }^{146} \mathrm{Sm}$ reaction has been recorded at $5^{\circ}$ intervals between $10^{\circ}$ and $60^{\circ}$. This range will be extended to $80^{\circ}$. The plates are being scanned. Absolute Cross Sections. Absolute cross sections for the $(p, t)$ reaction on naturally-occurring isotopes of samarium have been measured in the following way. A target of natural samarium was bombarded with $19 \mathrm{MeV}$ protons and the outgoing tritons were observed at $25^{\circ}$. This gave the relative counting rateg for gluund stare-ground state $(p, t)$ reactions on the various naturally-occurring isotopes. The relative cross sections for these isotopes were then calculated from the measured counting rates and the isotopic abundances in the target (assumed to be the natural abundances). The results are given in the second column of Table 26-3.

The absolute $(p, t)$ cross section for one isotope, ${ }^{154} \mathrm{Sm}$, was then calculated from the ${ }^{154} \mathrm{Sm}(\mathrm{p}, \mathrm{p})$ absolute cross section by measuring the ${ }^{154} \mathrm{Sm}(\mathrm{p}, \mathrm{t})$ and ${ }^{154} \mathrm{Sm}(\mathrm{p}, \mathrm{p})$ counting rates from a common ${ }^{154} \mathrm{Sm}$ target. The absolute $(p, p)$ cross we used was a theoretical prediction of the optical model, ${ }^{7}$ using optical model parameters which fit the ratio of observed cross section to Rutherford cross section at small angles. Finally, the absolute $(p, t)$ cross sections for other isotopes were calculated from the relative $(p, t)$ cross sections and the absolute 
cross sectinn for ${ }^{154} \mathrm{Sm}(\mathrm{P}, \mathrm{t})$, The results are 1 isted in the third column of Table 26-3.

\section{References}

${ }^{1}$ P. Debenham and N. Hintz, Williams Laboratory of Nuclear Physics, Annual Report (1968) p. 115.

${ }^{2}$ P. Debenham and N. M. Hintz, Williams Laboratory of Nuclear Physics, Annual Report (1969) p. 66.

${ }^{3}$ Philip Debenham and Norton M. Hintz, Phys. Rev. Lett. 25, 44 (1970).

${ }^{4}$ S. Hinds, J. H. Bjerregaard, 0. Hansen, and 0. Nathan, Phys. Lett. 14 , 48 (1965).

${ }^{5}$ J. H. Bjerregaard, 0. Hansen, 0. Nathan, and S. Hinds, Nucl. Phys. $\underline{86}$, 145 (1966).

${ }^{6}$ W. McLatchie, J. E. Kitching, and W. Darcey, Phys, Lett. $36 \mathrm{~B}, 529$ (1969).

${ }^{7}$ F. D. Becchetti, Jr., and G. W. Greenlees, Phys. Rev. 182, 1190 (1960).

${ }^{8}$ C. M. Lederer, J. M. Hollander, and I. Perlman, Table of Isotopes (Wiley, New York, 1967) 6th ed.

${ }^{9}$ L. I. Riedinger, N. R. Johnson, and J. H. Hamilton, Phys. Rev. 179 (1969) 1214 
Table 26-1. Levels of ${ }^{152} \mathrm{Sm}$ Excited in ${ }^{154} \mathrm{Sm}(\mathrm{p}, \mathrm{t})$ at $\mathrm{Ep}=19 \mathrm{MeV}$.

\begin{tabular}{|c|c|c|c|c|c|}
\hline \multirow[b]{2}{*}{$\begin{array}{l}\text { Level } \\
\text { number }\end{array}$} & \multicolumn{3}{|c|}{ This Experiment } & \multicolumn{2}{|c|}{ Previous work $5,8,9$} \\
\hline & $\operatorname{Ex}(\mathrm{keV})$ & $\mathrm{J}^{\pi}$ & $\begin{array}{l}\sigma_{\text {Lab }}\left(25^{\circ}\right) \\
{[\text { arbitrary units ] }}\end{array}$ & $\operatorname{Ex}(k e V)$ & $\mathrm{J}^{\pi}$ \\
\hline 0 & G.S. & $0^{+}$ & $1000 \pm 16$ & G.S. & $0^{+}$ \\
\hline 1 & $122 \pm 3$ & & $74 \pm 4$ & 122 & $2^{+}$ \\
\hline 2 & $149 \operatorname{Sm}(p, t)$ & G.S. & & & \\
\hline 3 & $365 \pm 3$ & & $21_{ \pm} 2$ & 366 & $4^{+}$ \\
\hline 4 & $686 \pm 3$ & $0^{+}$ & $262 \pm 8$ & 685 & $0^{+}$ \\
\hline 5 & $152 \mathrm{Sm}(\mathrm{p}, \mathrm{t}) 1$ & $50 \mathrm{Sm}$ & $41 \mathrm{keV}, 0^{+}$) & & \\
\hline 6 & $810 \pm 3$ & & $33 \pm 3$ & 810 & $2^{+}$ \\
\hline 7 & $147 \mathrm{Sm}(p, t)$ & G.S. & & & \\
\hline 8 & $961 \pm 3$ & & $1.3 \pm 6$ & 963 & $1^{-}$. \\
\hline 9 & $1016 \pm 5$ & & $5.8 \pm 1.1$ & 1023 & $4^{+}$ \\
\hline 10 & $1039 \pm 5$ & & $6.6 \pm 1: 3$ & 1041 & $3^{-}$ \\
\hline 11 & $1086 \pm 3$ & & $44 \pm^{3}$ & 1086 & $2^{+}$ \\
\hline 12 & $152 \operatorname{Sm}(p, t) 1$ & $50 \mathrm{Sm}$ & $256 \mathrm{keV}, 0^{+}$) & & \\
\hline 13 & $1370 \pm 4$ & & $1.3 \pm .6$ & 1372 & $4^{+}$ \\
\hline 14 & $1511 \pm 4$ & & $1.3_{ \pm \cdot 6}$ & 1511 & $1^{-}$ \\
\hline 15 & $1581 \pm 4$ & & $5.5 \pm 1.2$ & 1578 & $\left(3^{-}\right)$ \\
\hline 16 & $1612 \pm 4$ & & $3.1 \pm .9$ & 1610 & \\
\hline 17 & $1660 \pm 5$ & & $6.6 \pm 1.3$ & & \\
\hline 18 & $1771 \pm 5$ & & $112 \pm 5$ & 1775 & $\left(3^{-}, 4^{-}\right)$ \\
\hline 19 & $1903 \pm 5$ & & $59 \pm 4$ & 1905 & \\
\hline 20 & $1960 \pm 6$ & & $8.5 \pm 1.7$ & 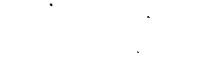 & \\
\hline 21 & $2014 \pm 6$ & & $8.2 \pm 1.8$ & & \\
\hline 22 & $2136 \pm 6$ & & $10.8 \pm 2.5$ & & \\
\hline 23 & $2253 \pm 6$ & & $26 \pm 3$ & & \\
\hline 24 & contaminant & & & & \\
\hline 25 & $2326 \pm 7$ & & $12.4 \pm^{2} .9$ & & \\
\hline
\end{tabular}


Tab1e 26-2. Levels in the Triton Spectrum of ${ }^{150} \mathrm{Sm}(\mathrm{p}, \mathrm{t})$ at $\mathrm{Ep}=19 \mathrm{MeV}$, $\theta_{\text {Lab }}=25^{\circ}$

\begin{tabular}{|c|c|c|c|c|c|c|}
\hline \multirow[b]{2}{*}{$\begin{array}{l}\text { Leve } 1 \\
\text { number }\end{array}$} & \multicolumn{4}{|c|}{ This Experiment } & \multicolumn{2}{|c|}{ Previous work ${ }^{8}$} \\
\hline & $\operatorname{Ex}(\mathrm{keV})$ & $\mathrm{J}^{\pi}$ & $\begin{array}{l}\sigma_{\text {Lab }}\left(25^{\circ}\right) \\
\text { [arbitrary }\end{array}$ & units] & $\operatorname{Ex}(\mathrm{keV})$ & $\mathrm{J}^{\pi}$ \\
\hline 0 & G.S. & $0^{+}$ & $1000_{ \pm} 20$ & & G.S. & $0^{+}$ \\
\hline 1 & $149 \operatorname{Sm}(p, t)$ & G.S. & & & & \\
\hline 2 & $550_{ \pm} 7$ & & $30 \pm 3:$ & & 551 & $2^{+}$ \\
\hline 3 & $148 \mathrm{Sm}(p, t)$ & G.S. & & & : & \\
\hline 4 & $152 \operatorname{Sm}(p, t)]$ & $50 \mathrm{Sm}(7$ & $1 \mathrm{keV}, 0^{+}$). & & & \\
\hline 5 & $147 \mathrm{Sm}(p, t)$ & G.S. & & & . & \\
\hline 6 & $1163 \pm 7$ & & $15 \pm 2$ & & 1162 & $3^{-}$ \\
\hline 7 & $1183 \pm 7$ & & $7.5 \pm 1.7$ & & 1181 & $4^{+}$ \\
\hline 8 & $152 \mathrm{Sm}(\mathrm{p} ; \mathrm{t})$ & $50 \mathrm{Sm}(1$ & $\left.56 \mathrm{keV}, 0^{+}\right)$ & & & \\
\hline 9 & $1428 \pm 7$ & $0^{+}$ & $188 \pm 9$ & & 1430 & \\
\hline 10 & $1597 \pm 7$ & & $1.6 \pm .8$ & & 1595 & $5^{-}$ \\
\hline 11 & $1667_{ \pm \prime}$ & & $20 \pm 3$ & & 1670 & \\
\hline 12 & $1738 \pm 7$ & & $8.7 \pm 1.9$ & & 1735 & $3,4^{+}$ \\
\hline 1.3 & $1892+7$ & & $1.6 \pm .8$ & & 1896 & $3^{-}$ \\
\hline 14 & $1925 \pm 7$ & & $10 \pm 1.3$ & & & \\
\hline 15 & $1976 \pm 7$ & & $2.8 \pm 1.0$ & & 1980 & \\
\hline $16 \ldots$ & $2006 \pm 7$ & - & $1.6 \pm .8=2$ & $\therefore=-x$ & $\ldots \ldots$ & \\
\hline 17 & $2105 \pm 7$ & & $3.6 \pm 1.3$ & & 2097 & $(6)^{+}$ \\
\hline 18 & $2153 \pm 7$ & & $7.5 \pm 1.7$ & & 2147 & $5^{+}$ \\
\hline 19 & $2208 \pm 7$ & & $26 \pm 4$ & . & 2215 & $5^{+}$ \\
\hline
\end{tabular}


Table 26-3. Relative and Absolute Cross Sections for the (p,t) Reaction on Natura1ly-Occurring Isotopes of Samarium. Ep $=19 \mathrm{MeV}$, $\theta_{\text {Lab }}=25^{\circ}$.

\begin{tabular}{lcc}
\hline Tárget nucleus & $\sigma_{\text {relative }}$ & $\sigma_{\text {absolute }}(\mu \mathrm{b} / \mathrm{sr})$ \\
\hline $154 \mathrm{Sm}$ & $78.6 \pm 3.1$ & $739 \pm 50$ \\
$152 \mathrm{Sm}$ & $51.9 \pm 2.3$ & $488 \pm 44$ \\
$150 \mathrm{Sm}$ & $123.9 \pm 13.6$ & $1166 \pm 156$ \\
$149 \mathrm{Sm}$ & $74.3 \pm 2.3$ & $699 \pm 59$ \\
$148 \mathrm{Sm}$ & $102.0 \pm 3.8$ & $959 \pm 83$ \\
$147 \mathrm{Sm}$ & $46.1 \pm 1.7$ & $433 \pm 38$ \\
\hline
\end{tabular}




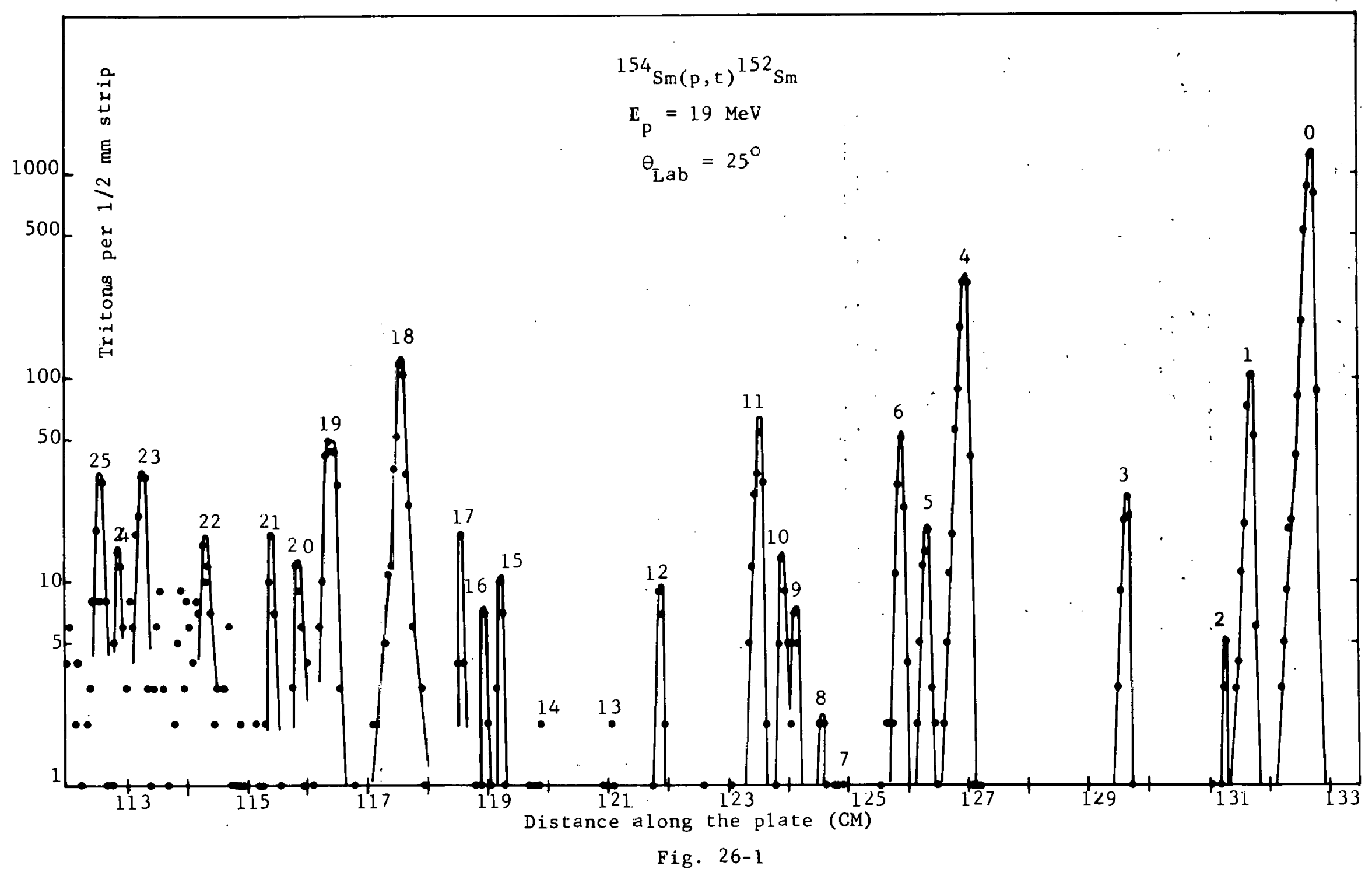




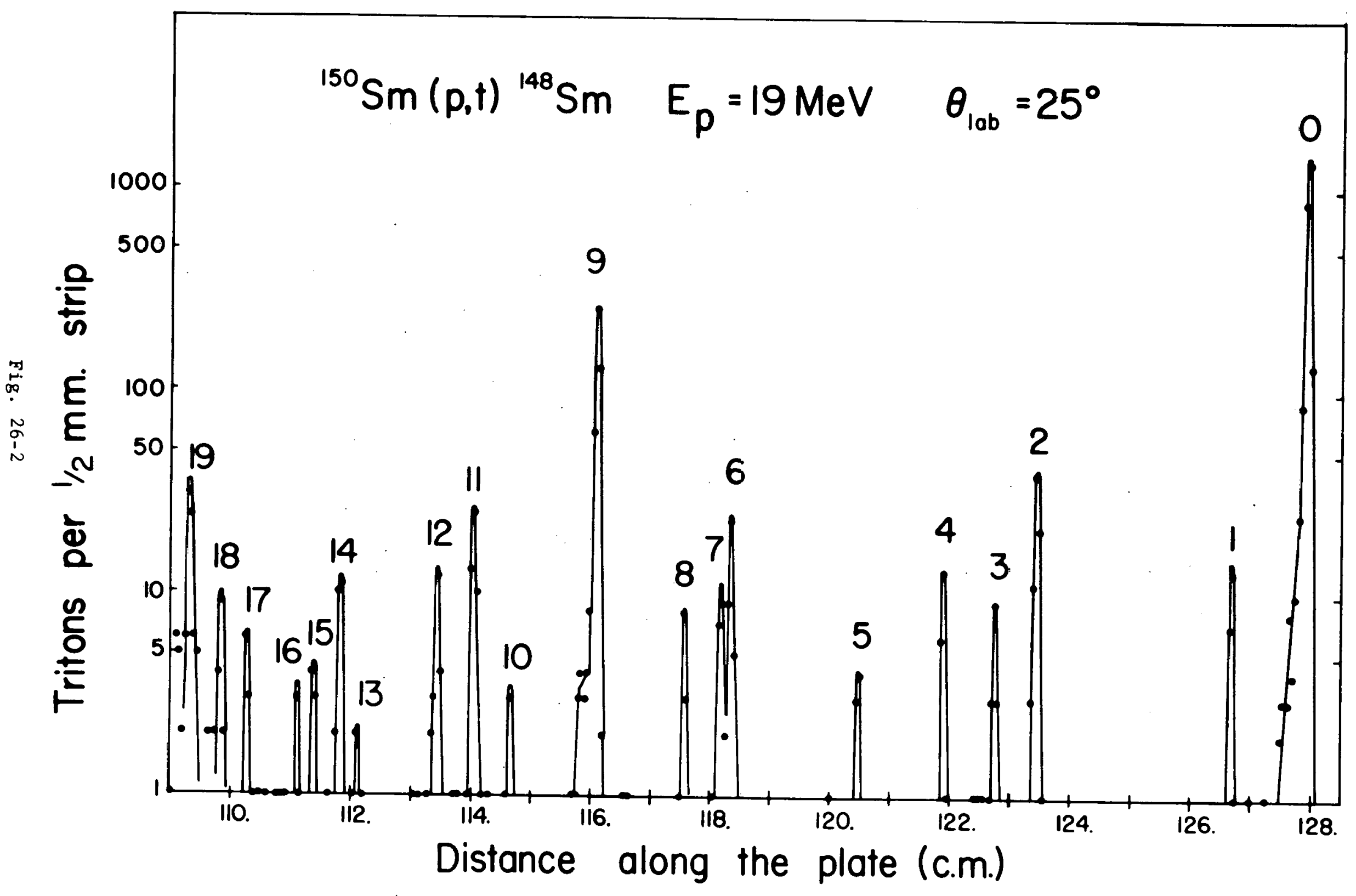


27. Elastic and Inelastic Scattering of Protons on $176 \mathrm{Yb}$

M. Oothoudt and N. M. Hintz

To get better optical parameters for fitting ${ }^{176} \mathrm{Yb}(\mathrm{p}, \mathrm{t}){ }^{174} \mathrm{Yb}$ with a coupled channel program, $19 \mathrm{MeV}$ protons were scattered from the ground state and first two excited states of ${ }^{176} \mathrm{Yb}$. 'The protons were analyzed in a. split-pole spectrometer and collected by a position-sensitive detector.

The angular distributions are. shown in Fig. $27-1$; statistical errors are smaller than the points except where shown. The absolute cross section was obtained by fitting the ground state angular distribution with an optical model code. ${ }^{1}$ At low angles the cross section is chiefly Coulombic and thus the fit should be independent of optical parameters; the program should then give absolute cross sections good to $5 \%$. Fig. $27-2$ shows a preliminary optical model $\mathrm{fit}$ to the elastic ratio to Rutherford. The parameters are given on the figure.

An attempt is now underway to fit these data using a program which includes inelastic coupling in the entrance and exit channels. 2

\section{$\underline{\text { References }}$}

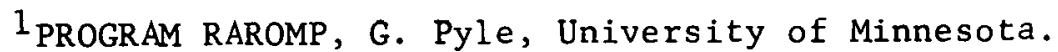

2 Private communication, S. Landowne and D. Bes, University of Minnesota. 


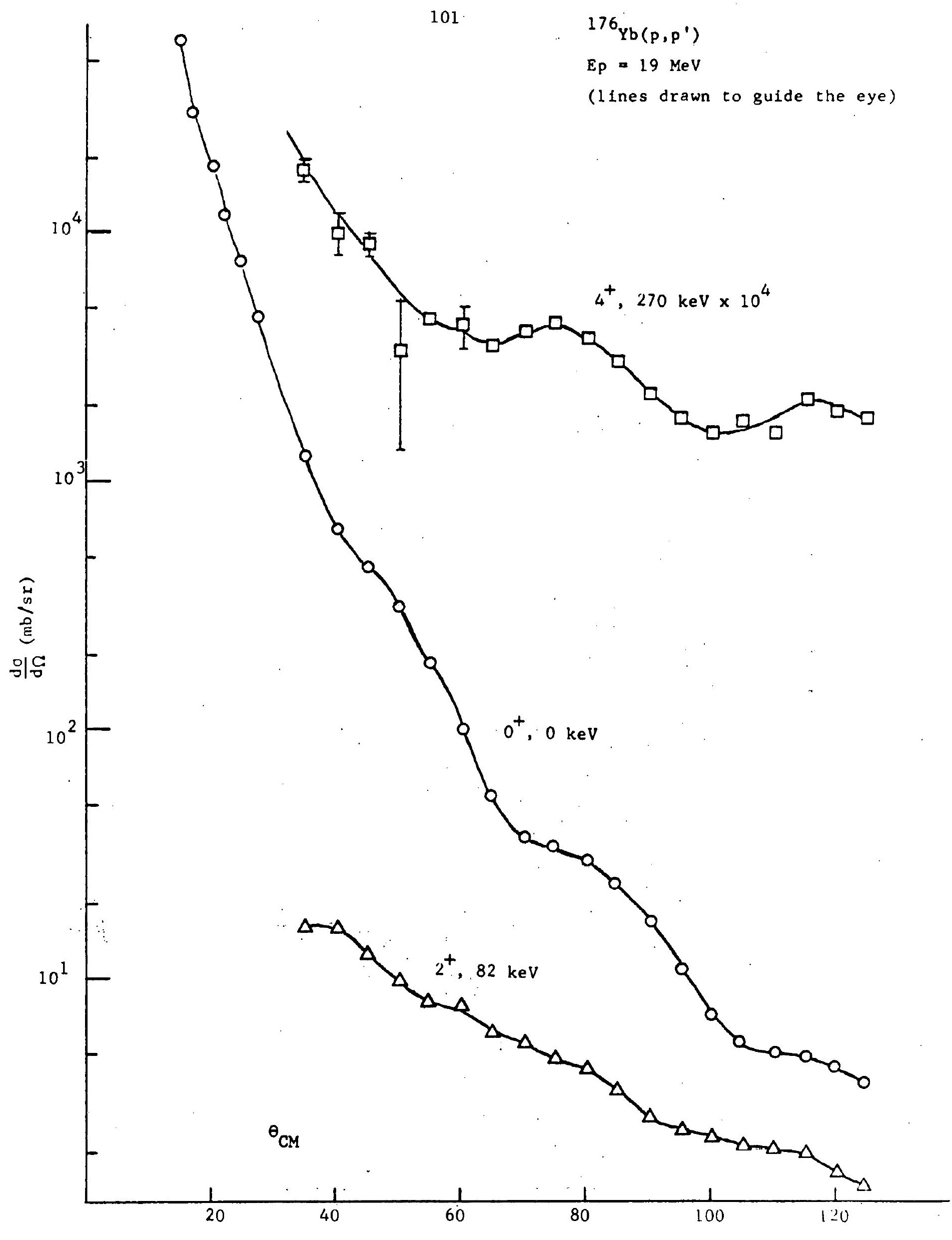

ANGLE

Fig. 27-1 


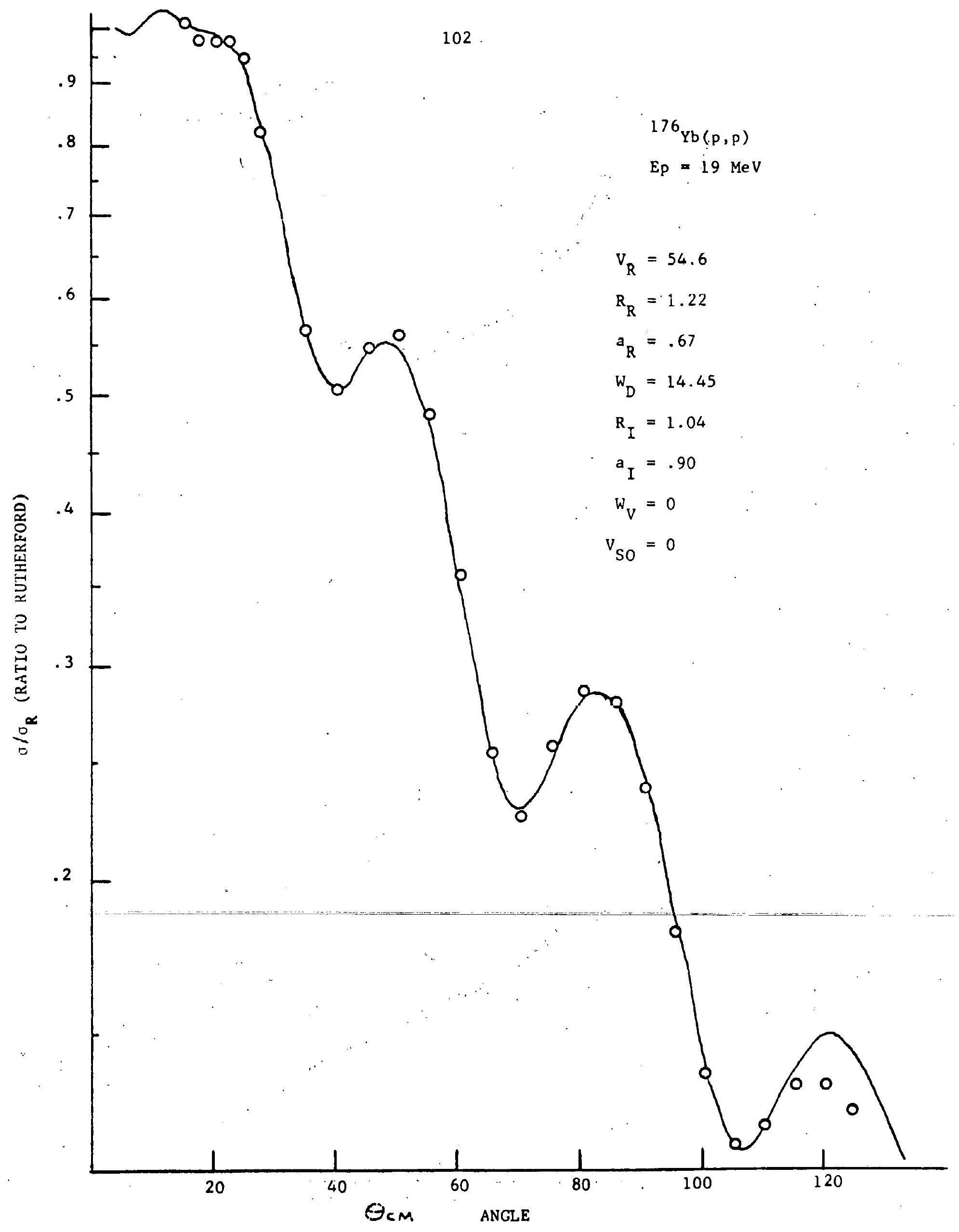

Fig. $27-2$ 
The study of $(p, t)$ on deformed nuclei at $E_{p}=19 \mathrm{MeV}$ has been continued. An angular distribution (Fig. $28-1$ ) has been taken for the $0^{+}, 2^{+}$, and $4^{+}$members of the ground state rotational band in ${ }^{168_{\mathrm{Yb}}}$ populated by ${ }^{170} \mathrm{Yb}(\mathrm{p}, \mathrm{t})$. The $0^{+}$angular distribution has been well fitted by a DWBA code. ${ }^{1}$ Fits to the $2^{+}$and $4^{+}$are poor as was the case for these states in ${ }^{174} \mathrm{Yb} .^{2}$

It was expected ${ }^{2}$ that excited rotational bands would be strongly populated by ${ }^{170} \mathrm{Yb}(\mathrm{p}, \mathrm{t})^{168} \mathrm{Yb}$ as they were in ${ }^{176} \mathrm{Yb}(\mathrm{p}, \mathrm{t})^{174} \mathrm{Yb}$. Such states have not been found. This may be explained by comparing the energy level spacings and the odd-even mass difference, $P_{n}$ (or energy gap parameter, $\Delta$ ). For ${ }^{176} \mathrm{Yb}, \mathrm{P}_{\mathrm{n}}$ is less than the level spacing, while for ${ }^{170} \mathrm{Yb}, \mathrm{P}_{\mathrm{n}}$ is greater than the level spacing. ${ }^{170} \mathrm{Yb}$ is thus superconducting and has little excited $l=0$ strength. Further details have been published. 3

Data has been taken to see if there exist excited $0^{+}$states in Gd, Dy, and Er isotopes populated by $(p, t)$. Nuclear emulsion plates were exposed to the tritons from natural targets of these elements at the maximum of the $\ell=0$ strength $\left(27 \frac{1}{2}^{\circ}\right)$. An attempt to scan the plates on the Argonne National Laboratory automatic plate scanner showed that the plates were not clean enough to get sufficiently low background for conclusive results. The plates are now being scanned by human scanners and work is being done to make future plates cleaner. 


\section{References}

${ }^{1}$ Program TWOPAR, Ben Bayman, Private Communication, University of Minn.

2

Williams Laboratory of Nuclear Physics, Annual Report, 1969, pp. 69-77.

${ }^{3}$ Physics Letters, 32B, 270 (1970). 


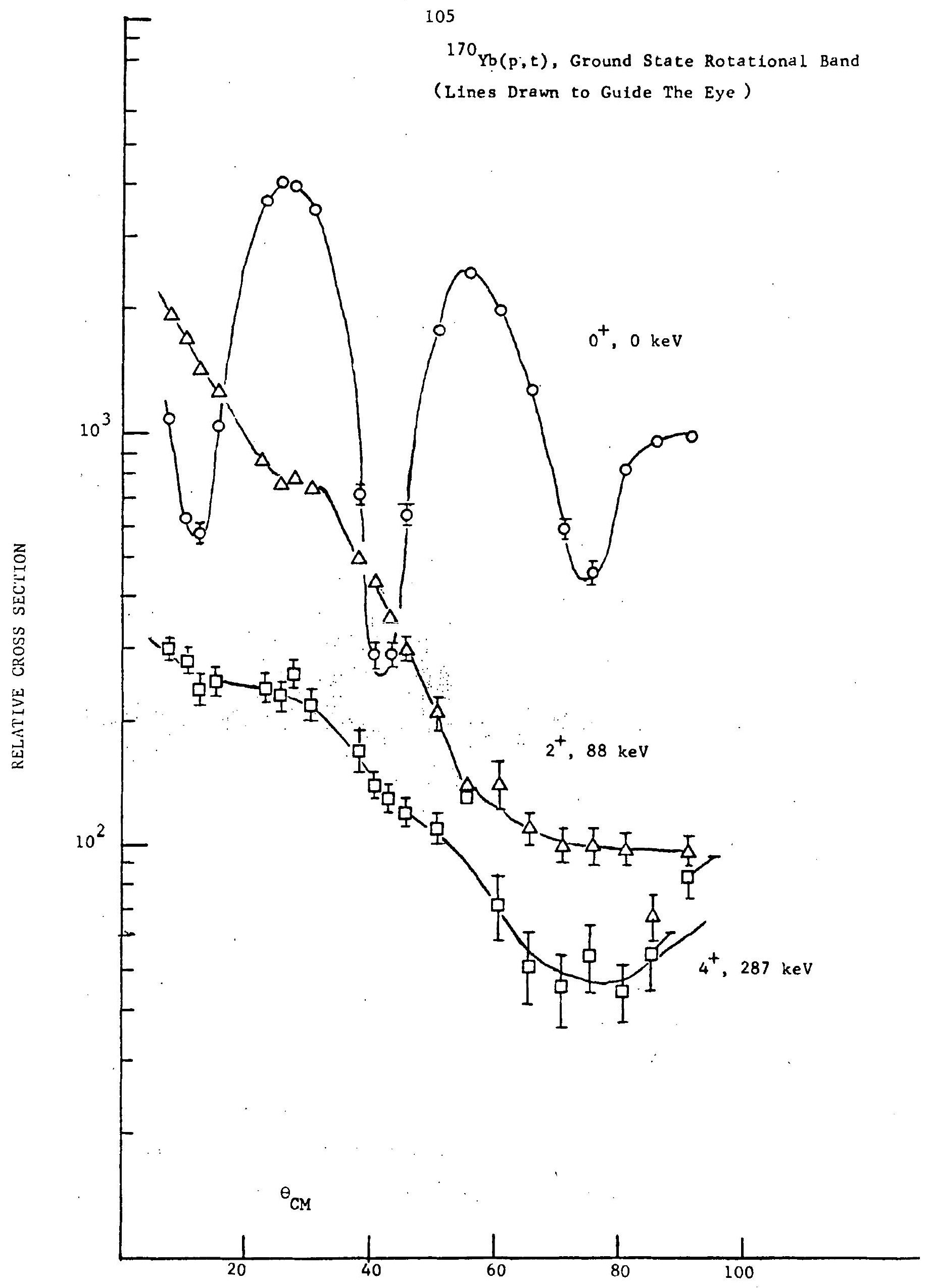




\section{INTERACTION OF SINGLE PARTICLE AND VIBRATION STATES}

29. $(\mathrm{p}, \mathrm{t})$ Reactions on $\mathrm{Ag}$ and $\mathrm{Pd}$ Isotopes

A. W. Kuhfeld and N. M. Hintz

The reactions ${ }^{108} \mathrm{Pd}(\mathrm{p}, \mathrm{t})$ and ${ }^{109} \mathrm{Ag}(\mathrm{p}, \mathrm{t})$ have been taken over a wider range of excitations and with improved statistics for some states since the 1969 Progress Report. In ${ }^{108} \mathrm{Pd}(\mathrm{p}, \mathrm{t}){ }^{106} \mathrm{Pd}$ the measured states are the ground state, the first excited $2^{+}$, the $\left(0^{+}, 2^{+}, 4^{+}\right)$multiplet near $1.2 \mathrm{MeV}$ (improved statistics) and the $3^{-}$octupole vibration at $2.084 \mathrm{MeV}$. In ${ }^{109} \mathrm{Ag}(\mathrm{p}, \mathrm{t})^{107} \mathrm{Ag}$ angular distributions have been taken for all states between 0 and $2.5 \mathrm{MeV}$ of excitation, the region in which multiplets built from excitations of the palladium core coupled to the extra $p_{1 / 2}$ proton might be expected. All states with cross-sections of magnitude $\geq 1 \mu \mathrm{b} / \mathrm{sr}$ at several angles have been detected. Resolution (FWHM) was on the order of $10 \mathrm{keV}$, depending upon the length of the run. The measurement accuracy of the excitations in ${ }^{107} \mathrm{Ag}$ went from abouc $3 \mathrm{keV}$ at $1 \mathrm{MeV}$ excitation, to perhaps $10 \mathrm{keV}$ at $2.5 \mathrm{MeV}$ excitation. The accuracy of measurements near $1 \mathrm{MeV}$ was obtained by comparing measured excitations to gamma-ray work; since precise measurements of higher excitations are not known, the resolution was taken for the accuracy of the higher excitations. However, Ford et al. ${ }^{1}$ did measure the excitation of an octupole state, and got $2.19 \mathrm{MeV}$; the weighted -center of the close octupole doublet seen at 2.182 and $2.203 \mathrm{MeV}$ in this experiment is $2.191 \mathrm{MeV}$. These excitations were taken on plates, and the position-vs-excitation relationship measured by a calibration plate on which the ground state of the reaction had been placed at several locations along the plate by varying the spectrometer field. Since the purpose of this experiment is to test the description of 


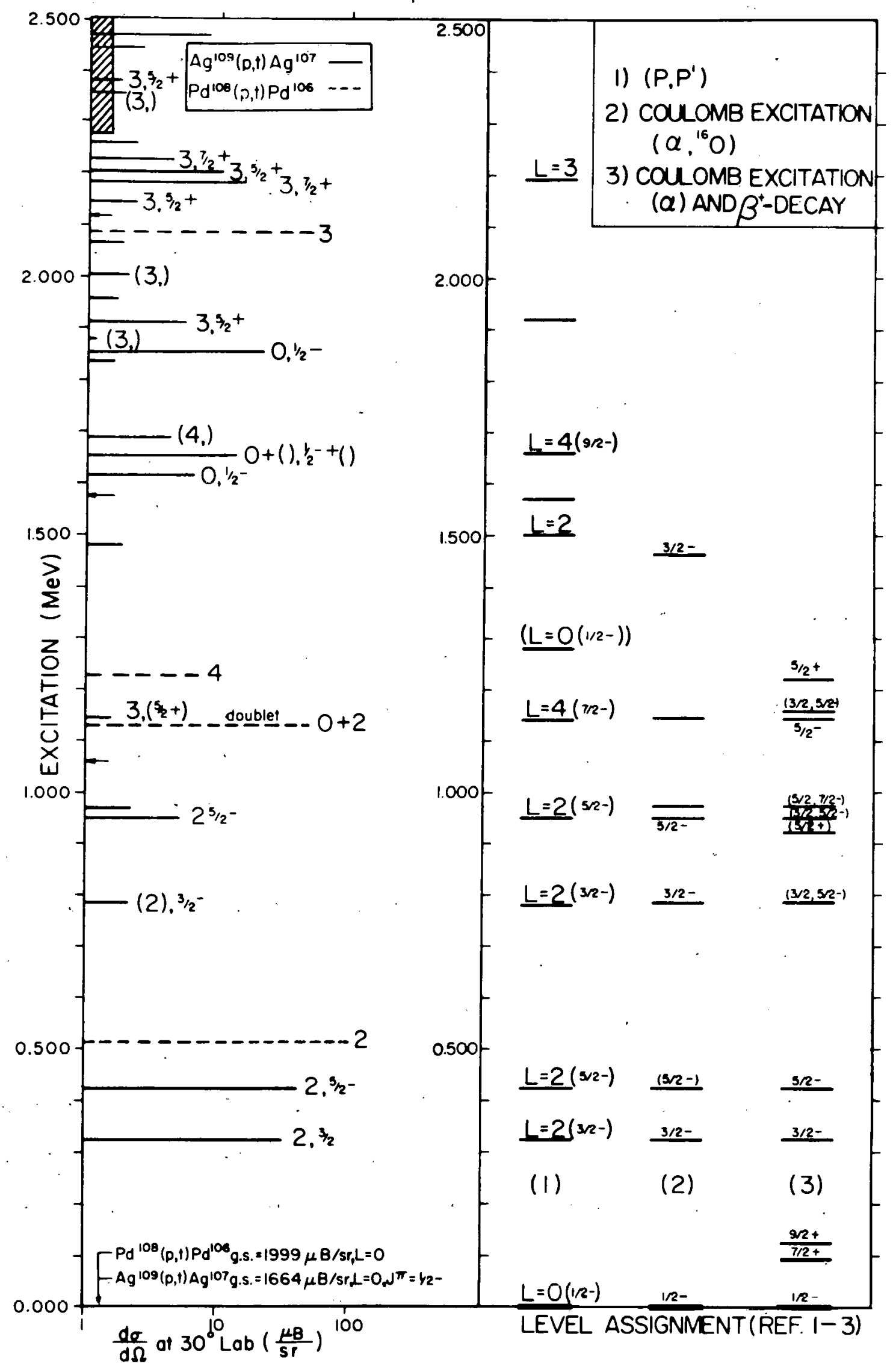

Fig. 29-1 
${ }^{107} \mathrm{Ag}$ in terms of ${ }^{106} \mathrm{Pd}-\mathrm{plus-a-proton}$ in the weak-coupling model, further discussion will be classified according to the putative core state in ${ }^{106} \mathrm{Pd}$.

$0^{+}$Ground State: The ${ }^{107} \mathrm{Ag}$ g.s. is a well-verified $1 / 2^{-}$; the $(\mathrm{p}, \mathrm{t})$ transition to this state is $\mathrm{L}=0$ with almost exactly the same shape as $(p, t)$ to the ${ }^{106} \mathrm{Pd}$ g.s. but only approx. $84 \%$ of the strength. This could be a Q-dependent effect, or a pairing-blocking effect. $2^{+}$One-Quadrupole-Phonon: The states at .324 and $.423 \mathrm{MeV}$ excitation have $\mathrm{L}=2$ angular distributions; the weighted center of the doublet is $.386 \mathrm{MeV}$, and the sum of the cross-sections has very much the same angular distribution as the palladium $2^{+}$at $.512 \mathrm{MeV}$, but only about $75 \%$ of the strength.

3- One-Octupole-Phonon: The octupole strength seen at $2.19 \mathrm{MeV}$ in ${ }^{107} \mathrm{Ag}\left(\mathrm{p}, \mathrm{p}^{\prime}\right)$ has been resolved in $(\mathrm{p}, \mathrm{t})$ into two strong levels $\mathrm{plus}$ two nearby weak levels. While the two strong levels had the same overall shape. to their angular distributions, the oscillations superimposed upon this shape were out of phase by some $12^{\circ}$, with the oscillations occurring sooner for the state with the larger overall cross-section. This is analogous to the one-quadrupole-phonon $\left(3 / 2^{-}, 5 / 2^{-}\right)$doublet, in which the oscillations of the larger state lead by about $8^{0.4}$ On this basis the state at $2.182 \mathrm{MeV}$ has been assigned angular momentum $7 / 2^{+}$, and the state at $2.203 \mathrm{MeV}, 5 / 2^{+}$. Besides this doublet there are eight smaller states having an $\mathrm{L}=3$ angular distribution between 1.144 $\mathrm{MeV}$ and $2.379 \mathrm{MeV}$; they are identified on the level diagram. The total octupole cross-section was taken to be the sum of these ten crosssections; its. angular distribution is very similar to the palladium $L=3$, and has very nearly the same strength. There is disagreement at $10^{\circ}$ 
and $15^{\circ}$, but these angles of the palladium octupole angular distribution are not to be trusted; an $\mathrm{L}=0$ contaminant from the reaction ${ }^{65} \mathrm{Cu}(\mathrm{p}, \mathrm{t}){ }^{63} \mathrm{Cu} \mathrm{g} . \mathrm{s}$. had to be subtracted out at these angles.
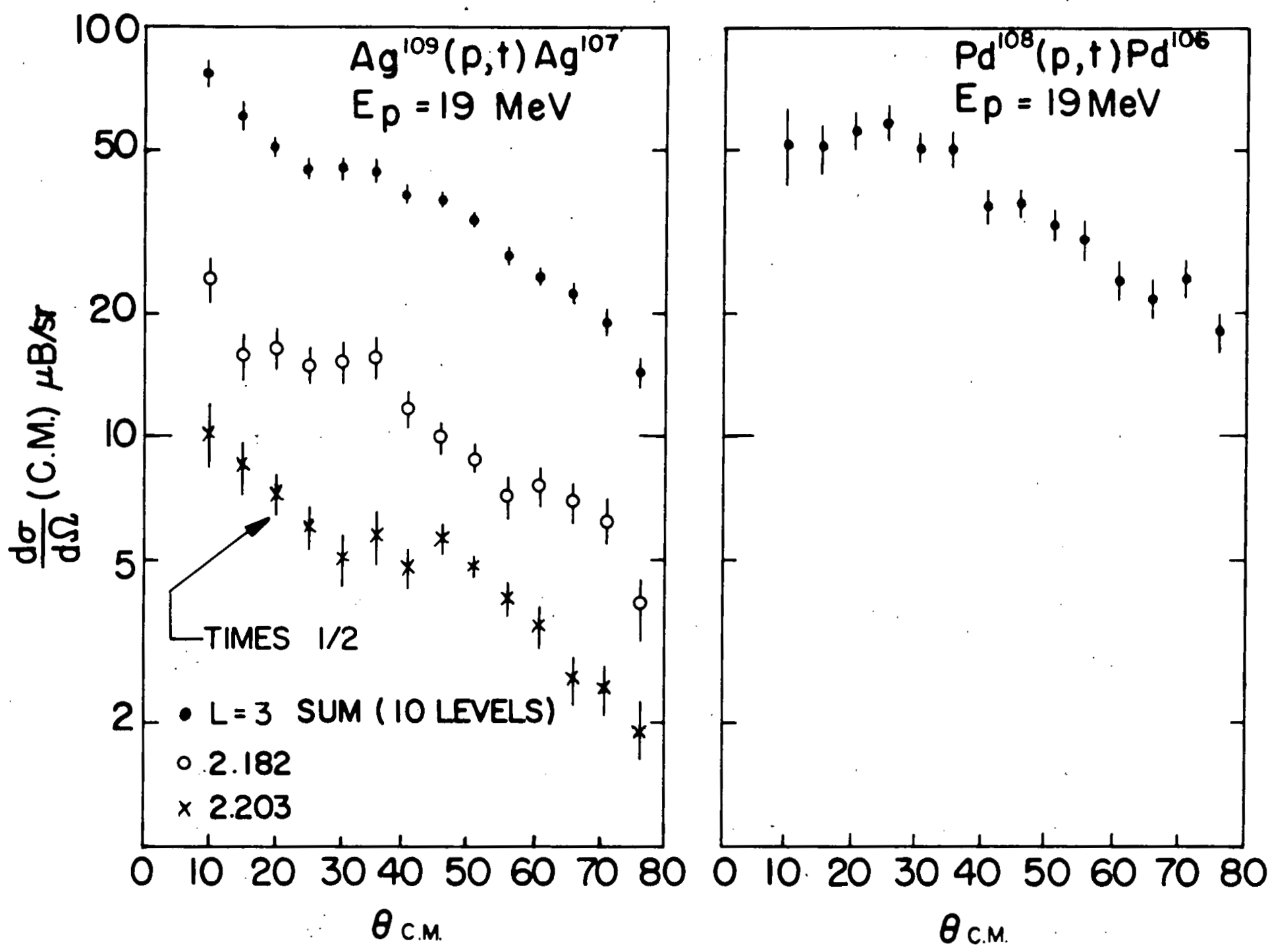

Fig. 20̈-2. Octupole Angular Distributions. 
$2^{+}$Two-Quadrupole-Phonon: Ford et al. suggest that from $\left(p, p^{\prime}\right)$ the levels belonging to this core state are at $.787, .949$, and $1.50 \mathrm{MeV}$, with the $.949 \mathrm{MeV}$ level having most of the strength. ${ }^{1}$ Black et a1. agree (from Coulomb excitation and beta-decay work) about the two lower levels, but add that there seems to be a $\mathrm{p}_{3 / 2}$ proton-hole component to the $.787 \mathrm{MeV}$ level. ${ }^{3}$ Robinson et al. assign the states to be respectively $3 / 2^{-}, 5 / 2^{-}$, and $3 / 2^{-}$by Coulomb excitation with alphas and oxygen. $^{2}$ In $(p, t)$ the .9490 seems to be a collective $L=2,5 / 2^{-}$level as expected; the $1.482 \mathrm{MeV}$ state (closest to 1.50 ) has a nondescript angular distribution rising at times to $2 \mu \mathrm{B} / \mathrm{sr}$, and hardly seems collective. The $.787 \mathrm{MeV}$ level is $3 / 2^{-}$from Coulomb excitation, betadecay, and $\left(p, p^{\prime}\right)$; the $(p, t)$ angular distribution to this state is more like $\mathrm{L}=2,3 / 2^{-}$than anything else, but there is a drastic dip in the cross-section near $60-65^{\circ}$; this dip was present in both plate and detector data, and is probably not a statistical artifact. Tentative$1 y$, this state is of the two-quadrupole-phonon $2^{+}$doublet, but has other aspects as we11.

$0^{+}$Two-Ouadrupole-Phonon: One $1 / 2^{-}$level is expected; Ford et al. tentatively assign it to be the $1.28 \mathrm{MeV}$ level, on the basis of ( $\left.p, \mathrm{p}^{\prime}\right) .^{1}$ This level was not seen in beta-decay or Coulomb excitation ${ }^{2,3}$, nor was it seen in $(p, t)$. The nearest $L=0$ transitions seen in $(p, t)$ are at $1.615,1.653$, and $1.854 \mathrm{MeV}$. The $1.854 \mathrm{MeV}$ level is strong enough to be this collective state; the other two would have to be summed to come close, and even then would probably have too little strength. $4^{+}$Two-Quadrupole-Phonon: The 1.14 and $1.66 \mathrm{MeV}$ states are fitted very well in $\left(P, P^{\prime}\right)$ by the experimental palladium $4^{+}$angular distribution, with intensity ratios suggesting that they are respectively the $7 / 2^{-}$ 
and $9 / 2^{-}$levels. 1 In $(p, t)$ the $1.144 \mathrm{MeV}$ state has an $\mathrm{L}=3$ angular distribution, suggesting $5 / 2^{+}$but not excluding $7 / 2^{+}$. The $1.653 \mathrm{MeV}$ level in $(p, t)$ is a doublet with an $L=0$ component which effectively masks the angular distribution of the other component; there is a level at $1.688 \mathrm{MeV}$ which has an extremely well-defined angular distribution which more resembles the palladium $\mathrm{L}=4$ than anything else; but this fit is far from good.

\section{$\underline{\text { References }}$}

${ }^{1}$ J. L. C. Ford, Jr., Cheuk-Yin Wong, Taro Tamura, R. L. Robinson, and P. H. Stelson, Phys. Rev. 158, 1194 (1967).

${ }^{2}$ R. L. Robinson, F. K. McGowan, P. H. Stelson, and W. T. Milner, Preprint, to be submitted to Nuclear Physics.

3 J. L. Black, W. Gruhle, and D. W. Heikkinen, Phys. Lett. 22 , 598 (1966). ${ }^{4}$ A. W. Kuhfeld, N. M. Hintz, Williams Laboratory Progress Report, p. 80, 1969. 
30. Levels of ${ }^{210}$ Po From the ${ }^{209} \mathrm{Bi}\left({ }^{3} \mathrm{He}, \mathrm{d}\right){ }^{210}$ Po Reaction

C. D. Kavaloski (Eastern Washington State College), J. S. Lilley, and .

\section{H. Ohnuma}

States in ${ }^{210}$ Po have been studied using the ${ }^{209} \mathrm{Bi}\left({ }^{3} \mathrm{He}, \mathrm{d}\right){ }^{210} \mathrm{Po}$ reaction. This reaction is expected to excite $\left(h_{9 / 2}, l_{j}{ }^{\prime}\right)$ two-proton configuration in ${ }^{210}$ Po where $\ell_{j}{ }^{\pi}$ are the single proton states in the $\mathrm{Z}=82$ - 126 shell, which are strongly excited in the ${ }^{208} \mathrm{~Pb}\left({ }^{3} \mathrm{He}, \mathrm{d}\right){ }^{209} \mathrm{Bi}$ reaction. An earlier study using the $(\alpha, t)$ reaction ${ }^{1}$ supports this expectation.

Thin $\left(100 \mu g / \mathrm{cm}^{2}\right)$ targets of ${ }^{209} \mathrm{Bi}$ were bombarded with a beam of $29-\mathrm{MeV}^{3} \mathrm{He}$ ions from the University of Minnesota MP tandem Van de Graaff. The resulting reaction products were analyzed by the Enge split-pole spectrograph.

Several runs were taken at $40^{\circ}$ and $60^{\circ}$ with Nuclear Diode positionsensitive detectors in the focal plane of the spectrograph. Many states and groups of states seen were identified with ${ }^{210}$ Po and preliminary values for their energies have been determined. These are given in Table 30-1. The $1.566-\mathrm{MeV}$ level probably is the missing $8^{+}$state of the $\left(\mathrm{h}_{9 / 2}{ }^{2}\right)$ configuration. Then the $11^{-}$level of the $\left(\mathrm{h}_{9 / 2} i_{13 / 2}\right)$ configuration, suggested by Yamazaki and $\operatorname{Ewan}^{2}$ at about $2.8 \mathrm{MeV}$, would be the 2.850-MeV state observed in this experiment. The energy difference of these two levels is $1294 \mathrm{keV}$, very close to the gamma-ray energy of $1292 \mathrm{keV}$ observed in Ref. 2 .

Additional runs were taken between $30^{\circ}$ and $80^{\circ}$ with nuclear emulsion plates in the focal plane. Analysis of these plates is in progress. References

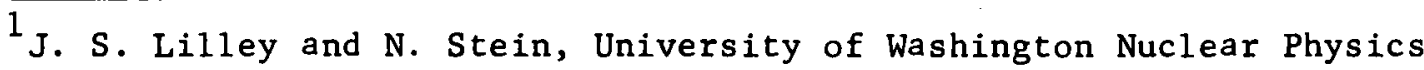
Laboratory Annual Report 1965, p. 34.

2. Yamazaki and G. T. Ewan, Phys. Letters 24B, 278 (1967). 
Table 30-1. Preliminary Energies of States in ${ }^{210}$ Po observed in the Present Experiment.

\begin{tabular}{|c|c|}
\hline $\mathrm{E}_{\text {exc }}(\mathrm{MeV})$ & $E_{\text {exc }}(\mathrm{MeV})$ \\
\hline 1.180 & 3.800 \\
\hline 1.425 & 4.029 \\
\hline 1.472 & 4.115 \\
\hline 1.556 & 4.145 \\
\hline 2.190 & 4.235 \\
\hline 2.288 & 4.329 \\
\hline 2.330 & 4.391 \\
\hline 2.391 & 4.478 \\
\hline 2.412 & 4.554 \\
\hline $2.1 / 16$. & 1.631 \\
\hline 2.493 & 4.657 \\
\hline 2.850 & 4.952 \\
\hline 3.015 & 5.004 \\
\hline 3.131 & 5.147 \\
\hline 3.185 & 5.222 \\
\hline
\end{tabular}


The Interaction of Alpha-Particles with ${ }^{208} \mathrm{~Pb}$ and ${ }^{209} \mathrm{Bi}$ Below The Barrier

A. R. Barnett and J. S. Lilley

I. Analysis of Early Data

Measurements of the total $(\alpha, n)$ cross sections and elastic scattering angular distributions for $\alpha$-particles on ${ }^{208} \mathrm{~Pb}$ and ${ }^{209} \mathrm{Bi}$ at 19-,

20- and $22-\mathrm{MeV}$ were reported in last year's progress report. 1

These data have been analyzed in terms of the optical model. At

19- and $20-\mathrm{MeV}$ the $(\alpha, n)$ data were shown to be a good representation of

the total reaction cross sections, $\sigma_{R} \cdot$ At $22 \mathrm{MeV}$, the known $(\alpha, 2 \mathrm{n})$

cross section for ${ }^{209} \mathrm{Bi}$ was included to give $\sigma_{\mathrm{R}}$.

The six angular distributions and five reaction cross sections were

fitted simultaneously with an energy-independent optical model using

different geometries for the real and imaginary potentials $\mathrm{V}$ and $\mathrm{W}$. The

fits were carried out using the global search routine BOMB $^{2}$ which

minimizes the quantity

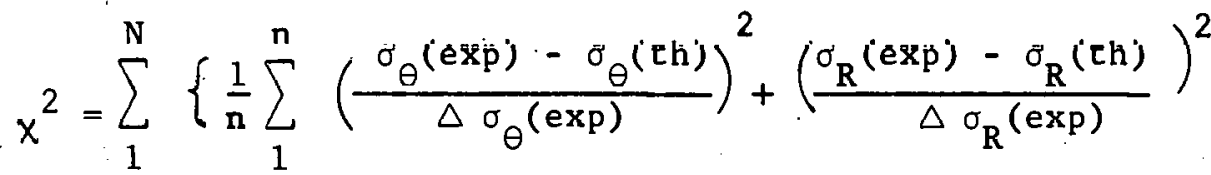

where $\mathrm{N}$ is the number of data sets and $\mathrm{n}$ the number of points in the angular distribution. Good overall fits were obtained for several

different sets of optical parameters. Fig. 31-1 compares the experimental data with predictions using one of these parameter sets.

The importance of the reaction cross section data is illustrated in Fig 32-2. The open circles show values of $\chi^{2}$ for a simultaneous fit to all the data on both target nuclei. Note that the contribution to $x^{2}$ from the reaction cross sections (solid circles) is quite sensitive to the value of the real diffuseness parameter, ${ }^{a}{ }_{R}$, whereas that due to the scattering data alone (crosses) is not. 
Real and imaginary potential form factors at large radii.corresponding to acceptable fits for different. values of $a_{R}$ are shown in Fig. 31-3. It is clear that at this low energy, the value of the real potential near 11 fermis is a well-determined quantity. This point lies about 4 fermis beyond the half-way radius of the nuclear potential and corresponds to the peak of the Coulomb barrier for an $\alpha$-particle on these nuclei. It is reassuring to find that the strong-absorption radius occurs near 11 fermis (see arrow in Fig.31-3) showing that the potential is determined most accurately where the interaction is most important.

These results are similar to those of Goldring et al. ${ }^{3}$ at stanford University, who have measured excitation functions of the elastic scattering on ${ }^{209} \mathrm{Bi}$ and several lead isotopes at several angles.

\section{Precision Elastic Scattering Data on ${ }^{209} \mathrm{Bi}$ at $22 \mathrm{MeV}$}

Some of the acceptable fits to the angular distributions described above showed a $\pm 5 \%$ oscillation in the predicted values of $d \sigma / d \Omega$ for angles less than $60^{\circ}$. Since there were no experimental points in this region, such fits could not be eliminated even though oscillations of this magni tude would be quite unexpected. In order to resolve this question and to look for possible small oscillations, it was decided to extend the $22 \mathrm{MeV}$ ${ }^{209} \mathrm{Bi}$ data forward to $30^{\circ}$. and to attempt an overall accuracy of $<1 \%$.

Four $700_{\mu}$ Si surface-barrier detectors, each separated by $10^{\circ}$ and mounted on a precision ring fitted into the ORTEC scattering chamber, were used to cover the angular range $30^{\circ}-100^{\circ}$. Pulse pile-up was reduced by using ORTEC 109A preamplifiers followed by Canberra 1416 postamplifiers. A pulse generator triggered by the current integrator output pulse and fed 
through the electronics system, furnished a measurement of the dead-time, which was kept down to a few percent. The target, set at $40^{\circ}$ to the incident beam, was $100 \mu \mathrm{g} / \mathrm{cm}^{2}{ }^{209} \mathrm{Bi}$ on a $10 \mu \mathrm{g} / \mathrm{cm}^{2} \mathrm{C}$ backing. Considerable care was taken with the beam quality and with detector aperture construction. As a result, no background subtraction was required for any of the data.

Fixed detectors at $\pm 30^{\circ}$ to the incident beam monitored the horizontal beam position on the target. The summed counts in the two monitor detectors was used to normalize the data. This was also checked against the beam current integrator and confirmed that the target thickness reamined essentially constant throughout the runs. A number of check runs showed good internal consistency. The zero angle of the ring was checked by several left-right measurements using different detectors.

Multiple overlaps of data taken independently by the four detectors at the same angles enabled an accurate set of ratios between the detector solid angles (al1 $1.02 \mathrm{msr}$ to within a few percent) to be determined, and hence a precise relative angular distribution over the entire range was obtained. This distribution was normalized by requiring that the weighted mean of 1.6 angles between $30^{\circ}$ and $60^{\circ}$ agree with pure Coulomb scattering: The maximum deviation of any point in this angular range is $1 \%$ which puts an upper limit on the magnitude of the oscillations. The previous $22 \mathrm{MeV}$ Bi data were reduced by $1.7 \%$ in order to renormalize them to the present data. The normalization error quoted previously was $3 \%$.

The final combined distribution is given in Fig. 31-4. The relative errors, which are $0.5-1.0 \%$ for $\theta<100^{\circ}$ and $1.5 \%$ for $\theta>100^{\circ}$, include effects due to statistics, normalization and angular uncertainties. The fit shown is preliminary, yet demonstrates the excellent agreement that can be obtained between theory and experiment at energies near the 
Coulomb barrier.

\section{Recent $\sigma(\alpha, \mathrm{n})$ Results}

The measurements of the total $(\alpha, n)$ cross sections for ${ }^{208} \mathrm{~Pb}$ and ${ }^{209} \mathrm{Bi}$ discussed in part I have been improved and extended to cover the range of $\alpha$-particle bombarding energy from $16-$ to $24-\mathrm{MeV}$.

Accurate, relative $(\alpha, n)$ data were obtained by using the technique of chopping the incident $\alpha$-beam and detecting the delayed $\alpha$-activity of the residual nuclei: ${ }^{211}$ Po and ${ }^{212}$ At. In general, alphas emitted from the ground and excited (metastable) states were easily resolved in each case. However, a large fraction of the $21 \mathrm{~m}_{\mathrm{A}}$ activity $\left(\mathrm{T}_{1 / 2}=.115 \mathrm{sec}\right.$.) decayed in the interval between beam-off and the start of the activity counting, and, even though a thick target was used below $18 \mathrm{MeV}$, the $212 \mathrm{~m}$ At activity was determined with poor statistics and gives the biggest contribution to the uncertainty in the data at the lowest energies. Only an upper 1 imit to the ${ }^{212 m}$ Po activity could be made below about $19 \mathrm{MeV}$. However, because of its relatively long half life (25 sec.), this activity could be detected efficiently and was shown to contribute a negligible amount to the total $(\alpha, n)$ cross section at all but the highest energies. Further details of these measurements are given in section 32 .

The data were normalized to a set of runs taken with the continuous beam at 20- and $22-\mathrm{MeV}$, where the decay alphas were recorded at the same time as the elastic scattering, which is well-known.

The final results for $\sigma(\alpha, n)$ on ${ }^{208} \mathrm{~Pb}$ and ${ }^{209} \mathrm{Bi}$ between 17 and $23 \mathrm{MeV}$ are shown in Fig. 31-5.

The reproducibility of the results for different target thicknesses and backings was considered carefully since it was essential to ensure 
that all the activated nuclei remained in the target. Carbon-backed $\mathrm{Pb}$ and $B i$ targets varying in thickness by a factor of five gave ratios of $\sigma(\alpha, n) / \sigma_{\text {elastic }}$ which agreed within experimental error after a small correction was made for the energy of the beam in the center of the target. Poor agreement was obtained with unbacked targets, the results indicating that $(50 \%-80 \%)$ of the compound nuclei recoiled out of a $100 \mu g$ unbacked target.

The solid curves in Fig. 31-5 are the ones that gave the best global fit to the earlier set of data as described in part I of this section. The agreement with the new data. is excellent, even below 19 $\mathrm{MeV}$ which was not considered in the original analysis. Indeed the deviations below $17 \mathrm{MeV}$ could be due to the growing importance of the $(\alpha, \gamma)$ process, which has been shown to be small only down to $18 \mathrm{MeV}$. The $(\alpha, n)$ thresholds occur at $15.26 \mathrm{MeV}$ for ${ }^{208} \mathrm{~Pb}$ and $15.53 \mathrm{MeV}$ for ${ }^{209} \mathrm{Bi}$.

The dotted curve, shown only for ${ }^{209} \mathrm{Bi}$, is a prediction using parameters which fit the accurate elastic scattering data on ${ }^{209} \mathrm{Bi}$ reported in part II of this section. Clearly, the data are quite sensitive to the shape as well as the magnitude of the tail of the nuclear potential and it is hoped they will yield detailed information about the distribution of matter in the outer regions of these nuclei.

\section{$\underline{\text { References }}$}

${ }^{1}$ A. R. Barnett, J. S. Lilley and F. Chwieroth, John H. Williams Laboratory, Annual Report 1969, p. 89.

2F. D. Becchetti, Jr., M.S. Thesis, University of Minnesota, June 1968. Unpub1ished.

${ }^{3}$ G. Goldring, B. Watson, M. Bertin, S. Tabor and M. Samuel, preprint. 
Elastic $\alpha$-Particle Distributions

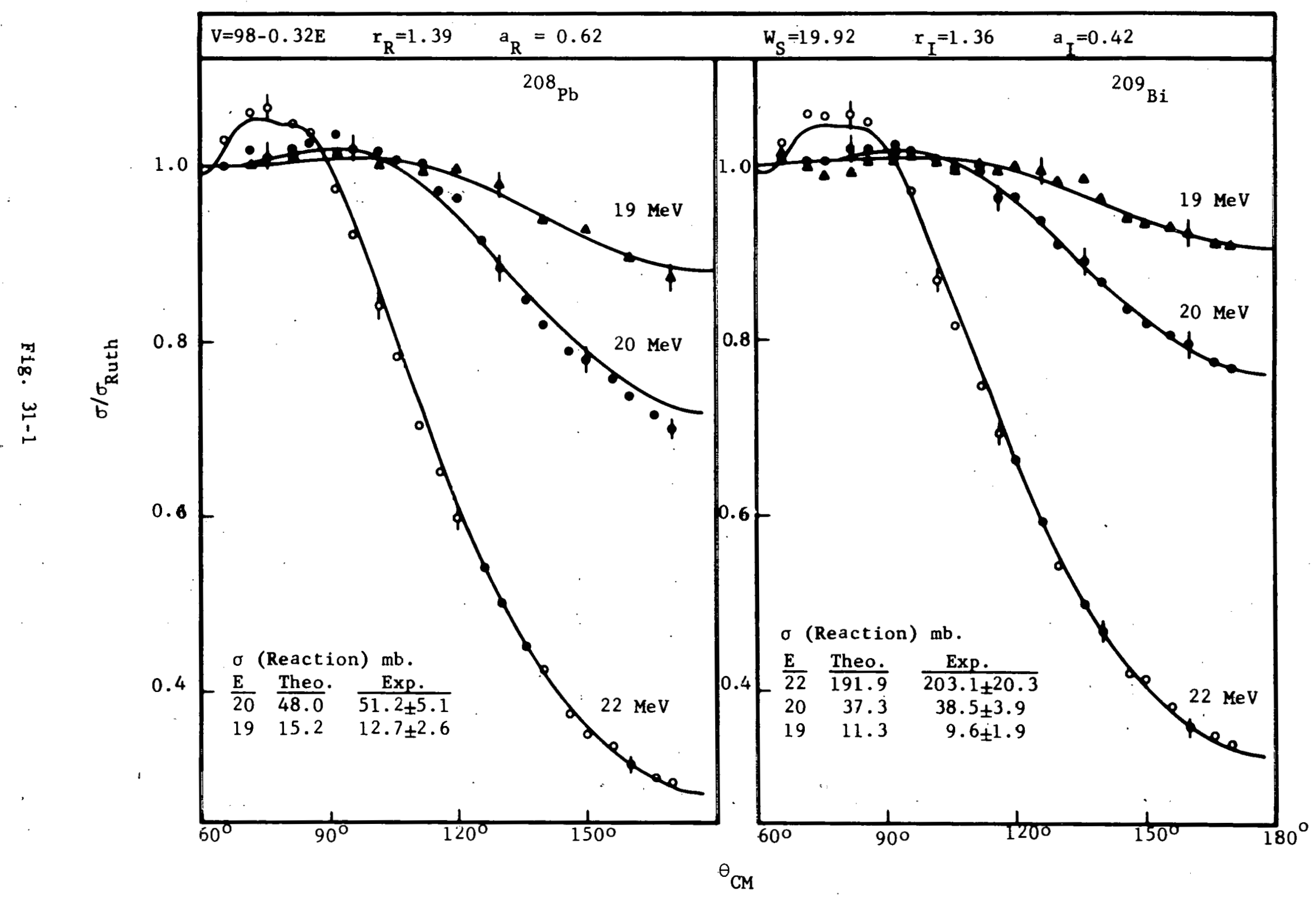




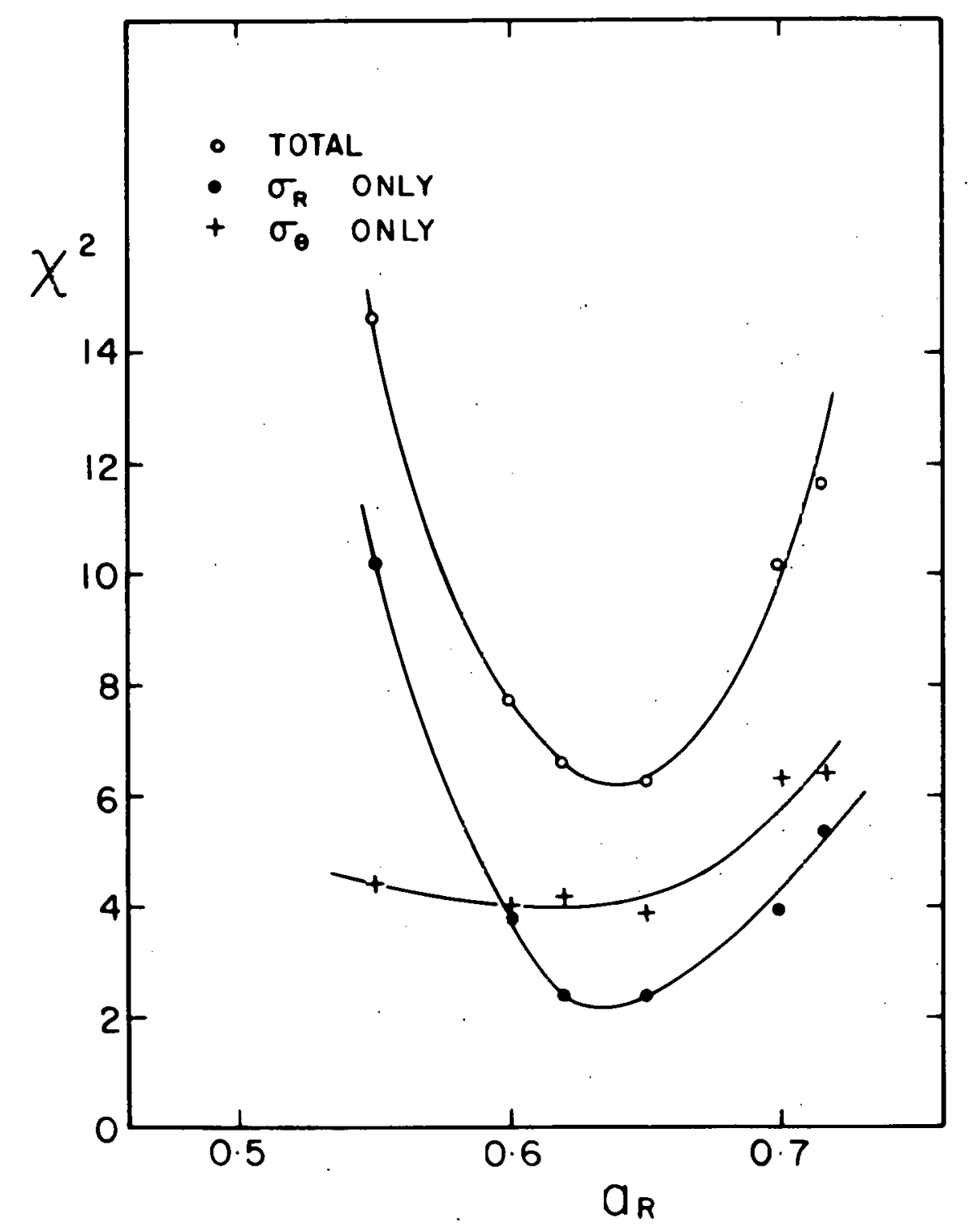

Fig. $31-2$

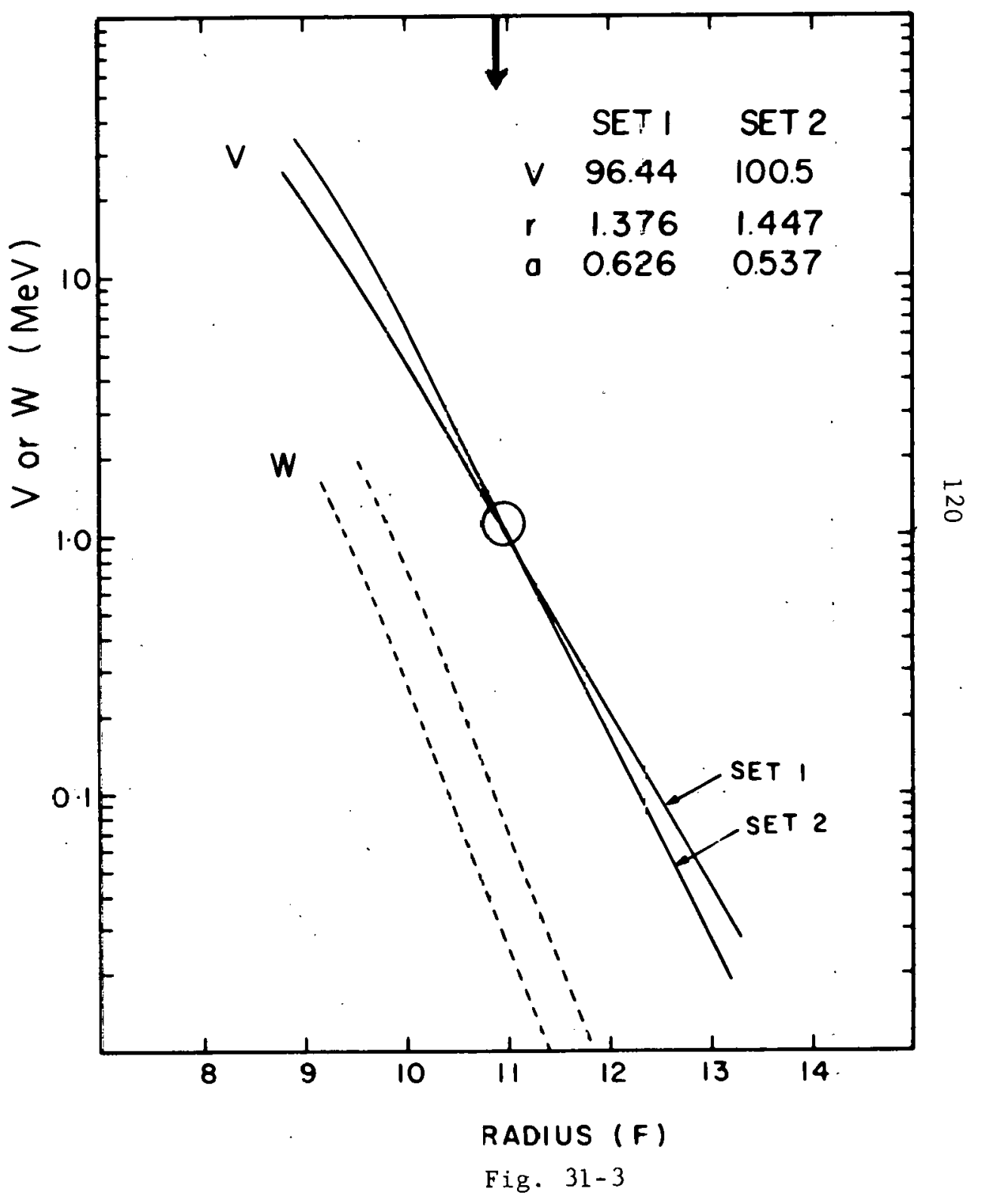




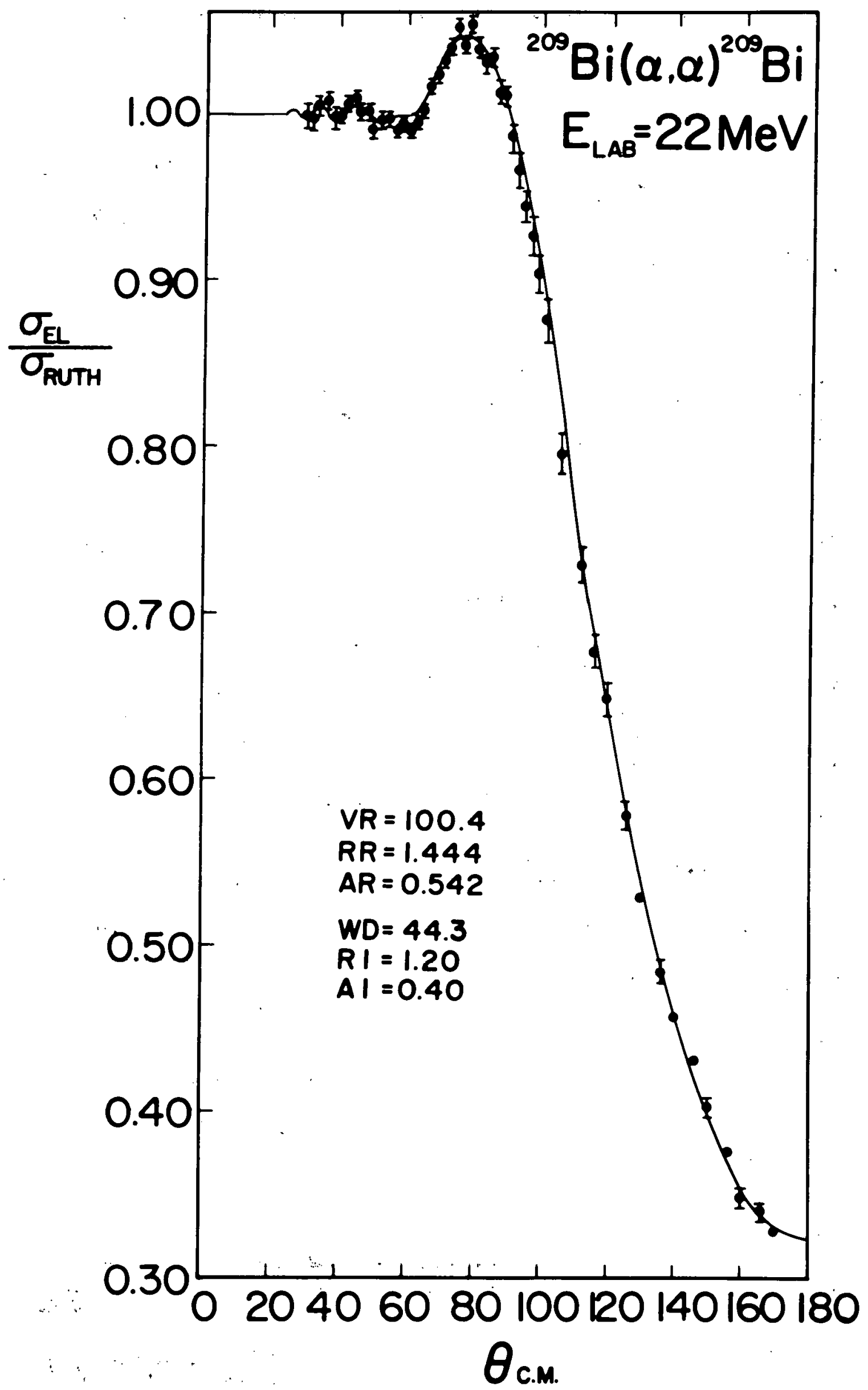




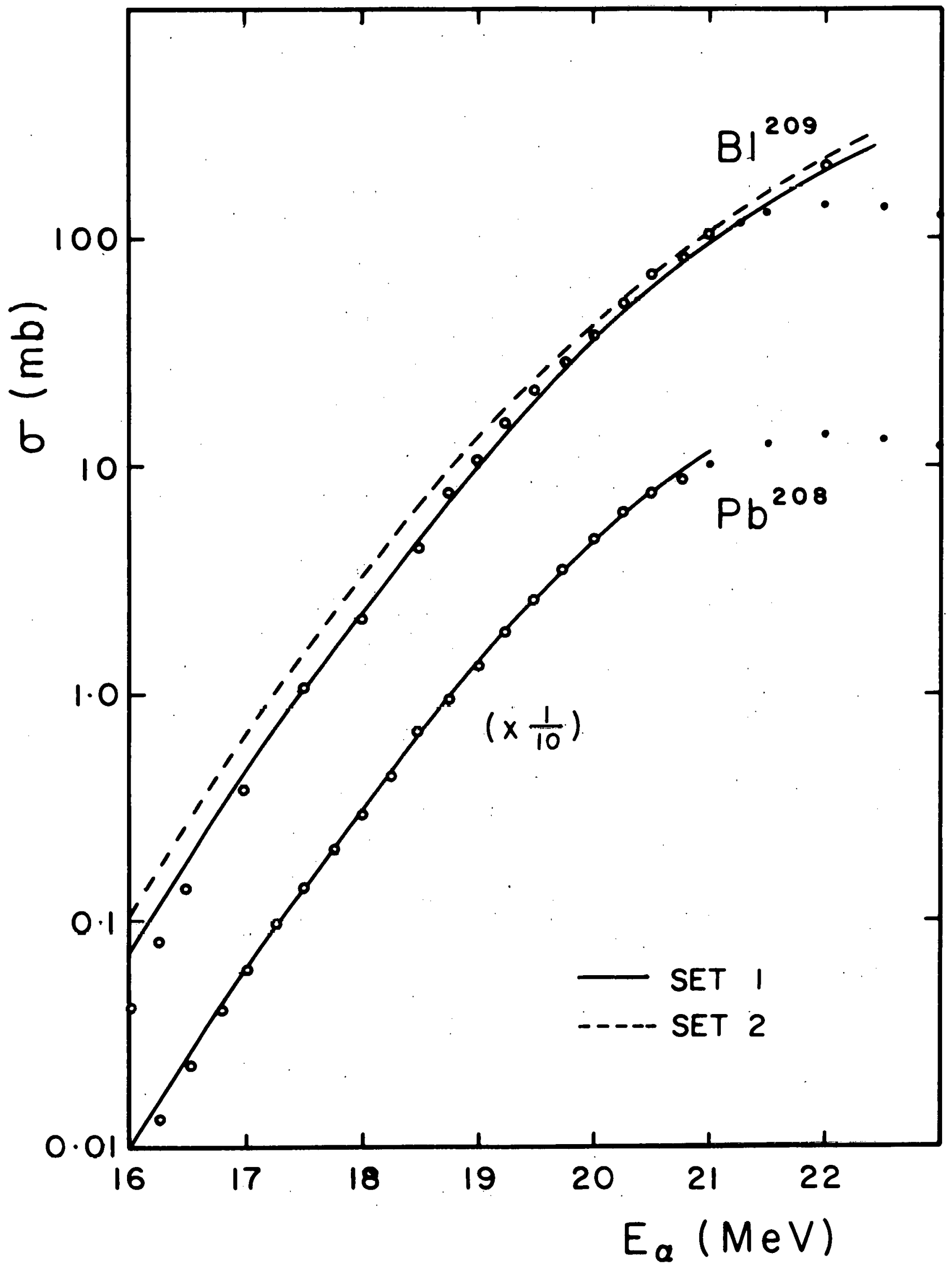

Fig. $31-5$ 
32. Half-1ives of $211 \mathrm{~g}, 211 \mathrm{~m}_{\mathrm{Po}}$ and $212 \mathrm{~g}, 212 \mathrm{~m}_{\mathrm{At}}$

A. R. Barnett and J. S. Lilley

The half-lives of the $\alpha$-emitting isomers ${ }^{212} \mathrm{~g}_{\text {Po }}(0.516 \mathrm{sec})$,

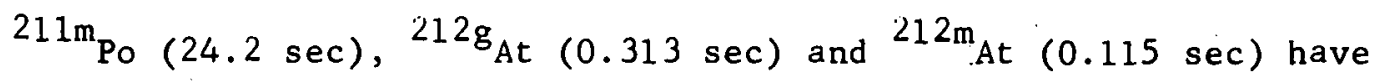
been determined from the analysis of numerous decay curves produced following the $(\alpha, n)$ reaction ${ }^{1}$ on ${ }^{208} \mathrm{~Pb}$ and ${ }^{209} \mathrm{Bi}$. The biassed $\alpha$-decay spectra, each of 128 energy channels and 32 time channels, were accumulated over many bombarding cycles (from 25-200 depending on the incident $\alpha$-energy) under the control of the activity routine ACT. ${ }^{2}$ After a bombardment time of several half-lives $(\sim 10)$ and a short waiting period of $100 \mathrm{msec}$ the decay curves were recorded in $200 \mathrm{msec}$ channels for the Po activity and $100 \mathrm{msec}$ for the At activity. For completeness, several runs were taken with a time scale of $2 \mathrm{sec} / \mathrm{channel}$ and a 64 sec bombardment to emphasize the $211 \mathrm{~m}$ Po decay; this, however, was not important for our $(\alpha, n)$ cross section measurements. ${ }^{1}$ A region of the energy spectrum (Fig. $32-1$ ) could be selected to contain either the ground state isomer or the metastable isomer free from other contaminants. The decay curves for each isomer (Fig. 32 -2) were extracted from the data and analyzed using the non-linear least squares routine EXPFIT.

The results of weighted fits to all our data are given in Table 32-1. Various checks were made during the experiment, e.g., varying the waiting period before accumulating the data and analyzing different portions of the decay curves, and the results are consistent with the errors quoted, which are statistical only. The time scale is derived from the $10 \mathrm{MH}_{z}$ crystal oscillator in the CDC 3100 computer and is common to all the results. Its accuracy, however, is higher than other uncertainties. 


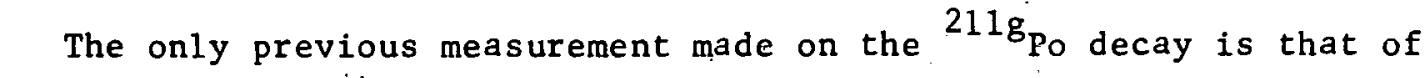
Spiess ${ }^{3}$ who obtained $0.52 \mathrm{sec}$ and also $25 \mathrm{sec}$ for the ${ }^{211 \mathrm{~m}_{\text {Po decay }}}$ (no error given). These values are consistent with ours, but that of Perlman et al. ${ }^{4}$ for ${ }^{211 \mathrm{~m}}$ Po $(25.5 \pm 0.3 \mathrm{sec})$ differs somewhat. For the At isomers the values of Jones ${ }^{5}$ are within $5 \%$ (again no errors are quoted) and while we agree with Reeder ${ }^{6}$ on the ${ }^{212 g}$ At value his measurement of the ${ }^{212 m}$ At decay is significantly higher than ours.

\section{References}

1A. R: Barnett and J. S. Lilley, 1970 Progress Report, Section 31 . ${ }^{2}$ A. R. Barnett, J. H. Broadhurst and R. Goodwin, 1969 Progress Report, pg. 119 .

${ }^{3}$ F. N. Spiess, Phys. Rev, 94, 1292 (1954).

${ }^{4}$ I. Perlman, F. Asaro, A. Ghiorso, A. Larsh and R. Latimer, Phys. Rev. 127, 917 (1962).

${ }^{5}$ W. B. Jones, Phys. Rev. 130, 2042 (1963).

${ }^{6}$ P. L. Reeder, Phys.: Rev. C, 1,721 (1970). 
Table $\quad 32-1$

Ha1f-1ives of $211 \mathrm{~g}, 211 \mathrm{~m}_{\mathrm{Po}}$ and $212 \mathrm{~g}, 212 \mathrm{~m}$ At

\begin{tabular}{lllll}
\hline Isomer & $211 \mathrm{~g}_{\mathrm{Po}}$ & $211 \mathrm{~m}_{\mathrm{Po}}$ & $212 \mathrm{~g}_{\mathrm{At}}$ & $212 \mathrm{~g}_{\mathrm{At}}$ \\
\hline
\end{tabular}

\section{Reference}

$\begin{array}{crr}\text { Present work } & 0.516 \pm 0.003 & 24.2 \pm 0.5 \\ \text { sec } & \text { sec } \\ \text { 3. } & 0.52^{\mathrm{b}} \cdot \mathrm{sec} & 25^{\mathrm{b}} \mathrm{sec} \\ 4 . & & 25.5 \pm 0.3 \\ \mathrm{sec}\end{array}$

5.

6.

a) Errors are statistical only.

b) No error quoted.
$0.305^{\mathrm{b}} \mathrm{sec}$
$0.122^{\mathrm{b}} \mathrm{sec}$
$0.315 \pm 0.003$
$0.122 \pm 0.001$
sec
sec 

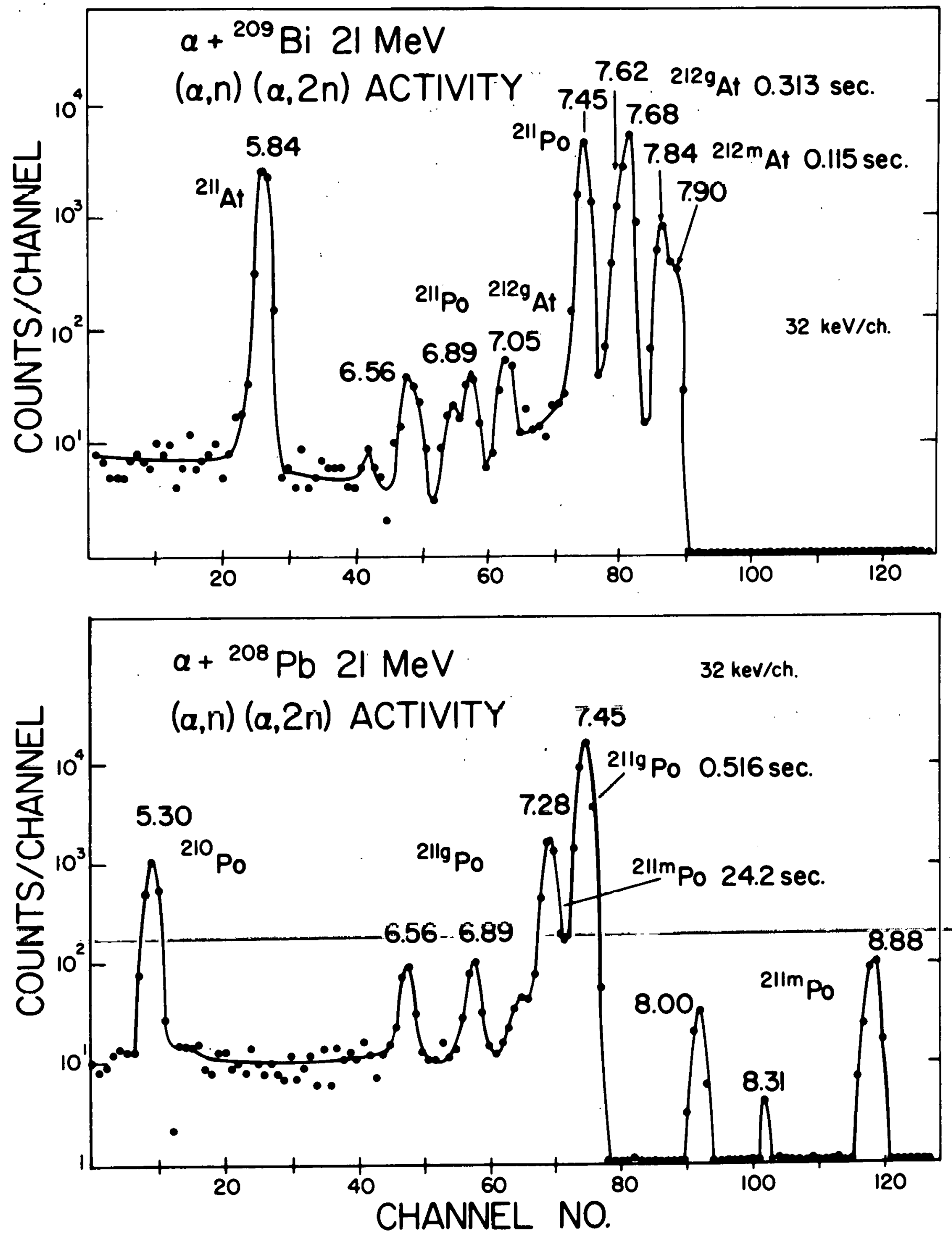

Fig. 32-1 

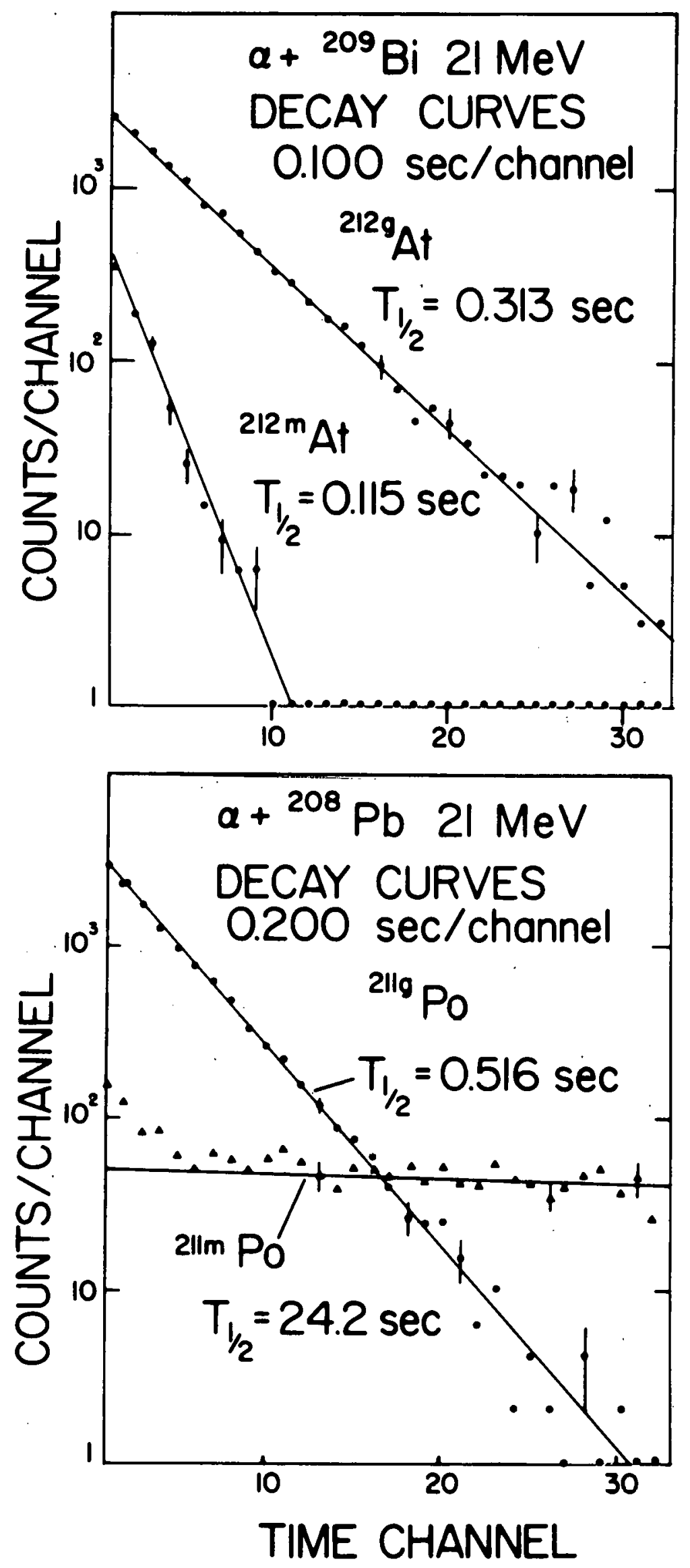

Fig. $32-2$ 
33. The Quadrupole Moment of the $3^{-}$State in ${ }^{208} \mathrm{~Pb}$ : A Summary

\section{A. R. Barnett}

Following the publication ${ }^{1}$ of the quadrupole moment measurement of the $2.614 \mathrm{MeV}^{-}$state in ${ }^{208} \mathrm{~Pb}$ a number of repeat runs with $\alpha^{\prime} \mathrm{s}$ at $18 \mathrm{MeV}$ and ${ }^{16} \mathrm{O}$ at $69.1 \mathrm{MeV}$ as well as an ${ }^{16} \mathrm{O}$ run at $66 \mathrm{MeV}$ have been carried out. These data, and those of the original measurement, are summarized in Table 33-1.

Particular attention has been paid to the quality of the $\alpha$ data and significant improvements have been achieved. Fig. $33-1$ shows a direct comparison of the earlier and later data: peak to background ratios of $10^{5}: 1$ are now being achieved and the tail extending $1 \mathrm{MeV}$ below the $\alpha$ peak has been demonstrated to be an electronic pulse shape pile-up effect. The current data were taken with Canberra 1416 pole zero compensated amplifiers and ORTEC 109A preamplifiers: the previous data were obtained with ORTEC 410 double RC clipped amplifiers and Williams Laboratory FET preamplifiers. A further improvement in the data resulted from the careful choice and preparation of the detector collimators. Another important point was the use of updating dead time discriminators 2 to prevent pulse pile up, especially in the forward angle detectors. Fig. 33-2 shows how difficult the presence of small impurities makes the forward angle measurements and hence we are investigating ${ }^{3}$ the preparation of $C$ backings using either LiF or an organic compound as a release agent.

The new data seem quite consistent with the earlier measurements and are being analyzed. 
${ }^{1}$ A. R. Barnett and W. R. Phillips, Phys. Rev. 186, 1205 (1969).

2 J. H. Broadhurst, Private Communication.

${ }^{3}$ G. Ott and H. Ohnuma, Private Communication.

Table 33-1

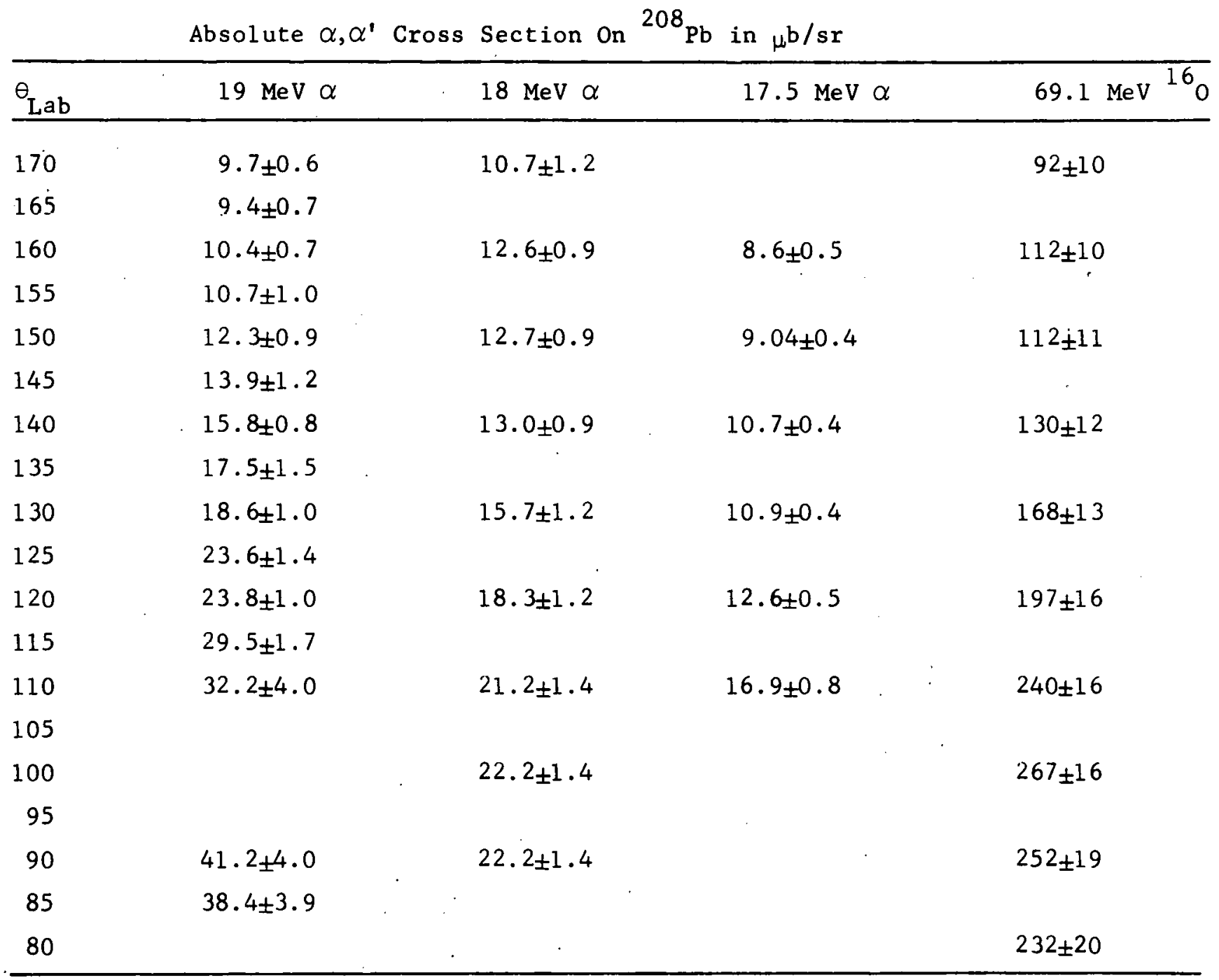




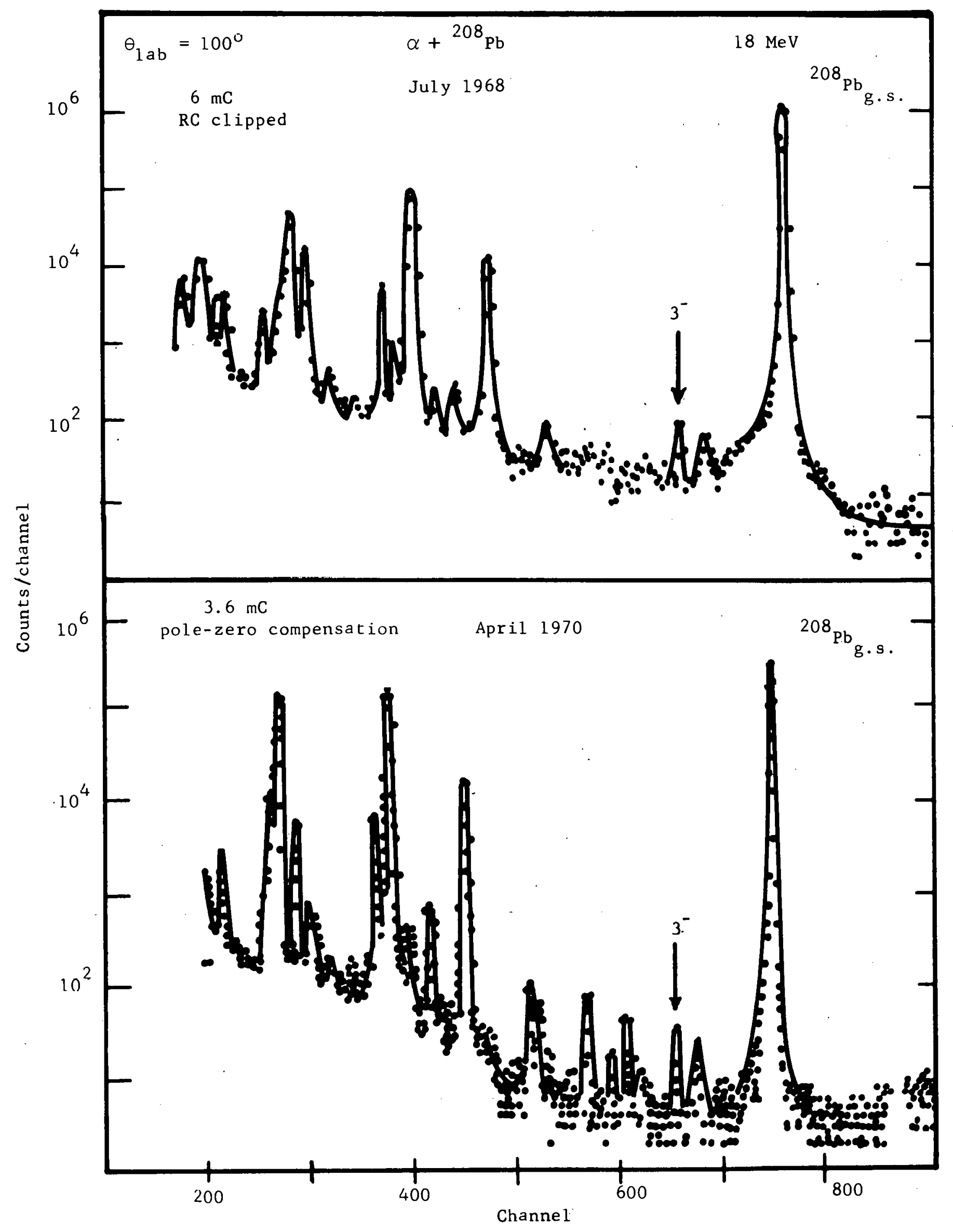

Fig. 33-1 


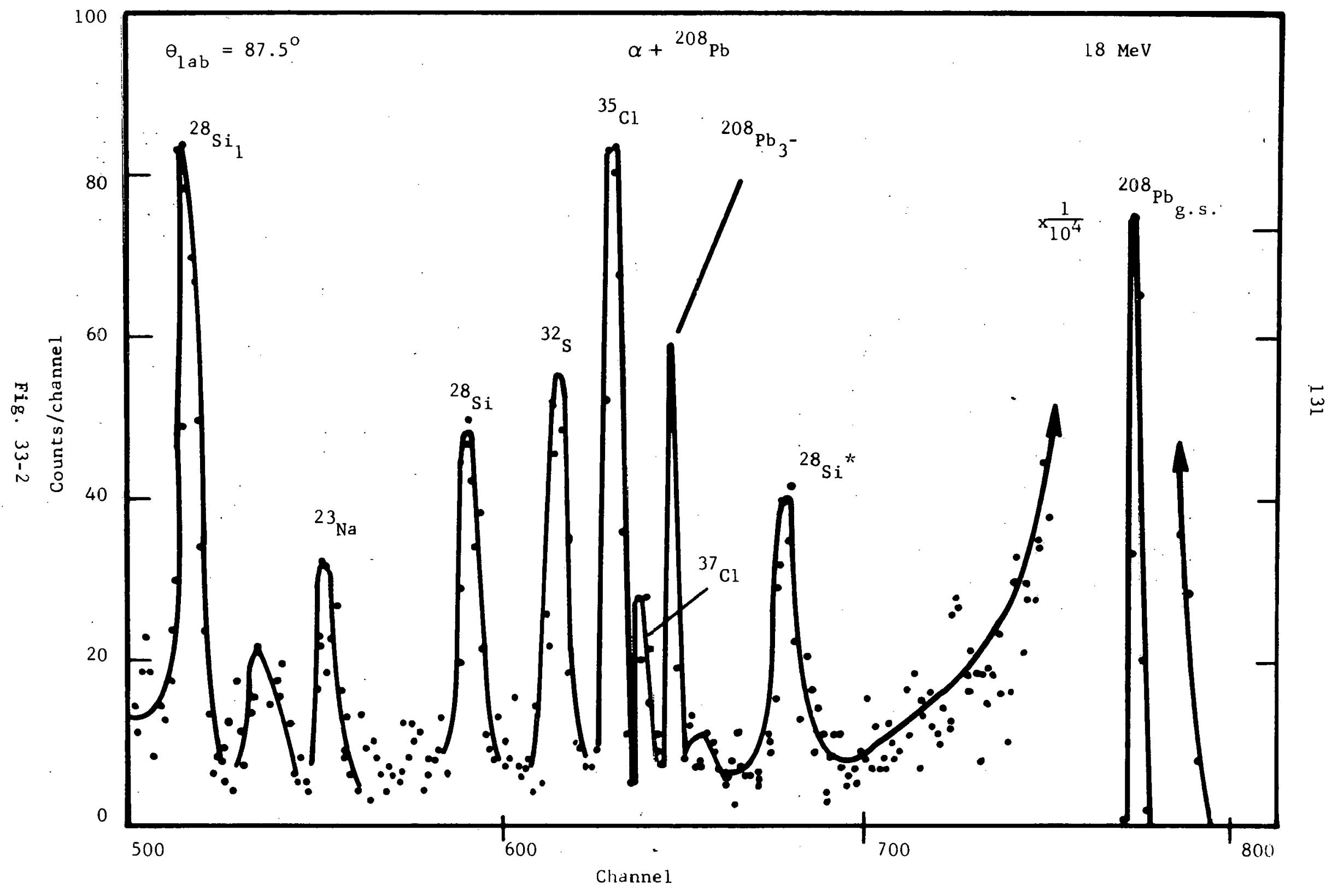




\section{ANALOG STATES AND COULOMB DISPLACEMENT ENERGIES}

34. The $\left({ }^{3} \mathrm{He}, t\right)$ Reaction to Analog States

W. Makofske, G. W. Greenlees, and H. Ohnuma

The magnetic spectrometer and position sensitive detectors áte being used for measurements on $\left({ }^{3} \mathrm{He}, t\right)$ angular distributions at $24.6 \mathrm{MeV}$ for the $0^{+} \rightarrow 0^{+}$IAS (isobaric analog state) and $0^{+} \rightarrow 2^{+}$IAS (excited isobaric analog state) transitions for ${ }^{46} \mathrm{Ti}\left({ }^{3} \mathrm{He}, t\right){ }^{46} \mathrm{~V}$ and ${ }^{48} \mathrm{Ti}\left({ }^{3} \mathrm{He}, \mathrm{t}\right){ }^{48} \mathrm{~V}$.

The data are being analyzed together with previously taken angular distributions for the ${ }^{58} \mathrm{Ni}\left({ }^{3} \mathrm{He}, \mathrm{t}\right){ }^{58} \mathrm{Cu}$ and ${ }^{60} \mathrm{Ni}\left({ }^{3} \mathrm{He}, \mathrm{t}\right){ }^{60} \mathrm{Cu}$ $0^{+} \rightarrow 0^{+}$IAS and $0^{+} \rightarrow 2^{+}$IAS $^{*}$ transitions ${ }^{1}$.

\section{Reference}

$1_{\text {F. D. Becchetti and G. W. Greenlees, Williams Laboratory of Nuclear }}$ Physics Annual Report, 1969, p. 59.

35. Coulomb Displacement Energies Using the ( 3 He,t) Reaction

F. D. Becchetti, D. Dehnhard, and T. G. Vzubay ${ }^{* *}$

of the Coulomb displacement energies $\Delta E_{C}$, which we measured using the $\left({ }^{3} \mathrm{He}, \mathrm{t}\right)$ reaction on thirty-three isotopes between ${ }^{42} \mathrm{Ca}$ and ${ }^{68} \mathrm{Zn}, 1$ we have analyzed those for most $\mathrm{f}_{7 / 2}$ shell in terms of the model of Hecht ${ }^{2}$ and Jänecke ${ }^{3}$. The experimental $\Delta E_{C}$ values (open circles) together with the calculated ones (crosses) are shown in Fig. $35-1$. The solid lines connect the experimental points.

The $\triangle E_{C}$ for isobaric pairs which have a stable $Z_{<}$member (i.e.; suitable for an investigation via the $\left({ }^{3} \mathrm{He}, t\right)$ reaction) are from the previously reported work ${ }^{1}$. All others were taken from numerous references, most of which were 1 isted in Ref. 4 . 


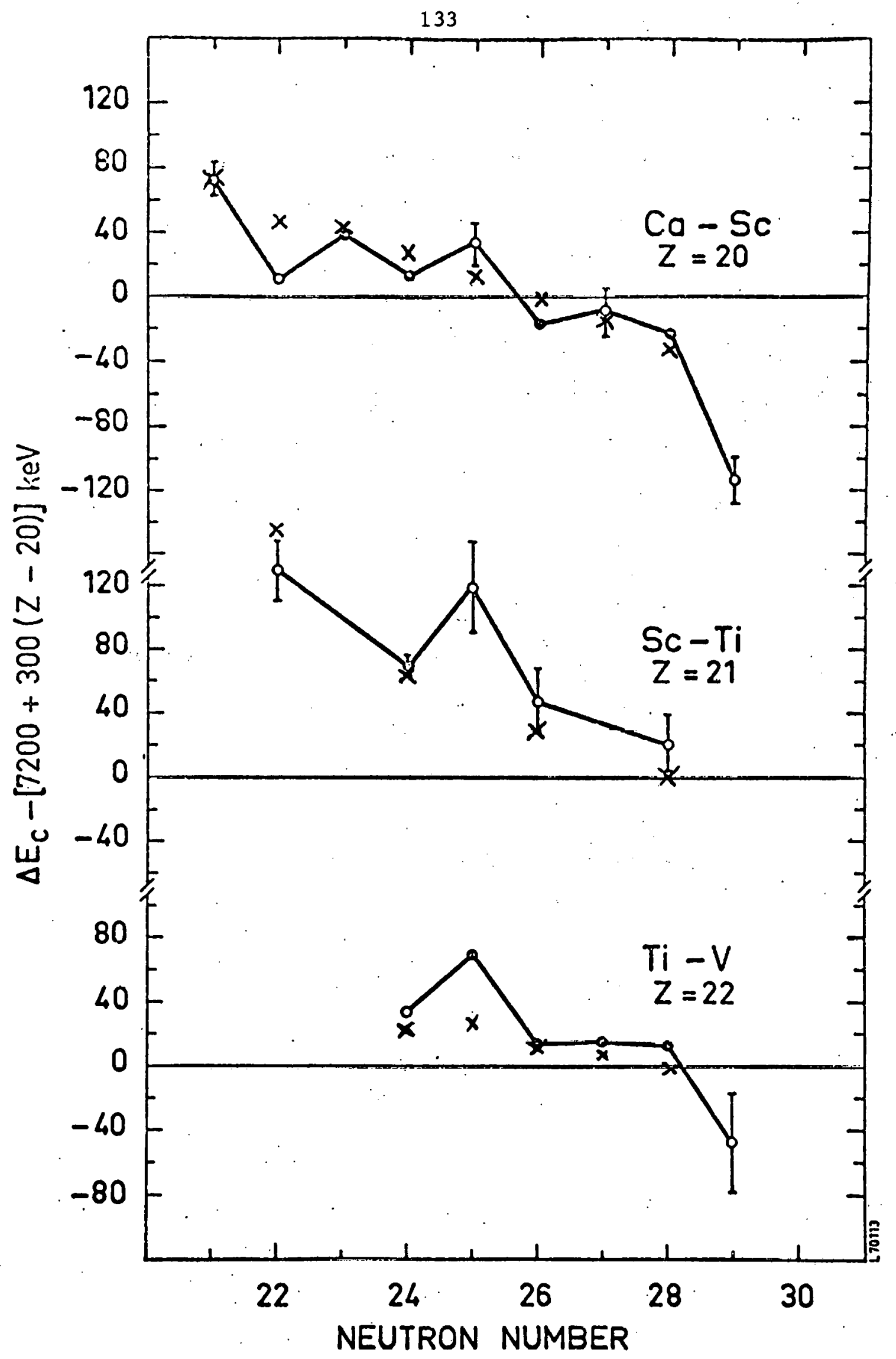

Fig. 35-1 


\section{$\underline{\text { References }}$}

${ }^{1}$ F. D. Becchetti, D. Dehnhard, and T. G. Dzubay, J. H. Williams Lab. Annual Report, 1969, p. 103, and preprint, to be submitted for publication in Nucl. Phys.

${ }^{2}$ K. T. Hecht, Nucl. Phys. Al02, 11 (1967), and Nucl. Phys. A114, 280 (1968).

$3_{\mathrm{J}}$. Jänecke, Nucl. Phys. Al14, 433 (1968).

${ }^{4} \mathrm{~J}$. A. Nolen and J. P. Schiffer, Ann. Rev. of Nucl. Science 19,471 (1969).

*Present address: The Niels Bohr Institute, University of Copenhagen, Denmark.

*** The Palmer Physical Laboratory, Princeton University, Princeton, New Jersey. Present address: Triangle Universities, Nuclear Laboratory and Department of Physics, Duke University, Durham, North Carolina. 
36. The ${ }^{137} \mathrm{Ba}\left({ }^{3} \mathrm{He}, \mathrm{d}\right){ }^{138} \mathrm{La}$ Reaction at $30 \mathrm{MeV}$

R. L. Shoup ${ }^{*}$, L. Parish ${ }^{*}$, G. Vourvopoulos ${ }^{*}$, and D. Dehnhard

We have studied the ${ }^{137} \mathrm{Ba}\left({ }^{3} \mathrm{He}, \mathrm{d}\right){ }^{138} \mathrm{La}$ reaction at $30 \mathrm{MeV}$ using the magnetic spectrometer together with nuclear emulsion plates. Spectra were taken at 11 angles from $7.5^{\circ}$ to $32^{\circ}$. The nuclear emulsion have. been scanned so far for a range of excitation energies between the g.s. and $10 \mathrm{MeV}$. Absolute cross sections were determined by comparison of the yield from elastic scattering with an optical model prediction.

The purpose of this experiment is to study the spreading of the "T $\mathrm{T}_{<}$strength" among the many $\mathrm{T}_{<}$states in a nucleus having four excess neutron shells. (see Ref.'1).

\section{References}

*Florida State University, Tallahassee, Florida.

${ }^{1}$ G. Vourvopoulos and J. D. Fox, Phys. Rev. 177, 1558 (1969). 
VII. OPTICAL MODEL OF THE NUCLEUS

G. W. Greenlees, C. H. Poppe, J. A. Sievers and D. L. Watson

An analysis of the differential cross section and polarization data ${ }^{1}$ (obtained on the Tandem and Linac respectively) at $9.8 \mathrm{MeV}$ has now been completed. Reaction cross section values were taken from published work, so that relatively complete and accurate data were available for seven elements from ${ }^{58} \mathrm{Ni}$ to ${ }^{120} \mathrm{Sn}$.

The optical model in its standard form was used to analyze individual sets of data and also for a simultaneous analysis of all the data sets using a global code. ${ }^{2}$ In the analysis of individual sets of data, wide variations in the parameters were found from element to element, using a 9-parameter model. The constraints imposed by the global procedure, of course, removed such variations but indicated a wide range of acceptable parametẹ values. For example, the rẹal radius parameter could be fixed anywhere in the range $1.07-1.34 \mathrm{~F}$ and still yield fits with $x^{2}$ values less than 1.5 times the minimum. Particularly surprising was the ill-defined nature of the spin-orbit parameters despite the availability of accurate polarization measurements. The data were also analyzed using the folding procedures of Greenlees et al. ${ }^{3}$

The general conclusion from this work is that the optical model is an inadequate description of proton elastic scattering around $10 \mathrm{MeV}$ and that any systematics derived from analyses of such data are more characteristic of the constraints imposed on the model parameters than of the properties of the nuclei involved. 


\section{$\underline{\text { References }}$}

${ }^{1} 1969$ Progress Report, p. 107.

2F. D. Becchetti and G. W. Greenlees, Phys. Rev. 182, 1190 (1969).

${ }^{3}$ G. W. Greenlees, G. J. Pyle and Y. C. Tang, Phys. Rev. 1.71, 1115 (1968).

${ }^{4}$ G. W: Greenlees, W. Makofske and G. J. Pyle, Phys. Rev. 1C, 1145 (1970).

38.

The Elastic Scattering of $16 \mathrm{MeV}$ Protons

W. Makofske and G. W. Greenlees

Measurements of the differential cross section for the elastic scattering of $16-\mathrm{MeV}$ protons from ${ }^{58} \mathrm{Ni},{ }^{60} \mathrm{Ni},{ }^{62} \mathrm{Ni},{ }^{64} \mathrm{Ni},{ }^{90} \mathrm{Zr},{ }^{120} \mathrm{Sn}$. and ${ }^{208} \mathrm{~Pb}$ have been completed. The modified ortec chamber system ${ }^{1}$ allowed data collection between $15^{\circ}$ and $160^{\circ}$ with a relative accuracy of better than 2.5\% for $\theta<40^{\circ}$ and $1 \%$ for $\theta \geq 40^{\circ}$. The absolute normalizations were determined to an accuracy of $2-4 \%$ assuming the cross sections measured at $4 \mathrm{MeV}$ obeyed a Rutherford law.

The data are currently being analyzed using the standard optical model, the folding model of Greenlees, Pyle and Tang ${ }^{2,3}$, and the global fitting procedure of Becchetti and Greenlees. 4

\section{References}

${ }^{1}$ John H. Williams Laboratory of Nuclear Physics, Annual Progress Report, 1969, p. 107.

${ }^{2}$ G. W. Greenlees, G. J. Pyle and Y. C. Tang, Phys. Rev. 171, 1115 (1968). ${ }^{3}$ G. W. Greenlees, W. Makofske and G. J. Pyle, Phys. Rev. C, Vol. 1, 1145 (1970)

${ }^{4}$ F. D. Becchetti, Jr., and G. W. Greenlees, Phys. Rev. 182, 1190. (1969). 
39.

Elastic and Inelastic Scattering of $18.6 \mathrm{MeV}$ Protons by ${ }^{68} \mathrm{Zn},{ }^{90} \mathrm{Zr}$, and $114 \mathrm{Cd}$

D. Tweeton and C. Poppe

Angular distributions of the differential cross sections for elastic and inelastic scattering of $18.6 \mathrm{MeV}$ protons by ${ }^{68} \mathrm{Zn},{ }^{90} \mathrm{Zr}$, and ${ }^{114} \mathrm{Cd}$ have been obtained. The inelastic scattering data are for the collective one-phonon quadrupole $\left(2^{+}\right)$and octupole $\left(3^{-}\right)$vibrations. The cross sections were measured in $5^{\circ}$ intervals from $20^{\circ}$ to $160^{\circ}$. The elastic scattering data are of $1 \%$ relative accuracy and $2 \%$ absolute-accuracy, and the inelastic scattering data is of 3 to $5 \%$ accuracy.

The elastic scattering data are being fit with the optical model. The optical model parameters obtained are being used in the coupled channels computer program JUPITOR-2B, written by $T$. Tamura, to try to fit the elastic and inelastic data simultaneously. 1,2

After the polarized source is operating, the corresponding scattering asymmetries will be measured and an attempt will be made to fit the polarization and cross section data simultaneously.

\section{$\underline{\text { References }}$}

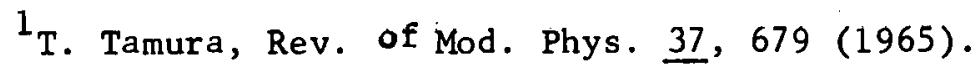

${ }^{2}$ N. Lingappa, Ph.D. Thesis, University of Minnesota, June 1969, unpublished. 
139

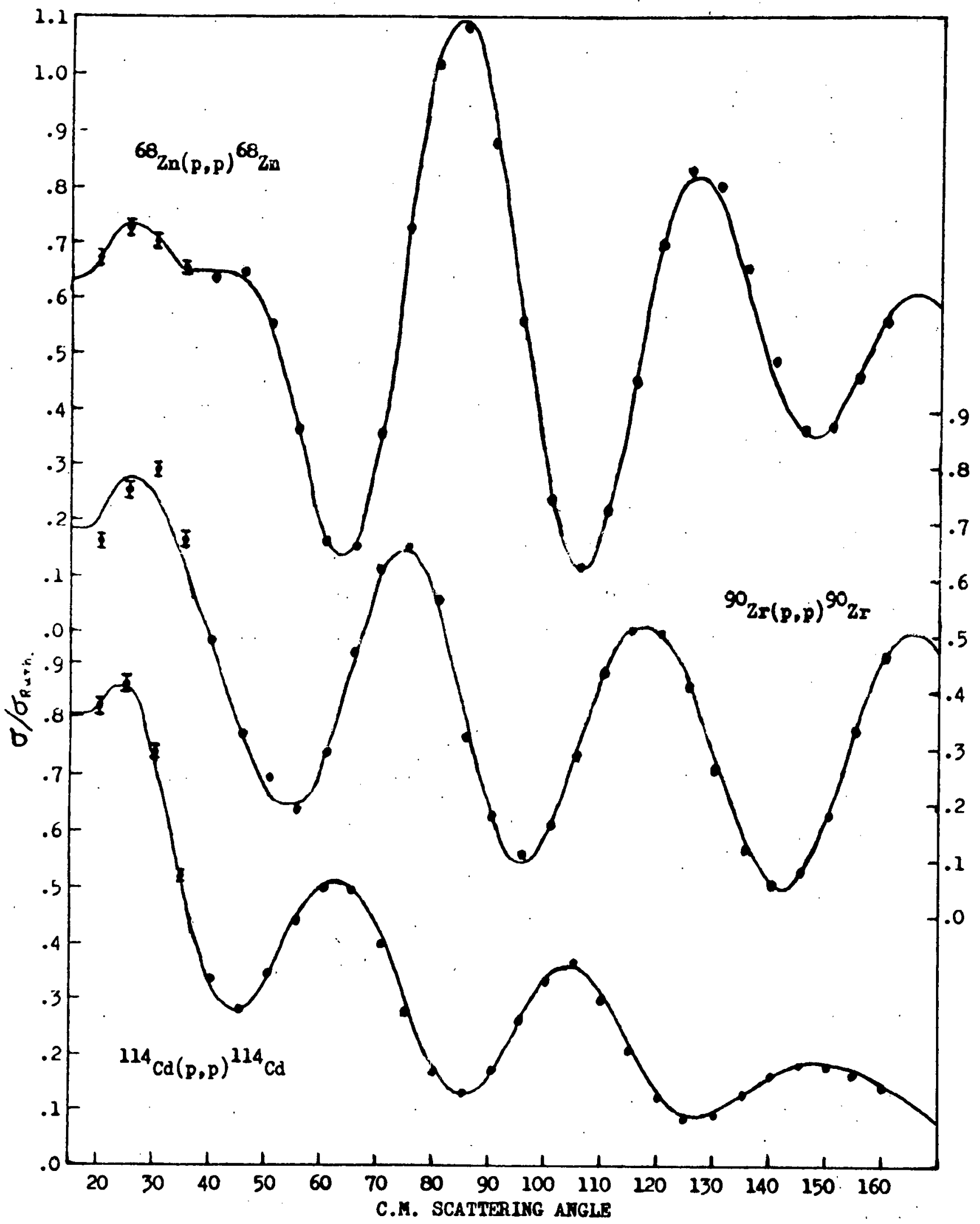

Proton elastic scattering at $18.6 \mathrm{MeV}$. The curves are optical model fits.

Fig. 39-1 
40 Elastic Scattering of ${ }^{3} \mathrm{He}$ From ${ }^{58} \mathrm{Ni}$ and ${ }^{48} \mathrm{Ti}$

\section{D. Leavitt and J. S. Lilley}

Angular distributions have been completed for $29.5 \mathrm{MeV}{ }^{58} \mathrm{Ni}\left({ }^{3} \mathrm{He},{ }^{3} \mathrm{He}\right){ }^{58} \mathrm{Ni}$ and for 27.0 and $29.5 \mathrm{MeV}{ }^{48} \mathrm{Ti}\left({ }^{3} \mathrm{He},{ }^{3} \mathrm{He}\right)^{48} \mathrm{Ti}$. These distributions cover the angular range from 10 to 170 degrees. The angular distribution from 22.5 to 170 degrees was taken in an Ortec scattering chamber using three E- $\triangle E$ detector telescopes. The pulses from each detector telescope pair were analyzed using the particle identification routine THRESHA, on a CDC 3100 on-1ine computer. Since the energy spectra of pickup and stripping reactions such as $\left({ }^{3} \mathrm{He},{ }^{4} \mathrm{He}\right),\left({ }^{3} \mathrm{He}, \mathrm{t}\right),\left({ }^{3} \mathrm{He}, \mathrm{d}\right),\left({ }^{3} \mathrm{He}, \mathrm{p}\right)$ interfere with the $\left({ }^{3} \mathrm{He},{ }^{3} \mathrm{He}\right)$ spectrum, care was taken to insure that the ${ }^{3} \mathrm{He}$ particle spectrum was well resolved from all others at all angles. This is particularly important at larger angles where the $\left({ }^{3} \mathrm{He},{ }^{4} \mathrm{He}\right)$ cross section is of the same magnitude as the elastic cross section. Both targets were approximately one milligram/ $\mathrm{cm}^{2}$ thick and, in each case, the elastic peak was well resolved from the first excited state at all angles. Background due to carbon, oxygen, and tantalum contaminants interfer ed with the titanium elastic peak for scattering angles smaller than 35 degrees.

Good data at forward angles were obtained by using nickel and titanium targets of thickness less than $100 \mathrm{micrograms} / \mathrm{cm}^{2}$, and analyzing the scattered particles with the split-pole magnetic spectrometer. The higher resolution of the spectrometer enabled us to resolve the $\mathrm{Ti}$ peak from the $\mathrm{Ta}, \mathrm{O}$, and $\mathrm{C}$ contaminants. Angular distributions were taken from 10 to 30 degrees for nickel and from 10 to 60 degrees for titanium. The region of overlap points allowed a normalization of the data taken in the ortec to that taken in the spectrometer. The 
forward angle spectrometer data gave a check to the target thickness, which had previously been determined from $5 \mathrm{MeV}$ Rutherford scattering.

Two monitor detectors were mounted, one on each side of the beam, in both chambers. The ratio of the monitor counts on one side of the beam to the counts on the other side allowed us to check for movement of the beam spot, while the ratio of the sum of monitor counts to beam current integrator counts gave a check of target deterioration during the run. A pulser was triggered every time a count was received from one of the monitor detectors. These pulses were counted by a scaler and were also fed into the ADC's. The ratio of monitor counts recorded by the $\mathrm{ADC}$ to monitor counts recorded by the scaler gave a measure of the dead time. Zero degree checks were made by measuring scattering cross sections on both sides of the beam at forward angles.

For all three data sets, the error is generally $2 \%$ for $\theta<90^{\circ}$; $5 \%$ for $\theta>90^{\circ}$, with a few points in the minima beyond 150 degrees having errors of approximately $10 \%$.

Good fits to the data are achieved using a regular optical model; the inclusion of a spin-orbit potential generally improved the fit. Only the ${ }^{58} \mathrm{Ni}$ data have been thoroughly analyzed. To determine the shape of the potential in the interaction region, a grid on the real and imaginary diffuseness was performed. An important feature of the results is that all fits to the data give the same value of the real potential at the strong absorption radius, and that, at this point, the imaginary potential has approximately the same strength as the real potential.

A comparison with the analysis of alpha elastic scattering on ${ }^{58} \mathrm{Ni}$ shows some interesting features. ${ }^{1}$ The real diffuseness for ${ }^{3} \mathrm{He}$ 
scattering is larger than that for alpha scattering. At the strong interaction radius the value of the real potential for àlpha scattering is larger than that for ${ }^{3} \mathrm{He}$ scattering, while just the opposite is true for the imaginary potential. This suggests the importance of absorption processes in an understanding of ${ }^{3}$ He elastic scattering.

\section{Reference}

${ }^{1}$ Weisser, Lilley, Hobbie: 1968 Progress Report, Williams Laboratory of Nuclear Physics, p. 69.

41. The Elastic Scattering of Alpha Particles P. Mailandt, R. Snyder, J. S. Lilley and G. W. Greenlees

A program has been initiated to study the elastic scattering of alpha particles in the energy range $20-30 \mathrm{MeV}$. Accurate differential cross section data are being obtained over a wide angular range for a number of nuclei. It is hoped that an analysis of such data will yield a better understanding of the reaction mechanism along with information concerning the density of nucleons in the nuclear surface.

The measurements are made using the eight-foot scattering chamber. ${ }^{1}$ The ion pump system on this chamber has been replaced by an oil diffusion pump/1iquid nitrogen trap arrangement to improve the pumping and the electrical feedthroughs have been isolated from the chamber (machine) ground to reduce electronic noise. A further modification incorporates two position-sensitive detectors mounted in the circular body of the chamber on a base plate which can be rotated in vacuum.

Measurements are possible over an angular range from $12^{\circ}$ to $175^{\circ}$ (Lab.). An array of four solid state detectors, mounted on a cart ${ }^{2}$ in the snout of the chamber, can be used to cover the angular region up to 
$165^{\circ}$ using conventional recording techniques. The position-sensitive detectors extend the angular range to $175^{\circ}$ and are particularly useful in regions where the cross sections are small.

The position-sensitive detectors are $30 \mathrm{~mm} \times 10 \mathrm{~mm}$ in area $(600 \mu$ thick) and are mounted at a radius of 6" from the target; they each cover an angular range of $10.1^{\circ}$ The $E$ and $X E$ signals are processed with a modified version of the program DIVIDE ${ }^{3}$ which includes correction for the kinematic spread across the detectors. The digital arithmetic involved tends to produce appreciable scatter for small $\mathrm{X}$ values so

the first $0.6^{\circ}$ of the detector are not used and a $9.5^{\circ}$ aperture covers each detector face. For analysis, the recorded counts are divided into bins of equal angle. The relatively large differential non-linearity in the XE signal causes the solid angles of the bins to vary appreciably. Calibration of each detector is therefore necessary using known Rutherford scattering. The technique appears to work well and ensures an economic use of time in regions where the counting rates are low. It is anticipated that this method will be used extensively in the present experiments at angles beyond about $100^{\circ}$.

A preliminary angular distribution from ${ }^{58} \mathrm{Ni}$ is shown in Fig. 41-1. A backward peak is seen in the distribution. This has been observed for several, but not all, of the nuclei investigated. Such peaks have been reported by the Cracow group ${ }^{4}$ and are sometimes called the 'glory' effect. 
144

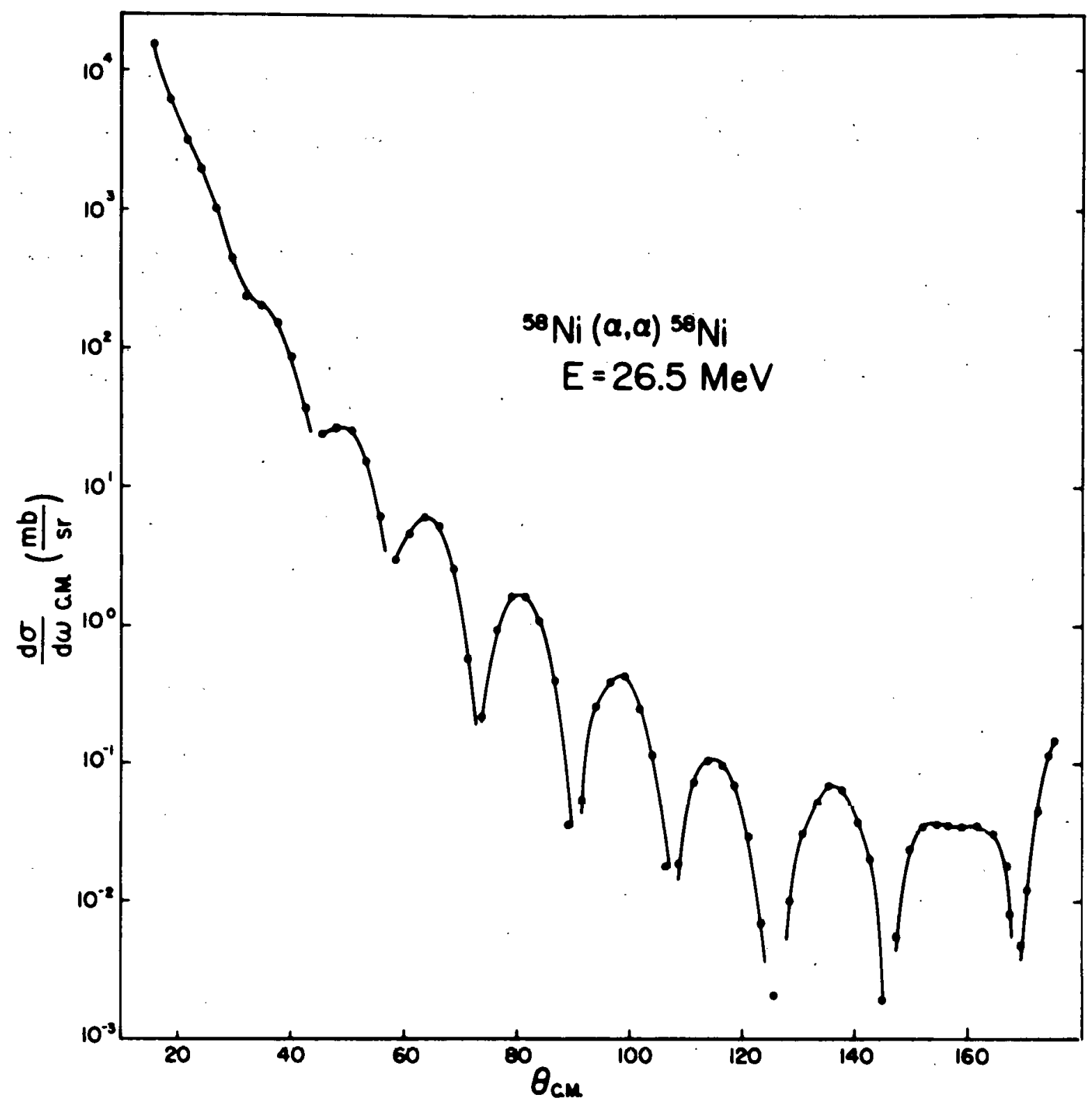

Fig. $41-1$ 


\section{$\underline{\text { References }}$}

${ }^{1}$. H. Hendricks, et $\underline{\text { a1. }} 1968$ Progress Report, p. 154.

2P. Mailandt and R. K. Hobbie, 1968 Progress Report, P. 175.

3. H. Debenham et a1., 1968 Progress Report, p. 170.

${ }^{4}$ Budzanewski, et $\underline{a 1}$., Physics Letters $\underline{16}, 135$ (1965).

42 .

An Analysis of $30.3 \mathrm{MeV}$ Elastic Scattering Data from ${ }^{40} \mathrm{Ca}$ and ${ }^{59} \mathrm{Co}$

W. Makofske and G. W. Greenlees

An optical model analysis has been performed on recently-taken polarized-proton data for ${ }^{40} \mathrm{Ca}$ and ${ }^{59} \mathrm{Co}{ }^{1}$ and previously reported differential cross section data ${ }^{2}$, both at $30.3 \mathrm{MeV}$. This analysis is similar to one performed for ${ }^{58} \mathrm{Ni},{ }^{120} \mathrm{Sn}$ and ${ }^{208} \mathrm{~Pb}{ }^{3}$ in which the standard ten-parameter version and the eight-parameter folding version of Greenlees et al. ${ }^{4,5}$ were used. Fits to the cross section and polarization data are shown in Figs. 42-1 and 42-2 respectively. Table 42-1 shows the contributions to the $\chi^{2}$ values for all five nuclei and indicates that the trend for larger $\chi^{2}$ values for smaller nuclei with data of comparable quality, which was reported in Ref. 3, is continued. For the standard version, the additional freedom associated with the spin-orbit term produces a peaking of the spin-orbit potential of about $0.5 F$ inside the half-density point for ${ }^{40} \mathrm{Ca}$ and ${ }^{59} \mathrm{Co}$. These results, including the detailed parameter variations, substantiate to a remarkable degree the observations made in Ref. 3 for smaller nuclei and give more credence to the suggestion that second-order corrections ignored in optical models cannot be neglected for medium-weight nuclei. 


\section{References}

${ }^{1}$ V. Hnizdo et a1., Rutherford Laboratory Report, RHEL/R185 (1969), pg. 40.

2 B. W. Ridley and J. F. Turner, Nucl. Phys. 58, 497 (1964).

${ }^{3}$ This Progress Report, section 43, G. W. Greenlees, V. Hnizdo, 0. Karban,

J. Lowe and W. Makofske (to be published in Physical Review).

${ }^{4}$ G. W. Greenlees, G. J. Pyle and Y. C. Tang, Phys. Rev. 171, 1115 (1968).

${ }^{5}$ G. W. Greenlees, W. Makofske and G. J. Pyle, Phys. Rev. C, Vol. 1, 1145 $(1970)$

Table 42-1: $x^{2}$ Contributions Using The Standard Ten-Parameter Optical Model and the Eight-Parameter Folding Model. The results for ${ }^{58} \mathrm{Ni},{ }^{120} \mathrm{Sn}$ and ${ }^{208} \mathrm{~Pb}$ are taken from Ref. 3.

\begin{tabular}{|c|c|c|c|c|c|c|}
\hline & & ${ }^{40} \mathrm{Ca}$ & ${ }^{58} \mathrm{Ni}$ & ${ }^{59} \mathrm{Co}$ & ${ }^{120} \mathrm{Sn}$ & ${ }^{208} \mathrm{~Pb}$ \\
\hline \multirow[b]{2}{*}{ STANDARD } & $\left(x^{2} \sigma\right.$ & 67.9 & 15.5 & 22.3 & 8.1 & 3.8 \\
\hline & $\left(x^{2} P\right.$ & 175.5 & 33.1 & 53.9 & 13.5 & 11.4 \\
\hline MODEL & $\left(x^{2} \mathrm{~T}\right.$ & 116.6 & 24.7 & 37.4 & .10 .7 & 7.8 \\
\hline & $\left(x^{2} u\right.$ & 68.9 & 24.0 & 64.4 & $11: 7$ & 3.8 \\
\hline FOLDING & $\left(x^{2} p\right.$ & 705.0 & 175.0 & 232.0 & 40.8 & 17.2 \\
\hline MODEL & $\left(x^{2} T\right.$ & 356.0 & 103.5 & 144.0 & 25.5 & 10.9 \\
\hline
\end{tabular}




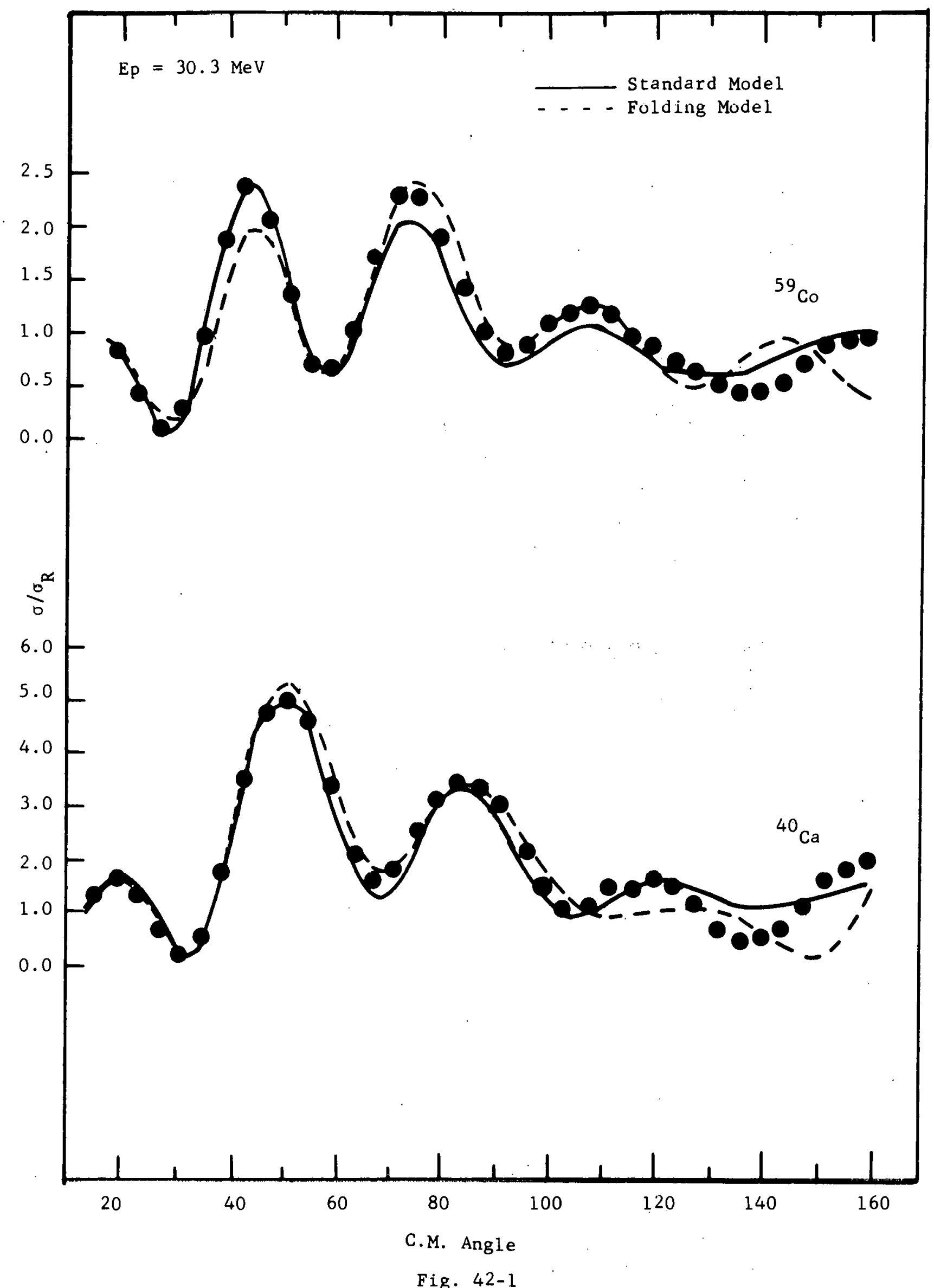




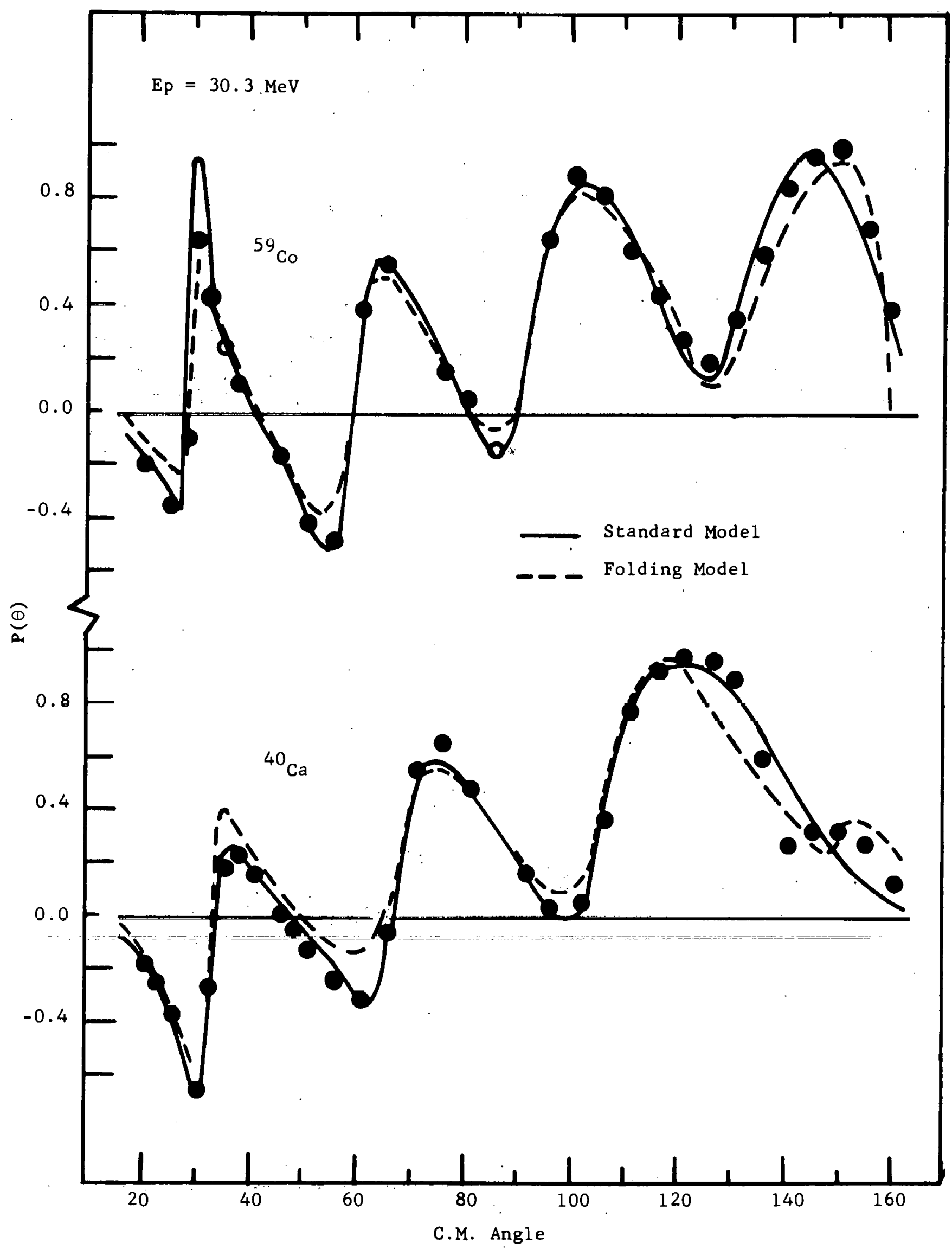

Fig. 42-2 
43.

An Analysis of $30.3 \mathrm{MeV}$ Elastic Scattering from ${ }^{58}{ }_{\mathrm{Ni}},{ }^{120} \mathrm{Sn}$ and ${ }^{208} \mathrm{~Pb}^{*}$

G. W. Greenlees and W. Makofske

An optical model analysis has been made of relatively accurate differential cross section and polarization data for the elastic scattering of $30.3 \mathrm{MeV}$ protons from ${ }^{58} \mathrm{Ni},{ }^{120} \mathrm{Sn}$ and ${ }^{208} \mathrm{~Pb}$. The angular region from $10^{\circ}$ to $165^{\circ}$ was covered with an absolute accuracy in the polarization measurements of about $0.01 .^{1}$ The cross section data were measured previously. 2

Two forms of the model have been used, the standard ten-parameter form with independent geometries and the eight-parameter folding version of Greenlees, Pyle and Tang ${ }^{3,4}$ with the inclusion of singlet and triplet two-body forces. In the case of ${ }^{208} \mathrm{~Pb}$ a good representation of the data is obtained and the fits with the two procedures are visually equivalent. Both versions of the model are less satisfactory for ${ }^{120} \mathrm{Sn}$ and ${ }^{58} \mathrm{Ni}$. In these latter cases, the standard model achieves a better representation than the folding model. This feature is associated with the additional freedom in the spin-orbit radius parameter allowed in the standard version which in the case of. Sn and $\mathrm{Ni}$ produces a peaking of the spin-orbit. potential about $0.5 F$ inside the half-density point for these nuclei. Evidence is presented to support the suggestion that such models are most satisfactory for large nuclei $\left({ }^{208} \mathrm{~Pb}\right)$ and that for smaller nuclei $\left({ }^{120} \mathrm{Sn}\right.$ and ${ }^{58} \mathrm{Ni}$ ), second-order corrections ignored in the model are playing a nonnegligible role.

* Work done in collaboration with V. Hnizdo, 0: Karban and J. Lowe, University of Birmingham, England. 


\section{References}

${ }^{1}$ G. W. Greenlees, J. Lowe, O. Karban and V. Hnizdo, Rutherfurd Laboratory Report RHEL/R170 (1968).

2 B. W. Ridley and J. F. Turner, Nucl. Phys. 58, 497 (1964).

${ }^{3}$ G. W. Greenlees, G. J. Pyle and Y. C. Tang, Phys. Rev. 171; 1115 (1968).

${ }^{4}$ G. W. Greenlees, W. Makofske and G. J. Pyle, Phys. Rev. C, Vol. 1, 1145 (1970)

44. Investigation of $\ell$-dependent Effects in the Optical Mode1

G. W. Greenlees, W. Makofske, and Y. C. Tang

Modifications of the computer code RAROMP have been made which allow the introduction of $\ell$-dependent terms into the optical model potential. This work has been concerned so far with the following two possibilities. 1) The usc of potentials which differ for even and odd $b$ values, i.e.,

$$
V_{\ell}(r)=C_{\ell} V_{D}(r)
$$

with $C_{\ell}=C e$ for $\ell$ even

$=$ Co for $\ell$ odd.

2) A particular application to ${ }^{40} \mathrm{Ca}$ at $30.3 \mathrm{MeV}$ with a more complicated $\ell$-dependence of the form

$$
\begin{aligned}
V_{\ell}(r) & =+\infty \quad r \leq r \ell 0 \\
& =c_{\ell} V_{D}(r) \quad r>r \ell 0
\end{aligned}
$$

where the hard-core radii rlo are determined from the positions of the nodes in oscillator-shell-model wave functions ${ }^{1}$ and the direct potential $V_{D}$ is obtained from a folding procedure with two-body potentials and nuclear matter distributions. ${ }^{2,3}$

Preliminary results indicate that only minor improvements to the quality of the fits to elastic proton data are achieved in this way. 


\section{References}

1D. R. Thompson, I. Reichstein, W. McClure and Y. C. Tang, Phys. Rev. 185, 1351 (1969).

${ }^{2}$ G. W. Greenlees, G. J. Pyle and Y. C. Tang, Phys. Rev. 171, 1115 (1968).

${ }^{3}$ G. W. Greenlees, W. Makofske and G. J. Pyle, Phys. Rev. C, Vol. 1, 1145 (1970). 


\section{B. EXPERIMENTAL INSTRUMENTATION}

45. Beam-Current-Integrator Calibration

W. S. Chien, J. H. Broadhurst and P. Stasz

The beam-current integrator (BCI) presently in use at the Williams Laboratory is Mode1 1000, Brookhaven Instruments Corporation, Brookhaven, New York. Experience with this BCI has shown that its calibration is somewhere within $\pm 0.5 \%$ of that stated by the manufacturer. In particular, accurate differential cross sections for $10-\mathrm{MeV}, \mathrm{p}-\mathrm{p}$ scattering (see sec. 1 of this report) have been reproduced in our laboratory. At present we are attempting to obtain a calibration of this BCI accurate to about $\pm 0.2 \%$. The standard technique is used of introducing into the $\mathrm{BCI}$ a constant current $\mathrm{I}$ for a known time interval $\mathrm{T}$. The introduced charge $Q$ is then found from $Q=I T$, and the calibration constant is obtained by dividing $Q$ by the number of output pulses generated by the $\mathrm{BCI}$. The time interval $\mathrm{T}$ can be measured quite accurately, and the current $I$ is determined by measuring the voltage drop $V$ across a resistance $R$. For a given current $I$, if $V$ is not too small (i.e., if $\mathrm{R}$ is not too smal1), then $\mathrm{V}$ may be measured to high accuracy. The problem is then to obtain an accurate value for the resistance $R$. In order to calibrate the most used ranges of the BCI, resistances of 10 to_100_Megaohms_are_used.__standard_resistance_bridges_are_not_able_..to__.... measure such high resistance values to the desired tenth percent accuracy. Therefore, a method for determining $\mathrm{R}$ is being developed in which the voltage decay in an RC circuit is employed.

Highly stable teflon capacitors calibrated to $\pm 0.08 \%$ have been incorporated into a circuit with the calibrating resistor $R$. A measurement of the voltage across the capacitor $C$ as a function of time allows the time constant RC to be determined, and from this $\mathrm{R}$ may be computed. 
The use of more than one capacitor allows one largely to eliminate the effects of stray capacitance.

The first method used to measure RC was to connect the capacitor voltage to the input of one of the laboratory analog-to-digital converters $(A D C)$ and to use a time-mark generator to gate the ADC on at appropriate time intervals. A computer code was then used to extract the time constant RC from the resulting spectrum (counts vs channel) produced by the ADC. Thorough testing of this method has indicated that the inherent stability and linearity of the ADC is not sufficient to attain the desired accuracy for RC. Therefore, a second method for obtaining $\mathrm{RC}$ is now under investigation. This method involves the use of a dual voltage comparator which will start and stop an electronic timer at two preset voltage levels. Preliminary results with this unit are very encouraging.

46. $\underline{\text { Position-Sensitive Detector Set-Up }}$

R. A. Wallen

Prior to the development of the system described here; the maximum number of position-sensitive detectors (PSD's) that could be used with our on-1ine DIVIDE routine was three ${ }^{1}$. The limitation being that the laboratory has only three pairs of ADC'S. Previous routing systems developed proved to be inadequate or too cumbersome for PSD use. 
Ordinarily with our DIVIDE and THRESH routines the most recent 256 events for each detector are displayed on a dot pattern with the energy of each event being the ordinate and $X E / E$ being the abscissa. Thresholds are set with the aid of a light pen on the energy axis to differentiate between types of particles. The new system uses this latter function to couple 2 or more detectors into one pair of ADC'S. Delayed $\mathrm{XE}$ and $\mathrm{E}$ signals are added from each detector in gated linear adders (Fig. 46-1).. Gating signals obtained from E signals prevent the addition of noise and allow for the addition of only desired events. The gains for $\mathrm{XE}$ and $\mathrm{E}$ signals are adjusted such that events of the same type give rise to different $E$ pulses. Thresholds are then set with THRESH in the same way as one would in differentiating between particles of several types with the same EP.

This system has been used successfully for both stopping and nonstopping particles. For stopping particles as many as 4 PSD'S have been put through one pair of ADC'S, but it is difficult to couple in more than two for non-stopping particles because of the greater energy spread for the latter.

\section{Reference}

${ }^{1}$ The use of an on-line computer to divide signals from a position-sensitive detector, P. H. Debenham, Nuc. Inst. 67, 288-292 (1969). 


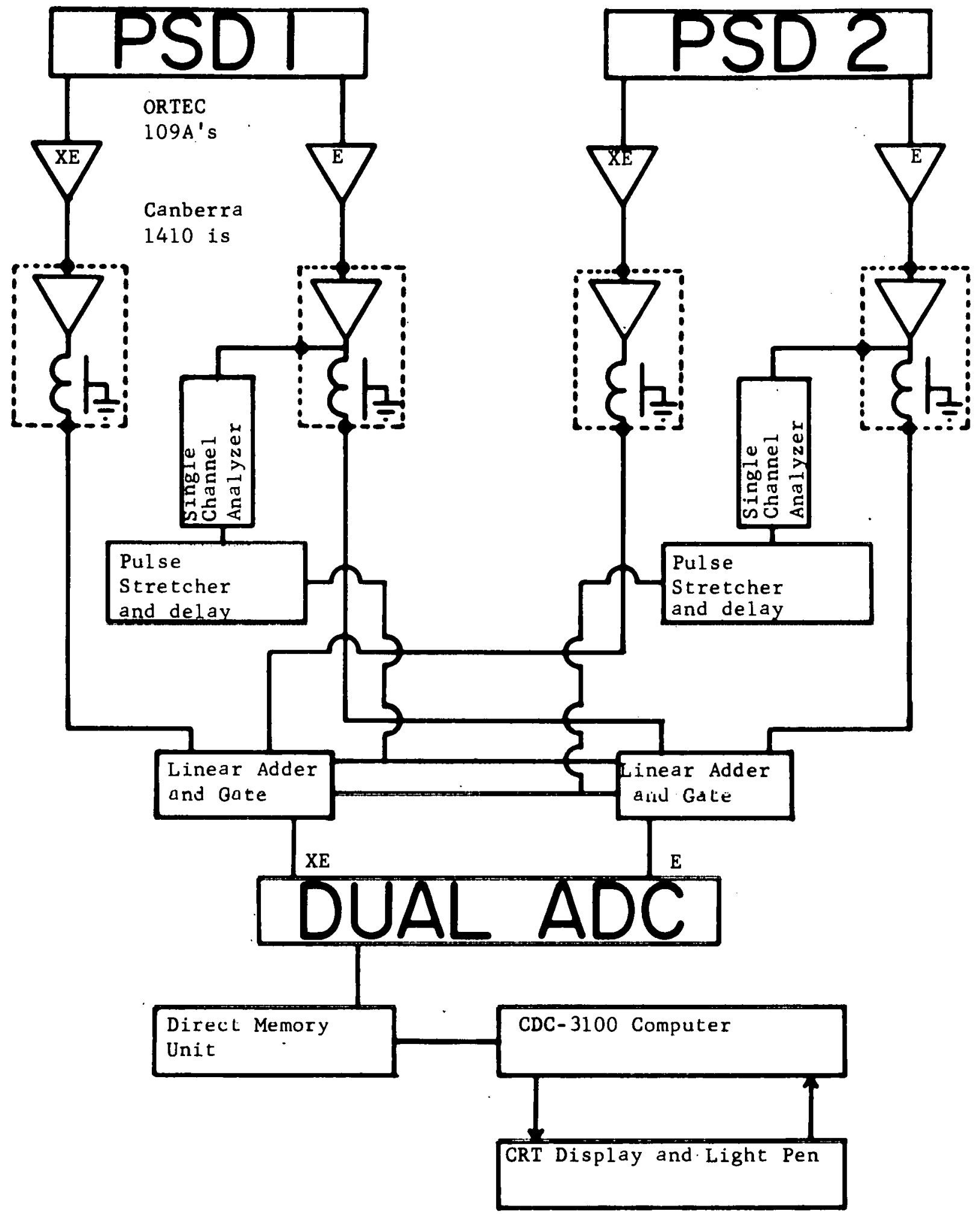

Fig. 46-1 
47.

True-Charge Fulser

J. H. Broadhurst

Experiments in the laboratory have recently been performed in which a weakly excited reaction was studied in the presence of a large yield of unwanted elastically-scattered particles.

It was therefore desirable to examine the behavior of various nuclear pulse-counting systems to a source of simulated monoergic random particles.

Accordingly, a system was constructed in which a pulse of infrared light was focussed on a $p-i-n$ semiconductor junction. The resultant photon-induced charge was collected and amplified in a manner identical to that of semiconductor particle detectors. A statistical distribution of light pulses approximating to a true random sequence was produced by an appropriate pulse generator, care being taken that the pulse length was not affected by the randomizing process.

The pulse shapes produced by this system were examined for different analysis systems down to a $10^{6}: 1$ peak to background ratio.

The absence of competing processes within the p-i-n junction akin to the presence of nuclear reactions within a semiconductor particle detector, was confirmed by some of the signal processing systems which showed Gaussian behavior down to the level above. other systems showed deviations at the $10^{3}: 1$ level, making them unsuitable for the proposed experiments. 
48.

Additions to the On-Line Computer

J. H. Broadhurst

32-Scaler System

This system, construction of which is nearing completion, is to provide a directly-computer-accessible scaler system for data acquisition.

The equipment comprises 32 blind scalers of $2^{8}$ count capacity and with 200 ns pulse pair resolution whose overflows increment via the direct memory access multiplexer, 32 contiguous, switch selectable addresses of the on-1ine computer's core storage. Each individual scaler can be enabled or disabled under program control, overall activation being by the particle-beam measuring system. Any scaler not enabled can also be interrogated under program control and its remainder ascertained.

Software support for this system has already been partially completed, as mentioned elsewhere, and it is forecast that this equipment will be in operation in December 1970 .

Disk Storage Unit, Time-Sharing Terminals

The demands of maintenance have slowed the construction of this equipment considerably. The Disk controller logic is now mainly tested and approved under computer simulation conditions, and installation of this part of the system is expected by January 1971 . Work on the terminals will not now be continued until the disk installation is completed. 
49.

High Resolution Proton Spectrometer (HRS) and Scattering Chamber for the Los Alamos Meson Physics Facility (LAMPE)

\author{
N. M. Hintz
}

A brief description of the work done by the author as a member of the HRS design committee appeared in the 1969 Progress Report.

The final magnet optics design has been completed by H. Enge and engineering drawings are being prepared by the staff at LRL, Berkeley, and Los Alamos: The final spectrometer configuration is shown in Fig. 49-1.

A sub-committee of the HRS design committee is now working on the design of the scattering chamber and targeting system. The group consists of the author, George Igo (UCLA), Nabe Tanaka (LASL) and Jack Gunn (LRL). The chamber will be of the order of 1 meter in diameter and will be coupled to the spectrometer through a sliding window vacuum sea1. An internal beam stop will be available for angles $\lesssim 10^{\circ}$. Special cryogenic or gas targets will be provided by a system of interchangeable lids. Multiple solid targets will be controlled from below. A preliminary design was discussed and modified at the 25 May HRS meeting at LASL. A separate system seems to be required for small angles. 
LAMPF HIGH RESOLUTION

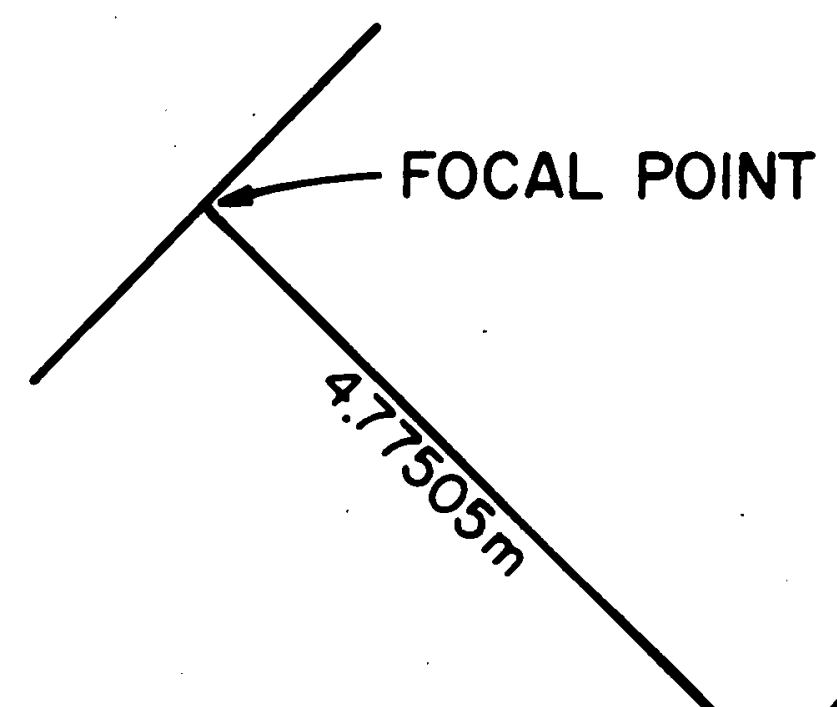

SPECTROMETER CONFIGURATION

3.5 meter system

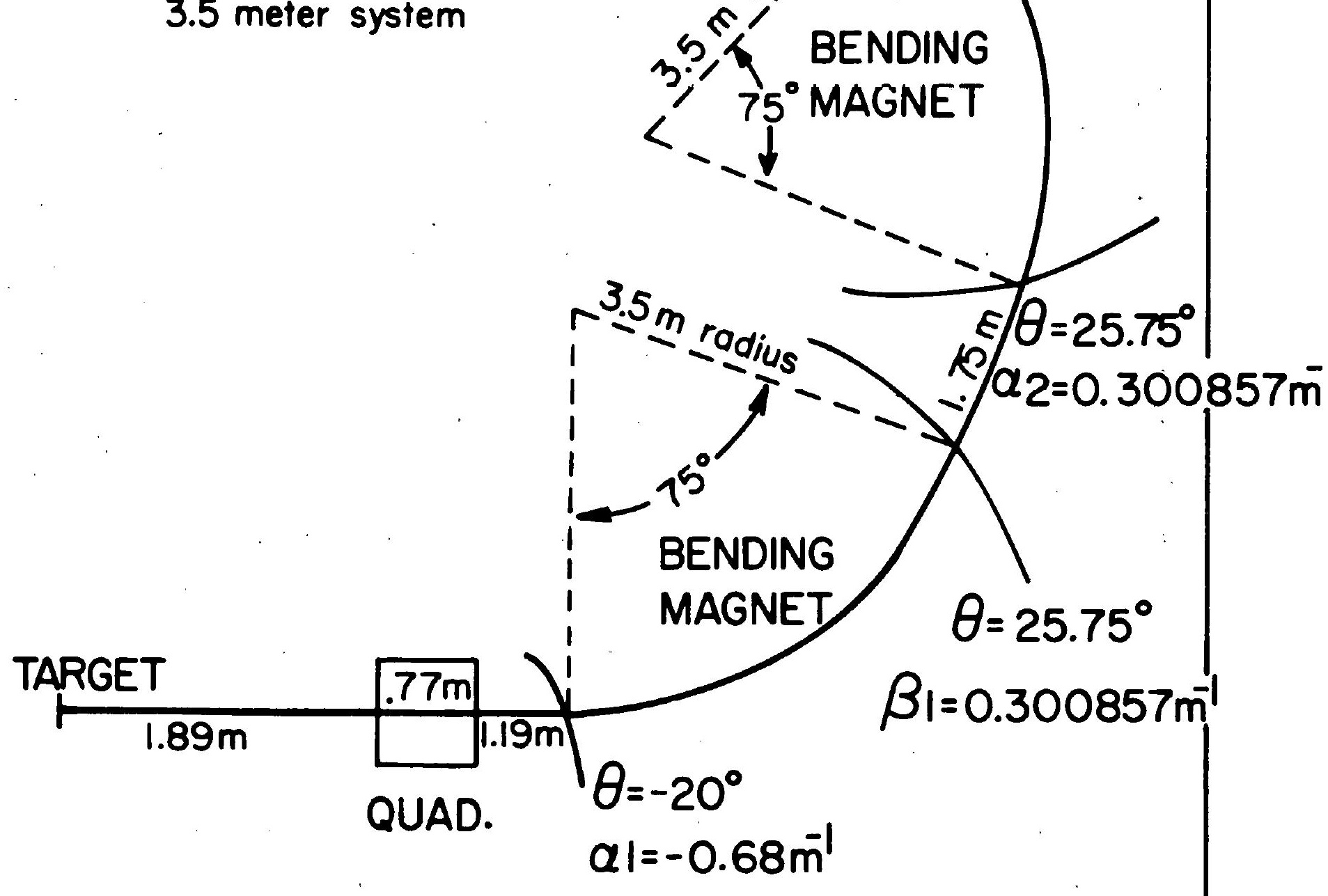




\section{ACCELERATOR PERFORMANCE AND DEVELOPMENT}

50.

General Operation of the Tandem Van de Graaff

\section{H. Poppe}

As in previous years the tandem was scheduled for 24-hour-a-day operation, 7 days a week, with the exception that Monday morning was reserved for maintenance. For approximately the last six months, however, maintenance has been extended to 4 P.M. so that installation of various items for the polarized ion source could be accomplished.

From August 1969 to the end of November, the machine ran extremely well, giving little trouble and not requiring any tank openings. On November 23, however, the charging belt broke and it was necessary to enter the tank. Initial inspection revealed that the interior of the tank was comparatively clean of belt dust, indicating that excessive wear of the belt was probably not the cause of failure. The belt broke after only 4,059 hours which is about half that of previous belts.

The break in the belt occurred near the alternator at the terminal. The microid bar was found to be broken and the six belt spacers adjacent to it were loose and damaged. This damage was probably caused by the broken belt. It is impossible to determine the cause of this belt failure, although there is some evidence that something may have fallen onto the belt about 3 to 4 inches from one end and became imbedded in it. However, the belt did tear along one of the over-lapping ply lines and weakness at this point, perhaps from incomplete impregnation of the plies, may have caused the failure.

With the belt removed and the belt tunnels disassembled a complete check of the accelerating column was made. No significantly bad areas were found and it was not necessary to short out any additional accelerating sections. 
A new belt and microid bar were installed and the belt tunnels aligned. New screens were installed and bad resistors replaced.

After closing up the tank and running the belt in normal operating circumstances, it was found to be extremely difficult to get the belt tracking properly and stably. Finally, the tank was re-opened and a realignment of the alternator subsequently cured the belt tracking problem.

Until recently the machine has run well with most of the operation being near the top end of the terminal voltage range (we generally do not try to exceed $10 \mathrm{MV})$. Late in June, after a power failure, the belt again became unstable. It was thought that perhaps the load cells on the motor were no longer properly calibrated and that the belt tension might. be considerably less than indicated causing unstable operation. At this time the injector isolation transformer also went bad. Operation was halted to enter the tank in order to recalibrate the load cells and to reinstall the generating voltmeter which had been removed earlier for modification. Contrary to expectation the load cells were not far off. The motor, however, was realigned slightly. Nothing else was done inside the tank and it was disturbed as little as posslble. The fault in the isolation transformer was a shorted primary on one of the phases and this was replaced. After closing up the tank, normal operation with a terminal potential of $9.5 \mathrm{MV}$ was achieved in less than two days--the belt now running more stably--and operation is again normal.

Beams of ${ }^{1} \mathrm{H},{ }^{2} \mathrm{H},{ }^{3} \mathrm{He},{ }^{4} \mathrm{He},{ }^{12} \mathrm{C}$ and ${ }^{16} \mathrm{O}$ have been used this year. $1_{H}$ and ${ }^{2} H$ have been used for approximately one-half the time and ${ }^{3} H e$ and ${ }^{4}$ He the remaining half. There have only been several runs using ${ }^{12} \mathrm{C}$ and 160.

The operation of the accelerator is summarized as follows: 


Used for experimental work
Scheduled maintenance
Machine conditioning
Fxperiment set-up time
Experiment change-over time
Machine development :
Trouble time
Surplus

\begin{tabular}{rr}
5130 hours & $58.6 \%$ \\
363 hours & $4.1 \%$ \\
920 hours & $10.5 \%$ \\
41.3 hours & $4.7 \%$ \\
297 hours & $3.4 \%$ \\
138 hours & $1.6 \%$ \\
1.386 hours & $15.8 \%$ \\
113 hours & $1.3 \%$ \\
\hline 8760 hours & $100.0 \%$
\end{tabular}

The relative amount of time devoted to experiments continues to increase--this year's amount is up $16 \%$ over last year. Much of this has come from a decrease in the amount of trouble, machine conditioning and scheduled maintenance time. There has been an increase in machine development caused largely by installation of polarized source items, and experiment set-up and change-over time has also increased. Surplus time, although very smal1, has increased from last year, probably indicating that machine demand has not always been as intense as last year. 
51. On-Line Computers, 3100 - PDP 8I

B. Brown and J. H. Broadhurst

The computers have been operational for $93 \%$ of the total running time during the last year, with no abnormal demands for service or repair. The shortage of core storage and the absence of time sharing have shown themselves more acutely this year, and for the first time it has been necessary to modify the scheduling of the accelerator at times to allow priority use of the computer for data reduction.

Due to a reduction of technical effort available in the laboratory, work on time sharing, and on the disk mass storage unit, has been suspended for a major part of the year, but is proceeding again and completion is expected during the next year. During this year the shortage of computer time has been alleviated to some extent by the use of a conversational language (FOCAL) on the PDP $8 \mathrm{~L}$. I'his is only a temporary measure, as this machine is not intended for data processing, and will soon be fully committed to monitoring of the accelerator.

No new peripherals were added to the machine, though one unit is currently under construction. This work is reported in the section 48 of this report.

The software development for the laboratory's on-line computer system consisted of optimization of the computer's monitor system and the inclusion of the 32 -scaler system into the existing data collection and analysis framework. The rewriting of parts of the monitor achieved faster interrupt processing and better operating-console display. The software for the control and integration into the existing experimental data collection routines of the 32 -scaler system is partially completed. The scaler selection and control programs are finished and the methods for the handling of the scaler data in conjunction with the normal experimental data are designed but not yet implemented. 
52.

The Enge Split-Pole Spectrometer

D. Dehnhard

During the last year the magnetic spectrometer of the Enge splitpole type ${ }^{1}$ has again proved to be one of our most often used pieces of experimental equipment. About one-half of the experimental investigations discussed in this annual report were performed with the use of the spectrometer. Again most of the experiments were done with an array of three position-sensitive detectors. Six detectors were used successfully in an experiment, in which the detected particles were stopped in the detéctors (see section 46 of this report ). The general-purpose pulse routing system is still in the process of being built.

Because our plate scanning facilities ( 3 part-time scanners) are rather limited, use of nuclear emulsions was reduced to a minimum. Some of our nuclear emulsions have been scanned by the Argonne Automatic Plate Scanner. ${ }^{2}$ However, large background counts showed that our plate developing procedure needs improvement. A darkroom was set up at the Williams Laboratory which has faciiities to develop plates at temperatures close to $0^{\circ} \mathrm{C}$ and preliminary results are encouraging. We hope that the efficiency of data taking can be increased considerably by use of the Argonne plate scanning facilities.

Still, for many experiments, position-sensitive detectors are superior to nuclear emulsions. A major improvement of our detector array system was the installation of the screw drive for locating the detectors along the focal plane (design: W. W. Dykoski). Several new detectors have been purchased, two of which have a thickness of $1000 \mu$. These detectors were found to be very good for detection of $25 \mathrm{MeV}$ 
protons for which the energy loss in the previously available detectors of $500 \mu$ thickness was too smal1.

\section{References}

${ }^{1}$ J. E. Spencer and H. E. Enge, Nucl. Instr. and Meth. 49, 181 (1967).

2 J. R. Erskine and R. H. Vonderobe, ANL, Informal Report PHY-1969F.

53. Polarized Negative-Ion Source for the MP Tandem

C. H. Poppe, V. Shkolnik, D. L. Watson, J. J. Turgeon, and T. O. May

The description of the polarized negative-ion source now nearing completion is given in the 1968 and 1969 Progress Reports. At this writing, most of the mechanical construction and assembly has been completed. Teste on the atomic beam and sextupole magnet have been completed, the ionizer has been installed and tests on the positive ion beam will begin shortly.

The following sections detail progress made in certain areas: 1. Injector Cage, Main Platform and Electronics Platform.

Enlargement of the injector cage to accommodate the polarized ion source has been completed. The insulated platform to support the ion source at injector potential has been installed and aligned and a similar platform to support the electronics racks has also been installed. A third insulated platform which will support the mechanical pumps will be installed when the source is moved over from its temporary location.

A $75 \mathrm{kVA}, 208 \mathrm{~V}$, 3-phase generator to supply the necessary power to. the source at the injector potential was installed on the electronics platform. The generator is driven via a belt from a $100 \mathrm{hp}$ motor. The 
motor was hung from the concrete floor directly under the injector and the drive belt passes through a hole in the floor. When the isolation transformer which supplies power to the normal source failed (see section 50--"General Tandem Operation"), power was supplied using this MG set as a temporary measure and to give it an extended test. It operated completely satisfactorily for more than one week of practically continuous operation. Operation was discontinued when the isolation transformer was repaired. The recirculating water cooling system for all three platforms has been designed and almost completed. As soon as the rest of the electronic components are at hand it will be tested, mainly for constancy of temperature $\left(60^{\circ} \mathrm{F}\right)$ of water supplied by the heat exchanger.

\section{Ion Source Assembly.}

As described in the 1969 Progress Report the atomic beam system, the sextupole magnet, the radio-frequency transition sections, the ionizer and the charge exchange system are all supported from the same I-beam framework. These systems are being assembled on this framework in a location removed from the injector cage. They are tested in this location and when suitable negative ion beam is extracted, the entire assembly will be transported to the injector cage and placed on the waiting insulated platform. The beam transport system connecting the ion source assembly and norma $\perp_{-}$source box_will then_be assembled.

At the date of this writing the atomic beam system, the sextupole magnet box and sextupole magnet, and the ionizer box and ionizer have been completed and installed on the main frame. The ionizer box and the sextupole box are connected by a pyrex tube about which the twolevel radio-frequency transition units will be placed. 
Tests on the atomic beam system and differential pumping column have been completed. The pumping system will satisfactorily handle the largest gas throughput anticipated, about one Torr-l/sec. Tests indicate that with a throughput of .25 Torr-l/sec. a dissociator with a nozzle. diameter of $2 \mathrm{~mm}$ will produce an atomic beam of $8 \times 10^{15}$ atoms $/ \mathrm{sec}$. satisfactorily focussed by the sextupole magnet at the ionizer. The ionizer is now installed and attempts to extract a positive-ion beam will begin short1y.

\section{Charge Exchange.}

Tests on a prototype charge exchange canal, described in the 1968 and 1969 Progress Reports, were completed during the past year. Using potassium a maximum charge exchange efficiency of about $3 \%$ for the process $\mathrm{H}_{1}{ }^{+} \rightarrow \mathrm{H}_{1}{ }^{-}$was measured for 2 to $3 \mathrm{keV} \mathrm{H}_{1}{ }^{+}$ions. A final version of the cxehange cdual has been built and is being tested using $\mathrm{Na}, \mathrm{K}$ and $\mathrm{Cs}$. The solenoid magnet for the charge exchange and the ". vacuum manifold are yet to be made.

\section{Beam Transport.}

The inflection magnet, spin rotator magnets, and electrostatic mirror boxes are all constructed." The einzel lenses and the accelerating column are in the process of being assembled, and a vacuum manifold to provide adequate pumping at these points along the beam transport system has been designed.

\section{Foil Stripper.}

The foil stripper assembly, detailed in the 1969 Progress Report, has been assembled and found to operate under vacuum conditions in a reliable fashion. Parts for remotely moving the normal gas stripper 
canal from the beam line when the foil stripper is to be used have been built. Only a delay in the delivery of the lucite control rods for the foil stripper and the lucite tubing for the pneumatic control of the gas stripper positioner assembly is preventing installation in the accelerator tank.

\section{RF Transition Sections.}

In addition to the low-field rf transition section which is already built and will be mounted directly on the sextupole magnet, three twolevel, high-frequency rf transition sections built by the Anac Company, have been purchased from Ortec, Inc. These units have all arrived and are being set up for testing. There are three separate cavities and oscillators, all using the same d.c. magnetic field. One of the cavities is to be used with protons and will be used in conjunction with the lowfield unit to provide fast switching of the polarization direction. The other two units are for use with the deuteron beam and will provide various combinations of vector and tensor polarization.

54.

Accelerator Improvements

Machine Energy Stabilization

J. H. Broadhurst

A phase and amplitude plot was made of the machine transfer function between the control grid of the vacuum tube regulating the corond current to the machine terminal, and a fast response Generating Voltmeter sensing the terminal potential. 
This plot showed that at least $35 \mathrm{~dB}$ of feedback could be applied to the system with a good margin of stability. The loop was accordingly closed, and the terminal potential behaved as expected. As other sources of variation of beam energy occur during the accelerating process it was still necessary to incorporate a secondary loop into the system to sense the position of the analyzed particle beam, and to apply appropriate minor corrections.

Control of other parameters affecting the terminal potential, namely corona point positioning and changing belt current, were left to the human operator, as these variables do not need adjustment unless a large change 1 s to be made in the potential of the terminal. Four-Quadrant S1it-Current Display P. Stasz and J. H. Broadhurst

This device uses the newly available integrated circuit fuurquadrant analogue multipliers to generate an X-Y c.r.t. display in the form of an ellipse whose centroid represents the centroid of the accelerator particle beam when it is incident on a four-jaw slit system, and whose major and minor axes represent the focussing of the beam in the two planes of the jaws. It is felt that this device will be cybernetically more efficient than the present switched pointer meters and should result in both a more rapid adjustment of the accelerator and improved beam trafectories. The device has been tested in prototype stage, but final construction has been suspended to await incorporation in a future redesigned particle beam-steering and focussing system. 
55. Revision of the Safety Survey and Interlock Systems

J. M. Blair

Experience has shown that the original system of interlocks on the doors and gates which separate the rooms of the laboratory where radiation may be produced from the areas where people may be working might allow an accidental exposure of personnel to radiation. Some of the circuits and some of the Faraday cup controls were not designed in a fail safe manner so that a possible malfunction of some component might give a false impression of safe conditions. To remedy this situation a complete revision of this equipment has been undertaken and is presently nearly completed. As revised, the safety survey and interlock system have the features described below.

The passage of the ion beam through the accelerator is controlled by two pneumatically operated Faraday cups; the low energy cup between the injector and the accelerator tank and the image cup between the analyzing magnet and the switching magnet. These block the ion beam if the air pressure falls ul the cloctrir rircuit is broken. The low energy cup can be withdrawn from the beam line if the safety survey of the accelerator hall and basement has been completed and if the vacuum valves in the beam line are open. Switches on the cup rod indicate if the cup is completely in or completely out. If the cup is not in when the control circuit demands that it be in, an alarm circuit is actuated and the injector power is cut off.

Removal of the image cup from the beam requires that the safety survey of the target room selected for the current experiment be completed and that all of the "safety keys" which may have been removed from the operating console have been returned. To avoid accidental operation of the "cup out" button, the "cup in" button must first be pushed before the "cup out" button is effective. As with the low energy 
cup, switches on the cup rod and a comparison circuit. give warning if the cup is not in when requested to be.

Under some operating conditions quite a bit of radiation is produced in and around the image cup. To block this radiation from passing through the holes in the thick shield wall through which the beam lines pass, heavy copper blocks are inserted in each of the five target lines except the one actually in use. For the target line being used, the copper block drops into the beam line when the image cup is put in to protect personnel who may go into that experimental area to adjust equipment. A circuit will not permit the low energy cup to be pulled out if, due to some malfunction, more than one copper block is raised at any time.

At each entrance to an area where a radiation hazard may be present there are flashing "Radiation Danger" lights. The ones for the accelerator hall and basement operate when the low energy cup is out. The ones fon each target room operate when the copper block in the corresponding target line is out and the low energy cup is out. The accelerator hall and target rooms have rotating magenta warning lights which operate under conditions when radiation may be produced in those areas.

The safety survey system has a relay logic circuit which requires that the accelerator operator walk to a number of points in the accelerator hall, accelerator basement, and which ever target room has been selected for use. At various points he must push buttons to record that he has been there on his inspection trip. During the inspection of a room an alarm sounds and upon completion of the survey in each room the lights are turned out. The logic circuit also requires that appropriate doors and gates be closed. When these conditions have been 
satisfied, the Faraday cups can be pulled out of the beam line. Entering one of these surveyed areas will put in a Faraday cup to interrupt the ion beam. The accelerator hall, accelerator basement, and the largest target room are divided into smaller areas by light beams so that only the section of the room entered since the last valid survey need be checked to reestablish the survey.

The controls for the heavy doors to the three target rooms are connected to the interlock system so that one can only open the door leading into the room being used for an experiment if one uses a "safety key." from the control console. Removing this key from the control console puts in the image cup so, the passage of the ion beam into the room is stopped before the door is opened. Opening the door also invalidates the safety survey which provides further assurance that the ion beam into that room has stopped. 
APPENDIX

56.

Laboratory Personne1

Research

Faculty

Research Associates

J. Morris Blair

A. Ross Barnett ${ }^{1}$

George W. Greenlees

James Lowe ${ }^{2}$

Norton M. Hintz

William Makofske

John H. Broadhurst

Hajime Ohnuma

Ronald E. Brown

Vladimir Shkolnik

Car1 H. Poppe

Douglas Watson ${ }^{3}$

Dietrich Dehnhard

John S. Lilley

Research Assistants

Jones W. Chien

Robert Cornett ${ }^{4}$

Frank Chwieroth ${ }^{4}$

Philip Debenham

Ralph DeLong

William Dykoski

Daniel Fitzgerald

Phillip Gavin ${ }^{4}$

Lowel1 Johnson 4

James Koepke

Thomas Krick ${ }^{4}$

Albert Kuhfeld

Gary Kyle $e^{4}$
Dennis Leavitt

Kin-Wah $\mathrm{Li}^{4}$

David Madland 5

Peter Mailandt

David 01 sen $^{5}$

Michael Oothoudt

Arimil1i Padmanabham ${ }^{4}$

Jerry Sievers ${ }^{5}$

Robert Snyder

Allen Sourkes

Dary1 Tweeton

Richard Wallen

David Webber ${ }^{4}$ 


\section{Engineering}

Electrical Design and Manufacture and Accelerator Uperation

$\begin{array}{ll}\text { Barry Brown (computer) } & \text { Thomas May } \\ \text { Peter Stasz (Tandem Engineer) } & \text { Dennis Olson } \\ \text { James Heinen } & \text { George Pottcr } \\ \text { Frank Lang } & \text { James Turgeon }\end{array}$

Curtis Lehrke

Mechanical Design and Manufacture

DeWayne Varnes (Shop Foreman) Ray Johnson

Victor Christianson Chester Peske

Michele Collins (Drafting) James Pilgram

Jon Dal rymple

Others

Kay Kirwin (Secretary)

Marjorie Maloney (Nuclear Plate Scanning, part-time)

Mary Evanson (Nuclear Plate Scanning, part-time)

Christie Helgeson (Nuclear Plate Scaning, part-time)

George Ott (Target Preparation)

Gordon Schisse1 (Principal Stores Clerk)

11 part-time undergraduate students

1 Terminated, Sept. 1970.

2Visiting from The University of Birmingham, England, April 1 - Aug. 31, 1970. 3 Terminated, Aug. 1970 .

${ }^{4}$ Summer only.

5 Terminated.

6erminated, Nov. 1969. 
175

57. Advanced Degrees Granted, Academic Year 1969-70

J. A. Silvers, Ph.D. "A Study of the $\left(\mathrm{He}^{3}, t\right)$ Reaction and Isobaric Analog States in $1 \mathrm{f}-2 \mathrm{p}$ Shell Nuclei."

F. D. Becchetti, Jr., Ph.D. "Polarization and Cross-Section Measurements of $9.7 \mathrm{MeV}$ Elastic Scattering By Nuclei."

David Midland, Ph.D. "Proton Reactions on Ne Isotopes at $40 \mathrm{MeV} . "$

David K. Olsen, Ph.D. "The $(p, t)$ and $\left(p,{ }^{3} H e\right)$ Reactions on Light Nuclei." 
58.

Reports and Publications

\section{(a) Publications}

"Octupole and Quadrupole Transition Rates in $\mathrm{F}^{19}$ from Scattering of 15-MeV Deuterons"

D. Dehnhard and Norton M. Hintz

Phys. Rev. $\underline{C_{1}}, 460$ (1970).

"A Pairing Phase Transition In The Yb Isotopes"

M. Oothoudt and N. M. Hintz

Physics Letters 32B, 270 (1970).

"Exclted Rotational Band In 'Spherical' $\mathrm{Sm}^{150 "}$

$P$. Debenham and N. M. Hintz

Phys. Rev. Letters 25, 44 (1970).

"Inelastic Scattering of Polarized Protons at $30.3 \mathrm{MeV}$ by ${ }^{54,56} \mathrm{Fe},{ }^{58} \mathrm{Ni}$, ${ }^{120} \mathrm{Sn}$ and ${ }^{208} \mathrm{~Pb}$ "

0. Karban, P. D. Greaves, V. Hnizdo, J. Lowe and G. W. Greenlees

Nucl. Phys. Al47, 461 (1970).

"Coulomb Excitation and Reorientation of the Octupole State in ${ }^{208} \mathrm{~Pb}$

A. R. Barnett and W. R. Phillips

Phys. Rev. 186, 1205 (1969).

"Isospin Mixing For Bound Analog States in ${ }^{56} \mathrm{Co}$ and ${ }^{58} \mathrm{Co} "$

T. G. Dzubay, R. Sherr, F. D. Becchetti, Jr., and D. Dehnhard

Nucl. Phys. A142, 488 (1970).

"Coulomb Excitatinn of Bismuth and the Weak Coupling Model"

R. A. Broglia, J. S. Lilley, R. Perazzo and W. R. Plitllipo

Phys. Rev. C1, 1508 (1970).

"Energy Levels in $\mathrm{P}^{33 \text { " }}$

G. Hardie, R. E. Holland, L. Meyer-Schützmeister, F. T. Kuchmir and H. Ohnuma Nucl. Phys. Al 34, 673 (1969).

"Study of the $\mathrm{Al}^{27}\left(\mathrm{He}^{3}, \mathrm{p}\right) \mathrm{Si}^{29}$ and $\mathrm{Al}^{27}\left(\mathrm{He}^{3}, \mathrm{pr}\right) \mathrm{Si}^{29}$ Reactions"

L. Meyer-Schützmeister, D. S. Gemme11, R. E. Holland, F. T. Kuchnir, H. Ohnuma, and N. G. Puttaswamy

Phys. Rev. 187, 1210 (1969).

"Study of the Excited States in $\mathrm{Si}^{30}$ by Means of the $\mathrm{Si}^{30}\left(\alpha, \alpha^{\prime} \gamma\right) \mathrm{Si}^{30}$ Reaction"

H. Ohnuma, F. T. Kuchnir, R. E. Holland, L. Meyer-Schützmeister, N. G.

Puttaswamy, and D. S. Gemme 11

Nuc1. Phys. Al49, 141 (1970).

"Level Structure of $\mathrm{Sc}^{48}$ from the $\mathrm{Ca}^{48}\left(\mathrm{He}^{3}, \mathrm{t}\right)$ Reaction"

H. Ohnuma, J. R. Erskine, J. P. Schiffer, J. A. Nolen, Jr., and Norman Williams

Phys. Rev. Cl, 496 (1970). 
"Accurate Proton-Proton Differential Cross Sections Near $10 \mathrm{MeV}$ " Nelson Jarmie, Ronald E. Brown, R. L. Hutson, and J. L. Detch, Jr. Phys. Rev: Letters 24, 240 (1970).

"Elastic Scattering of ${ }^{3} \mathrm{He}$ by ${ }^{4} \mathrm{He}$ from 17.8 to $30.0 \mathrm{MeV}^{\prime}$

C. G. Jacobs, Jr., and Ronald E. Brown

Phys. Rev. C1, 1615 (1970).

"Study of ${ }^{3} \mathrm{He}+{ }^{3} \mathrm{He}$ Elastic Scattering and the Nucleus ${ }^{6} \mathrm{Be}$ "

J. G. Jenkin, W. D. Harrison, and Ronald E. Brown

Phys. Rev. C1, 1622 (1970).

"Proton and Neutron Distributions Calculated Using an Effective Single Particle Potential"

C. J. Batty and G. W. Greenlees

Nuc1. Phys. Al 33, 673 (1969).

"The Elastic Scattering of Protons by $0^{16}$ in the Energy Range 16-30 MeV"

o. Karban, P. D. Greaves, V. Hnizdo, J. Lowe, N. Berovic, H. Wo jciechowski, and G. W. Greenlees

Nucl. Phys. Al 32, 548 (1969).

\section{(b) Papers in Press or Submitted for Publication}

"Nuclear Structure of $\mathrm{Sc}^{48}$ from the $\mathrm{Ti}^{49}\left(\mathrm{~d}, \mathrm{He}^{3}\right) \mathrm{Sc}^{48}$ Reaction"

H. Ohnuma and J. L. Yntema

Submitted to Phys. Rev.

"An Optical Model Analysis of 50 and $64 \mathrm{MeV}$ Alpha Particle Elastic Scattering from $58 \mathrm{Ni}$ and $58 \mathrm{Fe} "$

D. C. Weisser, J. S. Lilley, R. K: Hobbie, and G. W. Greenlees

Submitted to Phys. Rev.

"Inelastic Scattering of $40 \mathrm{MeV}$ Protons by ${ }^{58} \mathrm{Ni}$ and ${ }^{60} \mathrm{Ni}$ and Analysis in Coupled Channels"

N. Lingappa and G. W. Greenlees

Phys. Rev.

"Elastic Scattering of $30.3 \mathrm{MeV}$ Polarized Protons"

G. W. Greenlees, V. Hnizdo, O. Karban, J. Lowe, and W. Makofske

Phys. Rev.

"Study of Energy Levels of ${ }^{29} \mathrm{Si}^{\prime}$

D. Dehnhard and J. L. Yntema

Phys. Rev.

"Elastic Scattering of 39.6-MeV Protons by Even Isotopes of $\mathrm{Ni}$ and $\mathrm{Zn}$ " H. S. Liers, R. N. Boyd, C. H. Poppe, J. A. Sievers, and D. L. Watson Phys. Rev. 
(c) Papers Presented at Meetings and Conferences

"The Elastic Scattering of Protons by $0^{16}$ in the Energy Range 16-30 MeV""

O. Karban, P. D. Greaves, V. Hnizdo, J. Lowe, N. Berovic, H. Wojciechowski, and G. W. Greenlees

Paper 8.3, International Conference on Properties of Nuclear-States, Montrea1, Canada (1969).

"Two Nucleon Transfer Reactions on Deformed Nuclei"

Norton M. Hintz

Bu1.1. Am. Phys. Soc. 14, 1197 (1969).

"Proton-Proton Scattering at $10 \mathrm{MeV}$ ".

Nelson Jarmie, Ronald E. Brown, R. L. Hutson, and J. L. Detch, Jr.

Bul1. Am. Phys. Soc. 14, 1232 (1969).

"Precise Measurement of Coulomb Energies"

F. D. Becchetti, D. Dehnhard, and T. G. Dzubay

Conference on Coulomb Energies in Nuclei, Univ. of North Carolina, Chapel Hill (1970).

"Investigation of the Nuclear Surface Using Complex Particles"

J. S. Lilley

Bul1. Am. Phys. Soc. 15, 791 (1970).

"Experimental and Theoretical Investigation of $\mathrm{Cr}^{53}$ and $\mathrm{Fe}^{55 "}$

T. P. G. Carola, W. C. Olsen, D. M. Sheppard, V. K. Gupta, and H. Ohnuma

Bull. Am. Phys. Soc. 15, 784 (1970).

"Optica1. Model Analyses"

G. W. Greenlees

Gordon Conference on Nuclear Structure, July 1969.

"The University of Minnesota Polarized Negative Ion Source"

C. H. Poppe, V. Shkolnik and D. L. Watson

Third International Symposium on Polarization Phenomena in Nuclear Reactions Madison, Wisconsin (August 31 - September 4, 1970). 